\title{
IntechOpen
}

\section{Chemistry and Biological Activity of Steroids}

Edited by Jorge António Ribeiro Salvador and Maria Manuel Cruz Silva 



\section{Chemistry and Biological Activity of Steroids}

Edited by Jorge António Ribeiro Salvador and Maria Manuel Cruz Silva 

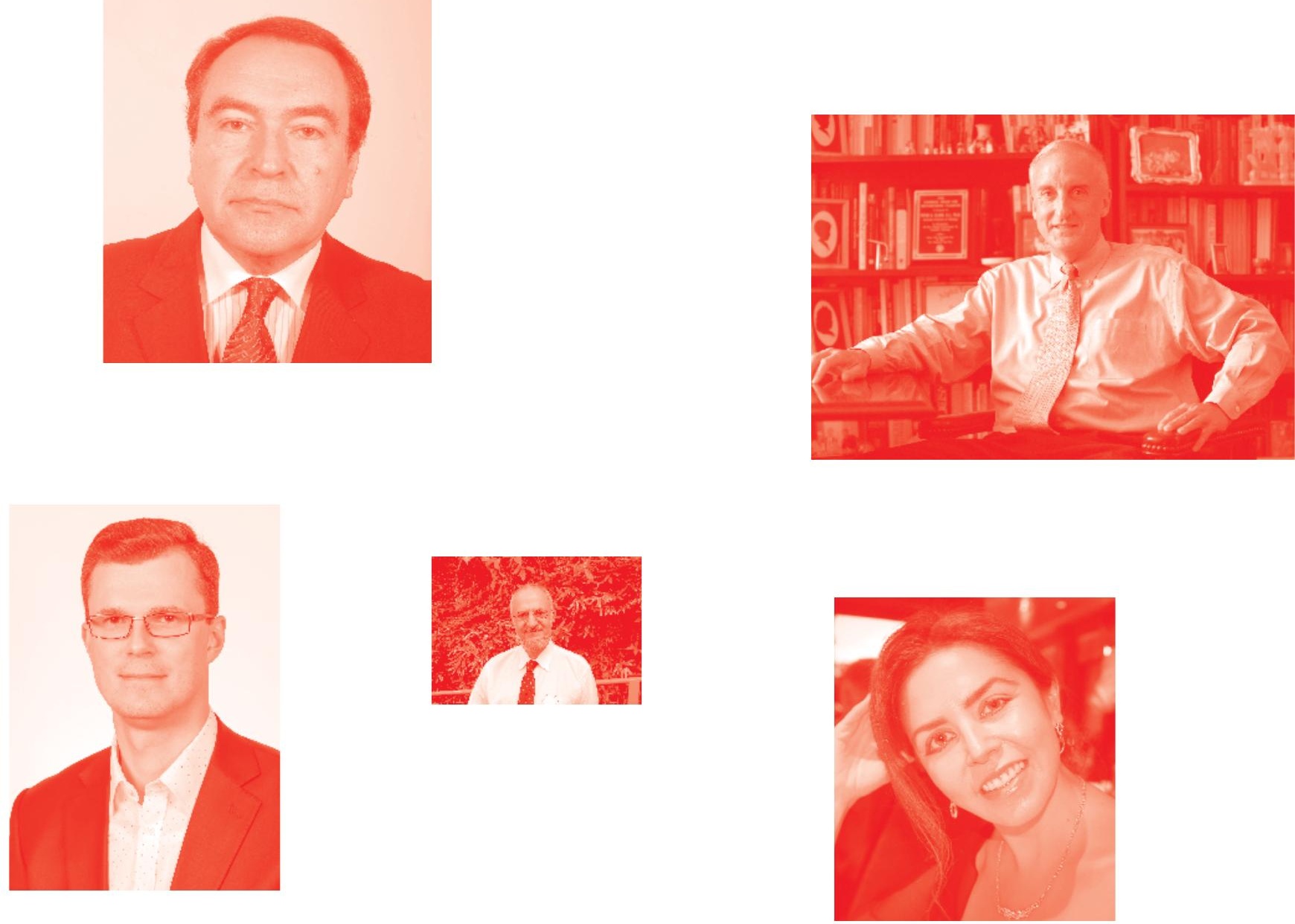

Supporting open minds since 2005
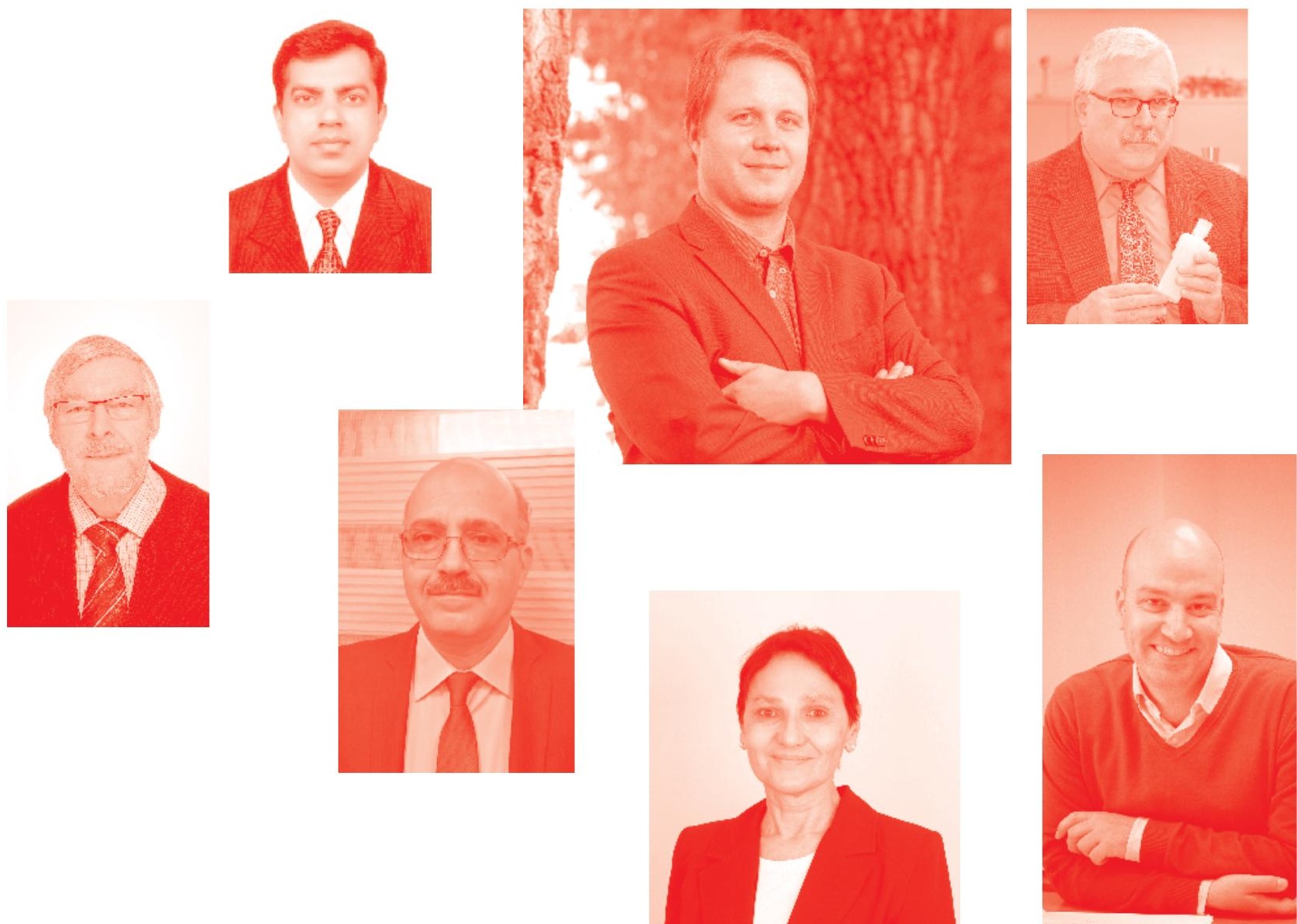
Chemistry and Biological Activity of Steroids

http: //dx. doi.org/10.5772/intechopen. 77331

Edited by Jorge António Ribeiro Salvador and Maria Manuel Cruz Silva

\section{Contributors}

Leandro Fernández-Pérez, Borja Guerra, Carlota Recio, Mercedes De Mirecki-Garrido, Svetlana Morozkina, Alexander Grigorievich Shavva, Ruilong Sheng, Dilip Mukherjee, Arturo Cano-Flores, Rigoberto Ramos, Javier Gomez, Maria Manuel Cruz Silva, Jorge António Ribeiro Salvador

() The Editor(s) and the Author(s) 2020

The rights of the editor(s) and the author(s) have been asserted in accordance with the Copyright, Designs and Patents Act 1988. All rights to the book as a whole are reserved by INTECHOPEN LIMITED . The book as a whole (compilation) cannot be reproduced, distributed or used for commercial or non-commercial purposes without INTECHOPEN LIMITED's written permission. Enquiries concerning the use of the book should be directed to INTECHOPEN LIMITED rights and permissions department (permissions@intechopen.com).

Violations are liable to prosecution under the governing Copyright Law .

\section{(cc) BY}

Individual chapters of this publication are distributed under the terms of the Creative Commons Attribution 3.0 Unported License which permits commercial use, distribution and reproduction of the individual chapters, provided the original author(s) and source publication are appropriately acknowledged. If so indicated, certain images may not be included under the Creative Commons license. In such cases users will need to obtain permission from the license holder to reproduce the material. More details and guidelines concerning content reuse and adaptation can be found at http : //www . intechopen . com/copyright-policy . html.

\section{Notice}

Statements and opinions expressed in the chapters are these of the individual contributors and not necessarily those of the editors or publisher. No responsibility is accepted for the accuracy of information contained in the published chapters. The publisher assumes no responsibility for any damage or injury to persons or property arising out of the use of any materials, instructions, methods or ideas contained in the book.

First published in London, United Kingdom, 2020 by IntechOpen IntechOpen is the global imprint of INTECHOPEN LIMITED, registered in England and Wales, registration number: 11086078 , 7th floor, 10 Lower Thames Street, London, EC3R 6AF, United Kingdom

Printed in Croatia

British Library Cataloguing-in-Publication Data

A catalogue record for this book is available from the British Library

Additional hard and PDF copies can be obtained from orders@intechopen.com

Chemistry and Biological Activity of Steroids

Edited by Jorge António Ribeiro Salvador and Maria Manuel Cruz Silva

p. cm.

Print ISBN 978-1-78985-515-9

Online ISBN 978-1-78985-516-6

eBook (PDF) ISBN 978-1-78985-608-8 


\section{We are IntechOpen, \\ the world's leading publisher of Open Access books}

\section{Built by scientists, for scientists}

\section{$4,600+$}

Open access books available

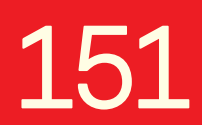

Countries delivered to

\section{$120,000+$}

International authors and editors

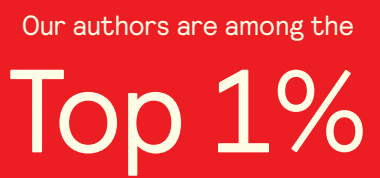

most cited scientists

Contributors from top 500 universities
$135 \mathrm{M}+$

Downloads
$12.2 \%$

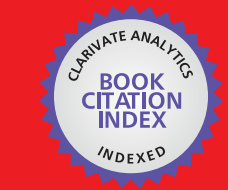

WEB OF SCIENCE ${ }^{\text {M }}$

Selection of our books indexed in the Book Citation Index in Web of Science ${ }^{\mathrm{TM}}$ Core Collection (BKCI)

\section{Interested in publishing with us? \\ Contact book.department@intechopen.com}

Numbers displayed above are based on latest data collected.

For more information visit www.intechopen.com 



\section{Meet the editors}

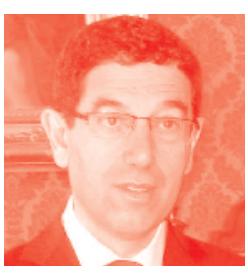

Jorge António Ribeiro Salvador has a degree in Pharmaceutical Sciences, a Master's degree in Organic and Technological Chemistry, and a PhD in Pharmaceutical Chemistry. He has a position as Full Professor at the Faculty of Pharmacy, University of Coimbra, Portugal, and is a non-executive member of the board of CHEM4PHARMA, a start-up pharmaceutical company located in Portugal. His research activity is focused on the development of new drugs, mainly for cancer treatment. He has published about 100 SCI journal papers, 13 book chapters, and 10 patents (two US patents). In addition, he is the author/coauthor of 250 presentations in national and international conferences and workshops. Over the last few years he has conducted several research projects in the field of pharmaceutical/medicinal chemistry, which have contributed to his significant expertise in drug discovery.

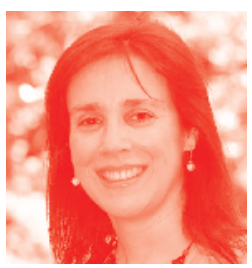

Maria Manuel Cruz Silva has a degree in Pharmaceutical Sciences, a Master's degree in Drugs Technologies, and a PhD in Pharmaceutical Chemistry from the University of Coimbra in collaboration with the CNR, Milan, Italy. She has a position as Assistant Professor at the Faculty of Pharmacy of the University of Coimbra, Portugal. Her research is currently devoted to the synthesis of novel bioactive steroids. She is the author and coauthor of 25 publications in peer-reviewed journals and three book chapters. 



\section{Contents}

Preface

Chapter 1

Introductory Chapter: Chemistry and Biological Activity

of Steroids - Scope and Overview

by Maria Manuel Cruz Silva and Jorge António Ribeiro Salvador

Chapter 2

Biotransformation of Steroids Using Different Microorganisms

by Arturo Cano-Flores, Javier Gómez and Rigoberto Ramos

Chapter 3

Estrone Sulfatase Inhibitors as New Anticancer Agents

by Svetlana N. Morozkina and Alexander G. Shavva

Chapter 4

Control of Liver Gene Expression by Sex Steroids and Growth Hormone Interplay

by Leandro Fernández-Pérez, Mercedes de Mirecki-Garrido, Carlota Recio and Borja Guerra

Chapter 5

Role of Androgens in Cardiovascular Diseases in Men: A Comprehensive Review

by Dilip Mukherjee, Koushik Sen, Shreyasi Gupta, Piyali Chowdhury,

Suravi Majumder and Payel Guha

Chapter 6

Steroid-Based Supramolecular Systems and their Biomedical Applications: Biomolecular Recognition and Transportation

by Ruilong Sheng 



\section{Preface}

Chemistry and Biological Activity of Steroids puts together recent contributions of scientific research to understand the physiological roles of steroids and discover new bioactive steroidal molecules.

The chapters that compose this book encompass the biotransformations of steroids, taking advantage of the striking regio- and stereoselectivity of oxidizing enzymes affording functionalized steroids that would be very difficult to obtain by conventional methods.

Estrone sulfatase is a clinically validated drug target in estrogen-dependent cancers and its inhibition by synthetic steroids is reviewed. The role of steroids in the somatotropic-liver axis, intermediate metabolism, or gender dimorphism is also discussed. Finally, exploitation of the steroid structure to develop supramolecular systems and nanomaterials for biomedical application is examined.

The editors sincerely thank the authors, who have shared their knowledge throughout the chapters of this book.

Maria Manuel Cruz Silva Centro de Neurociências e Biologia Celular,

Universidade de Coimbra, Coimbra, Portugal

Jorge António Ribeiro Salvador Laboratório de Química Farmacêutica, Faculdade de Farmácia, Universidade de Coimbra, Coimbra, Portugal 



\title{
Introductory Chapter: Chemistry and Biological Activity of Steroids - Scope and Overview
}

\author{
Maria Manuel Cruz Silva and \\ Jorge António Ribeiro Salvador
}

\section{Introduction}

Steroid compounds are widely present in living organisms playing an important role in their vital activities.

The steroidal basic structure is constituted by a common chemical skeleton of four fused rings, consisting of three six-membered rings and a five-membered ring. This hydrocarbon scaffold contains 17 carbons and has the cyclopentanoperhydrophenanthrene basic structure $[1,2]$. The four steroid rings are labelled as A, B, C and $\mathrm{D}$, and their carbon atoms are numbered according to the universal convention (International Union of Pure and Applied Chemistry/International Union of Biochemistry Joint Commission on Biochemical Nomenclature). Angular methyl groups at $\mathrm{C} 13$ and $\mathrm{C} 10$ are designated as $18-\mathrm{CH}_{3}$ and $19-\mathrm{CH}_{3}$, respectively, and alkyl substituents at C17 are the steroid side chain. The 18- and 19-methyl groups stand above the plane of the steroid skeleton and, by convention, have $\beta$-configuration. Therefore, other atoms or substituents located above this plane also have $\beta$-configuration, while those below it have $\alpha$-configuration [3].

Steroids interact with enzymes and receptors in a strikingly specific manner. Small changes in the steroid structure afford major biological differences.

Several natural and synthetic steroids are important therapeutic tools for a wide range of diseases $[4,5]$. The steroid classes present in drug therapy include, among others, corticosteroids, neurosteroids, sexual hormones, bile acids, vitamin D and cardiotonic steroids [4].

Hundreds of steroid compounds have been isolated from natural sources, and many thousands of them have been obtained synthetically over the last decades, and their chemical and biological investigation continues to be very active. In fact, the steroid scaffold continues to be the structural basis of new drugs for a variety of targets and diseases.

The book Chemistry and Biological Activity of Steroids aims to provide an updated overview of the recent advances in the medicinal chemistry of steroids.

Novel synthetic methods of steroids through the use of microorganisms as carriers of strikingly selective enzyme catalysts, able to promote reactions that would be very difficult by conventional chemical methods, continue to be an area of intensive research and enormous industrial interest. Several biotransformations at industrial scale have been applied in the production of steroids, through chemo-, regio- and stereoselective reactions, namely, hydroxylations. The chapter concerning steroid biotransformations gives an overview of the recent achievements in this field. 
The steroid hormones were discovered almost a century ago and have been found to be involved in important physiopathological conditions, being therefore important starting points for the development of drugs.

Oestrogens and androgens are two classes of steroid sex hormones responsible for female and male differentiation, respectively, and continue to be a source of questions and opportunities in deciphering the mechanisms of homeostasis and disease.

A chapter concerning the discovery of novel inhibitors of oestrone sulphatase, a clinically validated drug target in oestrogen-dependent cancers, presents the medicinal chemistry rational behind the design, synthesis and safety assessment of anticancer drug candidates for this pharmacological target. Furthermore examples of dual aromatase-sulfatase inhibitors are given, disclosing the potential of a synergistic dual inhibition.

On the other hand, sex steroids have important physiological actions, not limited to the reproductive organs. They exert important physiological roles, including the regulation of somatotropic-liver axis, intermediate metabolism or gender dimorphism. This is in part because the liver is a sex steroid-responsive organ where sex steroid- and growth hormone-dependent signalling pathways connect to regulate complex gene expression networks. Deficiency of sex steroid- and GH-dependent signalling pathways has an impact on the mammalian liver physiology. This interesting and vast topic is discussed in Chapter 4.

Finally, the usefulness of steroids in the cutting-edge technology of supramolecular systems and nanomaterials for biomedical application is discussed in the fifth chapter. The renewable and economic natural steroid compounds can be employed as building blocks in the design and construction of steroid-based supramolecular systems. Interesting characteristics of steroids, concerning physicochemical and biological properties, biocompatibility and bioactivities, make them attractive as building blocks of supramolecular systems to be employed in biomolecular recognition/sensing and biomolecular transportation.

The chemical and biological properties of steroids include a large variety of topics. This book contributes with a selection of different chapters that give updated information and critical discussions, illustrating the novelty of this old class of molecules.

\title{
Author details
}

\author{
Maria Manuel Cruz Silva ${ }^{1,2}$ and Jorge António Ribeiro Salvador ${ }^{1,2 *}$ \\ 1 Centro de Neurociências e Biologia Celular, Universidade de Coimbra, Coimbra, \\ Portugal
}
2 Laboratório de Química Farmacêutica, Faculdade de Farmácia, Universidade de Coimbra, Coimbra, Portugal

*Address all correspondence to: salvador@ci.uc.pt

\section{IntechOpen}

(C) 2020 The Author(s). Licensee IntechOpen. This chapter is distributed under the terms of the Creative Commons Attribution License (http://creativecommons.org/licenses/ by/3.0), which permits unrestricted use, distribution, and reproduction in any medium, provided the original work is properly cited. (cc) BY 


\section{References}

[1] Brueggemeier RW, Li P-K.

Fundamentals of steroid chemistry and biochemistry. In: Abraham DJ, editor. Burger's Medicinal Chemistry and Drug Discovery, Vol. 3: Cardiovascular Agents and Endocrines. 6th ed. New York: John Wiley \& Sons; 2003. pp. 594-627. DOI: 10.1002/0471266949

[2] Lednicer D. Steroid Chemistry at a Glance. Chichester: John Wiley \& Sons; 2011. DOI: $10.1002 / 9780470973639$. $144 \mathrm{p}$

[3] Moss GP. Nomenclature of steroids (recommendations 1989). Pure and Applied Chemistry. 1989;61(10):1783-1822

[4] Hill RA, Kirk DN, Makin HLJ, Murphy GM. Description of main steroid types. In: Dictionary of Steroids. London: Chapman \& Hill; 1991. pp. XIV-XXIX

[5] Salvador JAR, Carvalho JFS, Neves MAC, Silvestre SM, Leitão AJ, Silva MMC, et al. Anticancer steroids: Linking natural and semi-synthetic compounds. Natural Product Reports. 2013;30(2):324-374 



\title{
Biotransformation of Steroids Using Different Microorganisms
}

\author{
Arturo Cano-Flores, Javier Gómez and Rigoberto Ramos
}

\begin{abstract}
The introduction of a hydroxyl group "biohydroxylation" in the steroid skeleton is an important step in the synthesis of new steroids used physiologically as hormones and active drugs. There are currently about 300 known steroid drugs whose production constitutes the second category within the pharmaceutical market after antibiotics. Several biotransformations at industrial scale have been applied in the production of steroid hormones and drugs, which have functionalized different types of raw materials by means of chemo-, regio-, and stereoselective reactions (hydroxylation, Baeyer-Villiger oxidation, oxidation reactions, reduction of group carbonyl, isomerization, and Michael additions, condensation reactions, among others). In Green Chemistry, biotransformations are an important chemical methodology toward more sustainable industrial processes.
\end{abstract}

Keywords: biotransformation, steroid compounds, biological transformation, bioconversions, microorganisms

\section{Introduction}

Steroids (stereos $=$ solids) are organic compounds derived from alcohols, which are widely distributed in the animal and plant kingdoms. Their base skeleton has 17 carbon atoms in a tetracyclic ring system known as cyclopentanoperhydrophenanthrenes (gonane and estrane). In this group of substances, life-vital compounds are categorized, such as cholesterol, bile acids, sex hormones, vitamin D, corticosteroids, cardiac aglycones, and antibiotics, among others.

Some of the most potent toxins are steroid alkaloids. Steroids are responsible for important biological functions in the cell; for example, the steroids derived from androstane, pregnane, and estrane have hormonal activity [1-5]; bile acids are important for the digestion and absorption of fats; and cardiotonic aglycones are used for the treatment of heart disease. Sterols are constituents of the cell membrane, essential for cell stability and development; also, they are precursors of bile acids and steroid hormones.

A large number of steroids are used as anti-inflammatory agents [6], immunosuppressants, progestational agents, diuretics, anabolics, and contraceptives [7-9]. Some are used for the treatment of prostate and breast cancer [10, 11], for adrenal insufficiency [12], for prevention of heart disease [13], as antifungal agents [14], and as active ingredients used for the treatment of obesity [15] and AIDS [16]. Recently, the antiviral activity against the herpes simplex virus type I of some steroid glycosides was determined [17]. 
The therapeutic action of some steroid hormones has been associated with their interaction with intracellular receptors, which act as transcription factors in the regulation of gene expression [18]. It has been reported that some steroids, such as dehydroepiandrosterone (DHEA), progesterone, pregnenolone and its sulfated derivatives [19, 20], as well as, $17 \beta$-estradiol, allopregnanolone and its synthetic derivatives (afoxolaner and ganaxolone) are considered neurosteroids, due to their action at the level of the CNS [19].

The physiological activity of steroids depends on their structure, the type, number, spatial orientation, and reactivity of the different functional groups present in the tetracyclic core as well as the oxidation state of the rings. For example, the presence of an oxygenated function in $\mathrm{C}-11 \beta$ is crucial for the anti-inflammatory activity; the hydroxyl function in $\mathrm{C}-17 \beta$ determines androgenic properties; the aromatization of ring A confers estrogenic effect; and corticosteroids have the 3-keto-4-ene group and the pregnane side chain at C-17 [21, 22].

Currently, about 300 steroid drugs are known, and this number tends to grow. Their production represents the second category in the pharmaceutical market after antibiotics $[24,25]$. Nowadays, steroids represent one of the largest sectors in pharmaceutical industry with world markets in the region of US\$10 billion and the production exceeding 1,000,000 tons per year [23].

The production of steroid drugs and hormones is one of the best examples of the applications that biotransformations have on an industrial scale [3, 21]. Microbiological transformations are an effective tool for the preparation of various compounds [26], which can be difficult to obtain by conventional chemical methods and have been widely used in the bioconversion of steroids [25]. In 1950, the pharmacological effects of cortisol and progesterone were reported, in addition to the hydroxylation of the latter in C-11 $\alpha$ using Rhizopus species. This began a very important stage in the development of the synthesis of steroids with biological activity $[4,5]$.

Currently, a great versatility of microbial systems in the pharmaceutical industry for the commercial production of steroids and other drugs is recognized [27, 28]. Several hundreds of microbiological transformations of steroids have been reported in the literature; also, many bioconversions have been incorporated into numerous partial syntheses of new compounds for their evaluation such as hormones or drugs [21, 29-32]. Chemical derivatives of some steroids are reported to have better therapeutic advantages than the starting materials.

However, the main objectives in the research and development of the steroid drug industry currently consist of the detection and isolation of microbial strains with novel activity or more efficient transformation capacity, where genetic engineering and metabolic engineering can play a prominent role in the metabolism of bacteria, fungi, and plants [33-36].

The aim of the present review is to emphasize the importance of biotransformation using microorganisms to obtain steroid compounds with pharmaceutical interest, as a chemical-biological strategy that alternates with the chemical synthesis, and to highlight the chemical reaction made by different types of microorganisms in the functionalization of the steroid skeleton.

\section{Microbiological transformations of steroids}

In Green Chemistry, biotransformations constitute an important methodology in organic chemistry [37]. The microbiological transformations of steroids have been an essential chemical tool used for the preparation of many intermediaries and in the generation of new drugs, where chemical functionalization-hydroxylation, BaeyerVilliger oxidation, reduction, isomerization, Michael additions, and condensation 
reactions can be carried out in different positions of the steroid skeleton in chemo-, regio-, and stereoselective ways, being very complicated or even impossible by the classic chemical methods. Currently, any stereogenic center of the steroid skeleton can be specifically hydroxylated stereoselectively. Nowadays, biohydroxylations in $\mathrm{C}-11 \alpha, 11 \beta, 15 \alpha$, and $16 \alpha$ are industrially carried out via a microbial hydroxylation with good yields and enantiomeric excess (ee). Below are some of the microbiological transformations performed on different natural and synthetic steroids [25].

In the literature, it is the well-documented regio- and stereoselective hydroxylation in C-14 with $\alpha$ orientation in progesterone (1) and other steroids by well-functioning fungi, such as Thamnostylum piriforme (ATCC 8992), Mucor griseocyanus (ATCC 1207a), Actinomucor elegans (MMP 3132), and Zygodesmus sp. (ATCC 14716).

From the incubation of 1 with T. piriforme, 14 $\alpha$-hydroxyprogesterone (2, 32\%) and $9 \alpha$-hydroxyprogesterone $(3,1.4 \%)$ were obtained; whereas in the incubation of 1 with $M$. griseocyanus, 2 (13.4\%), 7 $\alpha, 14 \alpha$-dihydroxyprogesterone (4, 6.5\%) and $6 \beta, 14 \alpha$-dihydroxyprogesterone $(5,2.8 \%)$ were obtained. In the biotransformation of 1 using $A$. fumigatus after $24 \mathrm{~h}$ of incubation, different mono-and dihydroxylated products were obtained: $11 \alpha$-hydroxyprogesterone $(6,33 \%)$, $11 \alpha, 15 \beta$-dihydroxyprogesterone $(7,17 \%), 7 \beta, 15 \beta$-dihydroxyprogesterone $(8,14 \%)$, 15 $\beta$-hydroxyprogesterone (9), $7 \beta$-hydroxyprogesterone (10), where 9 and 10 were detected in minimal quantity. Finally, at $72 \mathrm{~h}$, the main products were $7(48 \%)$ and $8(25 \%)$, with the positions $11 \alpha$ and $15 \beta$ being hydroxylated more easily than the position $7 \beta$ in $1[38,39]$.

In the incubation of 1 with Saprolegnia hypogyna, 4-androstene-3,17-dione (11), testosterone (12), and testolactone (13) were obtained [40]. The compounds 13 (98\%) were also obtained from the bioconversion of 1 using A. sojae (PTCC 5196). The biotransformation pathway indicating the presence of Baeyer-Villiger monooxygenase (BVMO) can carry out both oxygenative esterification of 20-ketosteroids and oxygenative lactonization of 17-ketosteroids [41]. The compounds $15 \alpha$-hydroxyprogesterone $(\mathbf{1 4}, 47 \%)$ and $12 \beta, 15 \alpha$-dihydroxyprogesterone $(15,25 \%)$ were isolated in the biotransformation of 1 using Fusarium culmorum [42]. In the biotransformation of 1 using the bacterium, thermophilic Bacillus stearothermophilus, four products of monohydroxylation, $20 \alpha$-hydroxyprogesterone $(16,61 \%)$, $6 \beta$-hydroxyprogesterone $(17,21 \%)$ and $6 \alpha$-hydroxyprogesterone $(18,14 \%)$, and 9,10-seco-pregnen-3,9,20-trione (19, 4\%), were isolated [43].

An efficient regio- and stereoselectivity was observed in the biotransformation of 1 on a large scale by the system Mucor 881 (M881) to give the hydroxylated

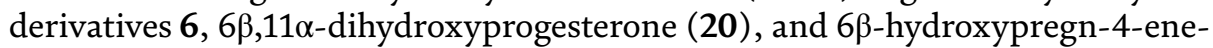
3,11,20-trione (21). In the literature, it is described that species of the genus Mucor and Rhizopus can hydroxylate said positions but with lower yields. The fungal system M881 showed the ability to carry out hydroxylation at $6 \beta$ and $11 \alpha$ positions of 4-ene-3-one steroids $(\mathbf{1}, \mathbf{1 1}, 12$ and 211) [44].

Recently, it was reported that in the biotransformation of $\mathbf{1}$ using Penicillium aurantiogriseum for 10 days, 11 and androsta-1.4-dien-3,17-dione (22) were obtained. These products were observed in the biotransformation of $\mathbf{1}$ using Bacillus sphaericus; the hydroxylation in C-17 was mainly observed [45, 46]. Biotransformation of 1 using Geobacillus gargensis (DSM 15378) has resulted in the production of secoderivatives: 19 and 23 (9,10-seco-4-pregnene-20 $\alpha$-hydroxy-3,9-dione), which are produced by the rupture of the ring B of $\mathbf{1}$ (Figure 1) [47]. Secosteroids are an important group, which exhibits a variety of different biological activities [48, 49].

In the biotransformation of $5 \beta$-dihydroprogesterone (24) using T. piriformis, $14 \alpha$-hydroxy-5 $\beta$-pregnan-3,20-dione $(25,11.8 \%), 3 \beta, 14 \alpha$-dihydroxy- $5 \beta$-pregnan-20one $(26,0.5 \%)$, and $14 \alpha, 15 \beta$-dihydroxy-5 $\beta$-pregnan-3,20-dione (27, $0.4 \%)$ were characterized, while in the biotransformation of $3 \beta$-hydroxy- $5 \beta$-pregnan-20-one (28), 26 


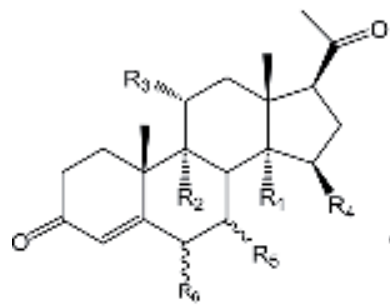

1) $R_{1}=R_{c}=R_{s}=R_{1}=R_{5}=R_{8}=H$

2) $R_{1}=O H, R_{2}=R_{3}=R_{2}=R_{r_{1}}=R_{t_{1}}=H$

3) $R_{1}=R_{5}=R_{4}=R_{5}=R_{8}=H, R_{2}=O H$

4) $R_{1}=O H, R_{2}=R_{3}=R_{4}=R_{t i}=H, R_{t}=\omega O H$

5) $R_{1}=O H_{4} R_{8}=\left[\% H_{2} R_{2}=R_{3}=R_{2}=R_{5}=H\right.$

6) $R_{1}=R_{2}=R_{4}=R_{5}=R_{12}=H, R_{3}=O H$

7) $\mathrm{R}_{1}=\mathrm{R}_{2}=\mathrm{R}_{\mathrm{s}}=\mathrm{R}_{\mathrm{g}}=\mathrm{H}_{2} \mathrm{R}_{3}=\mathrm{R}_{\mathrm{f}}=\mathrm{OH}$

8) $R_{1}=R_{2}=R_{3}=R_{5}=R_{t_{2}}=H, R_{4}=O H$

9) $R_{1}=R_{2}=R_{5}=R_{5}=R_{8}=H_{2} R_{4}=O H$

10) $R_{1}=R_{2}=R_{2}=R_{4}=R_{5}=H, R_{t_{1}}=\beta O H$

20) $R_{1}=R_{2}=R_{4}=R_{5}=H_{1}, R_{5}=O H, R_{6}=B O H$

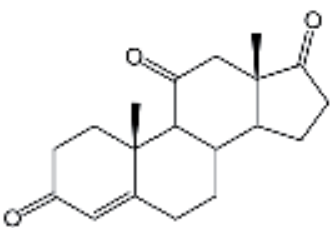

21<smiles>C[C@]12CCC3C(CCC4=CC(=O)C=C[C@@]43C)C1CCC(=O)O2</smiles>

13

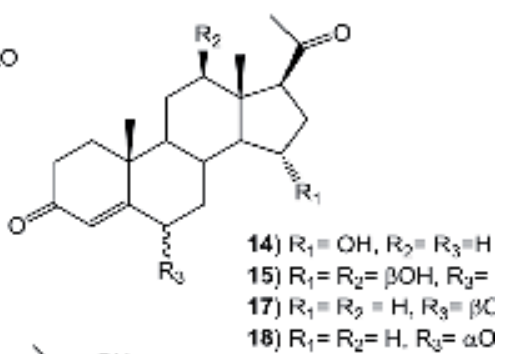<smiles>C[C@H](O)[C@H]1CCC2C3CCC4=CC(=O)CC[C@]4(C)C3CC[C@]21C</smiles>

16<smiles>C[C@]12CCC3C(CCC4=CC(=O)CC[C@]43C)C1CCC2=O</smiles>

22) $s^{1: 2}$

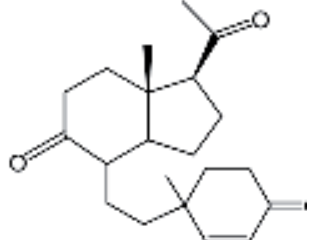

19

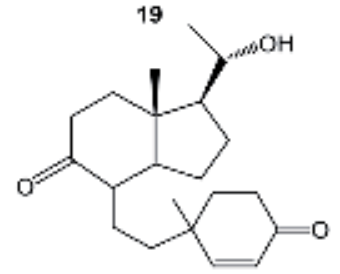

19

Figure 1.

Biotransformation products of progesterone (1).

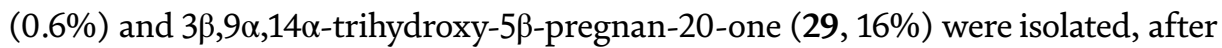
being incubated for $96 \mathrm{~h}$. The microbiological transformation of 28 using Actinomucor elegans produced the compounds $\mathbf{2 5}$ and $\mathbf{2 8}$ in lower yield than T. piriforme and a minor product identified as $3 \beta, 9 \alpha$-dihydroxy-5 $\alpha$-pregnan-20-one (30) (Figure 2) [38].

The biotransformation of 16-dehydroprogesterone (4,16-pregnadien-3,20-dione, 31) using Mucor piriformis has been reported to give different hydroxylation products: $14 \alpha$-hydroxypregna-4,16-dien-3,20-dione (32, 1\%), 7 $\alpha, 14 \alpha$-dihydroxypregna-4,16-

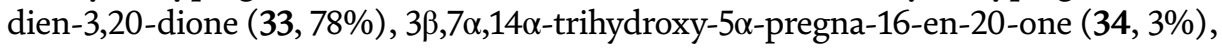
and $3 \alpha, 7 \alpha, 14 \alpha$-trihydroxy-5 $\alpha$-pregna-16-en-20-one $(35,2 \%)$; while the microsomes

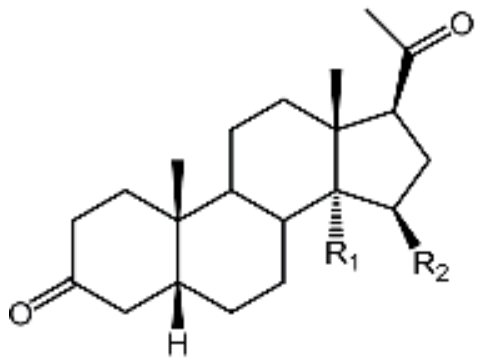

24) $R_{1}=R_{2}=H$

25) $\mathrm{R}_{1}=\mathrm{OH}, \mathrm{R}_{2}=\mathrm{H}$

27) $R_{1}=R_{2}=O H$

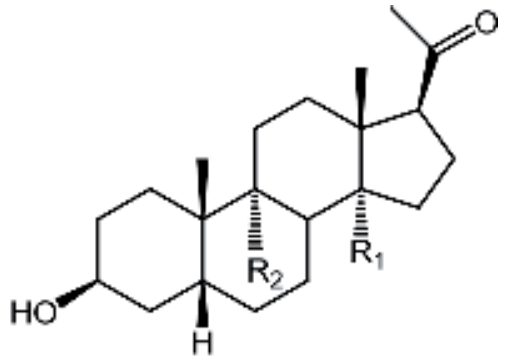

26) $\mathrm{R}_{1}=\mathrm{OH}, \mathrm{R}_{2}=\mathrm{H}$

28) $R_{1}=R_{2}=H$

29) $R_{1}=R_{2}=O H$

30) $R_{1}=H, R_{2}=O H$

Figure 2.

Biotransformation products of $5 \beta$-dihydroprogesterone (24). 
prepared from 31 transformed the hydroxylate to $14 \alpha$-hydroxy derivative (32).

Incubation of 32 with $M$. piriformis resulted in the formation of 33-35 (Figure 3) [50].

In contrast, in the biotransformation of $17 \alpha$-hydroxyprogesterone (36) using M. piriformis, after $48 \mathrm{~h}$ of incubation, four compounds were obtained: $17 \alpha, 20 \alpha-$ dihydroxypregn-4-en-3-one (37, 19\%), 7 $\alpha, 17 \alpha$-dihydroxypregn-4-en-3,20-dione

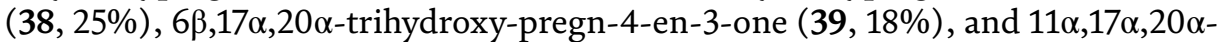
trihydroxypregn-4-en-3-one $(40,25 \%)$; it was observed that $M$. piriformis was able to hydroxylate the C-6, C-7, C-11, and C-14 positions stereospecifically, in addition to reducing the 4-en-3-one system in ring $\mathrm{A}$ and the keto group of C-20 (Figure 4) [50]. The biotransformation of 36 using Fusarium culmorum led to the formation of $14(47 \%)$ and $15(25 \%)$ [42].

Pregnenolone (3ß-hydroxypregn-5-en-20-one, 41), the precursor of many steroid hormones, was biotransformed by $M u c o r$ piriformis to obtain two metabolites, $3 \beta, 7 \alpha$-dihydroxypregn-5-en-20-one (42) and 3 $\beta, 7 \alpha, 11 \alpha$-trihydroxypregn-5-en20-one (43) [51], where 43 (46.4\%) was also a bioconversion product of 41 using Mucor circinelloides var. lusitanicus [52]. Two metabolites of pregnenolone (41) obtained from biotransformation of $B$. cinereae were characterized as $3 \beta, 11 \alpha, 16 \beta-$ trihydroxypregn-5-en-20-one $(44,39 \%)$ and $11 \alpha, 16 \beta$-dihydroxypregn-4-en-3,20dione $(45,6 \%)$. The formation of the hydroxylation products in C-11 and C-16 by B. cinereae can be determined by the presence of the acetyl group in C-20 [53]. The biotransformation of $\mathbf{4 1}$ using different microorganisms (Cunninghamella elegans, R. stolonifer, and G. fujikuroi) was reported by Choudhary et al. [54]. Incubation of 41 with C. elegans produced $3 \beta, 7 \beta, 11 \alpha$-trihydroxypregn-5-en-20-one $(46,28 \%)$, $3 \beta, 6 \alpha, 11 \alpha, 12 \beta, 15 \beta$-pentahydroxypregn-4-en-20-one (47, $4 \%)$, and $3 \beta, 6 \beta, 11 \alpha-$ trihydroxypregn-4-en-20-one (48,2\%), while incubation with G. fujikuroi, two products $3 \beta, 7 \beta$-dihydroxypregn-5-en-20-one $(49,3 \%)$ and $6 \beta, 15 \beta$-dihydroxypregn4 -en-3,20-dione $(50,2 \%)$ were obtained. In the microbiological transformation of 41 using different Bacillus strains, 42, 49, and 7-oxo-pregnenolone (51) were the major products obtained [55], while by using Fusarium oxysporum var. cubense, 42 was the only product obtained [56]. The biotransformation of pregnenolone acetate

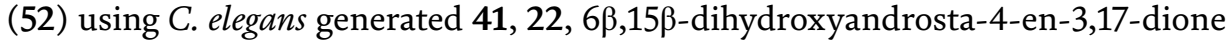
(53), and $11 \alpha, 15 \beta$-dihydroxypregn-4-en-3,20-dione (54), while by using $R$. stolonifer, 11 $\alpha$-hydroxypregn-4-en-3,20-dione (55) and 53 were obtained (Figure5) [54].

The microbiological transformation of the racemic mixture of 13-ethyl-17 $\beta$ hydroxy-18,19-dinor-17 $\alpha$-pregn-4-en-20-yn-3-one (56) was tested with different fungi Rhizopus nigricans, $R$. arrhizus, Aspergillus niger, A. ochraceus, and Curvularia lunata. The bioconversion of the racemic mixture of 53 by $R$. arrhizus produced only one major product, $( \pm$ )-13-ethyl-10 $\beta, 17 \beta$-dihydroxy-18,19-dinor-17 $\alpha$-pregn-4-en-20-yn-3-one
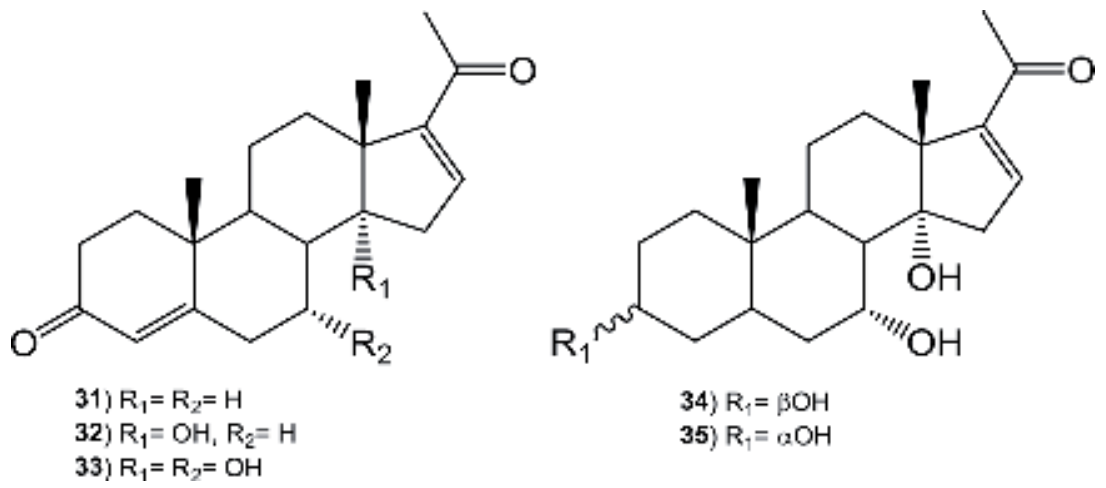

Figure 3.

Biotransformation products of 16-dehydroprogesterone (31). 


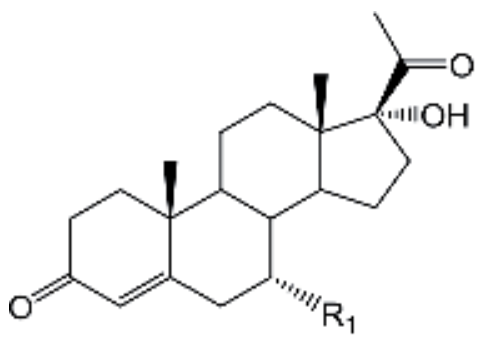

36) $\mathrm{R}_{1}=\mathrm{H}$

38) $\mathrm{R}_{1}=\mathrm{OH}$

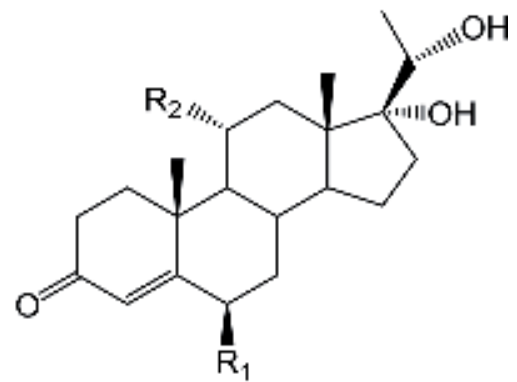

37) $\mathrm{R}_{1}=\mathrm{R}_{2}=\mathrm{H}$

39) $\mathrm{R}_{1}=\mathrm{OH} \mathrm{R}_{2}=\mathrm{H}$

40) $R_{1}=H, R_{2}=O H$

Figure 4.

Biotransformation products of $17 \alpha$-hydroxyprogesterone (36).

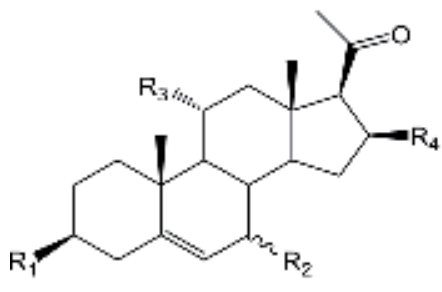

41) $R_{1}=O H, R_{2}=R_{2}=R_{4}=H$

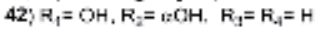

43) $\mathrm{R}_{1}-\mathrm{R}_{3}-\mathrm{OH}, \mathrm{R}_{2}=\mathrm{aCH}, \mathrm{R}_{2}-\mathrm{H}$

44: $\mathrm{R}_{1}=\mathrm{R}_{\mathrm{S}}=\mathrm{OH}, \mathrm{R}_{4}=\omega \mathrm{OH}, \mathrm{R}_{4}=\mathrm{H}$

46) $R_{1}=O H, R_{2}=P O H R_{3}=R_{2}=H$

49) $\mathrm{R}_{1}=\mathrm{OH}, \mathrm{R}_{2^{-}} \mathrm{BOH}, \mathrm{R}_{3}=\mathrm{R}_{4}=\mathrm{H}$

51) $R_{1}=O H, R_{2}=R_{3}=R_{4}=H$

52) $R_{1}=A$ c. $R_{2}=R_{3}=R_{1}=H$

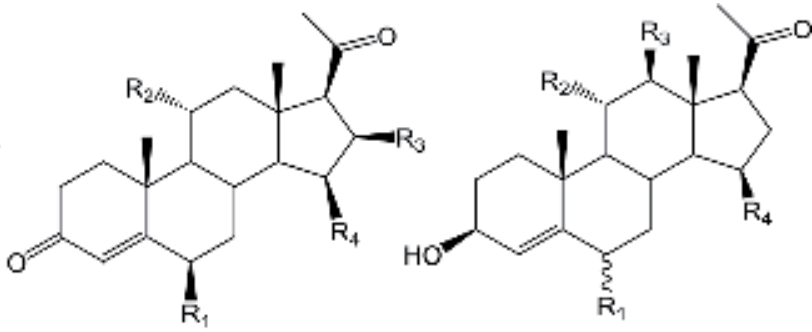

45) $\mathrm{R}_{1}-\mathrm{R}_{4}-\mathrm{H}_{1} \mathrm{R}_{2}-\mathrm{R}_{3}-\mathrm{OH}$ so) $R_{1}=R_{2}=C H$. $R_{2}=R_{3}=H$ 53) $\mathrm{R}_{1}-\mathrm{R}_{1}-\mathrm{OH}_{1} \mathrm{R}_{2}-\mathrm{R}_{2}-\mathrm{H}$ 54) $\mathrm{R}_{1}-\mathrm{R}_{3}-\mathrm{H}_{1} \mathrm{R}_{2}-\mathrm{R}_{4}-\mathrm{OH}$ 55) $R_{1}=R_{3}=R_{4}=H_{1} R_{2}=O H$
47) $\mathrm{R}_{1}=\alpha O H, \mathrm{R}_{2}=\mathrm{R}_{\mathrm{S}}=\mathrm{R}_{4}=\mathrm{OH}$ 48) $R_{1}=\mu C H, R_{2}=O H, R_{3}=R_{1}=H$

Figure 5.

Biotransformation products of pregnenolone (41) and acetyl derivate (52).

(57, 28.4\%), whereas $R$. nigricans, A. niger, and C. lunata biotransformed 56 to 57 more slowly and inefficiently [57].

The racemic mixture ( \pm )-13-ethyl-7 $\beta, 17 \beta$-dihydroxy-18,19-dinor-17 $\alpha$-pregn4-en-20-yn-3-one $(58,4.3 \%)$ was obtained as product of incubating mixture 56 with $A$. ochraceus; none of the fungi tested were able to differentiate the two enantiomers of 56 in the course of the hydroxylation reaction; in addition, the absence of the hydroxylated derivative in C-11 is due to the presence of the ethyl group in C-13 or the ethynyl group in C-17 [57]. The microbiological transformation of the racemic mixture and the dextro enantiomer of compound 56 has been described using different species of Cunninghamella [58]. For example, the transformation of the racemic mixture of 56 by C. blakesleeana (AS 3.910) produced

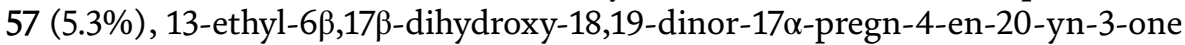
(59, 3.6\%), 13-ethyl-15 $\alpha, 17 \beta$-dihydroxy-18,19-dinor-17 $\alpha$-pregn-4-en-20-yn-3-one $(60,3.0 \%)$, and 13 -ethyl-6 $\beta, 10 \beta, 17 \beta$-trihydroxy-18,19-dinor-17 $\alpha$-pregn-4-en20-yn-3-one (61, 3.6\%), while by using C. echinulata (AS 3.1990), 61 (3.2\%), 57 $(1.2 \%)$, and enantiomer dextro of $58(2.9 \%)$ were obtained. The transformation of the enantiomer dextro of 56 using C. blakesleeana produced 57 (1.2\%), 58 (2.9\%), and 61 (3.2\%), by using C. echinulata, the same compounds were obtained but in lower yield. Therefore, the microbial transformation of the racemic mixture and the $d$-enantiomer of 56 using different Cunninghamella species gave poor yields and poor resolutions, which were obtained for the hydroxylation reaction (Figure 6) [58]. 


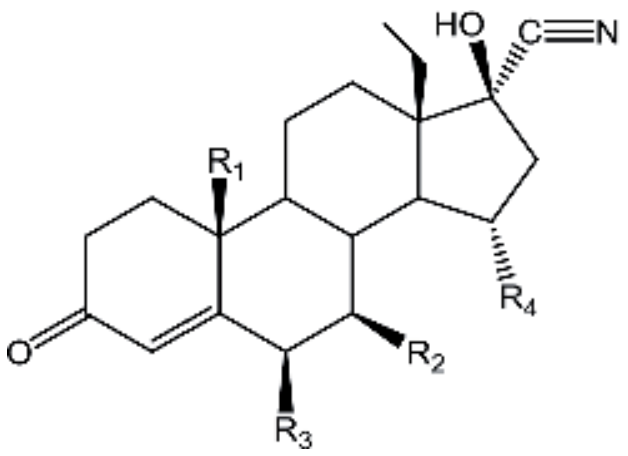

56) $R_{1}=R_{2}=R_{3}=R_{4}=H$
57) $R_{1}=O H, R_{2}=R_{3}=R_{4}=H$
58) $R_{1}=R_{3}=R_{4}=H, R_{2}=O H$
59) $R_{1}=R_{2}=R_{4}=H, R_{3}=O H$
60) $R_{1}=R_{2}=R_{3}=H, R_{4}=O H$
61) $R_{1}=R_{3}=O H, R_{2}=R_{4}=H$

Figure 6.

Biotransformation products of (+)-13-ethyl-17 $\beta$-hydroxy-18, 19-dinor-17 $\alpha$-pregn-4-en-20-yn-3-ona (56).

The biotransformation of danazol (17 $\beta$-hydroxy-17 $\alpha$-pregna-2,4-dien-20yno-[2,3-d]-isoxazole, 62), a heterocyclic steroid drug in which an isoxazole ring is fused with ring-A of a steroid nucleus, using Fusarium lini, A. niger and Cephalosporium aphidicola yielded 17 $\beta$-hydroxy-2-(hydroxymethyl)-17 $\alpha$-pregn-4en-20-yn-3-one (63) and 17 $\beta$-hydroxy-2-(hydroxymethyl)-17 $\alpha$-pregn-1,4-dien-20yn-3-one (64); while Bacillus cereus afforded 64, as the only product [59]. Microbial transformation of danazol (62) using C. blakesleeana yielded four compounds: $14 \beta, 17 \beta$-dihydroxy-2-(hydroxymethyl)-17 $\alpha$-pregn-4-en-20-yn-3-one $(65,1.2 \%)$, $1 \alpha, 17 \beta$-dihydroxy-17 $\alpha$-pregna-2,4-dien-20-yno-[2,3-d]-isoxazole $(66,1.2 \%)$, and $6 \beta, 7 \beta$-dihydroxy-17 $\alpha$-pregna-2,4-dien-20-yno-[2,3-d]-isoxazole $(67,0.8 \%)$ and 64 (1.2\%). This involves hydroxilations al C-1, C-6 and C-15, whereas oxidation at C-3, and N-O bond cleavage has also occurred (Figure 7) [60].

Norethisterone (17 $\alpha$-ethynyl-19-nortesterone, 68 ) is a potent progestin used as a contraceptive agent; its biotransformation with Cephalosporium aphidicola (IMI $68689)$ produced the aromatization of ring A that yielded $17 \alpha$-ethynylestradiol (69), whereas 69 was biotransformed by Cunninghamella elegans (NRRL 1392) producing the compounds 19 -nor-17 $\alpha$-pregna-1,3,5(10)-trien-20-yn3,4,17 $\beta$-triol (70), 19-nor-17 $\alpha$-pregna-1,3,5(10)-trien-20-yn-3,7 $\alpha, 17 \beta$-triol (71), 19 -nor-17 $\alpha$-pregna-1,3,5(10)-trien-20-yn-3,11 $\alpha, 17 \beta$-triol (72), 19-nor-17 $\alpha$ pregna-1,3,5(10)-trien-20-yn-3,6 $\beta, 17 \beta$-triol (73), and 19-nor-17 $\alpha$-pregna-1,3,5(10)trien-20-yn-3,17 $\beta$-diol-6 $\beta$-methoxy (74) (Figure 8) [61].

Mestranol (75) and 17 $\beta$-methoxymestranol (76) are the mono- and dialkylated derivatives of 69 , respectively. In incubating 75 with C. elegans, two hydroxylated compounds were obtained: $6 \beta$-hydroxymestranol $(77,2.8 \%)$ and $6 \beta, 12 \beta$ dihydroxymestranol $(78,3.6 \%)$, inferring that the presence of the methoxyl group in $\mathrm{C}-3$ reduces the number of biotransformation products and introduces hydroxyl groups in C- 6 and C-12 with $\beta$ orientation, while 76 was not biotransformed due to the presence of the methoxyl group in C-17 (Figure 9) [62].

Microbial transformation of 6-dehydroprogesterone (79) using $A$. niger yielded five metabolites: $6 \beta$-chloro-7 $\alpha, 11 \alpha$-dihydroxypregna-4-en-3,20-dione $(80,1.0 \%)$,

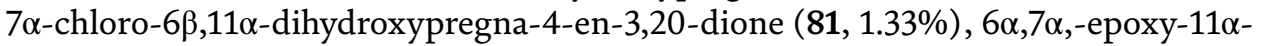
hydroxypregna-4-en-3,20-dione (82, 1.33\%), 6 $\alpha, 7 \alpha$,-epoxy-pregna-4-en-3,20-dione $(83,2.0 \%)$, and $11 \alpha$-hydroxypregna-4,6-dien-3,20-dione $(84,2.33 \%)$. Compound $11 \alpha$-hydroxyandrosta-4,6-dien-3-one $(85,15.4 \%)$ was obtained through whole cell biotransformation of 79 by G. fujikuroi (ATCC 10704). The formation of 80 and 81 is an interesting finding. This route provides an efficient method for the obtention of chlorohydrins from alkene functionality [63]. The compound 84 was obtained through the microbial transformation of 79 using R. nigricans [64], Nigrospora sphaerica, Mucor racemosus, and Botryosphaeria obtusa. 6-dehydroprogesterone (79) 

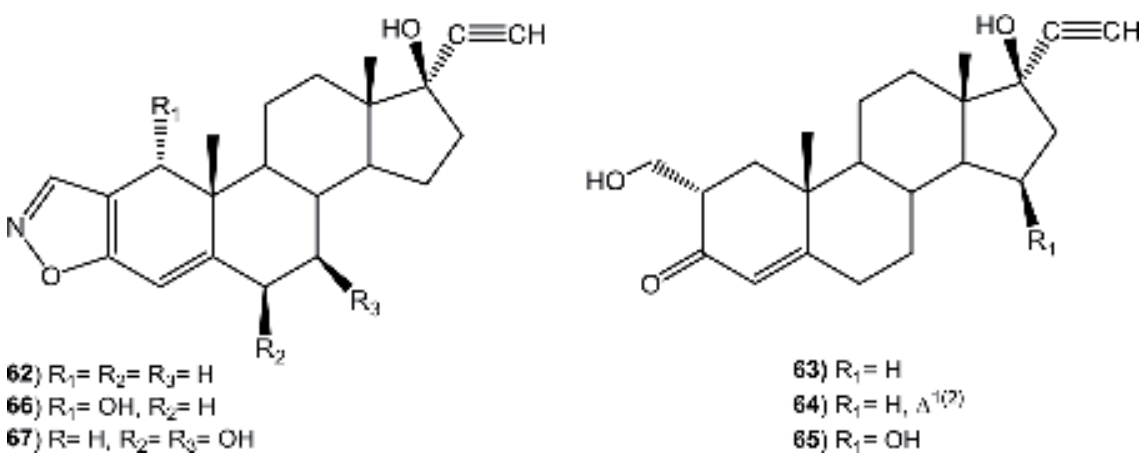

63) $\mathrm{R}_{1}=\mathrm{H}$

64) $\mathrm{R}_{1}=\mathrm{H}, \mathrm{A}^{-1 \mathrm{i} ?}$ ?

65) $\mathrm{R}_{1}=\mathrm{OH}$

Figure 7.

Biotransformation products of danzol (62)

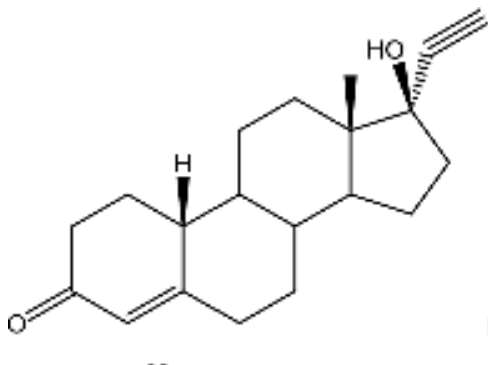

68

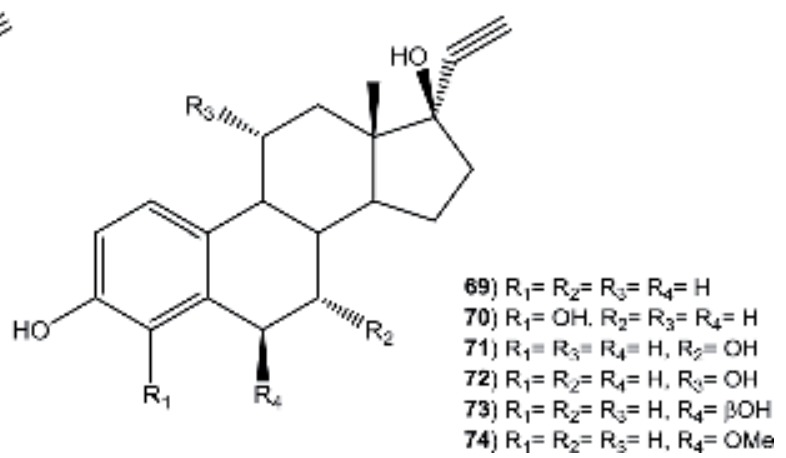

Figure 8.

Biotransformation products of norethisterone (68) and 170-ethinylestradiol (69).

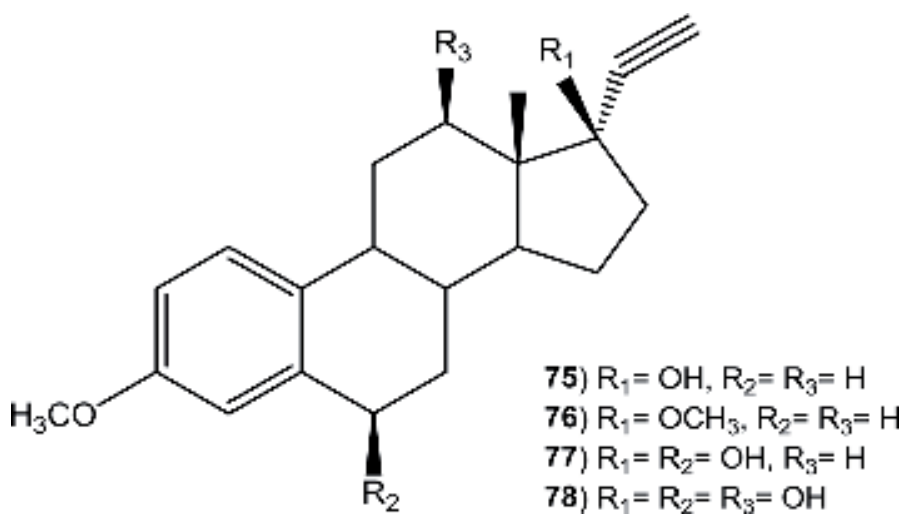

Figure 9.

Biotransformation of products of mestranol (75).

is a synthetic derivate of progesterone. Botryodiplodia theobromae was used for the synthesis of 6-DPH from progesterone (Figure 10) [65].

Incubation of melengestrol acetate (86) with C. blakesleeana, which provides an route for the monohydroxylation of the (86) at C-11, yielded a $17 \alpha$-acetoxy-11 $\beta$ hydroxy-6-methylenepregna-4,6-diene-3,20-dione (87) (Figure 11) [66].

Biotransformation of $3 \beta$-hydroxy- $17 \beta$-carboxyethyl- $5 \beta$ androstenol (88) using T. pyriformis resulted in the mixture of 
<smiles>[R2][C@H]1C[C@]2(C)[C@@H](C(C)=O)CC[C@H]2C2C=CC3=CC(=O)CC[C@]3(C)[C@H]21</smiles>

79) $R_{1}=H$

84) $\mathrm{R}_{1}=\mathrm{OH}$

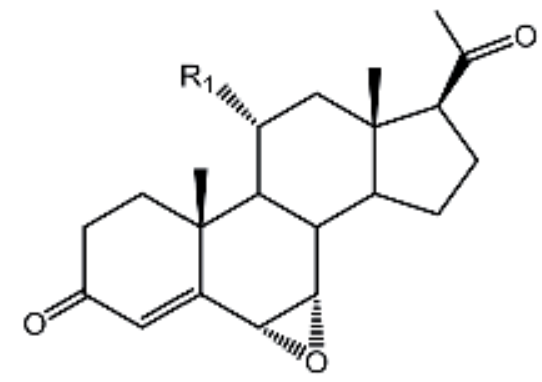

82) $\mathrm{R}_{1}=\mathrm{OH}$

83) $R_{1}=H$

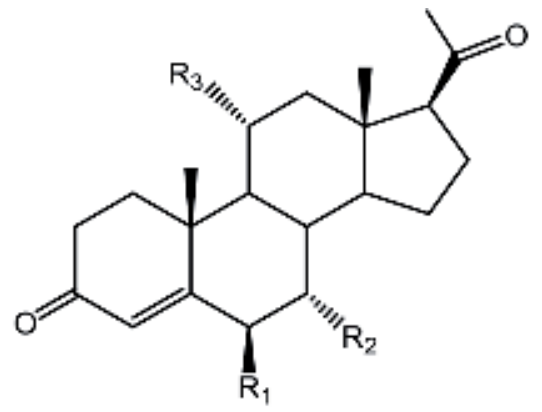

80) $\mathrm{R}_{1}=\mathrm{Cl}, \mathrm{R}_{2}=\mathrm{R}_{3}=\mathrm{OH}$

81) $R_{1}=R_{3}=O H, R_{2}=C l$<smiles>C[C@]12CCC(=O)C=C1C=CC1C2[C@@H](O)C[C@]2(C)C1CC[C@@H]2O</smiles>

85

Figure 10.

Biotransformation products of 6-dehydroprogesterone (79).

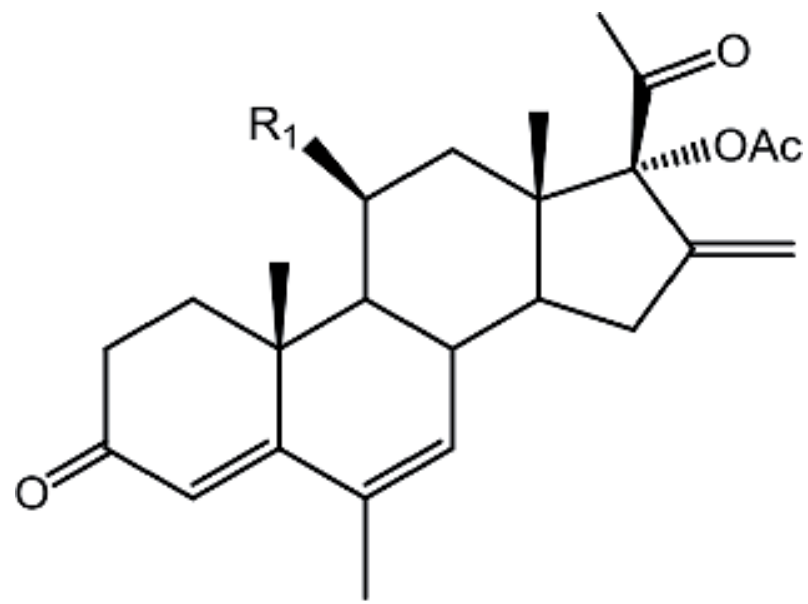

$$
\begin{aligned}
& \text { 86) } \mathrm{R}_{1}=\mathrm{H} \\
& \text { 87) } \mathrm{R}_{1}=\mathrm{OH}
\end{aligned}
$$

Figure 11.

Biotransformation products of melengestrol acetate (86). 


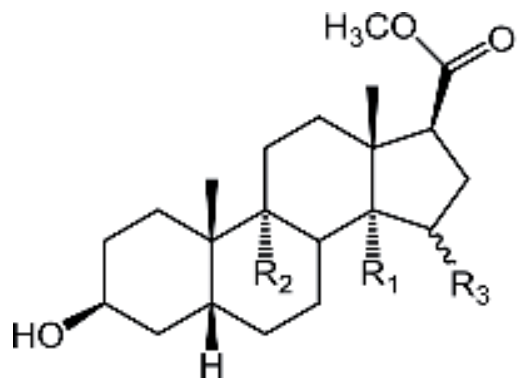

88) $R_{1}=R_{2}=R_{3}=H$

89) $R_{1}=O H, R_{2}=R_{3}=H$

90) $\mathrm{R}_{1}=\mathrm{R}_{2}=\mathrm{OH}_{1} \mathrm{R}_{3}=\mathrm{H}$

91) $\mathrm{R}_{1}=\mathrm{OH}, \mathrm{R}_{2}=\mathrm{H}, \mathrm{R}_{3}=\alpha \mathrm{OH}$

92) $R_{1}=R_{2}=H, R_{3}=\beta O H$

Figure 12.

Biotransformation products of $3 \beta-17 \beta$-carboxyethyl-5 $\beta$-androsteno (88).

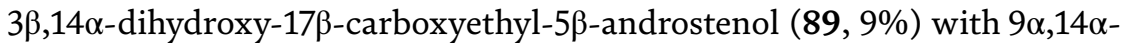
dihydroxy derivative $(90,12 \%)$ and two minor products $14 \alpha, 15 \alpha$-dihydroxy (91) and 15 1 -hydroxy (92). Compound 92 was identified as a product of biotransformation using A. elegans, M. griseocyamus, and Zygodesmus sp. (Figure 12) [38].

Androst-4-en-3,17-dione (11), which plays an important role in the metabolism of drugs, among many other functions, was biotransformed using $M$. piriformis to give one main product, $6 \beta$-hydroxyandrost-4-en-3,17-dione $(93,13 \%)$, and four minor products, $14 \alpha$-hydroxyandrost-4-en-3,17-dione (94, 2\%), $7 \alpha$-hydroxyandrost4-en-3,17-dione $(95,2 \%)$, testosterone $(12,3 \%)$, and $6 \beta$-hydroxytestosterone (96, 1\%). In the biotransformation of 11 using M. griseocyamus 94 (9\%), 95 (4\%) and $14 \alpha$-hydroxytestosterone (97, 9\%) were the major products obtained; likewise, 11 and 93 were identified in the mixture of biotransformation products [67]. From the incubation of 11 with $M$. piriformis, 94-97 and 7 $\alpha, 14 \alpha$-dihydroxytestosterone (98) were obtained [38]. Hydroxylated steroids in C-9 are important intermediaries in the synthesis of highly effective anti-inflammatory drugs. The microbiological transformation of $\mathbf{1 1}$ to $9 \alpha$-hydroxyandrost-4-en-3,17-dione (99) was studied using Rhodococcus sp. in a low-nutrient culture medium at a fixed pH (Figure 13) [68]. When 11 was incubated with Bacillus strain HA-V6-3, the metabolites 12, 93-97,

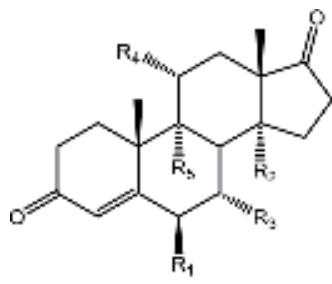

11) $R_{1}-R_{0}-R_{3}-R_{-}-R_{5}-H$ 93) $R_{1}=O H . R_{2}=R_{2}=R_{1}=R_{8}=H$

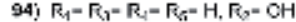
95) $\mathrm{R}_{1}-\mathrm{R}_{2}-\mathrm{R}_{4}-\mathrm{R}_{\mathrm{z}}-\mathrm{H} . \mathrm{R}_{\mathrm{y}}-\mathrm{CH}$ 99; $R_{1}-R_{2}-R_{3}-R_{3}-H . R_{3}-C H$ 100) $R \cdot-R_{2}-O H, R_{3}-R_{2}-R_{t}-H$ 101) $F \cdot=R_{2}=F_{s}=R_{y}=H_{1} R_{1}=O H$ 108) $F \cdot=R_{1}=O H \quad R_{2}=R_{g}=R_{g}=H$

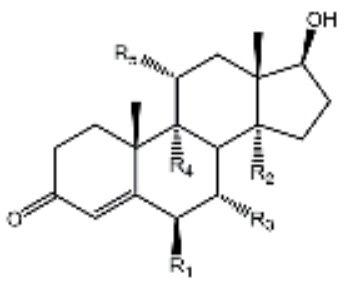

12) $R_{1}-R_{2}-R_{2}-R_{c}-R_{5}-H$ 96) $R_{4}=C H, R_{0}=R_{1}=R_{4}=R_{6}=H$ 97) $R_{1}=R_{2}=R_{4}=R_{5}-H$. $R_{2}=\mathrm{OH}$ 9U) $R_{1}=R_{4}=R_{2}=H . \quad R_{2}=R_{3}=\mathrm{dH}$ 104i $R_{1}=R_{2}=R_{3}=R_{c}=R_{j}=H$, s s: $^{1: 2}$ 106) $R_{1}=R_{3}=R_{2}=R_{2}=H_{2}, R_{r}=O H$ 110) $F_{1}=R_{5}=O H \quad R_{2}=F_{3}-F_{4}=H$<smiles>C[C@]12CCC(C3CC(=O)C4CC(=O)CC[C@@]43C)[C@@]1(C)CCC2=O</smiles>

102) $3^{451}$

103<smiles>CC[C@@H](O)C[C@@]1(C)C2CC[C@@]3(C)C[C@H](O)CC[C@]3(C)C2CC[C@@H]1O</smiles><smiles>[R8][C@@H]1CC(=O)[C@]2(C)CCC3[C@@H](CCC4=CC(=O)C=C[C@]43C)[C@]12[R]</smiles>

105) $R_{1}-R_{2}-H$ 107) $R_{1}=\mathrm{OH} . \mathrm{R}_{2}-\mathrm{H}$ 111) $\mathrm{R}_{1}-\mathrm{H} . \mathrm{R}_{2}-\mathrm{OH}$

Figure 13.

Biotransformation products of androst-4-en-3, 17-diona (11). 


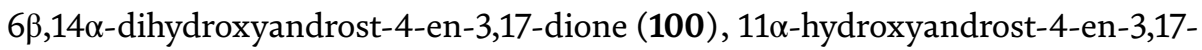
dione (101), androst-4-en-3,6,17-trione (102), and 5 $\alpha$-androst-3,6,17-trione (103) were produced as described by Schaaaf and Dettner [69].

In the bioconversion of $\mathbf{1 1}$ using C. aphidicola, 93 and 94 were obtained [70], while in the fermentation of $\mathbf{1 1}$ using Curvularia lunata, the products $\mathbf{1 0 1}$ (4\%), 17 $\beta$-hydroxyandrost-1,4-dien-3-one (104, 4.4\%), androsta-1,4-dien3,17-dione (105, 3\%), 11 $\alpha, 17 \beta$-dihydroxyandrost-4-en-3-one (106, 4\%), and 107 (15 $\alpha$-hydroxyandrost-1,4-dien-3,17-dione, 2.8\%) were obtained (Figure 13) [71]. Biotransformation of $\mathbf{1 1}$ using Beauveria bassiana was studied in times and with culture media at different $\mathrm{pH}$ (pH 6 and 7) [72]. At $\mathrm{pH} \mathrm{6,} \mathrm{two} \mathrm{products} \mathrm{were} \mathrm{obtained:}$ 106 and $6 \beta, 11 \alpha$-dihydroxyandrost-4-en-3,17-dione (108), where the stereoselective hydroxylation was observed at C-11 $\alpha$ and $\mathrm{C}-6 \beta$; while at $\mathrm{pH} 7$, the compounds 12 , 106, $3 \alpha, 11 \alpha, 17 \beta$-trihydroxy-5 $\alpha$-androstane (109), and $6 \beta, 11 \alpha, 17 \beta$-trihydroxyandrost-4-en-3-one (110) were obtained. Products 93 (14\%) and 94 (75\%) were isolated from the biotransformation of $\mathbf{1 1}$ using Chaetomium sp. (Figure 13) [73].

Obtaining hydroxylated derivatives in a specific position is one of the objectives of the steroid industry; for example, $14 \alpha$-hydroxysteroids are shown to have antiinflammatory, contraceptive, and antitumor activities. With the biotransformation of 11 and 105 using different strains of the fungus, C. lunata allowed in the case of 11, the production of a major product, 94 ; while with $105,14 \alpha$-hydroxyandrost-1,4dien-3,17-dione (111, 70\%) was obtained (Figure 13) [74].

Androsta-1,4-dien-3,17-dione (105) is a useful precursor in the chemical or microbiological preparation of other steroid hormones and pharmaceutical. Transformation of $\mathbf{1 0 5}$ by Colletotrichum lini (As3.486) produced the hydroxylated compounds at C-11 $\alpha$ and C-15 $\alpha$ : $15 \alpha$-hydroxyandrost-1,4-dien-3,17-dione (107), $11 \alpha, 15 \alpha$-dihydroxyandrost-1,4-dien-3,17-dione (112), and $15 \alpha, 17 \beta$ dihydroxyandrost-1,4-dien-3-one (113) (Figure 14) [75].

Testosterone (12) was metabolized by M. griseocyamus and T. piriforme. In the biotransformation of 12 using $M$. griseocyamus, 97 (35\%) and other products were obtained, where 94 was identified as the major product. Conversely, the microbiological transformation of 12 using T. piriforme produced 97 (10\%), as the main product at $24 \mathrm{~h}$; after $72 \mathrm{~h}$ of biotransformation, four products were obtained: 93 (13\%), 96 (7\%), 97 (13\%), and 111 (5\%). It was discovered that T. piriforme produced smaller quantity of $14 \alpha$-hydroxy derivatives (Figure 15) [38].

In the biotransformation of $\mathbf{1 2}$ using Nectria haematococca, four substances were isolated, whose performance was dependent on the incubation time; majority of the products were produced at $72 \mathrm{~h}$. The hydroxylated derivatives in C-11 with $\alpha$

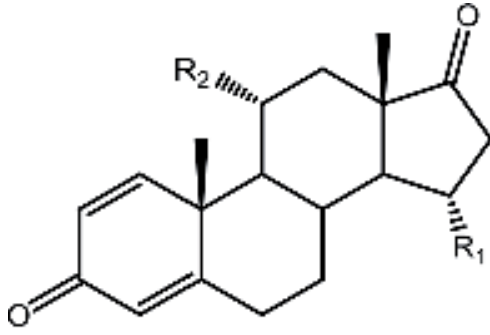

105) $R_{1}=R_{2}=H$

112) $\mathrm{R}_{1}=\mathrm{OH}, \mathrm{R}_{2}=\mathrm{H}$

113) $R_{1}=R_{2}=O H$

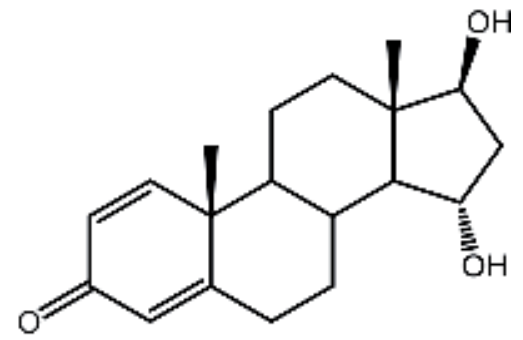

114

Figure 14.

Biotransformation products of androsta-1,4-dien-3, 17-dione (105). 


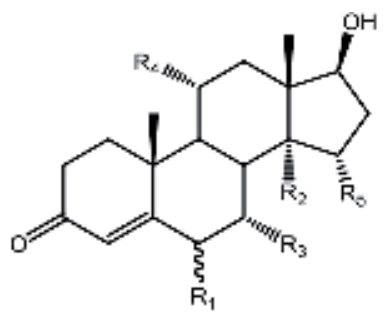

12) $R_{1}-R_{2}-R_{3}-R_{2}-R_{5}-H$ 118) $R_{1}=R_{2}=R_{4}=R_{5}=H_{1} \lambda^{1 / 21}, R_{4}=O H$ 117) $R_{1}=R_{7}=R_{3}=R_{1}=H, R_{s}=O H$ 119) $\mathrm{R}_{1}-\mathrm{R}_{2}-\mathrm{R}_{4}-\mathrm{R}_{5}-\mathrm{H}_{1} \mathrm{R}_{3}-\mathrm{OH}$ 120) $R_{1}=\kappa O H, R_{2}=R_{4}=R_{4}=R_{5}=H$

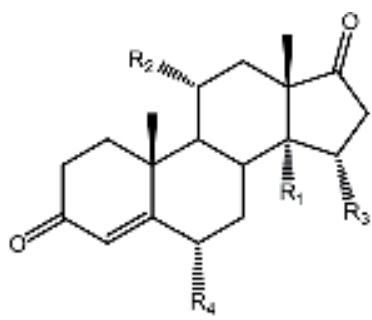

115) $\mathrm{H}_{1}=\mathrm{R}_{2}=\mathrm{R}_{1}=\mathrm{H}, s^{1121}, \mathrm{P}_{2}=\mathrm{OH}$ 118) $\mathrm{R}_{1}-\mathrm{R}_{2}-\mathrm{R}_{4}-\mathrm{H}_{2} \mathrm{R}_{3}-\mathrm{OH}$ 125) $R_{1}=R_{2}=R_{3}=H, R_{4}=O H$<smiles>CC1CCC(=O)C=C1CCC1C(=O)CC[C@]2(C)C(=O)CCC12</smiles>

121<smiles>C[C@@]12CCC(=O)CC1C(=O)CC1C2CC[C@@]2(C)C1CC[C@@H]2O</smiles><smiles>C[C@]12CC[C@@H](O)C=C1C(=O)CC1C2CC[C@]2(C)C1CC[C@@H]2O</smiles><smiles>C[C@]12CCC(O)[C@@H](O)CC1C1C=CC3=CC(=O)CC[C@]3(C)C1C2</smiles>

Figure 15.

Biotransformation products of testosterone (12).

orientation and dehydrogenation in $\mathrm{C}_{1}-\mathrm{C}_{2}$ resulted in the following compounds: $11 \alpha$-hydroxyandrost-1,4-dien-3,17-dione (114, 8.0\%), 11 $\alpha, 17 \beta$-dihydroxyandrost1,4-dien-3-one (115, 4.3\%), 101 (1.9\%), and 104 (2.3\%) [76]. Incubation of 12 with Fusarium culmorum produced $93(10 \%)$ and 96 (32\%) with hydroxylated derivatives at C-6 $\beta$, including the products, $15 \alpha, 17 \beta$-dihydroxyandrost-4-en-3-one $(116,22 \%)$ and $15 \alpha$-hydroxyandrost-4-en-3,17-dione (117). Selective hydroxylation of 103 at C-6 with a $\beta$ orientation and allylic position at the unsaturated 3-keto-system is favored by the system $\pi$ and the presence of the hydroxyl group at C-17, while hydroxylation at C-15 is a very frequent process carried out by fungi of the genus Fusarium [42]. Metabolites 11, 85, 105, and 115 were obtained as oxidation and hydroxylation products of 12 using the fungus F. oxysporum var. cubense [56]. The fungus, Cephalosporium aphidicola, was hydroxylated with 12 to give the products 96 (47\%) and 97 (3\%), with hydroxylated derivatives in C-6 $\beta$ and C-14 $\alpha$, respectively [70]. Incubation of 12 with C. lunata and Pleurotus ostreatus yielded compounds 11 (17\%) and 115 (13\%), respectively [77]. The phytopathogenic fungus, Botrytis cinerea, produced $7 \beta, 17 \beta$-dihydroxyandrost-3-one $(\mathbf{1 1 8}, 73 \%)$, as the only biotransformation product of 12. It seems that the presence of the hydroxyl group in C-17 in the androstane skeleton directed the hydroxylation at C-7 with a $\beta$ orientation (Figure 15) [53].

In the biotransformation of 12 using Bacillus stearothermophilus, thermophilic bacterium, the major product obtained was 11 (90.2\%); it was generated by the oxidation of C-17, and the hydroxylated derivatives of 11 in C-6 (93, C-6 $6,1.1 \%)$ and

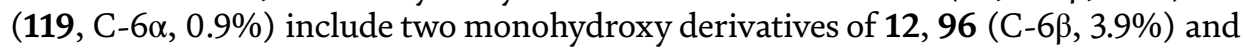
$120(\mathrm{C}-6 \alpha, 3.9 \%)$. This indicates that hydroxylation with $\alpha$ orientation in C- 6 may be a common action of some thermophilic bacteria [78]. Biotransformation of $\mathbf{1 1}$ using B. stearothermophilus in the presence of hydrolase inducers-salicylic acid, chloramphenicol, cyclodextrin, dexamethasone, riboflavin, and rifampicin-resulted in obtaining a higher concentration of the compounds: 9,10-seco-4-androst-3,9,17-trione (121), $5 \alpha$-androst-3,6,17-trione (103), 17 $\beta$-hydroxy-5 $\alpha$-androst-3,6-dione (122), $3 \beta, 17 \beta$-dihydroxyandrost-4-en-6-one (123), and $17 \beta$-hydroxyandrost-4,6-dien-3-one 
(124). For example, the presence of glucose and cycloheximide favored the obtaining of 123, while the production of $\mathbf{1 2 4}$ was achieved in the presence of rifampicin [79]. The products isolated from the biotransformation of $\mathbf{1 2}$ using Chaetomium sp. were $93(21 \%), 94(39 \%)$, and 99 (19\%); after $24 \mathrm{~h}$ of incubation, the presence of 11 was detected. Janeczko et al. [73] concluded that the steric factors associated with the substrate determine the location and orientation of the hydroxyl group. For example, the carbonyl group in C-17 at $\mathbf{1 1}$ directs the entry of the hydroxyl group at C-14 with $\alpha$ orientation, while the hydroxylation in $C-6 \beta$ is favored by the presence of the hydroxyl group in C-17, as in 12. In the case of progesterone (1), which has an acyl group, dihydroxylated derivatives were observed in C-6 and C-14 (Figure 15) [73].

Incubation of $\mathbf{1 1}$ and $\mathbf{1 2}$ with C. lini ST-1 displayed different catalytic characteristics. Biotransformation of $\mathbf{1 1}$ afforded two products: $15 \alpha$-hydroxyandrost-4-en3,17-dione $(117,5 \%)$ and $11 \alpha, 15 \alpha$-dihydroxyandrost-4-en-3,17-dione $(125,64 \%)$, while 12 yielded $15 \alpha$-hydroxyandrost-4-en-3,17-dione (117, 60\%). Incubation of 1 resulted in the isolation of $\mathbf{1 4}$. Wu et al. [80] concluded that the different hydroxylation sites between $\mathbf{1 1}$ and $\mathbf{1 2}$ suggested that the hydroxyl group or carbonyl group on the substrate at C-17 had influence on the location of introduced hydroxyl groups (Figure 15).

Dehydroepiandrosterone (3 $\beta$-hydroxyandrost-5-en-17-one, 126) endogenous prohormone secreted by the adrenal glands is a precursor of androgens and estrogens. Incubation with $M$. piriformis allowed the isolation of five compounds: $3 \beta, 17 \beta$-dihydroxyandrost-5-ene (127), 3 $3,7 \alpha$-dihydroxyandrost-5-en-17-one (128),

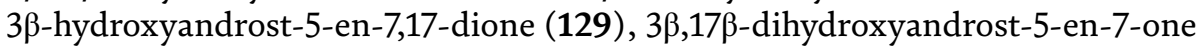
(130), and $3 \beta, 7 \alpha, 17 \beta$-trihydroxyandrost-5-ene (131). The action of the fungus was the stereospecific hydroxylated products at C-7 $\alpha(128$ and 131) and the reduction of the carbonyl group at C-17 [51]. From the microbiological transformation of 126 using Rhizopus stolonifer, six poducts were isolated: 127 (20\%), 128 (12\%),

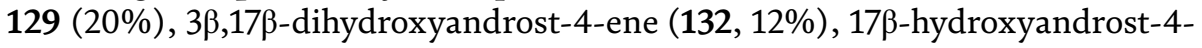
en-3-one $(133,34 \%)$, and $3 \beta, 11 \beta$-dihydroxyandrost-4-en-17-one $(134,15 \%)$ [81]. Fusarium oxysporum biotransformed to 126 in a mixture of four hydroxylated derivatives (127-129 and 130), which were characterized as their acetylated derivatives; the hydroxylation was favorably in C-7 stereospecifically ( $\alpha$ orientation) in the 3 $\beta$-hydroxy- $\Delta^{5}$-steroids, while Colletotrichum musae biotransformed to 126-127 by reducing the carbonyl group in C-17 (Figure 16) [56].

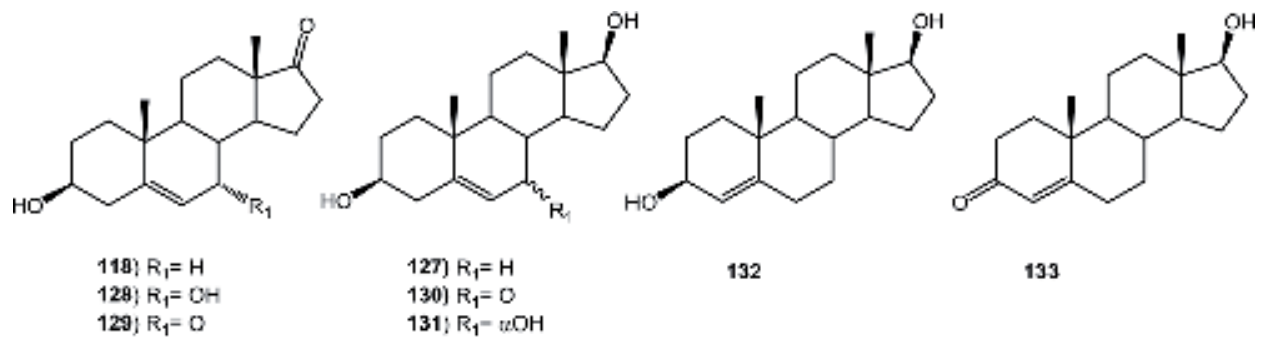

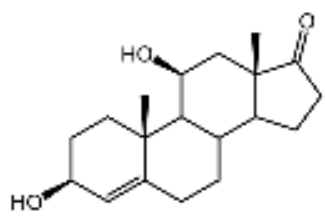

134

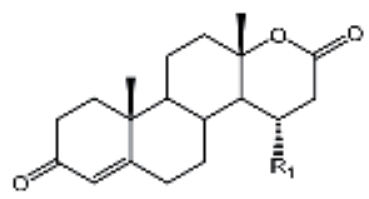

13) $\mathrm{R}_{1}=\mathrm{H}$ 135) $R_{1}=\mathrm{OH}$<smiles>C[C@]12CCC3C(CCC4CC(=O)CC[C@]43C)C1CCC(=O)O2</smiles>

136) $\lambda^{15 ! 3}$ 137

Figure 16.

Biotransformation products of dehydroepiandrosterone (126). 
In the biotransformation of $\mathbf{1 2 6}$ using Penicillium griseopurpureum and P. glabrum, the following was produced; hydroxylated derivatives in C-7 $\alpha$ (95), C-14 $\alpha$ (94) and C-15 $\alpha$ (117), with 11 being the main product. In addition, P. griseopurpureum generated products for the Baeyer Villiger oxidation to give the lactone $\mathrm{D}$ ring (testolactone, 13) and its hydroxylated derivative at C-15 $\alpha$ (15 $\alpha$-hydroxy17 $\alpha$-oxa-D-homo-androst-4-en-3,17-dione, 135); while P. glabrum generated the compounds, $3 \beta$-hydroxy-17 $\alpha$-oxa-D-homo-androst-5-en-17-one (136) and $3 \beta$-hydroxy-17 $\alpha$-oxa-D-homo-5 $\alpha$-androstan-17-one (137) (Figure 16) [82].

The biotransformation of $17 \alpha$-ethynyl-17 $\beta$-hydroxyandrost-4-en-3-one (ethisterone, 138) and $17 \alpha$-ethyl-17 $\beta$-hydroxyandrost-4-en-3-one (139) was described using the fungi Cephalosporium aphidicola and Cunninghamella elegans. The bioconversion of 138 using C. aphidicola yielded $17 \alpha$-ethynyl-17 $\beta$-hydroxyandrost1,4-dien-3-one (140, 5.5\%), while by using C. elegans, $17 \alpha$-ethynyl-11 $\alpha, 17 \beta$ dihydroxyandrost-4-en-3-one $(\mathbf{1 4 1}, 3.4 \%)$ was obtained. The biotransformation of 138 using C. aphidicola generated $17 \alpha$-ethyl-17 $\beta$-hydroxyandrost-1,4-dien-3-one $(142,2.2 \%)$. In contrast, when incubating 139 with $C$. elegans, two new products were obtained: $17 \alpha$-ethyl-11 $\alpha, 17 \beta$-dihydroxyandrost-4-en-3-one $(143,2.8 \%)$ and $17 \alpha$-ethyl-6 $\alpha, 17 \beta$-dihydroxy-5 $\alpha$-androstan-3-one (144, 1.6\%) (Figure 17) [83].

Adrenosterone (145) is an inhibitor of the enzyme estrogen synthetase responsible for the formation of estrogen, and it has a great clinical application. Biotransformation of 145 using $C$. aphidicola produced androst-1,4-dien-3,11,17-trione (146, 3\%), $17 \beta$-hydroxyandrost-4-en-3,11-dione (147, 2\%), and 17 $\beta$-hydroxyandrost-1,4-dien3,11-dione (148, 17\%). 145 (11.2\%) and 12 (8.1\%) were obtained from the biotransformation of 145 using Fusarium lini, while 147 (36.8\%) was obtained from the biotransformation of 145 using Trichothecium roseum (Figure 18) [84].

The biotransformation of mesterolone ( $1 \alpha$-methyl-17 $\beta$-hydroxy- $5 \alpha$-androst-3one, 149), a synthetic androgenic steroid, was performed using different fungi as described by Choudhary et al. [85]. From the biotransformation of 149 using $C$. aphidicola, the compounds $1 \alpha$-methyl-5 $\alpha$-androst-3,17-dione (150), $1 \alpha$-methyl-5 $\alpha$ androst-3,17-diol (151), and 1 $\alpha$-methyl-15 $\alpha$-hydroxy-5 $\alpha$-androst-3,17-dione (152) were obtained. Incubation of $\mathbf{1 4 9}$ with Fusarium lini produced the compounds 152, 1-methyl-5 $\alpha$-androst-1-en-3,17-dione (153), $1 \alpha$-methyl- $6 \alpha, 17 \beta$-dihydroxy-5 $\alpha$ androst-3-one (154), $1 \alpha$-methyl-15 $\alpha, 17 \beta$-dihydroxy-5 $\alpha$-androst-3-one (155), and 1-methyl-15 $\alpha, 17 \beta$-dihydroxy-5 $\alpha$-androst-1-en-3-one (156). The products obtained from the biotransformation of 149 using $R$. stolonifer were 150, 154, 156, $1 \alpha$-methyl$7 \alpha, 17 \beta$-dihydroxy- $5 \alpha$-androst-3-one (157), and $1 \alpha$-methyl- $11 \alpha, 17 \beta$-dihydroxy- $5 \alpha$ androst-3-one (158) [85]. Bioconversion of 149 using C. blakesleeana produced
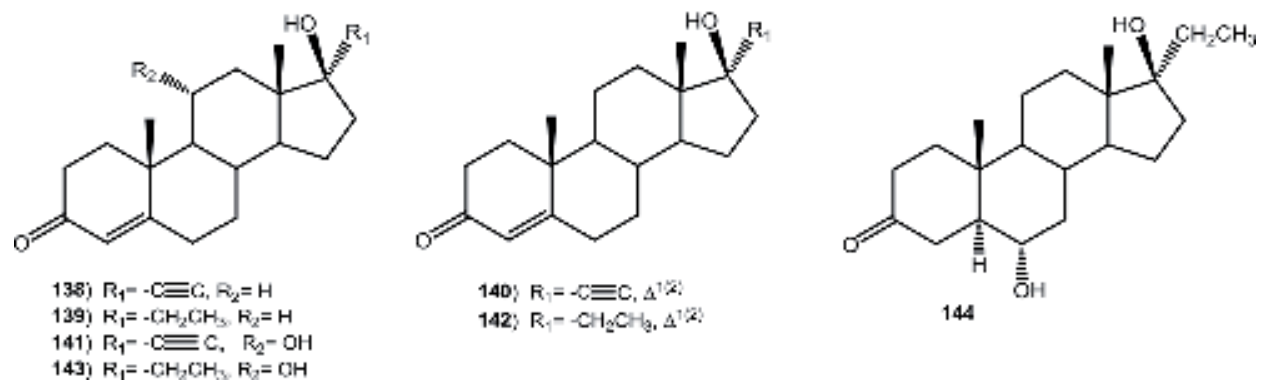

Figure 17.

Biotransformation products of $17 \alpha$-ethynyl-17 $\beta$-hydroxyandrost-4-en-3-one (138) and $17 \alpha$-ethyl-17 $\beta$ hydroxyandrost-4-en-3-one (139). 


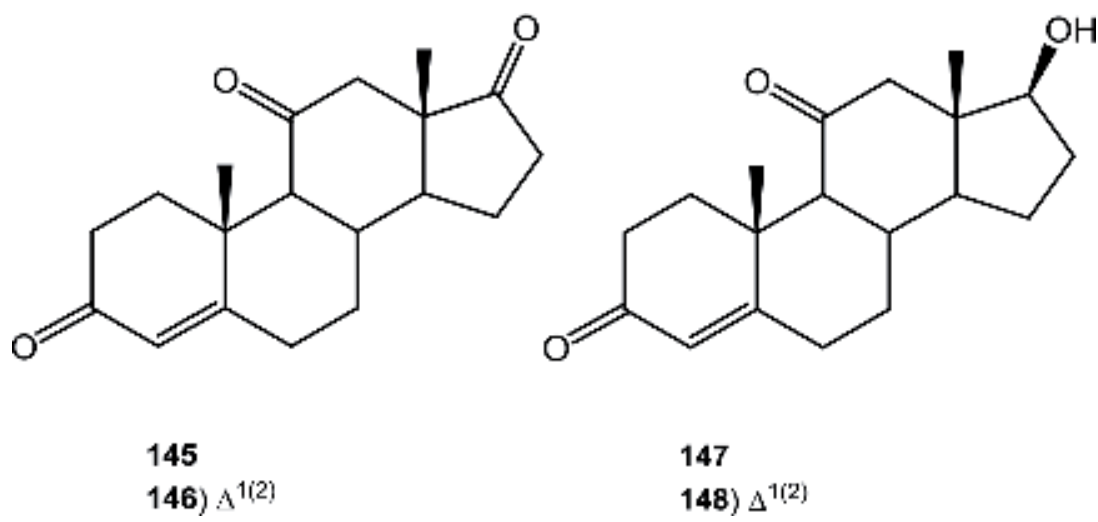

Figure 18.

Biotransformation products of andresterone (145).

seven biotransformation products, such as $154,157,158$, in addition to $1 \alpha$-methyl$1 \beta, 11 \beta, 17 \beta$-trihydroxy- $5 \alpha$-androst-3-one (159), $1 \alpha$-methyl- $7 \alpha, 11 \beta, 17 \beta$-trihydroxy$5 \alpha$-androst-3-one (160), $1 \alpha$-methyl-1 $\beta, 6 \alpha, 17 \beta$-trihydroxy- $5 \alpha$-androst-3-one (161),

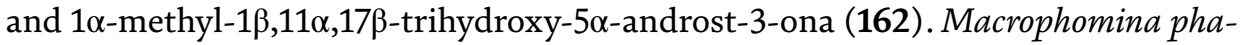
seolina biotransformed 149 to obtain $1 \alpha$-methyl-17 $\beta$-hydroxy- $5 \alpha$-androst-3,6-dione (155) [86]. Additionally, the biotransformation of 141 using C. blakesleeana (ATCC $8688 \mathrm{~A}$ ) yielded three metabolites: $1 \alpha$-methyl-11 $\beta, 14 \alpha, 17 \beta$-trihydroxy- $5 \alpha$-androstan3 -one $(163,0.4 \%), 1 \alpha$-methyl-7 $\beta, 17 \beta$-dihydroxy-5 $\alpha$-androstan-3-one $(164,0.47 \%)$, and $1 \alpha$-methyl-17 $\beta$-hydroxy-5 $\alpha$-androstan-3,7-dione $(165,0.67 \%)$. C. blakesleeana catalyzed the $\beta$-hydroxylation in C-11, and dihydroxylation and oxidations at various positions of steroid skeleton (Figure 19) [87].

In the microbiological transformation of 3-hydroxyestra-1,3,5-(10)-trien17-one (166) using Fusarium oxysporum var. cubense, the compounds, reduced in C-17 (3,17-dihydroxyestra-1,3,5-(10)-triene, 167) and hydroxylated in C-15 (3,15 $\alpha$-dihydroxiestra-1,3,5-(10)-triene, 168), were isolated (Figure 20) [56].

Prednisone (169) is a synthetic corticosteroid (prodrug) used for the treatment of autoimmune, inflammatory and kidney diseases, among others.

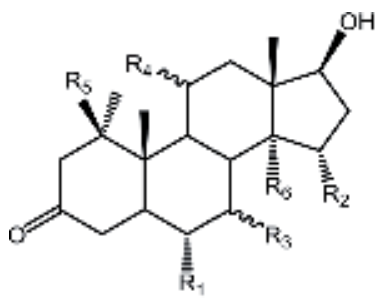

149) $R_{1}=R_{2}=R_{3}=R_{4}=R_{5}=R_{i j}=H$

154) $R_{1}=O H, R_{2}=R_{3}=R_{4}=R_{5}=R_{9}=H$

155) $R_{1}=R_{3}=R_{4}=R_{6}=R_{t}=H, R_{2}=O H$

157) $R_{1}=R_{2}=R_{4}=R_{6}=R_{f}=H, R_{3}=O H$

158) $R_{1}=R_{2}=R_{3}=R_{6}=R_{6}=H . R_{4}=a O H$

159) $R_{1}=R_{2}=R_{g}=R_{6}=H, R_{4}=B O H . R_{g}=O H$

160) $R_{1}=R_{2}=R_{5}=R_{8}=H, R_{3}=O H_{1} R_{c}=\rho O H$

161) $R_{1}=R_{51}=O H, R_{2}=R_{3}=R_{4}=R_{g}=H$

162) $R_{1}=R_{2}=R_{9}=R_{8}=H, R_{4}=a O H, R_{5}=O H$

163) $R_{1}=R_{2}=R_{2}=R_{6}=H, R_{4}=c_{2} O H, R_{t i}=O H$

164) $R_{1}=R_{2}=R_{4}=R_{6}=R_{f}=H, R_{3}=B O H$

165) $R_{1}=R_{2}=R_{4}=R_{f}=R_{6}=H, R_{3}=0$<smiles>[R4][C@H]1CC(=O)[C@]2(C)CC[C@H]3[C@@H](CC[C@@H]4CC(=O)C[C@H](C)[C@@]34C)[C@H]12</smiles>

150) $R_{1}=H$

152) $\mathrm{R}_{1}=\mathrm{OH}$

153) $\mathrm{R}_{1}=\mathrm{H}, \Delta^{1(2)}$

156) $\mathrm{R}_{1}=\mathrm{OH}_{2} \mathrm{~s}^{\prime|2|}$<smiles>C[C@H]1C[C@H](O)CC2CCC3C(CC[C@]4(C)C3CC[C@@H]4O)[C@]21C</smiles>

151

Figure 19.

Biotransformation products of mesterelone (149). 


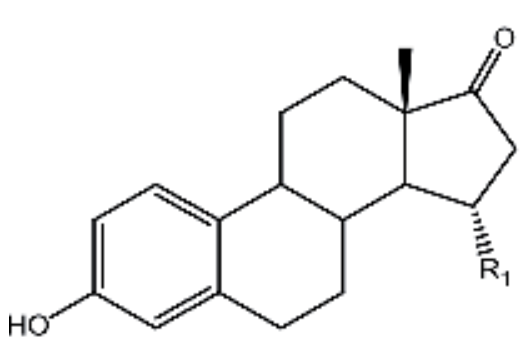

166) $\mathrm{R}_{1}=\mathrm{H}$

168) $\mathrm{R}_{1}=\mathrm{OH}$<smiles>C[C@]12CCC3c4ccc(O)cc4CCC3C1CC[C@@H]2O</smiles>

167

Figure 20.

Biotransformation products of 3-hydroxy-1,3,5-(10)-trien-17-one (166).

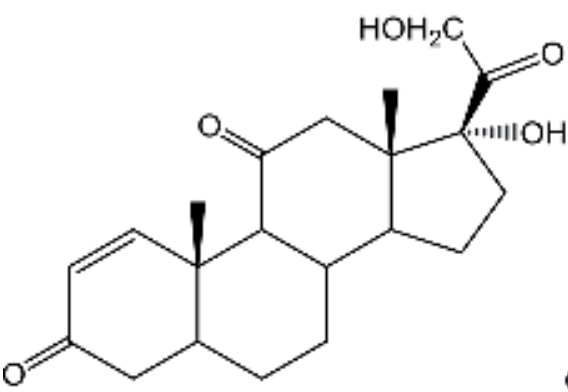

169) $\Delta^{4(5)}$

170<smiles>C[C@]12C=CC(=O)CC1CCC1C2C(=O)C[C@]2(C)C1CC[C@]2(O)[C@H](O)CO</smiles>

171) $R_{1}=H$

172) $\mathrm{s}^{4(5)}$

Figure 21.

Biotransformation products of prednisone (169).

Biotransformation of 169 using C. elegans occurred by hydrogenation of the $\Delta^{4(5)}$ and reduction of C-20, to produce the compounds $17 \alpha, 21$-dihydroxy-5 $\alpha$-pregn1-en-3,11,20-trione $(170,15.6 \%)$ and $17 \alpha,(20 S), 21$-trihydroxy-5 $\alpha$-pregn-1-en3,11-dione (171, 6.5\%); whereas as the only biotransformation product, 169 using F. lini (5.2\%), R. stolonifer (5.5\%) and C. lunata (6.2\%), was 1,4-pregnadien$17 \alpha,(20 S), 21$-trihydroxy-3,11-dione (172) (Figure 21) [88].

The main chemical transformation carried out by different Acremonium species in various steroid compounds have been oxidations, reductions, hydroxylations in different positions, isomerizations, and hydrolysis of the chain in C-17. Hydrocortisone (173) is an important anabolic, used clinically as anti-inflammatory and antiallergic drug, besides being a raw material for the synthesis of many steroid hormones. Biotransformation of $\mathbf{1 7 3}$ using Acremonium strictum generated

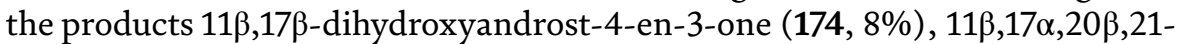
tetrahydropregn-4-en-3-one $(\mathbf{1 7 5}, 11.2 \%)$, and 21 -acetoxy-17 $\beta, 17 \alpha, 20$ trihydroxypregn-4-en-3-one (176, 7.6\%); it was observed that the actions of the said species were as the reduction, acetylation and degradation of the chain in C-17, without modification of the unsaturated ketone- $\alpha, \beta$ [89]. Biotransformation of $\mathbf{1 7 3}$ using Gibberella fujikuroi yielded 11 $\beta$-hydroxyandrost-4-en-3,17-dione (177, 41\%), while $B$. subtilis and $R$. stolonifer yielded $175(15 \%)$. The products $173(45 \%)$ and $3 \beta, 11 \beta, 17 \alpha, 21$-tetrahydroxy-5 $\alpha$-pregnan-20-one $(178,31 \%)$ were obtained from the bioconversion of 173 using Bacillus cereus (Figure 22) [90]. 

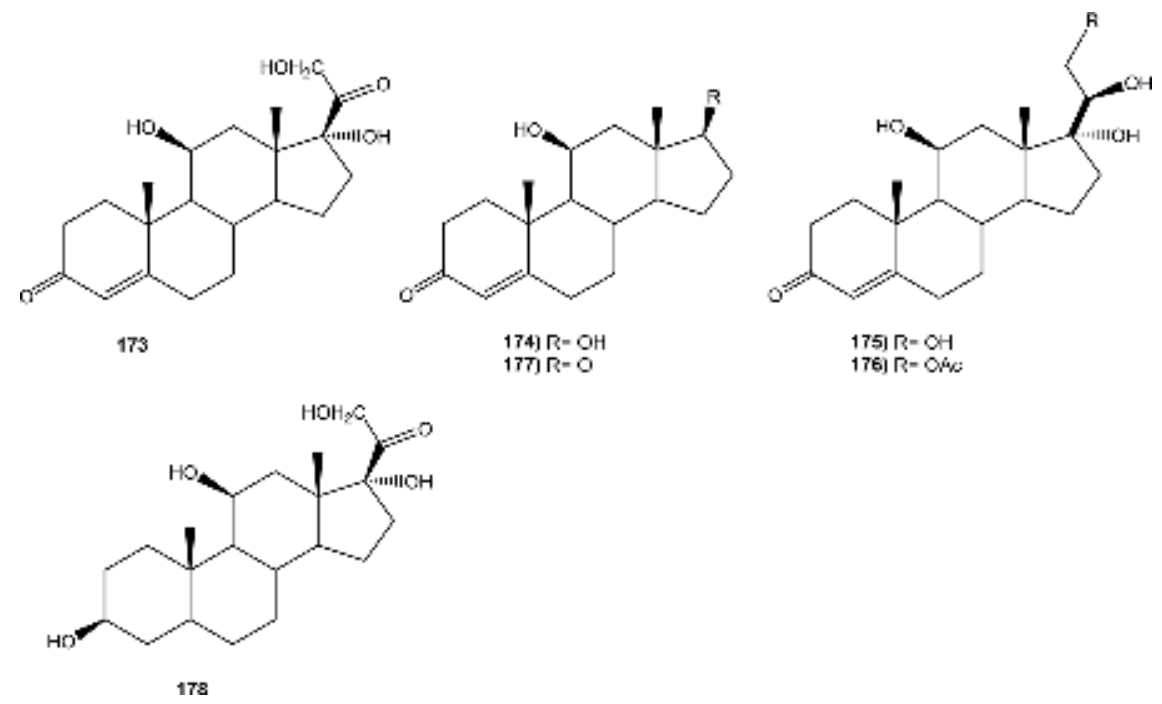

Figure 22.

Biotransformation products of hydrocortisone (173).

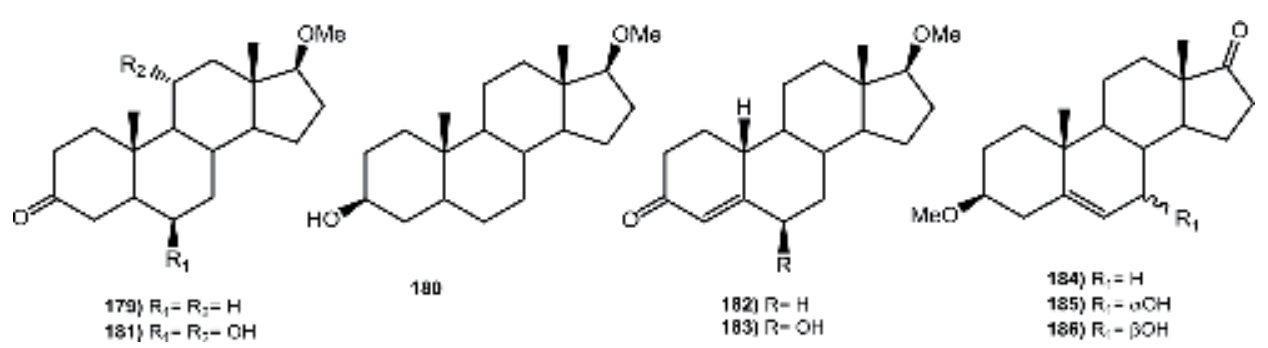

Figure 23.

Biotransformation products of $17 \beta$-methoxy-5 $\alpha$-androst-3-one (179).

Incubation of $17 \beta$-methoxy-5 $\alpha$-androst-3-one (179) with Cephalosporium aphidicola produced $17 \beta$-methoxy- $5 \alpha$-androst- $3 \beta$-ol (180) and $6 \beta, 11 \alpha$ dihydroxy-17 $\beta$-methoxy- $5 \alpha$-androst-3-one (181); while the biotransformation of $17 \beta$-methoxyestra-4-en-3-one (182) using $C$. aphidicola produced a major metabolite $6 \beta$-hydroxy-17 $\beta$-methoxyestra-4-en-3-one (183). Similarly, the microbiological transformation of $3 \beta$-methoxyandrost-5-en-17-one (184) gave a mixture

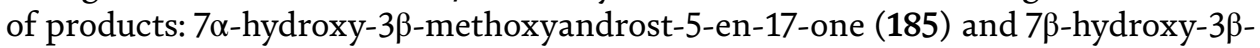
methoxyandrost-5-en-17-one (186) (Figure 23) [91].

In the literature, several species of fungi belonging to the genera Aspergillus, Fusarium, Mortierella, and Penicillium and capable of hydroxylating various steroids in C-15 have been described. For example, Jekkel et al. [92] described that more than 3000 fungi hydroxylate $13 \beta$-ethyl-4-gonene-3,17-dione (187) in C-15 position, the genus being Fusarium, particularly $F$. nivale; the fungus preferentially

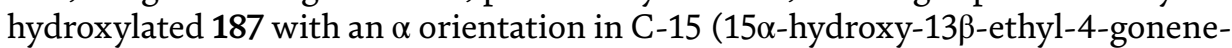
3,17-dione, 188, 77\%) and C-7 $\beta(7 \beta, 15 \alpha$-dihydroxy-13 $\beta$-ethyl-4-gonene-3,17diona, 189). On the other hand, the biotransformation of 187 using Mortierella pusilla produced 188, 190 (10 $\beta$-hydroxy-13 $\beta$-ethyl-4-gonene-3,17-dione) and 191 (6 $\beta$-hydroxy-13 $\beta$-ethyl-4-gonene-3,17-dione) (Figure 24).

The ethynodiol diacetate (192) is a synthetic derivative 1 , used as an oral contraceptive because it inhibits the ovulation process. The microbiological transformation of 192 using Cunninghamella elegans produced four hydroxylated compounds 


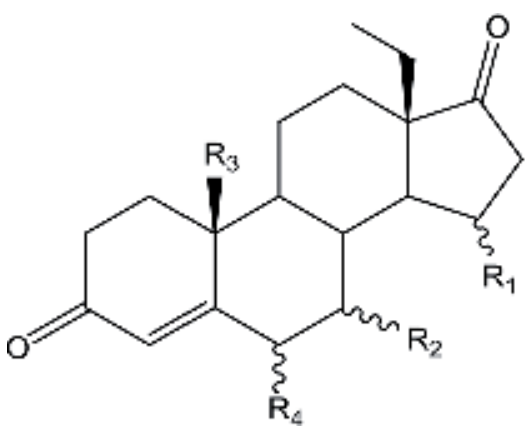

187) $R_{1}=R_{2}=R_{3}=R_{4}=H$

188) $\mathrm{R}_{1}=\alpha \mathrm{OH}, \mathrm{R}_{2}=\mathrm{R}_{3}=\mathrm{R}_{4}=\mathrm{H}$

189) $\mathrm{R}_{1}=\alpha \mathrm{OH}, \mathrm{R}_{2}=\beta O \mathrm{H}_{1}, \mathrm{R}_{3}=\mathrm{R}_{4}=\mathrm{H}$

190) $R_{1}=R_{2}=R_{4}=H, R_{3}=O H$

191) $R_{1}=R_{2}=R_{3}=H, R_{4}=\beta O H$

Figure 24.

Biotransformation products of $13 \beta$-ethyl-4-gonene-3, 17-dione (187).

characterized as: $17 \alpha$-ethynylestr-4-en-3 $\beta, 17 \beta$-diacetoxy- $6 \alpha$-ol $(\mathbf{1 9 3}, 0.5 \%)$, $17 \alpha$-etynylestr-4-en-3 $\beta, 17 \beta$-diacetoxy- $6 \beta$-ol $(194,1.0 \%), 17 \alpha$-etynylestr-4-en$3 \beta, 17 \beta$-diacetoxy-10 $\beta$-ol $(195,0.5 \%)$, and $17 \alpha$-ethynyl-17 $\beta$-acetoxiestr-4-en-3-one (196, 1.4\%) (Figure 25) [93].

Desogestrel (13-ethyl-17-methylene-18,19-dinor-17 $\alpha$-pregn-4-en-20-yn-17-ol, $197)$ is an orally active third-generation contraceptive steroid drug. Conversion of 197 by C. blackesleeana (ATCC 8688 A) yielded four metabolites: 13-ethyl11-methylene-18,19-dinor-17 $\alpha$-pregn-4-en-20-yn-6 $\beta, 15 \beta, 17 \beta$-triol (198), 13-ethyl-11-methylene-18,19-dinor-17 $\alpha$-pregn-4-en-20-yn-3 $\beta, 6 \beta, 17 \beta$-triol (199), 13-ethyl-11-methylene-18,19-dinor-17 $\alpha$-pregn-4-en-20-yn-3 $\alpha, 5 \alpha, 6 \beta, 17 \beta$-tetraol (200), and 13-ethyl-11-methylene-18,19-dinor-17 $\alpha$-pregn-4-en-20-yn-6 $\beta, 17 \beta$ dihydroxy-3-one (201). Compounds 197 and 198 showed a potent growth inhibition against drug-resistant strains of $S$. aureus (Figure 26) [94].

The drugs mexrenone (202) and canrenone (203) are steroids with a spironolactone in C-17 and are potent antagonists of mineralocorticoids [95]. The biotransformation of 202 and 203 using a wide variety of microorganisms resulted in the production of monohydroxylated products in different positions, where Beauveria bassiana generated $11 \alpha$-hydroxymexrenone $(204,67 \%)$ as the major product, while $12 \beta$-hydroxymexrenone $(205,50 \%)$ and $6 \beta$-hydroxymexrenone (206, 33\%) were obtained using Mortierella isabellina. The dehydrogenation product ( $\Delta^{1(2)}$-mexrenone, 207, 15\%) was favored with Bacterium cyclooxidants as well as Rhodococcus equi, Nocardia aurentia, and Comamonas testosteroni. From the biotransformation of $\mathbf{2 0 3}$ using Corynespora cassiicola, $9 \alpha$-hydroxycanrenone

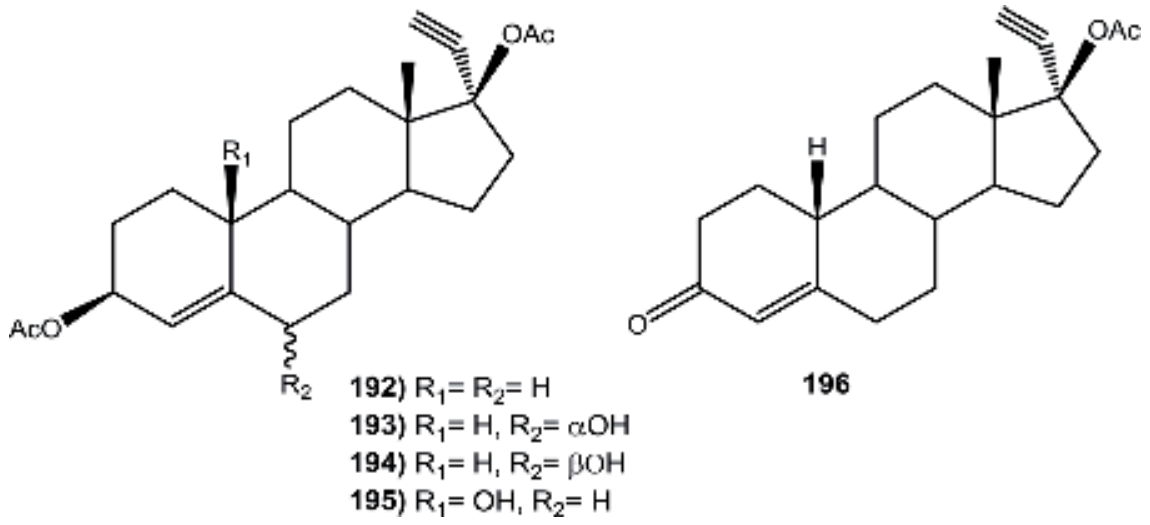

Figure 25.

Biotransformation products of ethynodiol diacetate (192). 


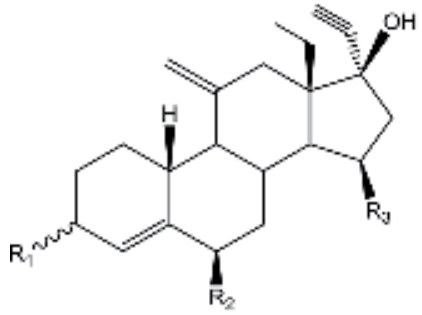

197) $R_{1}=R_{2}=R_{3}=H$

198) $\mathrm{R}_{1}=\mathrm{H}, \mathrm{R}_{2}=\mathrm{R}_{3}-\mathrm{OH}$

199) $R_{1}=\mathrm{BOH}, \mathrm{R}_{2}=\mathrm{OH}, \mathrm{R}_{3}=\mathrm{H}$

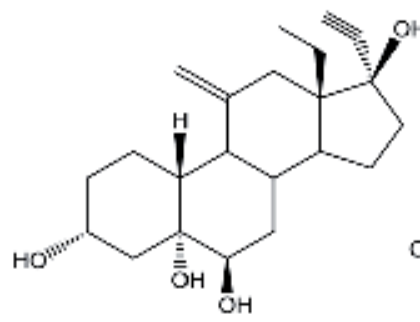

200<smiles>C=C[C@]1(O)CC[C@H]2C3C[C@H](O)C4=CC(=O)CC[C@H]4[C@H]3C(=C)C[C@]21C</smiles>

201

Figure 26.

Biotransformation products of desogestrel (197).

(208, 30\%) was obtained, [96]. Conversion of canrenone (203) by Colletotrichum lini ST-1 gave two hydroxyl compounds, $15 \alpha$-hydroxy-canrenone $(209,22 \%)$ and $11 \alpha, 15 \alpha$-dihydroxy-canrenone (210, 47\%) (Figure 27) [80].

One of the steroids used in the treatment of breast cancer is exemestane (211), an inhibitor of steroidal aromatase. From the transformation of 211 using Macrophomina phaseolina, 16 $\beta, 17 \beta$-dihydroxy-6-methylene-androsta-1,4-diene3-one (212), 17 $\beta$-hydroxy-6-methylene-androsta-1,4-diene-3,16-dione (213), and 17 $\beta$-hydroxy-6-methylene-androsta-1,4-diene-3-one (214) were obtained, while by using Fusarium lini, the only product obtained was $11 \alpha$-hydroxy-6-methyleneandrosta-1,4-diene-3,17-dione (215) (Figure 28) [97].

4-Hydroxyandrost-4-ene-3,17-dione (formestane, 216) is an irreversible aromatase inhibitor and therapeutically used in breast cancer treatment in postmenopausal women. Bioconversion of 216 using Rhizopus oryzae (ATCC 1145) resulted in the production of $4 \beta, 5 \alpha$-dihydroxyandrost-3,17-dione $(217,8.6 \%)$ and 3,5 $\alpha$-dihydroxyandrost-2-ene-4,17-dione (218) [98], while the biotransformation of 217 using Beauveria bassiana produced 4,17 $\beta$-dihydroxyandrost-4-en-3-one (219, 5.3\%), $3 \alpha, 17 \beta$-dihydroxy- $5 \beta$-androstan-4-one (220,0.9\%), and $4,11 \alpha, 17 \beta$ trihydroxyandrost-4-en-3-one (221, 2.4\%) (Figure 29) [99].

Methyltestosterone (222), an anabolic steroid, was transformed by $M$ ucor racemosus in 5 days to produce two monohydroxylated

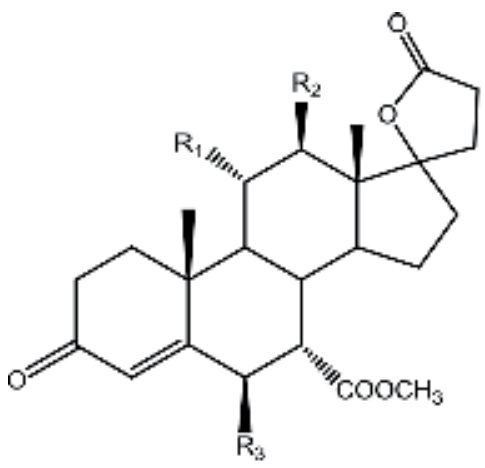

202) $R_{1}=R_{2}=R_{3}=H$

204) $R_{1}=O H, R_{2}=R_{3}=H$

205) $R_{1}=R_{3}=H_{1} R_{2}=O H$

206) $R_{1}=R_{2}=H, R_{3}=O H$

207) $\mathrm{R}_{1}=\mathrm{R}_{2}=\mathrm{R}_{3}=\mathrm{H}, \Delta^{(2)}$

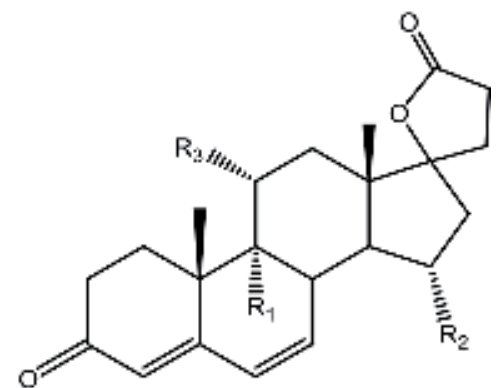

203) $\mathrm{R}_{1}=\mathrm{H}$

208) $R_{1}=O H, R_{2}=R_{3}=H$

209) $R_{1}=R_{3}=H_{2} R_{2}=O H$

210) $R_{1}=H, R_{2}=R_{3}=O H$

Figure 27.

Biotransformation products of mexrenone (202) and canrenone (203). 
<smiles>C=C1CC2C([C@@H](P)C[C@]3(C)C(=O)CCC23)C2(C)C=CC(=O)C=C12</smiles>

211) $R_{1}=H$

215) $\mathrm{R}_{1}=\mathrm{OH}$

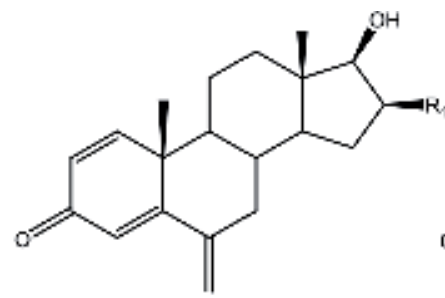

212) $\mathrm{R}_{1}-\mathrm{OH}$

214) $\mathrm{R}_{1}=\mathrm{H}$

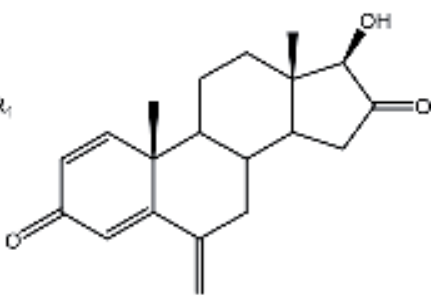

213

Figure 28.

Biotransformation products of exemestane (211).

products in the C-7 (7 $\alpha$-hydroxymethyltestosterone, 223, 35\%) and C-15

(15 $\alpha$-hydroxymethyltestosterone, $224,21 \%$ ) positions, plus a dihydroxylated product (12,15 $\alpha$-dihydroxymethyltestosterone, 225, 22\%) [100]. Recently, three additional products were identified: $11 \alpha$-hydroxy-17 $\alpha$-methyltestosterone (226), $6 \beta$-hydroxy-

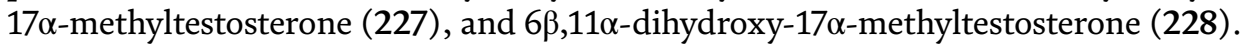
Isolation of hydroxylation products have been reported in different carbons from 222 with different orientations, C-6 $\beta$, C-7 $\beta$, C-9 $\alpha$, C-11 $\alpha$, C-12 $\beta$, and C-15 $\alpha$ (Figure 30).

Dianabol (methandrostenolone, $17 \alpha$-methyl-17 $\beta$-hydroxyl-androst-1,4-dien3 -on, 229) is an oral anabolic steroid that promotes the synthesis of proteins (increasing the muscle tissue). From the biotransformation of 229 using Cunninghamella elegans, five bioconversion products were obtained: $6 \beta$-hydroxydianabol (230), $15 \alpha$-hydroxydianabol (231), $11 \alpha$-hydroxydianabol (232), $6 \beta, 12 \beta$-dihydroxydianabol (233), and 6 $\beta, 15 \alpha$-dihydroxydianabol (234). The products $17 \beta$-hydroxy-17 $\alpha$ methyl-5 $\alpha$-androst-1,4-dien-3,6-dione (235), 7 $\beta$-hydroxydianabol (236), 15 $\beta$-hydroxydianabol (237), 17 $\beta$-hydroxy-17 $\alpha$-methyl-5 $\alpha$-androst-1,4-dien-3,11-dione

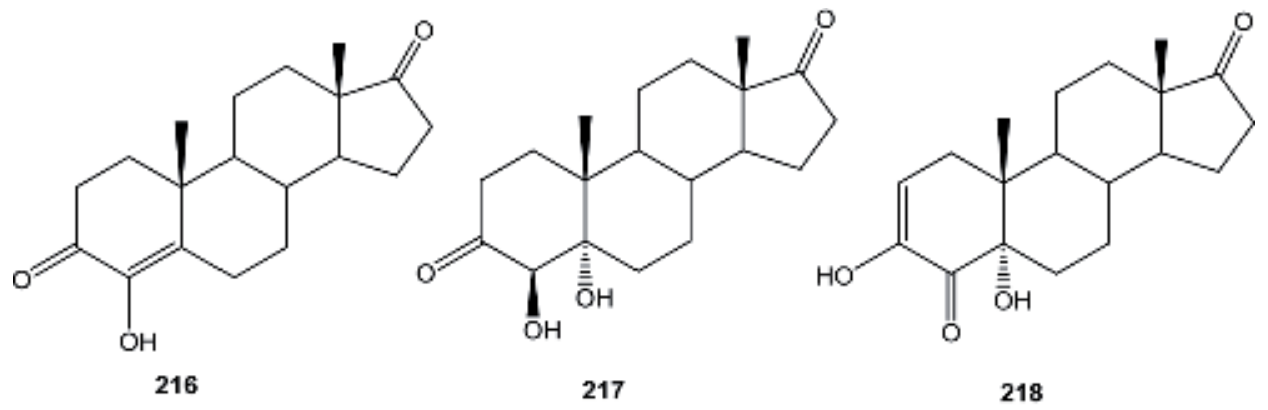

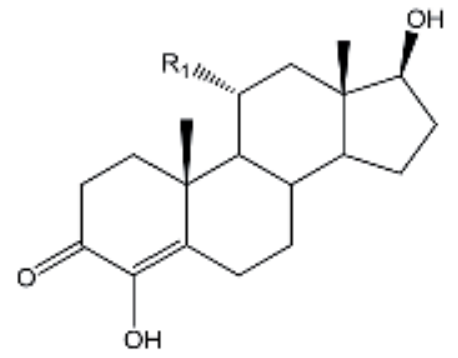

219) $R_{1}=H$ 221) $\mathrm{R}_{1}=\mathrm{OH}$<smiles>C[C@]12CCC3C4CCC(=O)[C@H]4CCC3[C@@H]1CC[C@@H](O)C2=O</smiles>

220

Figure 29.

Biotransformation products of formestane (216). 


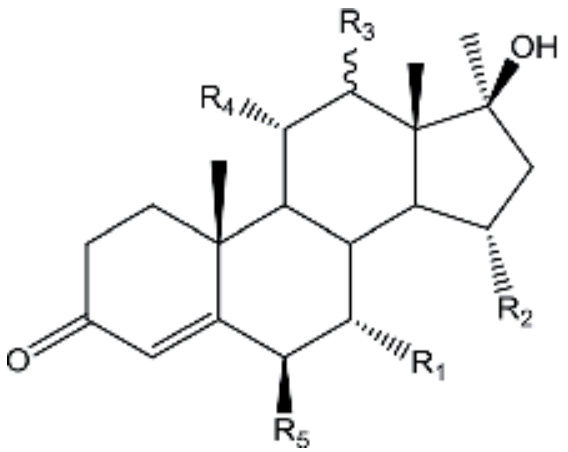

Figure 30.

Biotransformation products of methyltestosterone (222).
222) $R_{1}=R_{2}=R_{3}=R_{4}=R_{5}=H$

223) $R_{1}=O H, R_{2}=R_{3}=R_{4}=R_{5}=H$

224) $R_{1}=R_{3}=R_{4}=R_{5}=H, R_{2}=O H$

225) $R_{1}=R_{2}=R_{5}=H_{1} R_{2}=R_{3}=O H$

226) $R_{1}=R_{2}=R_{3}=R_{5}=H, R_{4}=O H$

227) $R_{1}=R_{2}=R_{3}=R_{4}=H, R_{5}=O H$

228) $R_{1}=R_{2}=R_{3}=H, R_{4}=R_{5}=O H$

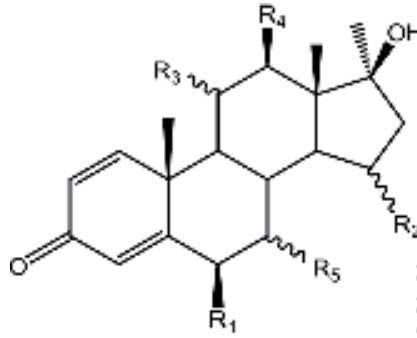

229) $R_{4}=R_{2}=R_{3}=R_{4}=R_{5}=H$ 230) $R_{4}=O H . \quad R_{2}=R_{3}=R_{4}=R_{5}=H$ 231) $R_{2}=R_{3}=R_{2}=R_{0}=H, R_{2}=\alpha O H$ 232) $R_{1}=R_{2}=R_{8}=R_{5}=H, R_{9}={ }_{2} O H$ 233) $R_{1}=R_{4}=O H, R_{2}=R_{3}=R_{5}=H$ 234) $R_{2}=\mathrm{OH}_{4} \mathrm{R}_{2}=\alpha O \mathrm{H}_{1} \mathrm{R}_{3}=\mathrm{R}_{4}=\mathrm{R}_{3}=\mathrm{H}$

236) $R_{1}=R_{2}=R_{3}=R_{4}=H, R_{6}=R O H$ 237) $R_{2}=R_{3}=R_{2}=R_{5}=H, R_{2}=\rho O H$ 239) $R_{1}=R_{2}=R_{2}=R_{5}=H_{4} R_{3}=B O H$ 240) $R_{1}=R_{2}=R_{3}=R_{4}=H, R_{6}={ }_{2} O H$<smiles>[R]C1C[C@H]2[C@@H]3CC[C@](C)(O)[C@@]3(C)CC([R])[C@@H]2[C@]2(C)C=CC(=O)C=C12</smiles>

235) $R_{1}=O, R_{2}=H$ 238) $R_{1}=H, R_{2}=O$

Figure 31.

Biotransformation products of dianabol (229).

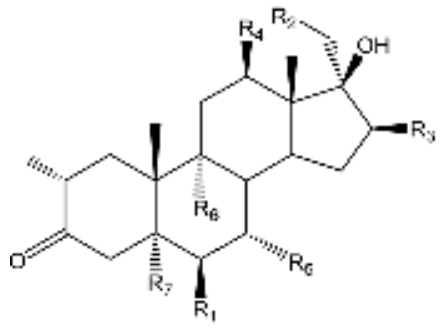

241) $R_{1}=R_{2}=R_{s}=R_{1}=R_{s}=R_{r}=R_{f}=H$ 242) $R_{1}=O, R_{2}=R_{3}=R_{4}=R_{5}=R_{6}=R_{7}=H$ 243) $R_{1}=R_{2}=R_{3}=R_{1}=R_{0}=H . R_{5}=O H$ 244) $R_{1}=R_{2}=R_{4}=R_{8}=R_{7}=H, R_{5}=R_{5}=O H$ 245) $R_{1}=R_{2}=R_{3}=R_{5}=R_{6}=H, R_{4}=R_{7}=O H$ 246) $R_{1}=R_{z}=R_{3}=R_{s}=R_{7}=H, R_{1}=R_{s}=O H$ 247) $R_{1}=R_{2}=R_{3}=R_{4}=R_{3}=H, R_{3}=R_{7}=O H$

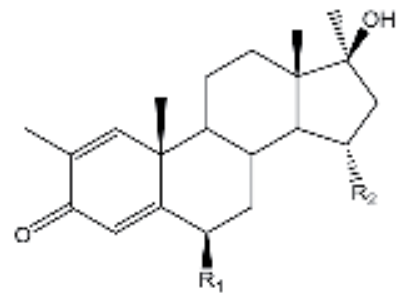

249) $R_{1}=R_{2}=O H_{1} \Delta^{* 0: 15 y}$ 249) $\mathrm{R}_{1}=\mathrm{H}_{3} \mathrm{R}_{2}=\mathrm{OH}$ 252) $\mathrm{R}_{1}=\mathrm{O}, \mathrm{R}_{2}=\mathrm{H}$ 253) $R_{1}=R_{2}=H$<smiles>CC1=C[C@]2(C)C(=CC1=O)CCC1C2CC[C@]2(C)C(C)=C[C@H](O)[C@@]12O</smiles>

251

Figure 32.

Biotransformation products of masthasterone (241).

(238), and 11ß-hydroxydianabol (239) were obtained from the biotransformation of 229 using Macrophomina phaseolina [101]. Biotransformation of 229 using several microorganisms has been reported, for example, Penicillium notatum [102] transformed 229 into 230 and 231, while Trichoderma hamatum produced 232 [103]. 
Similarly, B. bassiana, A. ochraceus, Colletotrichum lagenarium, and Sporotrichum sulfurreducens gave a biotransformed product 232 [104]. Absidia glauca metabolized 229 in compounds 230 , and 236-237 [105]. In contrast, the biotransformation of 229 using A. coerula yielded 239 along with $7 \alpha$-hydroxydianabol (240) [106], while by using $B$ cinerea, 237 was obtained as the only product (Figure 31) [107].

Methasterone (241) is a synthetic anabolic steroid, known to gain muscle mass. Microbial transformation of $\mathbf{2 4 1}$ using $M$ phaseolina yielded 17 $\beta$-hydroxy$17 \alpha$ (hydroxymethyl)-2 $\alpha$-methyl- $5 \alpha$-androstane-3,6-dione (242), while by using $C$. blakesleeana, $7 \alpha$-hydroxymethasterone $(243,2.0 \%), 7 \alpha, 16 \beta$-dihydroxymethasterone (244, 0.7\%), 5 $\alpha, 12 \beta$-dihydroxymethasterone $(245,1.0 \%), 7 \alpha, 12 \beta$ -

dihydroxymethasterone $(246,1.5 \%)$, and $7 \alpha, 9 \alpha$-dihydroxy-methasterone $(247,0.5 \%)$ were obtained. Incubation of $\mathbf{2 4 1}$ with Fusarium lini yielded different metabolites with dehydrogenation in ring $A$ and $D: 6 \beta, 17 \beta$-dihydroxy-2,17 $\alpha$-dimethyl-5 $\alpha$-androst-1,4diene-3-one $(248,1.0 \%), 15 \alpha, 17 \beta$-dihydroxy-2 $\alpha, 17 \alpha$-dimethyl-5 $\alpha$-androst-1,4-diene3 -one (249, 0.6\%), 6 $\beta, 17 \beta$-dihydroxy-2,17 $\alpha$-dimethylandrost-1,4-diene-3-one (250, $0.4 \%), 14 \alpha, 15 \alpha$-dihydroxy-2,17-dimethyl-5 $\alpha$-androst-1,4,16-trien-3-one (251, 0.3\%), $17 \beta$-hydroxy-2,17 $\alpha$-dimethyl-5 $\alpha$-androst-5 $\alpha$-1,4-dien-3,6-dione (252, 0.3\%), and $17 \beta$-hydroxy-2,17 $\alpha$-dimethyl-5 $\alpha$-androst-1,4-dien-3-one (253, 1.0\%) (Figure 32) [108].

\section{Conclusions}

The biotransformation processes of different steroid compounds described in this review, although not exhaustive, aim to highlight the importance of biotransformation through different microorganisms, as a useful chemical-biological tool for obtaining novel derivatives for research purpose and as industrial applications. An example includes obtaining steroid compounds for the pharmaceutical industry.

Biotransformation of steroids has been implemented in an important way in the partial synthesis of new steroids, for their evaluation as hormones and drugs. Currently, there is a wide variety of steroids used as diuretics, anabolic, anti-inflammatory, antiandrogenic, anticontraceptive, antitumor, among other applications. Chemical functionalization in different carbon atoms of the sternum skeleton is related to the biological activity of the molecule. This is why microbiological transformations play an important role in obtaining these compounds through chemical transformations, such as the oxidation of hydroxyl group at C-3 and C-17, isomerization of the double bond $\Delta^{5(6)}$ to $\Delta^{4(5)}$, hydrogenation of double bonds $\Delta^{1(2)}$ and $\Delta^{4(5)}$, and reduction of the carbonyl group at $\mathrm{C}-17$ and $\mathrm{C}-20$ with $\beta$ orientation. Biohydroxylations performed in different positions of the steroid skeleton-C-11 $\alpha, \mathrm{C}-11 \beta, \mathrm{C}-15 \beta$, and C-16 $\alpha-$ using different species of fungi of the genera Rhizopus, Aspergillus, Curvularia, Cunninghamella, and Streptomyces with high yields are an important chemical transformation in many synthesis schemes of new steroids with a determined biological activity.

Hydroxylation of steroids-progesterone, testosterone, $17 \alpha$-methyltestosterone, and 4-androsten-3,17-dione-presenting the 4-en-3-one system, proceeds with a high stereo- and regioselectivity in the C- 6 and C- 11 positions, with a $\beta$ orientation in C- 6 and $\alpha$ orientation in C-11. The presence of the methyl group in C-10 is necessary for the hydroxylation in $\mathrm{C}-11$, as can be seen in the derivatives of 19-nortesterone.

The interest in the biotransformation of steroid compounds has been increasing in recent years, due to the obtaining of new and useful pharmacologically active compounds. In addition to the development of new genetically modified strains, there is an increase in the availability of immobilized enzymes and the manipulation of culture media. 
Biotransformation of steroids proceeds with low to moderate yields in general. One of the main causes is their low solubility in water. Currently, methodologies are developed that allow the incorporation of chemicals-surfactants, ionic liquids, cyclodextrins, liposomes, among others-that contribute to improve the yields of each biotransformation process and the processes friendly to the environment.

\section{Acknowledgements}

A la Carrera de Biología, FES-Zaragoza, UNAM. Ms. Fabiola Cano thank for her suggestions and comments toward improving the manuscript.

\section{Author details}

Arturo Cano-Flores*, Javier Gómez and Rigoberto Ramos

Laboratorio de Biotransformaciones y Química de Productos Naturales, L-314, Facultad de Estudios Superiores Zaragoza, UNAM, México, D.F., Mexico

*Address all correspondence to: acano1750@gmail.com

\section{IntechOpen}

(C) 2019 The Author(s). Licensee IntechOpen. This chapter is distributed under the terms of the Creative Commons Attribution License (http://creativecommons.org/licenses/ by/3.0), which permits unrestricted use, distribution, and reproduction in any medium, provided the original work is properly cited. (cc) BY 


\section{References}

[1] Mensah-Nyagan AG, Meyer L, Schaeffer V, Kibaly C, PatteMensah C. Evidence for a key role of steroids in the modulation of pain. Psychoneuroendocrinology. 2009;34:169-177. DOI: 10.1016/j. psyneuen.2009.06.004

[2] Funder JW. Minireview: Aldosterone and mineralocorticoid receptors: Past, present, and future. Endocrinology. 2010;151:5098-5102. DOI: 10.1210/ en.2010-0465

[3] Fernandez P, Cruz A, Angelova B, Pinheiro HM, Cabral JMS. Microbial conversion of steroid compounds: Recent developments. Enzyme and Microbial Technology. 2003;32:688-705. DOI: $10.1016 /$ S0141-0229(03)00029-2

[4] Hogg JA. Steroids, steroids community and Upjohn in perspective: A profile of innovation. Steroids. 1992;257:593-616

[5] Sedlaczek L. Biotransformations of steroids. Critical Reviews in Biotechnology. 1988;7:187-236. DOI: 10.3109/07388558809146602

[6] Ko D-H, Heiman AS, Chen M, Lee HJ. New steroidal anti-inflammatory antedrugs: Methyl 21-desoxy-21-chloro$11 \beta, 17 \alpha$-dihydroxy-3,20-dioxo-1,4pregnadiene-16 $\alpha$-carboxylate, methyl 21-desoxy-21-chloro-11/-hydroxy-3,20dioxo-1,4-pregnadiene-16 $\alpha$-carboxylate, and their $9 \alpha$-fluoro derivatives. Steroids. 2000;65:210-218

[7] Fragkaki AG, Angelis YS, Koupparis M, Tsantili-Kakoulidou A, Kokotos G, Georgakopoulus C. Structural characteristics of anabolic androgenic steroids contributing to binding to the androgen receptor and to their anabolic and androgenic activities: Applied modifications in the steroidal structure.
Steroids. 2009;74:172-197. DOI:

10.1016/j.steroids.2008.10.016

[8] Agoston ES, Hastcher MA, Kensler TW, Posner GH. Vitamin D analogs as anti-carcinogenic agents. Anti-Cancer Agents in Medicinal Chemistry. 2006;6:53-71. DOI: 10.2174/187152006784111369

[9] Tuba Z, Barden CW, Dancsi A, Francsics-Czinege E, Molnar EC, Csorgei J, et al. Synthesis and biological activity of a new progestogen, 16-methylene-17 $\alpha$-hydroxy-18-methyl19-norpregn-4-ene-3,20-dione acetate. Steroids. 2000;65:266-274. DOI: 10.1016/S0039-128X(99)00109-9

[10] Siemes C, Visser LE, De-Jong FH, Jan-Willem Coebergh W, Uitterlinden AG. Cytochrome P450 3A gene variation, steroid hormone serum levels and prostate cancer. Steroids. 2010;75:1024-1032. DOI: 10.1016/j. steroids.2010.07.001

[11] Diaz-Chico BN, Rodriguez FG, Gonzalez A, Ramirez R, Bilbao C, Leon $\mathrm{AC}$, et al. Androgens and androgen receptores in breast cáncer. Journal of Steroid Biochemistry and Molecular Biology. 2007;105:1-15. DOI: 10.1016/j. jsbmb.2006.11.019

[12] Johnston JO. Aromatase inhibitors. In: Parish EJ, Nes WD, editors.

Biochemistry and Function of Sterols. Boca Raton, FL: CRC Press; 1987.

pp. 23-53

[13] Craigie E, Mullins JJ, Bailey MA.

Glucocorticoids and mineralocorticoids. In: Bader M, editor. Cardiovascular Hormone Systems: From Molecular Mechanisms to Novel Therapeutics. Weinheim: Wiley-VCH Verlag GmbH \& Co; 2009. pp. 1-64

[14] Chung SK, Ryoo CH, Yang HW, Shim JY, Kang MG, Lee KW, et al. 
Synthesis and bioactivites of steroids derivatives as antifungal agents.

Tetrahedron. 1998;52:15899-15914. DOI: 10.1016/S0040-4020(98)01000-X

[15] Suzuki K, Nakata T, Shimizu T, Enomoto K. Anti-obesity agents. US Patent 5,846,962; 1998

[16] Dombrowski AW, Hazuda DJ, Polishook JD, Felock PJ, Singh SB, Zink DL. HIV-integrase-inhibitors. WO Patent 0036132; 2000

[17] Athan D, Svasti J, Kittakoop P, Pittayakhachonwut D, Tanticharpen M, Thebtaranoth Y. Antiviral isoflavonoid sulfate and steroidal glycoside from the fruits of Solanum torvum. Phytochemistry. 2002;59:459-463. DOI: 10.1016/S0031-9422(01)00417-4

[18] Rupprecht R, Holsboer F.

Neuoroactive steroids: Mechanisms of action and neuropsychopharmacology perspectivs. Trends in Neurosciences. 1999;22:410-416. DOI: $10.1016 /$ S0166-2236(99)01399-5

[19] Mellon SH, Griffin LD. Neurosteroids: Biochemistry and clinical significance. Trends in Endocrinology and Metabolism. 2002;13:35-43. DOI: 10.1016/ S1043-2760(01)00503-3

[20] Baulieu E-E, Schumacher M. Progesterone as a neuroactive neurosteroid, with special reference to the effect of progesterone on myelination. Steroids. 2000;65:605-612

[21] Fernandez P, Cabral JMS. Steroid bioconversion. In: Flickinger M, editor. Enciclopedia of Industrial Biotechnology: Bioprocess, Bioseparation, and Cell Technology. New York: John Wiley \& Sons, Inc.; 2010. pp. 1-32

[22] Donova MV, Ergova OV. Microbial steroid transformations: Current state and prospect. Applied
Microbiology and Biotechnology. 2012;94:1423-1447. DOI:

10.1007/978-1-4939-7183-1

[23] Sultana N. Microbial biotransformation of bioactive and clinically useful steroids and some salient features of steroids and biotransformation. Steroids. 2018;136:76-92. DOI: 10.1016/j. steroids.2018.01.007

[24] Tong W-Y, Dong X. Microbial biotransformation: Recent developments on steroid drugs. Recent Patents on Biotechnology. 2009;3:141-153

[25] Bureik M, Bernhardt R. Steroid hydroxilation: Microbial steroid biotransformation using cytochrome P450 enzymes. In: Schmid RD, Urlacher VB, editors. Modern Bioxidation: Enzymes, Reactions and Applications. Wienheim: Wiley-VCH Verlag GmbH \& Co. KGaA; 2007. pp. $155-176$

[26] Lehman LR, Stewart JD.

Filamentous fungi: Potentially useful for the biohydroxilation of non-actived carbón centres. Current Organic Chemistry. 2001;5:439-470. DOI: $10.2174 / 1385272013375490$

[27] Pollard DJ, Woodley JM. Biocatalysis for pharmaceutical intermediates: The future is now. Trends in Biotechnology. 2006;25:66-72. DOI: 10.1016/j. tibtech.2006.12.005

[28] Straathof AJJ. The production of fine chemicals by biotransformation. Current Opinion in Biotechnology. 2002;13:548-546. DOI: 10.1016/ S0958-1669(02)00360-9

[29] Mahato SB, Majumdar I. Current trends in microbial steroid biotransformation. Phytochemistry. 1993;34:883-898. DOI: $10.1016 /$ S0031-9422(00)90685-X 
[30] Mahato SB, Garai S. Advances in microbial steroid biotransformation. Steroids. 1997;62:332-345. DOI: 10.1016/ S0039-128X(96) 00251-6

[31] Donova MV. Transformation of steroids by actinobacteria. Applied Biochemistry and Microbiology. 2007;43:1-14

[32] Prabha V, Ohri M. Review: Bacterial transformations of bile acids. World Journal of Microbiology and Biotechnology. 2006;22:191-196. DOI: 10.1007/s11274-005-9019-y

[33] Huttel W, Hoffmeister D. Fungal Biotransformation in pharmaceutical sciences. In: Hofrichter M, editor. Industrial Applications, the Mycota. Berlin: Springer; 2010. pp. 293-317

[34] Petric S, Hakki T, Bernhardt R, Zigon D, Cresnar B. Discovery of a steroid $11 \alpha$-hydroxylase from Rhizopus oryzae and its biotechnological application. Journal of Biotechnology. 2010;150:428-437. DOI: 10.1016/j. jbiotec.2010.09.928

[35] Rodina NV, Andryushina VA, Stysenko TS, Turova TP, Baslerov RV, Panteleeva AN, et al. The introduction of the $9 \alpha$-hydroxy group into andros-4-en-3,17-dione using a new actinobacterium strain. Applied Biochemistry and Microbiology. 2009;45:395-400

[36] Faber K, Kroutil W. New enzymes for biotransformation. Current Opinion in Chemical Biology. 2005;9:181-187. DOI: DOI 10.1016/j.cbpa.2005.01.0

[37] Ran N, Zhao L, Chen Z, Tao J. Recent applications of biocatalysis in developing green chemistry for chemical synthesis at the industrial scale. Green Chemistry. 2008;10:361372. DOI: $10.1039 / \mathrm{b} 716045 \mathrm{c}$

[38] Hu SH, Genain G, Azerad R. Microbial transformation of steroids:
Contribution to $14 \alpha$-hidroxilations. Steroids. 1995;60:337-352

[39] Smith KE, Ahmed F, Williams RAD, Kelly SL. Microbial transformations of steroids-VIII. Transformation of progesterone by whole cells and microsomes of Aspergillus fumigatus. The Journal of Steroid Biochemistry and Molecular Biology. 1994;49:93-100

[40] Khalil AM, Eman MM.

Microbiological transformation of progesterone by some zoosporic fungi. Journal of Basic Microbiology. 1996;36:255-259

[41] Javid M, Nickavar B, Vahidi H, Faramarzi MA. Baeyer-Villiger oxidation of progesterone by Aspergillus sojae PTCC 5196. Steroids. 2018;140:52-57. DOI: 10.1016/j.steroids.2018.07.008]

[42] Kolek T, Swizder A.

Biotransformation XLV.

Transformations of 4-ene-3-oxosteroids in Fusarium culmorum culture. The Journal of Steroid Biochemistry and Molecular Biology. 1998;67:63-69

[43] Al-Awadi S, Afzal M, Oommen S. Studies on Bacillus stearithermophillus. Part I. Transformation of progesterone to a new metabolite 9,10-seco-4pregnene-3,9,20-trione. The Journal of Steroid Biochemistry and Molecular Biology. 2001;78:493-498

[44] Kolet SP, Niloferjahan S, Haldar S, Gonnade R, Thulasiram HV. Biocatalyst mediated production of $6 \beta, 11 \alpha-$ dihydroxy derivatives of 4-ene-3-one steroids. Steroids. 2013;78:1152-1158. DOI: $10.116 /$ j.steroids.2013.08.00

[45] Eshrat G-F, Aroona C.

Biotransformation of progesterone by Penicillum aurantiogriseum. Research Journal of Microbiology. 2011;6:98-104. DOI: $10.3923 / j m .2011 .98 .104$

[46] Gopal SKV, Naik S, Somal P, Sharma P, Arjuna A, Hassam R, et al. Production 
of 17-ketoandrostene steroids by the side chain cleavage of progesterone with $B$. sphaericus. Biocatalysis and Biotransformation. 2008;26:272-279. DOI: $10.1080 / 10242420701707637$

[47] Al-Beloshei NE, Al-Awadhi HA, Al-Khalaf RAR, Oommen S, Afzal M. Biocatalyzed transformation of progesterone by Geobacillus gargensis DSM 15378. Applied Biochemistry and Microbiology. 2015;51:321-328

[48] Gas KP, Sakac M, JovanovicSanta S, Djurendic E. An overview of partial synthesis and transformations of secosteroids. Current Organic Chemistry. 2014:216-259. DOI: 10.2174/138527281131176660147.]

[49] Lin Z, Marepally SR, Ma D, Kim T-K, Oak ASW, Myers LK, et al. Synthesis and biological evaluation of vitamin D3 metabolite 20S,23S-dihydroxyvitamin D3 and its 23R epimer. Journal of Medicinal Chemistry. 2016:136, 5102-5108. DOI: 10.1021/acs.jmedchem.6b00182

[50] Madyastha KM, Joseph T.

Transformation of 16-dehydroprogesterone and 17 $\alpha$-hydroxyprogesterone by Mucor piriformis. Applied Microbiology and Biotechnology. 1994;41:170-177

[51] Madyastha KM, Joseph T.

Transformation of dehydroepiandrosterone and pregnenolone by Mucor piriformis. Applied Microbiology and Biotechnology. 1995;44:339-343

[52] Shan L-H, Liu H-M, Huang K-H, Dai G-F, Cao C, Dong R-J. Synthesis of $3 \beta, 7 \alpha, 11 \alpha$-trihidroxy-pregn-21benzylidene-5-en-20-one derivatives and their cytotoxic activities. Bioorganic \& Medicinal Chemistry Letters. 2009;19:6637-6639. DOI: 10.1016/j. bmcl.2009.10.019

[53] Farooq A, Tahara S. Biotransformation of testosterone and pregnenolone catalyzed by the fungus Botrytis cinerea. Journal of Natural Products. 2000;63:489-491. DOI: 10.1021/np990520b

[54] Choudhary MI, Batool I, SAA S, Nawaz SA, Ali Shah SA, Atta-urRahman. Microbial hydroxylation of pregnenolone derivatives. Chemical \& Pharmaceutical Bulletin. 2005;55:1455-1459

[55] Schaaaf O, Dettner K.

Transformation of steroids by Bacillus strains isolated from the foregut of water beetles (Coloptera: Dytiscidae): II. Metabolism of 3 $\beta$-hydroxypregn-5en-20-one (pregnenolone). The Journal of Steroid Biochemistry and Molecular Biology. 2000;75:187-199

[56] Wilson MR, Gallimore WA, Reese PB. Steroid transformations with Fusarium oxysporum var. cubense and Colletotrichum musae. Steroids. 1999;64:834-843. DOI: $10.1016 /$ S0039-128X(99)00067-7

[57] Hu SH, Tian XF, Sun YH, Han GD. Microbial hydroxylation of 13-ethyl$17 \beta$-hydroxy-18,19-dinor-17 $\alpha$ pregn-4-en-20-in-17-ona. Steroids. 1996;61:407-410

[58] Hu SH, Tian XF, Han GD. Novel microbial hydroxylation of 13-ethyl$17 \beta$-hydroxy-18,19-dinor-17 $\alpha$-pregn-4en-20-yn-3-one. Steroids. 1998;63:88-92

[59] Choudhary MI, Azizuddin, Atta-ur-Rehman. Microbial transformation of danazol. Natural Product Letters. 2002;16:101-106. DOI: 10.1080/10575630290019994

[60] Baydoun E, Atia-tul-Wahab, Mehmood H, Ahmad MS, Malik R, Smith C, et al. Microbial transformation of danazol with Cunninghamella blakesleeana and anti-cancer activity of danazol and its transformed products. Steroids. 2016;105:121-127. DOI: 10.1016/j.steroids.2015.11.010 
[61] Choudhary MI, Musharraf SG, Ali RA, Atif M, Atta-ur-Rahman. Microbial transformation of antifertility agents. Norethisterone and $17 \alpha$-ethynylestradiol. Zeitschrift für Naturforschung. 2004;59B:319-323

[62] Choudhary MI, Musharraf SG, Ali-Siddiqui Z, Khan NT, Alli RA, Attaur-Rahman. Microbial transformation of mestranol by Cunninghamella elegans. Chemical \& Pharmaceutical Bulletin. 2005;53:1011-1013

[63] Ahmad MS, Zafar S, Yousuf S, Atta-tul-Wahab, Atta-ur-Rahman, Choudhary MI. Biotransformation of 6-dehydroprogesterone with Aspergillius niger and Gibberella fujikuroi. Steroids. 2016;112:62-67. DOI: 10.1016/j. steroids.2016.04.008

[64] Peterson DH, Nathan AH, Meister PD, Eppstein SH, Murray HC, Weintraub A, et al. Microbiological transformation of steroids VI. Preparation of 11 $\alpha$-hydroxy-6-dehydroprogesterone. Journal of the American Chemical Society. 1953;75:419-421

[65] Smith KE, Latif S, Kirk DN, White KA. Microbial transformations of steroids IV. 6,7-dehydrogenation; a new class of fungal steroids transformation product. Journal of Steroid Biochemistry. 1989;33:271-276. DOI: 10.1016/0022-4731(89)90304-X

[66] Baydoun E, Bano S, Atia-tu-Wahab, Jabeen A, Yousuf S, Mesaik A, et al. Fungal transformation and T-cell proliferation inhibitory activity of melengestrol acetate and its metabolite. Steroids. 2014;86:56-61. DOI: 10.1016/j. steroids.2014.04.012

[67] Madyasth KM. Novel microbial transformation of steroids. Advances in Experimental Medicine and Biology. 1995;405:259-270

[68] Angelova B, Mutafov S, Avramova T, Dimova I, Boyadjieva L.
$9 \alpha$-Hydroxylation of 4-androstene-3,17dione by resting Rhodococcus sp. cells. Process Biochemistry. 1996;31:179-184

[69] Schaaaf O, Dettner K.

Transformation of steroids by Bacillus strains isolated from the foregut of water beetles (Coleoptera: Dytiscidae): I. Metabolism of androst-4-en-3,17diona (AD). The Journal of Steroid Biochemistry and Molecular Biology. 1998;67:451-465

[70] Hanson JR, Nasir H, Pervez A. The hydroxilation of testosterone and some derivates by Cephaslosporium aphidicola. Phytochemistry. 1996;42:411-415

[71] Choudhary MI, Sultan S, MTH K, Yasin A, Shaheen F, Atta-ur-Rehman. Biotransformation of $(+)$-androst4-ene-3,17-diona. Natural Product Research. 2004;18:529-535. DOI: 10.1080/14786410310001620628

[72] Xiong Z, Wei Q, Chen H, Chen S, $\mathrm{Xu}$ W, Qiu G, et al. Microbial transformation of androst-4-en-3,17dione by Beauveria bassiana. Steroids. 2006;71:979-983. DOI: 10.1016/j.

steroids.2006.07.007

[73] Janeczko T, Dmochowska-Gładysz J, Kostrzewa-Susłow E, Białonska A, Ciunikb Z. Biotransformations of steroid compounds by Chaetomium sp. KCH 6651. Steroids. 2009;74:657-661. DOI: 10.1016/j.steroids.2009.02.006

[74] Andryushina VA, Voishvillo NE, Druzhinina AV, Stytsenko TS, Yaderets VV, Petrosyan MA, et al. $14 \alpha$-hydroxylation of steroids by mycelium of the mold fungus Curvularia lunata (VKPM F-981) to produce precursors for synthesizing new steroidal drugs. Pharmaceutical and Chemical Journal. 2013;47:103-108

[75] Qiao Y, Shen Y, Huang W, Wang Y, Ren J, Xia T, et al. Biocatalyst-mediated production of 11,15-dihydroxy derivates 
of androst-1,4-dien-3,17-dione. Journal of Bioscience and Bioengineering. 2017;123:692-697. DOI: 10.1016/j. jbiosc.2017.01.008.], 10.1016/j. jbiosc.2017.01.008.]

[76] Ahmed F, Williams RAD, Smith KE. Microbial transformations of steroids-X. Cytochromes P-450 $11 \alpha$-hydroxylase and C17-C20 lyase and a 1-ene-dehydrogenase transform steroids in Nectria haematococca. The Journal of Steroid Biochemistry and Molecular Biology. 1996;58:337-349. DOI: 10.1016/0960-0760(96)00032-5

[77] Atta-ur-Rahman, Choudhary MI, Asif F, Farooq A, Yaqoob M. Microbial transformations of testosterone. Natural Product Letters. 1998;12:255-261. DOI: 10.1080/10575639808048299

[78] Al-Awadi S, Afzal M, Oommen S. Studies of Bacillus stearothermophilus. Part III. Transformation of testosterone. Applied Microbiology and Biotechnology. 2003;62:48-52. DOI: $10.1007 / \mathrm{s} 00253-003-1269-8$

[79] Al-Awadi S, Afzal M, Oommen S. Studies on Bacillus stearothermophilus. Part IV. Influence of enhancers on biotransformation of testosterone. Steroids. 2005;70:323-327

[80] Wu Y, Li H, Zhang XM, Gong JS, Ra ZM, Shi JS, et al. Efficient hydroxylation of functionalized steroids by Colletotrichum lini ST-1. Journal of Molecular Catalysis B: Enzymatic. 2015;120:111-118. DOI: 10.1016/j. molcatb.2015.07.003

[81] Choudhary MI, Ali Shah SA, Musharraf SG, Shaheen F, Atta-urRahman. Microbial transformation of dehydroepiandrosterone. Natural Product Research. 2003;17:215-220. DOI: 10.1080/1057563021000040835

[82] Huang L-H, Li J, Xu G, Zhang X-H, Wang Y-G, Yin
Y-L, et al. Biotransformación of dehydroepiandrosterone (DHEA) with Penicillum griseopurpureum Smith and Penicillum glabrum (Wehmer) Westling. Steroids. 2010;75:1039-1046. DOI: 10.1016/j. steroids.2010.06.008

[83] Choudhary MI, Sultan S, Khan MTH, Atta-ur-Rehman. Microbial transformation of $17 \alpha$-ethynyl- and $17 \alpha$-ethylsteroids, and tyrosinase inhibitory activity of transformed products. Steroids. 2005;70:798-802. DOI: 10.1016/j.steroids.2005.05.002

[84] Musharraf SG, Atta-ur-Rahman, Choudhary MI, Sultan S. Microbial transformation of $(+)$-adrenosterone. Natural Product Letters. 2002;16:345349. DOI: $10.1080 / 10575630290033105$

[85] Choudhary MI, Sultan S, Jalil S, Anjum S, Rahman AA, Fun HK, et al. Microbial transformation of mesterelone. Chemistry \& Biodiversity. 2005;2:392-400. DOI: 10.1002/ cbdv.200590019

[86] Ahmad MS, Zafar S, Bibi M, Bano S, A-tul W, Atta-ur-Rahman, et al. Biotransformation of androgenic steroid mesterolone with Cunnighamella blakesleeana and Macrophomina phaseolina. Steroids. 2014;82:53-59. DOI: 10.1016/j.steroids.2014.01.001

[87] Ahmada MS, Farooqa R, Hussaina N, Atia-tul-Wahabb, Atta-ur-Rahmana, Choudhary MI. Three new analogues of androgenic drug mesterolone through biotransformation with Cunninghamella blakesleeana. Journal of Molecular Catalysis B: Enzymatic. 2016;133:S395-S399. DOI: 10.1016/j. molcatb.2017.03.001

[88] Choudhary MI, Siddiqui ZA, Musharraf SG, Nawaz SA, Atta-urRahman. Microbial transformation of prednisone. Natural Product Research. 2005;19:311-317. DOI: 10.1080/14786410410001729168 
[89] Faramarzi MA, Yazdi MT, Shafiee A, Zarrini G. Microbial transformation of hydrocortisone by Acremonium strictum PTCC 5282. Steroids. 2002;67:869-872. DOI: $10.1016 /$ S0039-128X(02)00049-1

[90] Choudhary MI, Sultan S, Yaqoob M, Musharraf SG, Yasin A, Shaheen F, et al. Microbial transformation of cortisol and prolyl endopeptidase inhibitory activities of its transformed products. Natural Product Research. 2003;17:389-395. DOI: $10.1080 / 14786410310001617640$

[91] Kiran I, Hanson JR, Hunter AC. The microbiological hydroxylation of some methoxysteroids by Cephalosporium aphidicola. Journal of Chemical Research. 2004;5:362-363. DOI: $10.3184 / 0308234041639827$

[92] Jekkel A, Ilkoy E, Horvath G, Pallagi I, Süto J, Ambrus G. Microbial hydroxylation of 13 $\beta$-ethyl-4-gonene-3, 17-dione. Journal of Molecular Catalysis B: Enzymatic. 1998;5:385-387. DOI: 10.1016/S1381-1177(98)00097-6

[93] Zafar S, Yousuf S, Kayani HA, Saifullah S, Khan S, Al-Majid AM, et al. Biotransformation of oral contraceptive ethynodiol diacetate with microbial and plant cell cultures. Chemistry Central Journal. 2012;6:109-116. DOI: 10.1186/1752-153X-6-109

[94] Atia-tul-Wahab, Siddiqui

M, Ibrahin I, Hussain A, Ajandouz EH, Hijazi A, et al. Cunnighamella blakesleeana mediated biotransformation of a contraceptive drug, desogestrel, and anti-MDRStaphylococcus aureus activity of its metabolites. Bioorganic \& Medicinal Chemistry. 2018;77:152-158. DOI: 10.1016/j.bioorg.2017.12.027

[95] Huyet J, Pinon GM, Fay MR, Fagart J, Rafestin-Oblin M-E. Structural basis of spirolactone recognition by the mineralocorticoid receptor. Molecular
Pharmacology. 2007;72:563-571. DOI: 10.1124/mol.107.036459

[96] Preisig CL, Laakson JA, Mocek UM, Wang PT, Baez J, Byng G. Biotransformation of the cardiovascular drugs mexrenone and canrenone. Journal of Natural Products. 2003;66:350-356. DOI: 10.1021/ np020347a

[97] Baydoun E, Bibi M, Iqbal MA, Wanab A, Farran D, Smith C, et al. Microbial transformation of anti-cancer steroid exemestane and cytotoxicity of its metabolites against cancer cell lines. Chemistry Central Journal. 2013;7:57-63. DOI: 10.1186/1752-153X-7-57

[98] Martin GDA, Narvaez J, Bulmer R, Durrant MC. Biotransformation and molecular docking studies of aromatase inhibitor. Steroids. 2016;113:95-102. DOI: 10.1016/j.steroids.2016.07.003

[99] Martin GDA, Narvaez J, Marti A. Synthesis and bioconversions of formestane. Journal of Natural Products. 2013;76:1966-1969. DOI: $10.1021 / \mathrm{np} 400585 \mathrm{t}$

[100] Torshabi M, Badiee M, Faramarzi MA, Rastegar H, Forootanfar H, Mohit E. Biotransformation of methyltestosterone by the filamentous fungus Mucor racemosus. Chemistry of Natural Compounds. 2011;47:59-63

[101] Khan NT, Zafar S, Noreen S, Al Majid AM, Al Othman ZA, Al-Rasayes SI, et al. Biotransformation of dianabol with the filamentous fungi and $\beta$-glucoronidase inhibitory activity of resulting metabolites. Steroids. 2014;85:65-72. DOI: 10.1016/j. steroids.2014.04.004

[102] Bartmanska A, DmochowskaGladysz J, Huszcza E. Steroids transformation in Penicillum notatum culture. Steroids. 2005;70:193-198. DOI: 10.1016/j.steroids.2004.11.011 
[103] Bartmanska A, DmochowskaGladysz J. Transformation of steroids by Trichoderma hamatum. Enzyme and Microbial Technology. 2007;40:1651-1621

[104] Huszcza E, Dmochowska-Gladysz J, Bartmanska A. Transformation of steroids by Beauveria bassiana. Zeitschrift für Naturforschung. 2005;60c:103-108

[105] Huszcza E, Dmochowska-Gladysz J. Transformation of testosterone and related steroids in Absidia glauca culture. Journal of Basic Microbiology. 2003;43:113-120

[106] Brezezowska E, DmochowskaGladysz J, Kolek T. Biotransformation XXXIX. Metabolism of testosterone, androstenediona, progesterone and testosterone derivates in Absidia coerula culture. The Journal of Steroid Biochemistry and Molecular Biology. 1996;57:357-362

[107] Huszcza E, Dmochowska-Gladysz J. Transformation of testosterone and related steroids by Botrytis cinerea. Phytochemistry. 2003;62:155-158

[108] Ahmad MS, Yousuf S, Atia-tulWahab, Jabeen A, Atta-ur-Rahman, Choudhary MI. Biotransformation of anabolic compound methasterone with Macrophomina phaseolina, Cunnighamella blackesleeana, and Fusarium lini, and TNF- $\alpha$ inhibitory effect of transformed products. Steroids. 2017;128:75-84. DOI: 10.1016/j. steroids.2017.04.001 



\title{
Estrone Sulfatase Inhibitors as New Anticancer Agents
}

\author{
Svetlana N. Morozkina and Alexander G. Shavva
}

\begin{abstract}
Enzyme steroid sulfatase (STS) is considered as a promising therapeutic target for the treatment of hormone-dependent oncological diseases such as breast, endometrial, prostate cancers, and endometriosis. The discovery of potent and irreversible STS inhibitors stimulated huge efforts of preclinical and clinical work. Various STS inhibitors such as steroid sulfamate, steroid nonsulfamate, nonsteroidal sulfamate, and nonsteroidal nonsulfamate-based inhibitors have been developed. In the review known STS inhibitors from the point of view of their safety, side-effects and perspectives for clinical application are considered. Among STS inhibitors several dual (multitargeted) compounds have huge potential being nonestrogenic and acting in nanomolar levels on the targets. The dual aromatasesulfatase inhibitors (DASI) approach has a great potential when a synergy between STS and aromatase inhibition is expected and, thus it could address acquired resistance mechanisms. Among STS inhibitors based on steroid skeleton $17 \alpha$-benzyl-, $17 \beta$-arylsulfonamides, 17-diisopropylcarbamoyl-3-O-sulfamates exhibit the best properties, especially as dual anticancer potential drugs. The same modifications result in the increased activity against STS in 2-OMe-3-O-sulfamates as well as 2-OMe-3, 17 $\beta$-bissulfamates, which are also active against triple negative breast cancer. $8 \alpha$-Steroid estrogen analogs without estrogenic properties also possess high STS-inhibitory activity and block breast cancer cells growth with the activity comparable to tamoxifen.
\end{abstract}

Keywords: steroid sulfatase (STS), inhibitors, breast cancer, hormone-dependent diseases

\section{Introduction}

Breast cancer (BC) is the most common malignant tumor in women (12\%) worldwide and is the second leading cause of cancer mortality after lung cancer (26\%) [1].

Approximately $95-97 \%$ of tumors are estrogen-dependent in the early stages of their development $[2,3]$ and more than $70 \%$ express very high levels of estrogen receptor alpha $(E R \alpha)[4]$. The fundamental difference of extragonadal estrogen synthesis is its autocrine nature-that an organ producing estrogens is a target organ at the same time. Thus, local concentration of estrogens in such organs may be markedly elevated. Peripheral estrogens formation is increased after menopause, and compensates estrogens deficiency in different organs and tissues [5]. Extragonadal estrogens' production may rise with the aging. Moreover, it was continually emphasized in the literature that the increased level of estrogens in the body is considered as a risk of the $\mathrm{BC}$ development $[6,7]$. 
Biologically active hormones, in particular the most active estrogen estradiol (E2), play a critical role in the initiation and development of hormone-dependent breast cancer (HDBC). In premenopausal women, estrogens are mainly (75\%) synthesized in the ovaries, and thus, a luteinizing hormone-releasing hormone (LH-RH) agonist [8, 9] is useful to suppress the function of pituitary hormone. In postmenopausal women estrogens are produced in peripheral tissues such as adipose tissues, skin, and mammary glands [10,11].

Adrenal dehydroepiandrosterone sulfate (DHEAS), dehydroepiandrosterone (DHEA), and adrenal or ovarian androstenedione are also sources of E2 in peripheral tissues. In postmenopausal women, concentrations of DHEAS, DHEA, and androstenedione in plasma are relatively high; approximately 1.8, 6.6, and $1.9 \mathrm{nM}$, respectively. In contrast, plasma concentrations of estrone (E1) and (E2) are several-fold lower (70 and $30 \mathrm{pM}$, respectively) [12].

Another important steroid precursor for estrogen formation is E1-sulfate (E1S). It is the most important estrogen in the peripheral blood, with relatively high $(0.6 \mathrm{nM})$ concentrations in postmenopausal women. E1S levels are associated with high bodymass index, which suggest that E1S originates from adipose tissue. Concentrations of E1S in plasma are 10-20 times higher than those of E1 and E2, as well as its half-life in the plasma is longer than the half-life of unconjugated estrogens.

Enzyme steroid sulfatase (STS) converts E1S to E1, followed by the reduction to the biologically active estrogen, E2, by $17 \beta$-hydroxysteroid dehydrogenase type 1 (17 $\beta$-HSD1), which is overexpressed in many breast tumors.

In $\mathrm{BC}$ tissues estrogens can be locally produced de novo by estrogen synthesis enzymes to promote tumor growth.

The level of estrogens in BC tissues of postmenopausal women can be 10-40 folds higher than in blood circulation and 5-10 times higher than in noncancerous breast tissues [13]. Furthermore, the intratumoral E2/E1 ratio is significantly higher in postmenopausal $\mathrm{BC}$ than in premenopausal BC. High concentrations of estrogen in breast tissue increase the risk of $\mathrm{BC}$ development $[14,15]$.

Thus, inhibition of enzymatic synthesis of estrogens is an effective therapeutic strategy for postmenopausal women with estrogen receptor-positive $(\mathrm{ER}+)$ tumors $[16,17]$. In situ transformations of inactive steroids require activity of a series of enzymes that were found in hormone-sensitive cancers.

The scheme of estrogens formation in human body includes: (a) formation of E1 from androstenedione under the action of cytochrome $\mathrm{P} 450$ aromatase, (b) reduction of E1 by $17 \beta-\mathrm{HSD} 1$ leads to more active $\mathrm{E} 2$. Importantly, almost insoluble in aqueous media E1 is converted into water-soluble E1S under the action of

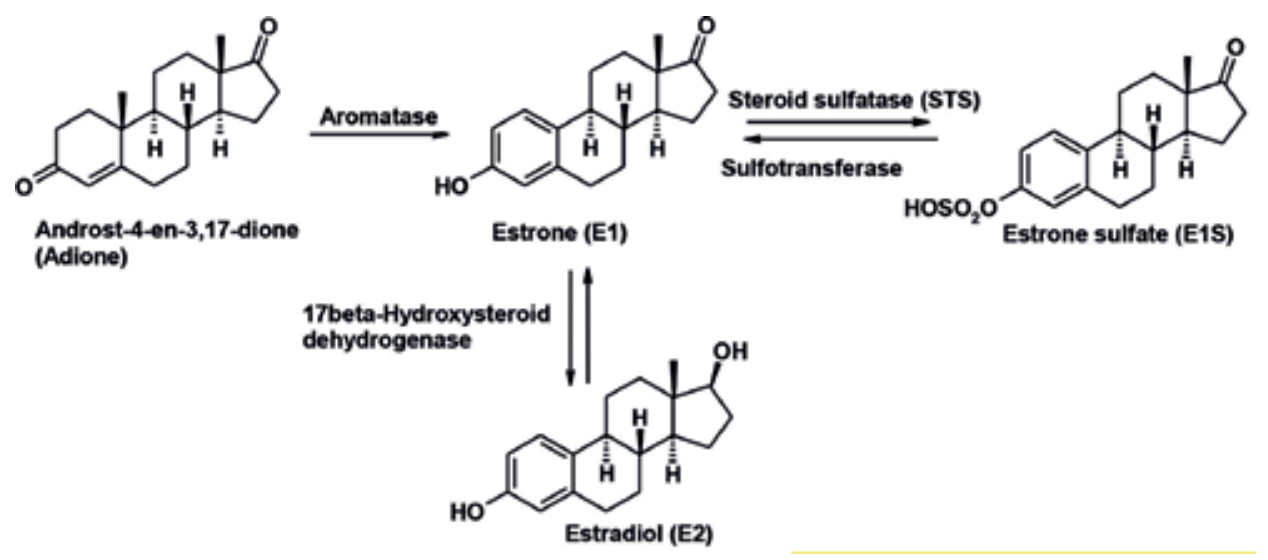

Figure 1.

Estrogens formation in human body. 
sulfotransferase (STS). E1S does not possess hormonal activity, however it may be transported into various targets (Figure 1) $[18,19]$. Several reviews focus on aspects of human steroidogenesis [18, 20-29].

Free hormones are formed from sulfates of estrogen and androgens under action of steroid sulfatase. At high concentrations, androgens compete for binding with ERs. The activation of ER $\alpha$ under the action of androstenediol and DHEA in $\mathrm{BC}$ cells has been detected. It is confirmed by the inhibition of cell growth in the presence of antiestrogens. The evaluation of E1S level during diagnostic of various oncological diseases (for example, prostate cancer) is of high importance [30].

\section{Approaches for the manipulation of estrogen level in tumors}

\subsection{Endocrine therapy}

Hormonal (endocrine) therapy is effectively used for the treatment of HDBC. Most types of BCs are estrogen-dependent, with approximately $55 \%$ in premenopausal women and 75\% in postmenopausal women [31-34].

Selective estrogen receptor modulators (SERMs) or down-regulators (SERD), such as tamoxifen, raloxifene, ospemifine, and fulvestrant are compounds that are currently used in clinical practice to treat BC $[9,35]$. In breast tissues, SERMs effectively block the activation of $\operatorname{ER}(\alpha)$ by endogenous ligands, preventing the transcription of genes mediated by estrogen response elements [36, 37]. SERMs have tissue-specific effects on ER $\alpha$ that results in antagonist activity in breast and uterus tissues as well as agonist activity in bone. Although tamoxifen and raloxifene possess the desired SERM activity, they also increase the risk of venous thromboembolism [38] and exhibit toxicity [22]. Given that resistance (de novo or acquired resistance) is a major limiting factor in the use of endocrine therapy, additional endocrine therapies with other mechanisms of action are needed [39, 40].

\subsection{Inhibitors of enzymes responsible for the estrogen formation in tumors}

The aromatase enzyme is responsible for the conversion of testosterone and androstenedione to E2 and E1, respectively. Thus, inhibition of the aromatase enzyme is one of the approaches for the development of new drugs to treat BC [41-43].

Nonsteroidal third-generation aromatase inhibitors (AIs), such as anastrozole (Arimidex), letrozole (Femara), and exemestane (Aromasin), are often used for postmenopausal hormone-dependent BC treatment in clinical practice. Despite the success of AIs in the clinic, numerous BC patients still progress after AI therapy due to the development of resistance to AIs and side-effects such as osteoporosis caused by whole-body deprivation of estrogen [44, 45]. Mechanisms of AI resistance include ligand-independent activation of the ER and signaling via other growth factor receptors; new insights about resistance are published recently [45].

The overall response rates for AIs (40-50\%) suggest the presence of alternative sources of estrogens. The production of E1, DHEA and androstenediol is an important mechanism of resistance to AI treatment [46].

It was demonstrated that AIs used sequentially with tamoxifen had higher efficacy compared to tamoxifen alone, with an improvement in overall survival [47].

There are other factors involved in tumor growth [48]. The enzymes STS and $17 \beta$-HSD1 have been identified as essential parts in E2 production and subsequent promotion of cancer growth. Recently it was shown that $17 \beta-$ HSD7 also plays a key role in increasing the E2/E1 ratio in BC tumors [49]. Very recently, some evaluations of the "sulfatase pathways" in tumor stroma have been carried out [50]. 
The STS is also responsible for the hydrolysis of DHEAS to DHEA, which is an immediate precursor of androstenediol, a potent estrogenic steroid [51], whose formation is not influenced by AIs. DHEAS stimulates proliferation of MCF-7 cells from BC, which could be blocked by an antiestrogen or STS inhibitor but by an AI. E1S and DHEAS are particularly abundant in blood circulation and could act as a reservoir of steroid precursors, specifically in BC [29,52]. The formation of DHEA through the STS pathway accounts for the production of $90 \%$ of the androgen androstenediol [52], which possesses estrogenic properties, that are 100-times weaker than estradiol $[13,53]$. Androstenediol is present at 100 -fold higher concentrations than estradiol in the circulation, and may have estrogenic properties that are equal to estradiol [54]. Thus, inhibition of STS has the dual property of reducing local androstenediol biosynthesis $[55,56]$.

\subsection{Steroid sulfatase enzyme (STS)}

The STS enzyme (EC 3.1.6.2, aryl sulfatase C, steryl-sulfatase) is widely distributed throughout the body and plays critical role in steroidogenesis [54]. Publications in recent years indicate the role of STS activity in gynecological diseases [57], mentioning diminished endometriosis in vivo under the action of STS inhibitors $[58,59]$. However, a phase II trial with STS inhibitors in endometrium cancer patients with advanced disease revealed no superior effects as compared to progestin megestrol acetate, and further studies are ongoing [60]. STS inhibitors are also useful for the treatment of ovary cancers and prostate cancer $[16,61]$.

According to the in vitro studies, STS is the main enzyme responsible for estrogen production in hormone-dependent breast tumors, and has several hundred times higher activity in liver and normal/malignant breast tissues than aromatase $[13,53,62]$. STS mRNA expression (74\%) in ER $\alpha$-positive breast tumors is an independent prognostic indicator in predicting relapse-free survival, with higher levels of expression being associated with a poor prognosis [63]. Like aromatase inhibitors, sulfatase inhibition can only be used in postmenopausal women. Probably, the greatest benefit with sulfatase inhibition is in those cases where DHEAS levels are high. To date, STS inhibitors are still in an early stage of development $[53,64,65]$.

The human STS is a protein, integrated in microsomal membrane. Its threedimensional structure has been determined (PDBcode 1P49) [66]. However, knowledge about regulation of its expression as well as activity is limited. The topology of the active site of the steroid sulfatase and the arylsulfatases A and B is similar [66].

Most of the STS inhibitors discovered to date, act as irreversible active-sitedirected inhibitors. An aryl sulfamate group $\left(\mathrm{ArOSO}_{2} \mathrm{NH}_{2}\right)$ is considered as the pharmacophore for irreversible inhibition of the enzyme. One of the first time-, pH-, and concentration-dependent irreversible active-site directed-steroidal inhibitor is estrone-3-O-sulfamate (EMATE), which inhibit STS in MCF-7 cells from BC by $99 \%$ at $0.1 \mu \mathrm{M}$ and has an $\mathrm{IC}_{50}$ value of $65 \mathrm{pM}$ ( $\mathrm{IC}_{50}=80 \mathrm{nM}$ in placental microsomes).

EMATE was evaluated in clinical trials [67]. The highest effectiveness of EMATE has been demonstrated in rats (subcutaneous and oral administration). STS activity was also inhibited when EMATE was administered to humans in dose $0.5 \mathrm{mg} / \mathrm{kg}$ [68].

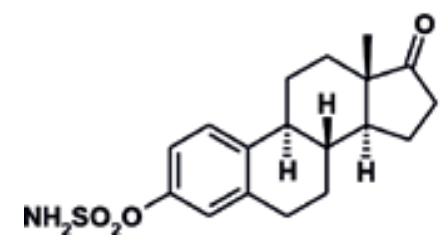


Despite the exceptional potency of the EMATE $[67,68]$, it is not used in clinical practice to treat hormone-dependent $\mathrm{BC}$ because metabolic conversion of EMATE by STS releases estrone, which act via estrogen receptors, and can directly promote tumor growth [69]. Nevertheless, EMATE is now the prototypical inhibitor, and used as standard during evaluation of other potential STS inhibitors [19].

\subsection{Mechanisms of inactivation of steroid sulfatase}

Several research groups made attempts to establish the mechanism(s) of sulfatase inactivation. However, the precise mechanism of inhibition is still uncertain. In 2010, Spillane and Malaubier have established that the hydrolysis of EMATE occurs by two different mechanisms: an SN2 mechanism below pH 9.5 and E1cB mechanisms involving $\mathrm{N}$-sulfonylamines at higher $\mathrm{pHs}$ [70]. Detailed presumable mechanisms have been discussed in recent reviews [71-73].

Based on the mechanisms, the result of the hydrolysis is free estrone. Moreover, under per os administration, the activity of EMATE is several times higher than the activity of estrone, due slow metabolism of EMATE in liver [68]. EMATE is not subjected to metabolic inactivation in red blood cells. Thus, consideration of hormonal activity and side-effects of steroids with free phenolic group is important in the modeling of sulfatase inhibitors for therapeutic use $[54,74,75]$.

The knowledge of the crystal structure opens the rational drug design of molecules for the inactivation of steroid sulfatase.

\subsection{Nonsteroidal STS inhibitors}

Many investigations have been carried out to develop nonsteroidal STS inhibitors, because nonsteroidal drugs and their metabolites may have less undesirable effects.

4-Methylcoumarin-7-O-sulfamate (1, Coumate) was the first time- and concentration-dependent STS inhibitor $\left(\mathrm{IC}_{50}=380 \mathrm{nM}\right)$ in oral dose $10 \mathrm{mg} / \mathrm{kg} / \mathrm{day}$, and in vivo has no estrogenic activity. 3,4-Dimethylcoumarin-7-O-sulfamate (2) was a more potent inhibitor $\left(\mathrm{IC}_{50}=30 \mathrm{nM}\right)$ [76].

A search of an orally active, nonestrogenic, nonsteroidal STS inhibitors among tricyclic compounds based around the coumarin core resulted in the discovery of Irosustat (667-coumate, STX64, BN83495) [77], which is the first-in-class irreversible time- and concentration-dependent STS inhibitor for the treatment of hormone-dependent BC in postmenopausal women that has been clinically evaluated in breast, endometrial, and prostate cancers [77] and there is potential for innovative dual-targeting approaches $[78,79]$, with an $\mathrm{IC}_{50}$ value of $8 \mathrm{nM}$ in placental microsomes. The inhibitor (2) does not possess any estrogenic activity in in vitro and in vivo assays [80].

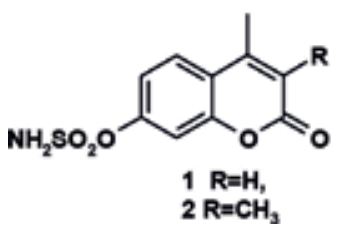

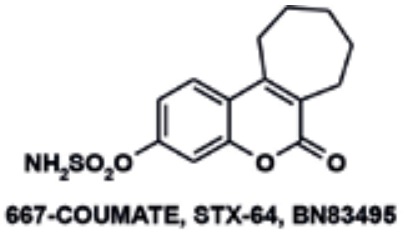

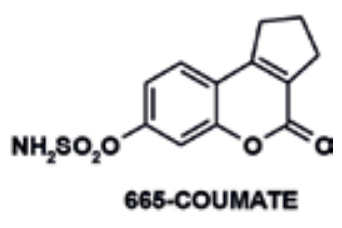

The optimum dose of $40 \mathrm{mg} /$ day was estimated in phase I/II trials [81].

Efficiency of Irosustat has also been demonstrated in a phase II study in (ER+) endometrial cancer in women with advanced or recurrent disease [82]. The high bioavailability of Irosustat is explained by the prevention of degradation by sequestration 
inside red blood cells where it, similarly to EMATE, binds to (and inhibits) carbonic anhydrase II $\left(\mathrm{IC}_{50}=22 \mathrm{nM}\right)$ [83]. The inactivation mechanism suggests that a sulfamate group is transferred to the gem-diol form of formylglycine 75 of steroid sulfatase due to a facile $\mathrm{E} 1 \mathrm{cB}$ elimination of sulfamate anion to give the corresponding coumarin, which has a long half-life in blood [84]. However, the further development of Irosustat in monotherapy was stopped in the phase I/II clinical studies, because Irosustat does not possess superior properties to the current standard of care megesterol acetate, and its relative bioavailability decreases with increasing dose. The study of its combination with other hormonal therapies (for example, with the aromatase inhibitor anastrozole) is underway [85]. Metabolism of Irosustat has been investigated [86]. Irosustat also inhibits skin and liver STS [86].

\subsubsection{Dual selective estrogen receptor modulators/STS inhibitors}

One of the first examples of the dual SERM/STS inhibitor was published by Duquesne University [87]. 4-Hydroxytamoxifen is a metabolite of main drug tamoxifen used as endocrine therapy in $(\mathrm{ER}+) \mathrm{BCs}$ [88]. This metabolite is a SERM and has antiestrogen effects in breast tissues, however, acts as an estrogen agonist in other tissues such as bone marrow. The sulfamate derivative 3 of 4-hydroxytamoxifen was shown to be an STS inhibitor with $\mathrm{Ki}=35.9 \mu \mathrm{M}$.

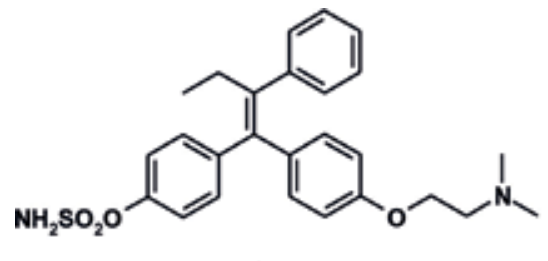

3

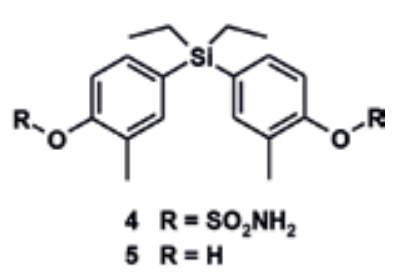

Surprisingly, among silicon-containing derivatives compound 4 exhibits strong STS-inhibitory activity $\left(\mathrm{IC}_{50}=0.17 \mu \mathrm{M}\right)$. Furthermore, its metabolite 5 possesses potent $\mathrm{ER} \alpha$-antagonistic activity $\left(\mathrm{IC}_{50}=29.7 \mathrm{nM}\right)$ [89].

Poirier with colleagues, among tetrahydroisoquinoline-N-substituted derivatives [90], found second-generation dual-action compounds that inhibit STS and act as a SERM. These compounds are devoid of estrogenic activity and toxicity. Their sulfamate derivatives possess high inhibitory activity toward STS $\left(\mathrm{IC}_{50}\right.$ of 3.9, 8.9, and $16.6 \mathrm{nM}$ ). Both phenolic and their sulfamate derivatives show no estrogenic activity and moderate antiestrogenic properties. All compounds significantly stimulate osteoblast-like Saos-2 cell proliferation, thus suggesting a SERM activity. The results of molecular docking experiments suggest that the most active compounds 6 and 7 bind in a competitive manner with E2 [91].

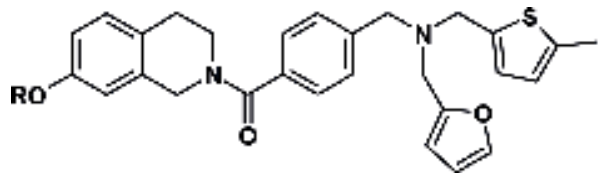

$6 \mathrm{R}=\mathrm{SO}_{2} \mathrm{NH}_{2}$

$7 \quad R=H$

\subsubsection{Dual aromatase/STS inhibitors}

Another approach for the treatment of hormone-dependent BC is the development of DASIs, which may have an additive or synergistic antitumor effect. The potential advantages of a single chemical agent with the ability to interact with 
multiple biological targets were highlighted previously [92]. In the case of DASIs, this goal is being pursued by the introduction of the critical sulfamate unit in structures with known aromatase-inhibiting properties [93, 94]. All DASIs are still in preclinical investigations [95].

One of the best dual inhibitors is compound 8 with nonestrogenic properties. 2',4'-Di-cyanobiphenyl-4-O-sulfamate (TZS8478) (9) also shows the best STS inhibition [96].

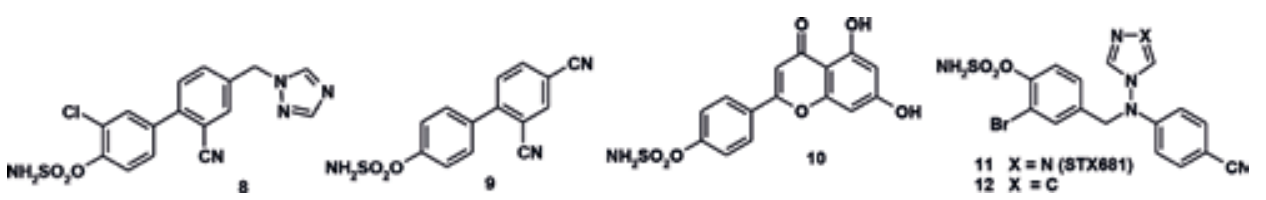

One of the most potent dual inhibitor is compound 10 with 98 and $85 \%$ inhibition of STS and aromatase, respectively, at $10 \mu \mathrm{M}$ [97]. A series of DASIs have been investigated $[98,99]$. Compound 11 (STX681, $\mathrm{IC}_{50}=0.82 \mathrm{nM}$ for aromatase and $\mathrm{IC}_{50}=39 \mathrm{nM}$ for STS) and similar analog 12 also exhibit an excellent profile against aromatase $\left(\mathrm{IC}_{50}=0.13 \mathrm{nM}\right)$ and STS $\left(\mathrm{IC}_{50}=3.5 \mathrm{nM}\right)$ and are not estrogenic [100]. Bissulfamate 13 at a single oral dose of $10 \mathrm{mg} / \mathrm{kg}$ inhibits aromatase and rat liver STS by 60 and $88 \%$, respectively. The anastrazole inspired compound 12 is also potent dual inhibitor in vivo $[101,102]$.

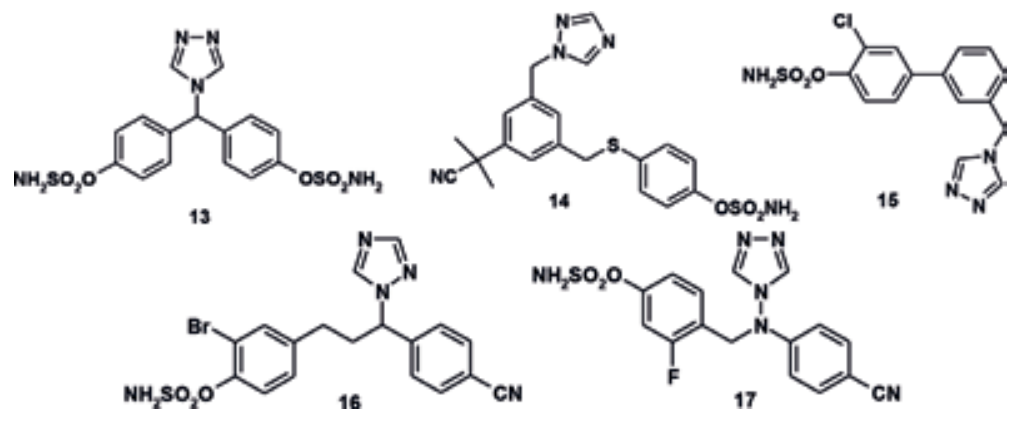

Among compounds on letrozole and vorozole templates, the most potent inhibitors were compounds 15 (aromatase IC IC $_{50}=0.5 \mathrm{nM}$ and STS IC I0 $_{50}=5.5 \mathrm{nM}$ ) and $16\left(\mathrm{IC}_{50}=0.0001 \mu \mathrm{M}\right)$ [103]. When orally dosed, compound 15 reduces plasma estradiol levels and inhibits liver STS activity [103].

Potter with coauthors published the successful realization of the strategy when the core components of the two leading DASIs resulted in the hybrid structures that exhibit a very high level of dual inhibition against aromatase and STS in vitro $\left(\mathrm{IC}_{50}=0.015-0.75 \mathrm{nM}\right)$. Most active compound is analog $17\left(\mathrm{IC}_{50}\right.$ for aromatase $=0.0002 \mu \mathrm{M}$, for STS $=0.0025 \mu \mathrm{M})[104]$.

The latest achievements in the field of nonsteroidal AIs are presented in recent reviews $[105,106]$.

\subsection{Steroidal STS inhibitors}

\subsubsection{Steroid-based STS inhibitors without sulfamate group}

Nonsulfamated STS inhibitors based on estrogens are weaker than EMATE. Most active STS inhibitors without sulfamate group with highest activity are represented by compounds 18, 19, and 20 ( $\mathrm{IC}_{50}=12,21$, and 9, respectively) [107-109]. 


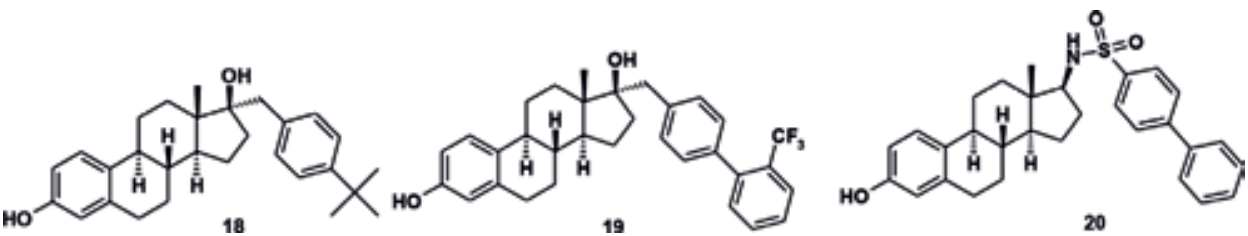

Estradiol dimer 21 also exhibits STS inhibitory activity in nanomolar range [110]. STS inhibitors are exemplified by tetrazole derivative 22 and boronic derivative 23 [111-113].
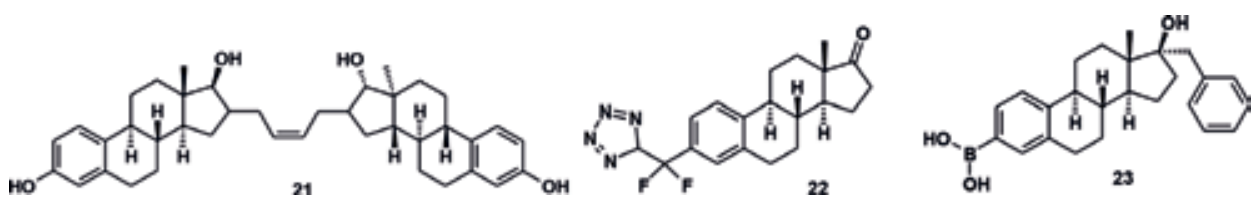

In the series of 4 -substituted $17 \beta$-arylsulfonamides of $17 \beta$-aminoestra-1,3,5(10)trien-3-ol, compounds $\mathbf{2 4}$ and 25 are tight-binding inhibitors with Ki app values of 1 and $2.5 \mathrm{nM}[114]$.

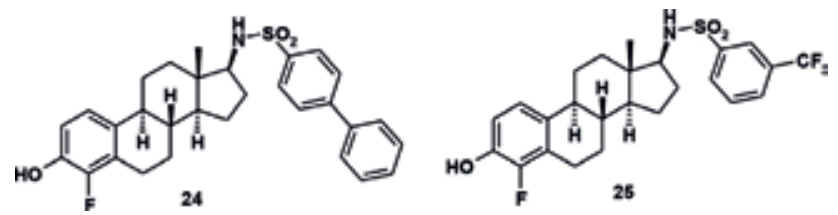

\subsubsection{Steroid-based STS inhibitors with sulfamate group}<smiles>CC12CC[C@H]3c4ccc(OS(N)(=O)=O)cc4CC[C@H]3[C@@H]1CC[C@@H]2O</smiles>

26 E2MATE, PGL2001, J995

The estrogenicity of EMATE and estradiol-3-O-sulfamate (26, E2MATE, PGL2001, J995) is the serious restriction for their development as anticancer agents. E2MATE effectively inhibits STS activity in endometrial tissue in vitro and in vivo (in doses 1.0 and $0.5 \mathrm{mg} / \mathrm{kg}$ ) without affecting systemic E2 levels [58, 59, 115, 116], and is introduced into Phase IIa of clinical trials [117]. E2MATE has been also clinically investigated as a pro-drug for hormone-replacement therapy and some limited clinical data are available. EMATE and E2MATE are bound to carbonic anhydrase (for EMATE $\mathrm{IC}_{50}=23 \mathrm{nM}$ ) within red blood cells, being dual inhibitors of carbonic anhydrases and STS [118].
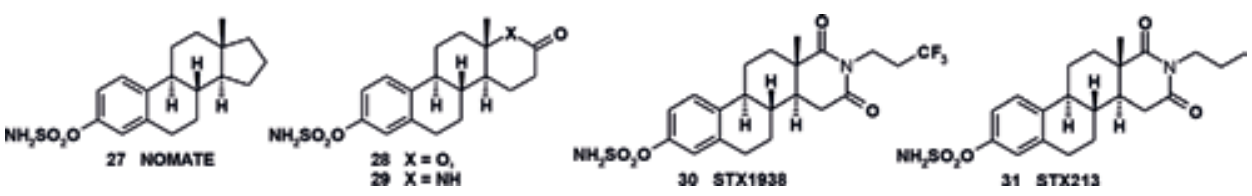

The sulfamate 27 (NOMATE) was evaluated as an STS inhibitor. This steroid without the 17-carbonyl group possesses ablated estrogenicity as well as reduced 
STS activity compared to EMATE. NOMATE was shown to exhibit antitumor activity against a range of tumor cell lines [119].

D-ring lactone $\mathbf{2 8}$ has been developed as an orally available STS inhibitor [114]. The latest together with related lactam 29 were independently developed by Imperial College and University of Bath [120]. These compounds are potent STS inhibitors (98 and 91\% inhibition of STS activity in MCF-7 cells at $0.1 \mu \mathrm{M}$, respectively; oral dose of $2 \mathrm{mg} / \mathrm{kg} /$ day) without estrogenic effects.

Simple modifications of the D-ring have led to dramatic variations in estrogenicity. Thus, the conversion of EMATE to the oxime results in a super-estrogen. From the other hand, D-ring heterocyclic derivatives exhibit reduced estrogenicity [121, 122].

The replacement of ring D with $\mathrm{N}$-substituted piperidinedione moiety results in the loss of estrogenic properties and greater STS inhibitory activity in vivo compared to STX64, as it was shown by the compounds STX213 (31) [123] and STX1938 (30) [124]. The STX1938 (30) and STX213 (31) inhibit STS with IC 50 of $1 \mathrm{nM}$ and $35 \mathrm{pM}$ correspondingly (90- and 18-fold more potent than EMATE, respectively) [125]. STX213 and STX1938 possess superior properties in comparison with STX64 in vivo models with once weekly oral dose $1 \mathrm{mg} / \mathrm{kg}[125,126]$. The docking studies explained the greater potency of STX1938 in comparison with STX213 by the increased lipophility of $\mathrm{CF}_{3}$ group and the ability of the fluorine atoms to participate in C-F---H-O and C-F --- H-N interactions in the STS binding site. STX213 (31) demonstrates a greater effect on tumor growth than Irosustat (oral dose $10 \mathrm{mg} /$ $\mathrm{kg}$ /day) [21]. Most active among 17-modified EMATE derivatives as STS inhibitors was steroid $32\left(\mathrm{IC}_{50}=11 \mathrm{pM}\right)$ [126]. The saturated analog 33 possesses similar potency $\left(\mathrm{IC}_{50}=34 \mathrm{pM}\right)$, and is not estrogenic [126].

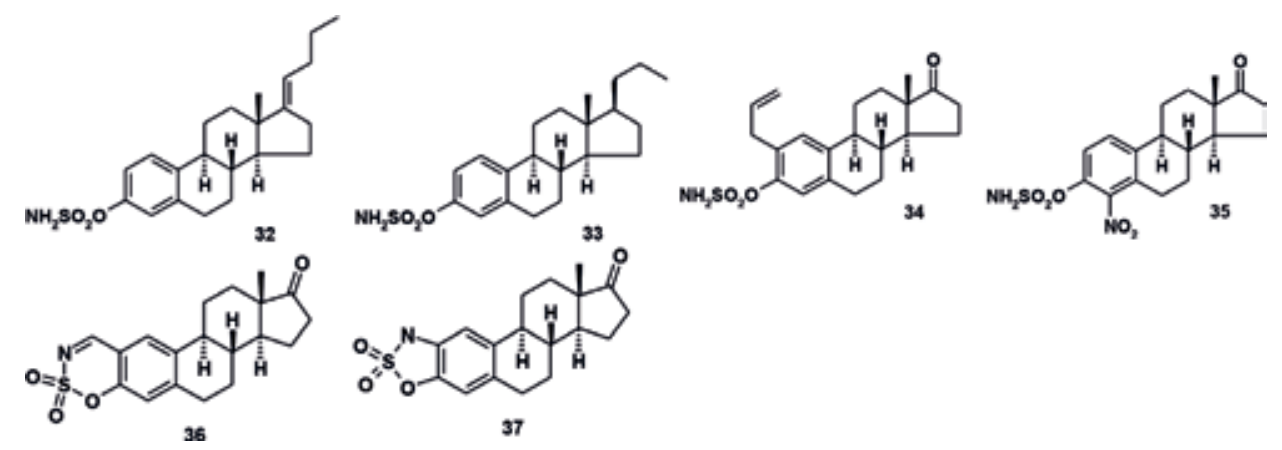

Among various 2- and 4-substituted and 2,4-disubstituted EMATE derivatives, most active compounds are 2-(2-prop-2-enyl)-EMATE (34, $\mathrm{IC}_{50}=37 \mathrm{nM}$ in MCF-7 cells) [126]; and 4-nitro-EMATE (35, $\mathrm{IC}_{50}=0.01 \mathrm{nM}$ in MCF-7 cells) (EMATE; $\mathrm{IC}_{50}=0.83 \mathrm{nM}$ in MCF-7 cells), and steroid 34 is nonestrogenic [127].

Cyclic sulfamate 36 is an effective STS inhibitor $\left(\mathrm{IC}_{50}=9.3 \mathrm{nM}\right)$ in vivo with dose regime $1 \mathrm{mg} / \mathrm{mouse} /$ day for 5 weeks [128]. The derivatives of oxathiazine 36 are claimed as estrogen-ablative agents; however, no data on their activity have been published [129]. Cyclic sulfamates with six-membered ring are time-dependent inactivators [130]. Acyclic mono-alkylated sulfamates are not time-dependent inactivators of sulfatases. Probably, imino compound 36 hydrolyzes to the orthoformyl sulfamate in situ [53]. The five-membered ring compounds such as 37 are not time-dependent inactivators of STS [131].

\subsubsection{Dual 17 $\beta$-HSD1/STS inhibitors}

$17 \beta$ HSD converts E1 to E2 and DHEA to androstanediol [132]. Several inhibitors based on steroidal skeleton have been successfully developed [133, 134]. Few dual 
inhibitors of $17 \beta$-HSD and STS for the treatment of steroid hormone-dependent diseases are patented [135]. The example of such inhibitors is represented by the compound 38 .

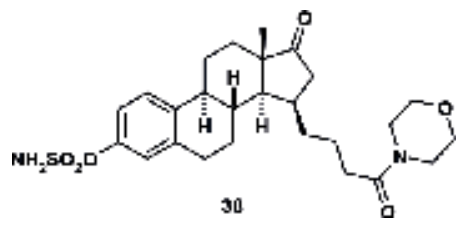

A-ring-modified steroidal sulfamates, for example, series of 2-OMe-estradiol sulfamates and analogs have been investigated as nonestrogenic STS inhibitors $[136,137]$. 2-MeO-EMATE 39 demonstrates the excellent inhibitory properties in the relation to STS in vitro $\left(\mathrm{IC}_{50}=30 \mathrm{nM}\right)$ and in vivo and is not estrogenic [138]. It strongly shows the antiproliferative effects toward BC cells by inducing apoptosis and cell cycle arresting in the G2/M phase [139].

2-Ethyl-EMATE $\mathbf{4 0}$ was identified as a promising multitargeted anticancer agent with strong ability to arrest the cell cycle, inhibit angiogenesis, as well as inhibit tumor growth in a xenograft model [140]. It was found that 2-ethylestrone (desulfamoylated compound 40) belongs to series of potent superoxide dismutase inhibitors [141].

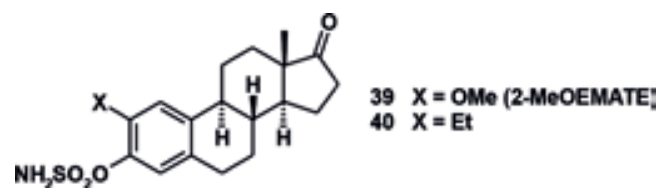

It is known that 2-methoxyestradiol, a metabolite of E2, possesses antiangiogenic properties and prevents tumor growth through disrupting tubulin polymerization by binding at the colchicine-binding site [142, 143]. 2-Methoxyestradiol is considered as the perspective compound for the treatment of endometriosis [144].

The anticancer effects of the 2-substituted sulfamate estrogen derivatives arise from disruption of tubulin polymerization, and the compounds also binding at the colchicine site [145]. 3,17 $\beta$-Bissulfamates of estrogens are other representatives of multitargeted antitumor agents, acting as STS inhibitors with antiproliferative activity $\left(\mathrm{IC}_{50}=18-250 \mathrm{nM}\right)$ [146]. Such bissulfamates compete with colchicine for tubulin binding and disrupt microtubules resulting into cell cycle arrest just by apoptosis in vitro and in vivo $[147,148]$ and inhibit angiogenesis in vitro and in vivo [149]. The STS inhibitory activity of bissulfamate $\mathbf{4 1}$ is comparable to EMATE activity [150]. Bissulfamoylated derivatives with 2-MeO (42, STX140) and 2-Et (44, STX243) substituents in steroidal skeleton exhibit high STS inhibitory activity $\left(\mathrm{IC}_{50}=39\right.$ and $1000 \mathrm{nM}$, respectively) [151].

STX140 (42) and STX243 (44) possess in vivo activity also against the MDA-MB-435 cell line (at $20 \mathrm{mg} / \mathrm{kg}$ oral) [152]. STX140 in vivo inhibits MDA-MB-231 breast tumors [152-154].

Coordination of the 17-sulfamate residue to the zinc in active site of the complex of STX140 with human carbonic anhydrase II is revealed [155].
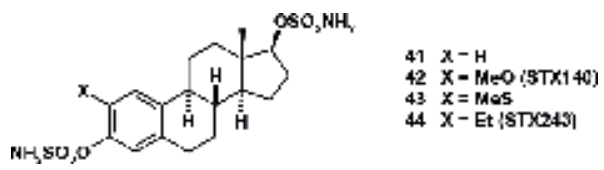

STX140 depolarizes mitochondrial bioenergetics, activates caspase 3/7 causing apoptosis through the intrinsic mitochondrial pathway, and downregulates 
the expression of caspase inhibitors [156]. The activity of such compounds is also explained by their ability to disrupt the tubulin-microtubule equilibrium in cells as being central to their antitumor activity. STX140 and STX243 bind with the colchicines binding site of tubulin. $2-\left({ }^{11} \mathrm{C}\right)$ Methoxy-3,17 $\beta$-OO-bis(sulfamoyl) estradiol has been proposed as a new potential PET agent for imaging of steroid sulfatase in cancers [157].

One more example of 2-MeO-derivatives as effective STS inhibitors is illustrated by compound 45 containing cyano group at position C-17 [158].

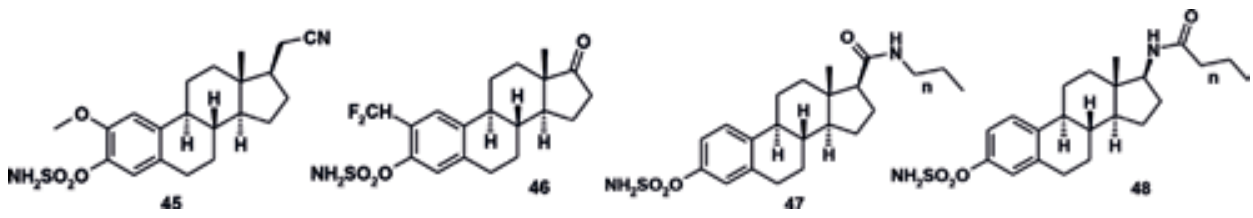

2-Difluoromethyl-E1-3-O-sulfamate (46) is 91-fold more potent inhibitor compared to EMATE ( $\mathrm{IC}_{50}=0.1$ and $9.1 \mathrm{nM}$, respectively) [159].

The level of STS inhibition for 17 $\beta$-(N-alkylcarbamoyl)-estra-1,3,5(10)-trien3-O-sulfamates (47) and $17 \beta$-(N-alkanoyl)-estra-1,3,5(10)-trien-3-O-sulfamates (48) is similar to or exceeded that of EMATE. Some of these compounds are nonestrogenic. 17-(N-alkylcarbamoyl)-estra-1,3,5(10)-triene-3-O-sulfamates and the inverse amides have been patented as good STS inhibitors [129].

Among a series of C17-ketone and amide-modified estrone-derived sulfamates, compound KW-2581 (49, 17-diisopropylcarbamoyl-1,3,5(10),16-estratetraen-3-ylsulfamate) is the most promising, not estrogenic, orally active anticancer agent for the treatment of hormone-dependent BC and endometrial cancer [160]. KW-2581 as STS inhibitor is five times more potent compared to STX-64 $\left(\mathrm{IC}_{50}=4 \mathrm{nM}\right)$ [161]. It was also demonstrated that the compound inhibits the ability of androstanediol-S to stimulate the in vivo growth of MCF-7 cells from BC overexpressing STS. However, $\mathrm{KW}-2581$ is practically insoluble in water (approx. $0.1 \mathrm{ng} / \mathrm{mL}$ ). The attempts to increase its oral bioavailability showed that the milled powder exhibited poorer properties than the intact sample, including a lower level of crystallinity, higher water content, and increased decomposition rate [162].
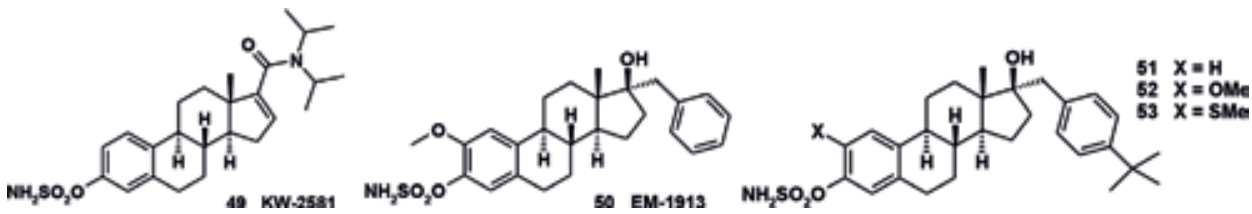

Diverse $17 \alpha$-alkylated estradiol sulfamates as STS inhibitors have been patented [163] and 17 $\alpha$-benzyl-derivatives have been investigated [164].

Compound EM-1913 (50) is nonestrogenic steroidal STS inhibitor with $\mathrm{IC}_{50}=0.05 \mathrm{nM}$ [165], which also inhibits dehydroepiandosterone sulfate action in androgen-sensitive tissues, being therefore considered as a potential drug for the treatment of prostate cancer [166].

$17 \alpha$-Benzyl substituent yields reversible STS inhibitors in the absence of a sulfamate group, and incorporation of an aryl sulfamate onto the A-ring results in a potent time-dependent irreversible inhibitor. $\mathrm{The}^{\mathrm{IC}_{50}}$ of the tert-butylbenzyl derivative $\mathbf{5 1}$ is low $(8.3 \mathrm{nM})$; however, steroid $\mathbf{5 1}$ is estrogenic. A-ring substitution leads to the reduced estrogenicity. 2-Methoxyderivative 52 has an $\mathrm{IC}_{50}=0.04 \mathrm{nM}$. The compound without the tert-butyl group is nonestrogenic and effective STS inhibitor in vivo [167]. 
In the series of A-ring thioether-modified sulfamates, the steroid 53 is 50 -fold more potent inhibitor of STS than steroid 52; however, it possesses weak inhibitory activity against MCF-7 cells proliferation $\left(\mathrm{IC}_{50}=10 \mu \mathrm{M}\right)$ [168].

\subsubsection{Dual STS/SERM inhibitors}

Maximum estrogen blockade in the treatment of (ER+) BC may be achieved using dual ER $\alpha$ antagonists and STS inhibitors, which might cause osteoporosis as a side effect [169]. In this case, the compound possessing SERM properties is needed.

Thus, a novel orally available irreversible dual STS/SERM inhibitor SR16157 (NSC 732011) $(60)\left(\mathrm{IC}_{50}=0.1 \mu \mathrm{M}\right)$ has been developed as a very promising inhibitor with excellent pharmacokinetics and acceptable toxicological profile [170].

Desulfamoylation of SR16157 (54) results in SR16137 (55), which is a tissueselective antiestrogen with beneficial effects on bone and cardiovascular system [171]. SR16157 is 10 times more potent as a growth inhibitor of MCF-7 cells than either the antiestrogens tamoxifen or SR1613. Additionally, SR16137 has a 10-fold higher affinity for ER $\alpha$ as compared to tamoxifen. SR16157 was shown to possess minimal genotoxic activity [172]. SR16157 has been recommended in initial phase I of clinical trials with the starting dose of $1.3 \mathrm{mg} / \mathrm{kg} / \mathrm{day}$ administered as a single dose in humans.

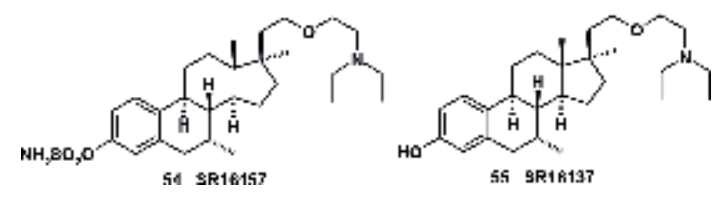

We demonstrated that 8-alpha-analogs of steroid estrogens effectively inhibit the growth of BC cells, including triple negative BC $[173,174]$.

\section{Conclusions}

Manipulation of hormone biosynthesis in tumors by enzymes inhibitors is a very attractive approach for the treatment of hormone-dependent tumors such as breast, prostate cancer, and endometriosis.

The importance of STS in human body has been underlined by many investigations. Thus, STS-catalyzed hydrolysis of pregnolone-3-sulfate and dehydroepiandro-sterone-3-sulfate in the brain regulates neurosteroid synthesis and influences memory. STS inhibition for the potentiation of memory in sufferers of neurological diseases such as Alzheimer's disease and dementia has been postulated [175]. The role of STS inhibitors as agents to reveal beneficial endogenous glucocorticoid effects was also claimed. The use of STS inhibitors in combination with the immunosuppressive ascomycin for the treatment of acne, seborrhoea, androgenetic alopecia, and hirsutism is patented. The administration of an estrogen (including norgestimate and norelgestromin), in combination with a progestogen in hormonereplacement therapy act by inhibiting STS, thus reduce estrogen production and protect the endometrium and breast from hormone-dependent cancers [176]. STS inhibitors prevent ovarian cycle disturbance, prolonged unopposed secretion of estrogens, and ovarian follicular cyst formation in premenopausal women, as well as prevent premature uterine contractions, particularly for preterm labor [177].

The importance of STS inhibition in endometriosis, prostate cancer, as well as latest discussions about mechanism of inhibition is well considered in the review of Prof. Potter [178]. The significance of steroid sulfatase and sulfotransferases in gynecological diseases are summarized in the review [57]. 
As far as estrogenic compounds may stimulate tumor cells growth, the main requirement for STS inhibitors and their metabolites is the absence of estrogenicity. Among nonsteroidal STS inhibitors only one nonestrogenic compound-Irosustate was evaluated in clinical trials with excellent properties, however its further development was stopped. Currently, the action of Irosustate in the combination with AIs is investigated.

The discovery of dual (multitargeted) inhibitors is the most promising nowadays. For example, several DASIs based on anastrazole, letrozole, and vorozole templates inhibit both STS and aromatase in nanomolar concentrations, being nonestrogenic; and have a chance to be introduced in clinical trials.

Among STS inhibitors based on steroid skeleton $17 \alpha$-benzyl-derivatives, $17 \beta$-arylsulfonamides, and 17-diisopro-pylcarbomoyl-3-O-sulfamates exhibit the best properties, especially as multitargeted (dual) anticancer potential drugs. The same modifications result in the increased activity against STS in the case of 2-OMe-3-O-sulfamates as well as 2-OMe-3,17 $\beta$-bissulfamates. The latter also possess activity against most aggressive form-triple negative $\mathrm{BC}$.

Additionally, $8 \alpha$-steroid estrogen analogs without estrogenic properties possess high STS activity and block BC cells growth with the activity comparable to standard of care for BC treatment tamoxifen.

\section{Acknowledgements}

The authors greatly appreciate Dr. Anna S. Chentsova for careful reading of the manuscript and her valuable comments. The reported study was funded by RFBR according to the Research Project No. 16-54-76024.

\section{Conflict of interest}

The authors confirm that this article content has no conflicts of interest.

\section{Abbreviations}

$\begin{array}{ll}\text { AIs } & \text { aromatase inhibitors } \\ \text { BC } & \text { breast cancer } \\ \text { COMT } & \text { catechol-O-methyltransferase } \\ \text { Coumate } & \text { 4-methylcoumarin-7-O-sulfamate } \\ \text { DASI } & \text { dual aromatase-sulfatase inhibitor } \\ \text { DHEAS } & \text { dehydroepiandrosterone sulfate } \\ \text { FGly } & \text { for-mylglycine } \\ \text { GPER, GPR30 } & \text { G-protein-coupled estrogen receptor } \\ \text { HDBC } & \text { hormone-dependent breast cancer } \\ \text { 17ßHSD } & \text { 17ß-hydroxysteroid dehydrogenase } \\ \text { E1 } & \text { estrone } \\ \text { E2 } & \text { estradiol } \\ \text { E2MATE } & \text { estradiol-3-O-sulfamate } \\ \text { EMATE } & \text { estrone-3-O-sulfamate } \\ \text { ER } & \text { estrogen receptor } \\ \text { LH-RH } & \text { luteinizing hormone-releasing hormone } \\ \text { 2-OHE1 } & \text { 2-hydroxyestrone } \\ \text { 4-OHE1 } & \text { 4-hydroxyestrone }\end{array}$




$\begin{array}{ll}\text { 2-OHE2 } & \text { 2-hydroxyestradiol } \\ \text { 4-OHE2 } & \text { 4-hydroxyestradiol } \\ \text { STS } & \text { steroid sulfatase } \\ \text { SERD } & \text { selective estrogen receptor down-regulators } \\ \text { SERM } & \text { selective estrogen receptors modulator } \\ \text { UGT } & \text { UDP-glucuronosyltransferase }\end{array}$

\section{Author details}

Svetlana N. Morozkina ${ }^{1,2 *}$ and Alexander G. Shavva ${ }^{1,2}$

1 Laboratory of Medicinal Chemistry, School of Biomedicine, Far Eastern Federal University, Vladivostok, Russia

2 ITMO University, Russia

*Address all correspondence to: morozkina.svetlana@gmail.com

\section{IntechOpen}

(C) 2019 The Author(s). Licensee IntechOpen. This chapter is distributed under the terms of the Creative Commons Attribution License (http://creativecommons.org/licenses/ by/3.0), which permits unrestricted use, distribution, and reproduction in any medium, provided the original work is properly cited. (cc) BY 


\section{References}

[1] Bray F, Ferlay J, Soerjomataram I, Siegel RL, Torre LA, Jemal A. Global cancer statistics 2018: GLOBOCAN estimates of incidence and mortality worldwide for 36 cancers in 185 countries. CA: A Cancer Journal for Clinicians. 2018;68(6):394-428

[2] Henderson BE, Ross R, Bernstein L. Estrogens as a cause of a human cancer: The Richard and Hinda Rosenthal Foundation award lecture. Cancer Research. 1988;48(2):246-253

[3] Lippman ME, Dickson RB, Bates S, Knabbe C, Huff K, Swain S, et al. Autocrine and paracrine growth regulation of human breast cancer. Breast Cancer Research and Treatment. 1986;7:59-70

[4] Fillmore CM, Gupta PB, Rudnick JA, Caballero S, Keller PJ, Lander ES, et al. Estrogen expands breast cancer stem-like cells through paracrine FGF/Tbx3. Proceedings of the National Academy of Sciences of the United States of America. 2010;107(50):21737-21742

[5] Purohit A, Reed MJ. Regulation of estrogen synthesis in postmenopausal women. Steroids. 2002;67(12):979-983

[6] Epstein FH. Estrogens and the risk of breast cancer. The New England Journal of Medicine. 2001;344(4):276-285

[7] Liehr JG. Is estradiol a genotoxic mutagenic carcinogen? Endocrine Reviews. 2000;21(1):40-54

[8] Nishimura R, Anan K, Yamamoto Y, Higaki K, Tanaka M, Shibuta K, et al. Efficacy of goserelin plus anastrozole in premenopausal women with advanced or recurrent breast cancer refractory to an LH-RH analogue with tamoxifen: Results of the JMTO BC0801 phase II trial. Oncology Reports. 2013;29(5):1707-1713
[9] Ghayee HK, Auchus RJ. Basic concepts and recent developments in human steroid hormone biosynthesis. Reviews in Endocrine \& Metabolic Disorders. 2007;8(4):289-300

[10] Lin SX, Chen J, Mazumdar M, Poirier D, Wang C, Azzi A, et al. Molecular therapy of breast cancer: Progress and future directions. Nature Reviews. Endocrinology. 2010;6(9):485-493

[11] Labrie F. All sex steroids are made intracellularly in peripheral tissues by the mechanisms of intracrinology after menopause. The Journal of Steroid Biochemistry and Molecular Biology. 2015;145:133-138

[12] Lepine J, Audet-Walsh E, Gregoire J, Têtu B, Plante M, Ménard V, et al. Circulating estrogens in endometrial cancer cases and their relationship with tissular expression of key estrogen biosynthesis and metabolic pathways. The Journal of Clinical Endocrinology and Metabolism. 2010;95(6):2689-2698

[13] Chetrite GS, Cortes-Prieto J, Philippe JC, Wright F, Pasqualini JR. Comparison of estrogen concentrations, estrone sulfatase and aromatase activities in normal, and in cancerous, human breast tissues. The Journal of Steroid Biochemistry and Molecular Biology. 2000;72(1-2):23-27

[14] Sasano H, Miki Y, Nagasaki S, Suzuki T. In situ estrogen production and its regulation in human breast carcinoma: From endocrinology to intracrinology. Pathology International. 2009;59(11):777-789

[15] Brueggemeier RW, Richards JA, Joomprabutra S, Bhat AS, Whetstone JL. Molecular pharmacology of aromatase and its regulation by endogenous and exogenous agents. The Journal of 
Steroid Biochemistry and Molecular Biology. 2001;79(1-5):75-84

[16] Poirier D. Recent patents on new steroid agents targeting the steroidogenesis for endocrine cancer treatments. Recent Patents on Endocrine, Metabolic \& Immune Drug Discovery. 2015;9(1):15-23

[17] Altundag K, Ibrahim NK.

Aromatase inhibitors in breast cancer: An overview. The Oncologist. 2006;11(6):553-562

[18] Thomas MP, Potter BVL. The structure biology of estrogen metabolites. The Journal of Steroid Biochemistry and Molecular Biology. 2013;137:27-49

[19] Shah R, Singh J, Singh D, Jaggi AS, Singh N. Sulfatase inhibitors for recidivist breast cancer treatment: $\mathrm{A}$ chemical review. European Journal of Medicinal Chemistry. 2016;114:170-190

[20] Miller WL, Auchus RJ. The molecular biology, biochemistry, and physiology of human steroidogenesis and its disorders. Endocrine Reviews. 2011;32(1):81-151

[21] Thomas MP, Potter BVL. Estrogen O-sulfamates and their analogues: Clinical steroid sulfatase inhibitors with broad potential. The Journal of Steroid Biochemistry and Molecular Biology. 2015;153:160-169

[22] Avendano C, Menendez JC. Chapter 3: Anticancer drugs that modulate hormone action. Medicinal Chemistry of Anticancer Drugs. 2nd ed. Elsevier Science; 2015. pp. 82-129

[23] Piccinato CA, Neme RM, Torres N, Sanches LR, Derogis PBMC,

Brudniewski HF, et al. Effects of steroid hormone on estrogen sulfotransferase and on steroid sulfatase expression in endometriosis tissue and stromal cells. The Journal of Steroid Biochemistry and Molecular Biology. 2016;158:117-126
[24] Rizner TL. Estrogen biosynthesis, phase I and phase II metabolism, and action in endometrial cancer. Molecular and Cellular Endocrinology. 2013;381(1-2):124-139

[25] Auchus RJ. Chapter 8: Human steroid biosynthesis. In: Knobil and Neill's Physiology of Reproduction. 4th ed. Academic Press; 2015. pp. 295-312

[26] Strauss JF III. Yen \& Jaffe's

Reproductive Endocrinology Physiology, Pathophysiology, and Clinical Management. 6th ed. Elsevier; 2009. p. 892

[27] Geyer J, Bakhaus K, Bernhardt R, Blaschka C, Dezhkam Y, Fietz D, et al. The role of sulfated steroid hormones in reproductive processes. The Journal of Steroid Biochemistry and Molecular Biology. 2017;172:207-221

[28] Hong Y, Chen S. Aromatase, estrone sulfatase, and $17 \beta-H S D$ :

Structure-function studies and inhibitor development. Molecular and Cellular Endocrinology. 2011;340(2):120-126

[29] Kulendran M, Salhab M, Mokbel K. Oestrogen-synthesising enzymes and breast cancer. Anticancer Research. 2009;9(4):1095-1109

[30] Giton F, de la Taille A, Allory Y, Galons H, Vacherot F, Soyeux P, et al. Estrone sulfate (E1S), a prognosis marker for tumor aggressiveness in prostate cancer. The Journal of Steroid Biochemistry and Molecular Biology. 2008;109(1-2):158-167

[31] International Breast Cancer Study Group. Toremifene and tamoxifen are equally effective for early-stage breast cancer: First results of International Breast Cancer Study Group Trials 12-93 and 14-93. Annals of Oncology. 2004;15(12):1749-1759

[32] Gennari L, Merlotti D, Paola VD, Nuti R. Raloxifene in breast cancer 
prevention. Expert Opinion on Drug Safety. 2008;7(3):259-270

[33] Wardell SE, Nelson ER, Chao CA, McDonnell DP. Bazedoxifene exhibits antiestrogenic activity in animal models of tamoxifen-resistant breast cancer: Implications for treatment of advanced disease. Clinical Cancer Research. 2013;19(9):2420-2431

[34] LaCroix AZ, Powles T, Osborne CK, Wolter K, Thompson JR, Thompson $\mathrm{DD}$, et al. Breast cancer incidence in the randomized PEARL trial of lasofoxifene in postmenopausal osteoporotic women. Journal of the National Cancer Institute. 2010;102(22):1706-1715

[35] Croxtall JD, McKeage K.

Fulvestrant. Drugs. 2011;71(3):363-380

[36] McDonnell DP, Wardell SE. The molecular mechanisms underlying the pharmacological actions of ER modulators: Implications for new drug discovery in breast cancer. Current Opinion in Pharmacology. 2010;10:620-628

[37] Barrios C, Forbes JF, Jonat W, Conte P, Gradishar W, Buzdar A, et al. The sequential use of endocrine treatment for advanced breast cancer: Where are we? Annals of Oncology. 2012;23(6):1378-1386

[38] Duggan C, Marriott K, Edwards R, Cuzick J. Inherited and acquired risk factors for venous thromboembolic disease among women taking tamoxifen to prevent breast cancer. Journal of Clinical Oncology. 2003;21(19):3588-3593

[39] Obiorah I, Jordan VC. Progress in endocrine approaches to the treatment and prevention of breast cancer. Maturitas. 2011;70(4):315-321

[40] Rajapaksa G, Thomas C, Gustafsson J-A. Estrogen signaling and unfolded protein response in breast cancer. The
Journal of Steroid Biochemistry and Molecular Biology. 2016;163:45-50

[41] Woo LWL. Enzyme inhibitors examples for the treatment of breast cancer. In: Smith HJ, Simons C, editors. Enzymes and Their Inhibition: Drug Development. Boca Raton: CRC Press LLC; 2005. pp. 221-241

[42] Johnson SRD, Martin L-A, Alex L, Heada J, Dowsett M. Clinical strategies for rational combinations of aromatase inhibitors with novel therapies for breast cancer. The Journal of Steroid Biochemistry and Molecular Biology. 2007;106(1-5):180-186

[43] Hong Y, Cho M, Yuan Y-C, Chen S. Molecular basis for the interaction of four different classes of substrates and inhibitors with human aromatase. Biochemical Pharmacology. 2008;75(5):1161-1169

[44] Dent SF, Gaspo R, Kissner M, Pritchard KI. Aromatase inhibitor therapy: Toxicities and management strategies in the treatment of postmenopausal women with hormonesensitive early breast cancer. Breast Cancer Research and Treatment. 2011;126(2):295-310

[45] Higuchi T, Endo M, Hanamura T, Gohno T, Niwa T, Yamaguchi Y, et al. Contribution of estrone sulfate to cell proliferation in aromatase inhibitor (AI)-resistant, hormone receptorpositive breast cancer. PLoS One. 2016;11(5):e0155844

[46] Janicke F. Are all aromatase inhibitors the same? A review of the current evidence. Breast. 2004;13(1):S10-S18

[47] Coombes RC, Hall E, Gibson LJ, Paridaens R, Jassem J, Delozier T, et al. A randomized trial of exemestane after two to three years of tamoxifen therapy in postmenopausal women with primary breast cancer. New England Journal of Medicine. 2004;350(11):1081-1092 
[48] Hanamura T, Niwa T, Gohno T, Kurosumi M, Takei H, Yamaguchi Y, et al. Possible role of the aromataseindependent steroid metabolism pathways in hormone responsive primary breast cancers. Breast Cancer Research and Treatment. 2014;143(1):69-80

[49] Haynes BP, Straume AH, Geisler J, A'Hern R, Helle H, Smith IE, et al. Intratumoral estrogen disposition in breast cancer. Clinical Cancer Research. 2010;16(6):1790-1801

[50] McNamara KM, Sasano H. The intracrinology of breast cancer. The Journal of Steroid Biochemistry and Molecular Biology. 2015;145C:172-178

[51] Stanway SJ, Delavault P, Purohit A, Woo LW, Thirieau C, Potter BVL, et al. Steroid sulfatase: A new target for the endocrine therapy of breast cancer. The Oncologist. 2007;12:370-374

[52] Chanplakhorn N, Chanplakhorn P, Suzuki T, Ono K, Chan MSM, Miki Y, et al. Increased estrogen sulfatase (STS) and $17 \beta$-hydroxysteroid dehydrogenase type 1(17b-HSD1) following neoadjuvant aromatase inhibitor therapy in breast cancer patients. Breast Cancer Research and Treatment. 2010;120(3):639-648

[53] Woo LWL, Purohit A, Potter BVL. Development of steroid sulfatase inhibitors. Molecular and Cellular Endocrinology. 2011;340(2):175-185

[54] Reed MJ, Purohit A, Woo LWL, Newman SP, Potter BVL. Steroid sulfatase: Molecular biology, regulation, and inhibition. Endocrine Reviews. 2005;26(2):171-202

[55] Poulin R, Labrie F. Stimulation of cell proliferation and estrogenic response by adrenal C19-delta 5-steroids in the ZR-75-1 human breast cancer cell line. Cancer Research. 1986;46(10):4933-4937
[56] Lasley BL, Chen J, Stanczyk FZ, El Khodary SR, Gee NA, Crawford S, et al. Androstenediol complements estrogenic bioactivity during the menopausal transition. Menopause. 2012;19(6):650-657

[57] Rižner TL. The important roles of steroid sulfatase and sulfotransferases in gynecological diseases. Frontiers in Pharmacology. 2016;7(30):1-16

[58] Elger W, Laehteenmaeki P, Lehtinen $M$, Reddersen $G$, Zimmermann $H$, Oettel M, Schwarz S. Use of biogenic estrogen sulfamates for hormone replacement therapy. PCT Int. Appl. WO0006175; 2000

[59] Potter BVL, Reed MJ, Lebrond B, Leese MP. 17-Aryl linker derivatised estrogen 3-sulfamates as inhibitors of steroid sulfatase. U.S. Pat. Appl. US7067503; 2006

[60] Pautier P, Vergote I, Joly F, Melichar B, Kutarska E, Hall G, et al. A phase 2, randomized, open-label study of Irosustat versus megestrol acetate in advanced endometrial cancer. International Journal of Gynecological Cancer. 2017;27(2):258-266

[61] Secky L, Svoboda M, Klameth L, Bajna E, Hamilton G, Zeillinger R, et al. The sulfatase pathway for estrogen formation: Targets for the treatment and diagnosis of hormone-associated tumors. Journal of Drug Delivery. 2013;957605:1-13

[62] Pasqualini JR, Chetrite GS. Recent insight on the control of enzymes involved in estrogen formation and transformation in human breast cancer. The Journal of Steroid Biochemistry and Molecular Biology. 2005;93(2-5):221-236

[63] Suzuki T, Nakata T, Miki Y, Kaneko C, Moriya T, Ishida T, et al. Estrogen sulfotransferase and steroid sulfatase in human breast carcinoma. Cancer Research. 2003;63(11):2762-2770 
[64] Geisler J, Sasano H, Chen S, Purohit A. Steroid sulfatase inhibitors: Promising new tools for breast cancer therapy? The Journal of Steroid Biochemistry and Molecular Biology. 2011;125(1-2):39-45

[65] Maltais R, Poirier D. Steroid sulfatase inhibitors: A review covering the promising 2000-2010 decade. Steroids. 2011;76(10-11):929-948

[66] Ghosh D. Human sulfatases: A structural perspective to catalysis. Cellular and Molecular Life Sciences. 2007;64(15):2013-2022

[67] Elger W, Barth A, Hedden A, Reddersen G, Ritter P, Schneider $\mathrm{PB}$, et al. Estrogen sulfamates: A new approach to oral estrogen therapy. Reproduction, Fertility, and Development. 2001;13(4):297-305

[68] Hidalgo Aragones MI, Purohit A, Parish D, Sahm UG, Pouton CW, Potter BVL, et al. Pharmacokinetics of oestrone-3-O-sulphamate. The Journal of Steroid Biochemistry and Molecular Biology. 1996;58(5-6):611-617

[69] Woo LWL, Leblond B, Purohit A, Potter BVL. Synthesis and evaluation of analogues of estrone-3-O-sulfamate as potent sulfatase inhibitors. Bioorganic \& Medicinal Chemistry. 2012;20(8):2506-2519

[70] Spillane WJ, Malaubier J-B. Mechanism of the hydrolysis of the sulfamate EMATE_An irreversible steroid sulfatase inhibitor. Tetrahedron Letters. 2010;51(15):2059-2062

[71] Mostafa YA, Taylor SD. Steroid derivatives as inhibitors of steroid sulfatase. The Journal of Steroid Biochemistry and Molecular Biology. 2013;137:183-198

[72] Williams SJ. Sulfatase inhibitors: A patent review. Expert Opinion on Therapeutic Patents. 2013;23(1):79-98
[73] Williams SJ, Denehy E, Krenske EH. Experimental and theoretical insights into the mechanisms of sulfate and sulfamate ester hydrolysis and the end products of type I sulfatase inactivation by aryl sulfamates. The Journal of Organic Chemistry. 2014;79(5):1995-2005

[74] Foster PA, Reed MJ, Purohit A. Recent developments of steroid sulfatase inhibitors as anti-cancer agents. Anti-Cancer Agents in Medicinal Chemistry. 2008;8(7):732-738

[75] Day JM, Purohit A, Tutill HJ, Foster PA, Woo LW, Potter BVL, et al. The development of steroid sulfatase inhibitors for hormone-dependent cancer therapy. Annals of the New York Academy of Sciences. 2009;1155:80-87

[76] Woo LWL, Fischer DS, Sharland CM, Trusselle M, Foster PA, Chander SK, et al. Anticancer steroid sulfatase inhibitors: Synthesis of a potent fluorinated second-generation agent, in vitro and in vivo activities, molecular modeling, and protein crystallography. Molecular Cancer Therapeutics. 2008;7(8):2435-2444

[77] Denmeade S, George D, Liu G, Peraire C, Geniaux A, Baton F, et al. A phase vertical bar pharmacodynamic dose escalation study of steroid sulphatase inhibitor Irosustat in patients with prostate cancer. European Journal of Cancer. 2011;47(Suppl. 1):S499

[78] Stanway SJ, Purohit A, Woo LWL, Sufi S, Vigushin D, Ward R, et al. Phase I study of STX 64 (667 Coumate) in breast cancer patients: The first study of a steroid sulfatase inhibitor. Clinical Cancer Research. 2006;12(5):1585-1592

[79] Lund MJ, Butler EN, Hair BY, Ward KC, Andrews JH, Oprea-Ilies $\mathrm{G}$, et al. Age/race differences in HER2 testing and in incidence rates for breast cancer triple subtypes: A populationbased study and first report. Cancer. 2010;116(11):2549-2559 
[80] Coombes R, Schmid P, Isambert N, Soulie P, Cardoso F, Besse-Hammer T, et al. Phase I dose escalation study of steroid sulfatase inhibitor BN83495/

STX64 in postmenopausal women with ER positive breast cancer. Cancer Research. 2009;69(24 Suppl):4097-4097

[81] Coombes RC, Cardoso F, Isambert N, Lesimple T, Soulié P, Peraire C, et al. A phase I dose escalation study to determine the optimal biological dose of irosustat, an oral sulfatase inhibitor, in postmenopausal women with estrogen receptor-positive breast cancer. Breast Cancer Research and Treatment. 2013;140(1):73-82

[82] Pautier P, Lobbedez FJ, Melichar B, Kutarska E, Hall G, Reed N. A phase II multicenter randomized open-label study of oral sulfatase (sulfatase) inhibitor Irosustat (BN83495) versus megestrol acetate (MA) in women with advanced/recurrent endometrial cancer (EC). Annals of Oncology. 2012;23(Suppl. 9):329

[83] Lloyd MD, Thiyagarajan N, Ho YT, Woo LWL, Sutcliffe OB, Purohit A, et al. First crystal structures of human carbonic anhydrase II in complex with dual aromatase-steroid sulfatase inhibitors. Biochemistry. 2005;44(18):6858-6866

[84] Woo LWL, Ganeshapillai D, Thomas MP, Sutcliffe OB, Malini B, Mahon MF, et al. Structure-activity relationship for the first-in-class clinical sulfatase inhibitor Irosustat (STX64, BN83495). ChemMedChem. 2011;6:2019-2034

[85] Palmieri C, Stein RC, Liu X, Hudson E, Nicholas H, Sasano H, et al. IRIS study: A phase II study of the steroid sulfatase inhibitor Irosustat when added to an aromatase inhibitor in ER-positive breast cancer patients. Breast Cancer Research and Treatment. 2017;165(2):343-353
[86] Parra-Guillen ZP, Cendros Carreras JP, Peraire C, Obach R, Prunynosa J, Chetaille E, et al. Population pharmacokinetic modelling of Irosustat in postmenopausal women with oestrogen-receptor positive breast cancer incorporating nonlinear red blood cell uptake. Pharmaceutical Research. 2015;32(4):1493-1504

[87] Li P-K, Selcer KW. Compounds for the treatment of estrogen-dependent illnesses and methods for making and using the same. U.S. Pat. Appl. US6288107; 2001

[88] Komm BS, Mirkin S. An overview of current and emerging SERMs. The Journal of Steroid Biochemistry and Molecular Biology. 2014;143:207-222

[89] Kajita D, Nakamura M, Matsumoto Y, Makishima M, Hashimoto Y. Design and synthesis of silicon-containing steroid sulfatase inhibitors possessing pro-estrogen antagonistic character. Bioorganic \& Medicinal Chemistry. 2014;22(7):2244-2252

[90] Ouellet C, Ouellet E, Poirier D. In vitro evaluation of a tetrahydroisoquinoline derivative as a steroid sulfatase inhibitor and a selective estrogen receptor modulator. Investigational New Drugs. 2014;33(1):95-103

[91] Ouellet C, Maltais R, Ouellet E, Barbeau X, Lagüe P, Poirier D. Discovery of a sulfamate-based steroid sulfatase inhibitor with intrinsic selective estrogen receptor modulator properties. European Journal of Medicinal Chemistry. 2016;119:169-182

[92] Zimmermann GR, Lehar J, Keith CT. Multi-target therapeutics: When the whole is greater than the sum of the parts. Drug Discovery Today. 2007;12(1/2):34-42

[93] Purohit A, Foster PA. Steroid sulfatase inhibitors for estrogen- and 
androgen-dependent cancers. The Journal of Endocrinology. 2012;212(2):99-110

[94] Woo LWL, Jackson T, Purohit A, Reed MJ, Potter BVL, Reed G. Compound. U.S. Pat. Appl. US20100173963; 2010

[95] Ahmad I, Shagufta. Recent developments in steroidal and nonsteroidal aromatase inhibitors for the chemoprevention of estrogendependent breast cancer. European Journal of Medicinal Chemistry. 2015;102:375-386

[96] Saito T, Kinoshita S, Fujii T, Bandoh K, Fuse S, Yamauchi Y, et al. Development of novel steroid sulfatase inhibitors: II. TZS- 8478 potently inhibits the growth of breast tumors in postmenopausal breast cancer model rats. The Journal of Steroid Biochemistry and Molecular Biology. 2004;88(2):167-173

[97] Reed MJ, Potter BVL. Compounds that inhibit oestrone sulphatase and/or aromatase and methods for making and using. U.S. Pat. Appl. US6506792; 2003

[98] Potter BVL, Reed MJ, Woo LWL, Purohit A, Burbert Ch, Wood PM, Sutcliffe OB. Sulfamic acid ester compounds useful in the inhibition of steroid sulphatase activity and aromatase activity. U.S. Pat. Appl. US20070213383; 2007

[99] Bubert C, Woo LWL, Sutcliffe OB, Mahon MF, Chander SK, Purohit A, et al. Synthesis of aromatase inhibitors and dual aromatase steroid sulfatase inhibitors by linking an arylsulfamate motif to 4-(4H-1,2,4-triazol-4-ylamino) benzonitrile: SAR, crystal structures, in vitro and in vivo activities.

ChemMedChem. 2008;3(11):1708-1730

[100] Lafay J, Rondot B, Bonnet P, Clerc Th, Shields J, Duc I, Duranti E, Puccio F, Blot Ch, Maillos Ph.
1-N-phenyl-amino-1h-imidazole derivatives and pharmaceutical compositions containing them. U.S. Pat. Appl. US20070112009; 2007

[101] Wood PM, Woo LWL, Labrosse JR, Trusselle MN, Abbate S, Longhi G, et al. Chiral aromatase and dual aromatasesteroid sulfatase inhibitors from the letrozole template: Synthesis, absolute configuration, and in vitro activity. Journal of Medicinal Chemistry. 2008;51(14):4226-4238

[102] Lawrence LVL, Jackson T, Bubert Ch, Purohit A, Reed MJ, Potter BVL. Phenyl-sulfamates as aromatase inhibitors. PCT Int. Appl. WO2005118560; 2005

[103] Wood PM, Woo LWL, Thomas MP, Mahon MF, Purohit A, Potter BVL. Aromatase and dual aromatasesteroid sulfatase inhibitors from the letrozole and vorozole templates. ChemMedChem. 2011;6(8):1423-1438

[104] Woo LW, Bubert C, Purohit A, Potter BVL. Hybrid dual aromatasesteroid sulfatase inhibitors with exquisite picomolar inhibitory activity. ACS Medicinal Chemistry Letters. 2011;2(3):243-247

[105] Gobbi S, Rampa A, Belluti F, Bisi A. Nonsteroidal aromatase inhibitors for the treatment of breast cancer: An update. Anti-Cancer Agents in Medicinal Chemistry. 2014;14(1):54-65

[106] Kumler I, Knoop AS, Jessing CAR, Ejlertsen B, Nielsen DL. Review of hormone-based treatments in postmenopausal patients with advanced breast cancer focusing on aromatase inhibitors and fulvestrant. ESMO Open. 2016;1:e000062

[107] Maltais R, Fournier D, Poirier D. Quantitative structure-activity relationship (QSAR) study with a series of $17 \alpha$-derivatives of estradiol: Model for the development of 
reversible steroid sulfatase inhibitors. QSAR and Combinatorial Science. 2009;28(11-12):1284-1299

[108] Phan C-M, Liu Y, Kim B-M, Mostafa Y, Taylor SD. Inhibition of steroid sulfatase with 4-substituted estrone and estradiol derivatives. Bioorganic \& Medicinal Chemistry. 2011;19(20):5999-6005

[109] Mostafa YA, Taylor SD. $17 \beta$-Arylsulfonamides of 17 $\beta$-aminoestra-1,3,5(10)-trien-3-ol as highly potent inhibitors of steroid sulfatase. Bioorganic \& Medicinal Chemistry. 2012;20(4):1535-1544

[110] Fournier D, Poirier D. Estradiol dimers as a new class of steroid sulfatase reversible inhibitors. Bioorganic \& Medicinal Chemistry Letters. 2009;19(3):693-696

[111] Lapierre J, Ahmed V, Chen M-J, Ispahany M, Guillemette JG, Taylor SD. The difluoromethylene group as a replacement for the labile oxygen in steroid sulfates: A new approach to steroid sulfatase inhibitors. Bioorganic \& Medicinal Chemistry Letters. 2004;14(1):151-155

[112] Ahmed V, Liu Y, Silvestro C, Taylor SD. Boronic acids as inhibitors of steroid sulfatase. Bioorganic \& Medicinal Chemistry. 2006;14(24):8564-8573

[113] Ahmed V, Liu Y, Taylor SD. Multiple pathways for the irreversible inhibition of steroid sulfatase with quinone methide-generating suicide inhibitors. Chembiochem: A European Journal of Chemical Biology. 2009;10(9):1457-1461

[114] Mostafa YA, Kralt B, Rao PPN, Taylor SD. A-ring substituted $17 \beta$-arylsulfonamides of $17 \beta$-aminoestra-1,3,5(10)-trien3-ol as highly potent reversible inhibitors of steroid sulfatase. Bioorganic \& Medicinal Chemistry. 2015;23(17):5681-5692
[115] Loumaye E, Gotteland J-P.

Treatment of oestrogen dependent conditions in pre-menopausal women. PCT Int. Appl. WO2009037539; 2009

[116] Pohl O, Bestel E, Gotteland J-P. Synergistic effects of E2MATE and norethindrone acetate on sulfatase inhibition: A randomized phase I proofof-principle clinical study in women of reproductive age. Reproductive Sciences. 2014;21(10):1256-1265

[117] https://clinicaltrials.gov/ct2/show/ NCT01631981

[118] Abbate F, Winum J-Y, Potter BVL, Casini A, Montero J-L, Scozzafava A, et al. Carbonic anhydrase inhibitors:

$\mathrm{X}$-ray crystallographic structure of the adduct of human isozyme II with EMATE, a dual inhibitor of carbonic anhydrases and steroid sulfatase. Bioorganic \& Medicinal Chemistry Letters. 2004;14(1):231-234

[119] Hillisch A, Peters O, Gege Ch, Regenhardt W, Kosemund D, Siemeister G, et al. 2-Substituted estra1,3,5(10)-triene-3-yl sulfamate with an anti-tumour action. U.S. Pat. Appl. US20090221841; 2009

[120] Reed MJ, Potter BVL. Steroid-3O-sulphamate derivatives as inhibitors of oestrone sulphatase. PCT Int. Appl. WO9927935; 1999

[121] Potter BVL, Reed MJ. Use of compound in the manufacture of a pharmaceutical for in-hibiting steroid sulphatase and steroid dehydrogenase activity. WO0232409; 2002

[122] Potter BVL, Reed MJ, Woo LWL, Purohit A, Foster P. Steroidal compounds as steroid sulphatase inhibitors. U.S. Pat. Appl. US20090182000; 2009

[123] Fischer DS, Woo LWL, Mahon MF, Purohit A, Reed MJ, Potter BV. D-ring modified estrone derivatives as novel 
potent inhibitors of steroid sulfatase. Bioorganic \& Medicinal Chemistry. 2003;11(8):1685-1700

[124] Foster PA, Newman SP, Chander SK, Stengel C, Jhalli R, Woo LWL, et al. In vivo efficacy of STX213, a secondgeneration steroid sulfatase inhibitor, for hormone-dependent breast cancer therapy. Clinical Cancer Research. 2006;12(18):5543-5549

[125] Foster P, Chander S, Parsons M, Newman S, Woo L, Potter B. Efficacy of three potent steroid sulfatase inhibitors: Preclinical investigations for their use in the treatment of hormone-dependent breast cancer. Breast Cancer Research and Treatment. 2008;111(1):129-138

[126] Numazawa M, Tominaga T, Watari Y, Tada Y. Inhibition of estrone sulfatase by aromatase inhibitorbased estrogen 3-sulfamates. Steroids. 2006;71(5):371-379

[127] Tanabe M, Peters RH, Chao W-R, Shigeno K. Estrone sulfamate inhibitors of estrone sulfatase, and associated pharmaceutical compositions and methods of use. US6046186; 2000

[128] Tanabe M, Peters RH, Chao W-R, Shigeno K. Steroid inhibitors of estrone sulfatase and associated pharmaceutical compositions and methods of use. US5861388; 1999

[129] Li P-K, Murakata C, Akinaga Sh. Steroid sulfatase inhibitors and methods for making and using the same. U.S. Pat. Appl. US6376687; 2002

[130] Hanson SR, Whalen LJ, Wong C-H. Synthesis and evaluation of general mechanism-based inhibitors of sulfatases based on (difluoro) methyl phenyl sulfate and cyclic phenyl sulfamate motifs. Bioorganic \& Medicinal Chemistry. 2006;14(24):8386-8395

[131] Peters RH, Chao WR, Sato B, Shigeno K, Zaveri NT, Tanabe M.
Steroidal oxathiazine inhibitors of estrone sulfatase. Steroids. 2003;68(1):97-110

[132] Purohit A, Tutill HJ, Day JM, Chander SK, Lawrence HR, Allan GM, et al. The regulation and inhibition of $17 \beta$-hydroxysteroid dehydrogenase in breast cancer. Molecular and Cellular Biology. 2006;248(1-2):199-203

[133] Laplante Y, Cadot C, Fournier M-A, Poirier D. Estradiol and estrone C-16 derivatives as inhibitors of type 17 $\beta$-hydroxysteroid dehydrogenase: blocking of ER+ breast cancer cell proliferation induced by estrone. Bioorganic \& Medicinal Chemistry. 2008;16(7):1849-1860

[134] He W, Gauri M, Li T, Wang R, Lin S-X. Current knowledge of the multifunctional $17 \beta$-hydroxysteroid dehydrogenase type 1 (HSD17B1). Gene. 2016;588(1):54-61

[135] Messinger J, Thole H-H, Husen B, Weske M, Koskimies P, Pirkkala L. 17SS-HSD1 and STS inhibitors. U.S. Pat. Appl. US20110021480; 2011

[136] Leese MP, Hejaz HAM, Mahon MF, Simone P, Newman SP, Purohit A, et al. A-ring-substituted estrogen-3O-sulfamates: Potent multitargeted anticancer agents. Journal of Medicinal Chemistry. 2005;48(16):5243-5256

[137] Reed EJ, Woo LWL, Robinson JJ, Leblond B, Leese MP, Purohit A, et al. 2-Difluoromethyloestrone 3-O-sulphamate, a highly potent steroid sulphatase inhibitor. Biochemical and Biophysical Research Communications. 2004;317(1):169-175

[138] Reed MJ, Potter BVL. Compound. U.S. Pat. Appl. US20040127473; 2004

[139] Purohit A, Hejaz HAM, Walden L, MacCarthy-Morrogh L, Packham G, Potter BVL, et al. The effect of 2-methoxyoestrone-3-O-sulphamate 
on the growth of breast cancer cells and induced mammary tumours. International Journal of Cancer. 2000;85(4):584-589

[140] Leese M, Purohit A, Reed M, Jourdan F, Potter BVL, Bubert Ch. Compound. U.S. Pat. Appl. US20070225256; 2007

[141] Potter BVL, Reed MJ, Packham GK, Leese MP. Thioether sulphamate steroids as steroid inhibitors and anti-cancer compounds. U.S. Pat. Appl. US20040009959; 2004

[142] Dahut WL, Lakhani NJ, Gulley JL, Arlen PM, Kohn EC, Kotz H, et al. Phase I clinical trial of oral 2-methoxyestradiol, an antiangiogenic and apoptotic agent, in patients with solid tumors. Cancer Biology \& Therapy. 2006;5:22-27

[143] Kumar BS, Raghuvanshi DS, Hasanain M, Alam S, Sarkar J, Mitra K, et al. Recent advances in chemistry and pharmacology of 2-methoxyestradiol: An anticancer investigational drug. Steroids. 2016;110:9-34

[144] Machado-Linde F, Pelegrin P, Sanchez-Ferrer ML, Leon J, Cascales P, Parrilla JJ. 2-Methoxyestradiol in the pathophysiology of endometriosis: Focus on angiogenesis and therapeutic potential. Reproductive Sciences. 2012;19(10):1018-1029

[145] Jourdan F, Leese MP, Dohle W, Hamel E, Fernandis E, Newman SP, et al. Synthesis, antitubulin, and antiproliferative SAR of analogues of 2-methoxyestradiol-3,17-O,Obis-sulfamate. Journal of Medicinal Chemistry. 2010;53(7):2942-2951

[146] Potter BVL, Reed MJ, Woo LWL, Hejaz H, Leblond B, Leese MP. Oestrogen-17-sulphamates as inhibitors of steroid sulphatase. U.S. Pat. Appl. US8030296; 2011
[147] Raobaikady B, Reed MJ, Leese MP, Potter BVL, Purohit A. Inhibition of MDA-MB-231 cell cycle progression and cell proliferation by C-2-substituted oestradiol mono- and bis-3-Osulphamates. International Journal of Cancer. 2005;117(1):150-159

[148] Foster PA, Ho YT, Newman SP, Kasprzyk PG, Leese MP, Potter BVL, et al. 2-MeOE2bisMATE and 2-EtE2bisMATE induce cell cycle arrest and apoptosis in breast cancer xenografts as shown by a novel ex vivo technique. Breast Cancer Research and Treatment. 2008;111(2):251-260

[149] Ireson CR, Chander SK, Purohit A, Perera S, Newman SP, Parish D, et al. Pharmacokinetics and efficacy of 2-methoxyoestradiol and 2-methoxyoestradiol-bis-sulphamate in vivo in rodents. British Journal of Cancer. 2004;90(4):932-937

[150] Leese MP, Leblond B, Smith A, Newman SP, Di Fiore A, De Simone G, et al. 2-substituted estradiol bissulfamates, multitargeted antitumor agents: Synthesis, in vitro SAR, protein crystallography, and in vivo activity. Journal of Medicinal Chemistry. 2006;49(26):7683-7696

[151] Peyrat J-F, Brion J-D, Alami M. Synthetic 2-methoxyestradiol derivatives: Structure-activity relationships. Current Medicinal Chemistry. 2012;19(24):4142-4156

[152] Newman SP, Foster PA, Stengel C, Day JM, Ho YT, Judde JG, et al. STX140 is efficacious in vitro and in vivo in taxane-resistant breast carcinoma cells. Clinical Cancer Research. 2008;14(2):597-606

[153] Tagg SLC, Foster PA, Leese MP, Potter BVL, Reed MJ, Purohit A, et al. 2-Methoxyoestradiol-3,17-O, O-bis-sulphamate and 2-deoxy-Dglucose in combination: A potential treatment for breast and prostate 
cancer. British Journal of Cancer. 2008;99(11):1842-1848

[154] Meyer-Losic F, Newman SP, Day JM, Reed MJ, Kasprzyk PG, Purohit A, et al. STX140, but not paclitaxel, inhibits mammary tumor initiation and progression in C3(1)/SV40 T/tantigen transgenic mice. PLoS One. 2013;8(12):e80305

[155] Lloyd MD, Pederick RL, Natesh R, Woo LWL, Purohit A, Reed MJ, et al. Crystal structure of human carbonic anhydrase II at $1.95 \AA$ resolution in complex with 667-coumate, a novel anti-cancer agent. The Biochemical Journal. 2005;385:715-720

[156] Foster PA, Ho YT, Newman SP, Leese MP, Potter BVL, Reed MJ, et al. STX140 and STX641 cause apoptosis via the intrinsic mitochondrial pathway and down-regulate survivin and XIAP expression in ovarian and prostate cancer cells. Anticancer Research. 2009;29(10):3751-3757

[157] Wang M, Xu K, Gao M, Miller KD, Sledge GW, Zheng QH. Synthesis of 2-(11C)methoxy-3,17 $\beta-O, O-$ bis(sulfamoyl) estradiol as a new potential PET agent for imaging of steroid sulfatase (STS) in cancers. Steroids. 2012;77(8-9):864-870

[158] Jourdan F, Leese MP, Dohle W, Ferrandis E, Newman SP, Chander S, et al. Structure-activity relationships of C-17-substituted estratriene-3$\mathrm{O}$-sulfamates as anticancer agents. Journal of Medicinal Chemistry. 2011;54(13):4863-4879

[159] Reed JE, Woo LWL, Robinson JJ, Leblond B, Leese MP, Purohit A, et al. 2-Difluoromethyloestrone 3-O-sulfamate, a highly potent steroid sulphatase inhibitor. Biochemical and Biophysical Research Communications. 2004;317(1):196-275

[160] Ishida H, Nakata T, Suzuki M, Shiotsu Y, Tanaka H, Sato N, et al. A novel steroidal selective steroid sulfatase inhibitor KW-2581 inhibits sulfatedestrogen dependent growth of breast cancer cells in vitro and in animal models. Breast Cancer Research and Treatment. 2007;106(2):215-227

[161] Ishida H, Sato N, Hosogi J, Tanaka H, Kuwabara T. Inactivation of recombinant human steroid sulfatase by KW-2581. The Journal of Steroid Biochemistry and Molecular Biology. 2008;108(1-2):17-22

[162] Aoki M, Nishimura $\mathrm{H}$, Mimura A, Kita S, Yasuzawa T, Terada K. Identification of the degradation products of the steroid. Sulfatase inhibitor KW-2581 in jet mill-micronized powder. Journal of Pharmaceutical Sciences. 2013;102(6):1760-1772

[163] Jinbo Y, Inoue Y. Novel estradiol derivatives. PCT Int. Appl. WO2000053620; 2000

[164] Ciobanu LC, Martel C, Labrie F, Poirier D. Inhibition of estrone sulfateinduced uterine growth by potent nonestrogenic steroidal inhibitors of steroid sulfatase. Cancer Research. 2003;63(19):6442-6446

[165] Poirier D, Roy J, Maltais R, Ayan D. A potent inhibitor of steroid sulfatase (EM-1913) blocks tumor growth in nude mice (MCF-7 xenograft). Current Enzyme Inhibition. 2015;11(1):65-73

[166] Roy J, Lefebvre J, Maltais R, Poirier D. Inhibition of dehydroepiandrosterone sulfate action in androgen-sensitive tissues by EM-1913, an inhibitor of steroid sulfatase. Molecular and Cellular Endocrinology. 2013;376(1-2):148-155

[167] Potter BVL, Reed MJ. 17-Alkyllinker derivatized estrogen 3-sulphamates as inhibitors of steroid sulphatase. PCT Int. Appl. WO0216393; 2002 
[168] Leese MP, Leblond B, Newman SP, Purohit A, Reed MJ, Potter BVL. Anticancer activities of novel D-ring modified 2-substituted estrogen-3O-sulfamates. The Journal of Steroid Biochemistry and Molecular Biology. 2005;94(1-3):239-251

[169] Imai Y, Nakamura T, Matsumoto T, Takaoka K, Kato S. Molecular mechanisms underlying the effects of sex steroids on bone and mineral metabolism. Journal of Bone and Mineral Metabolism. 2009;27(2):127-130

[170] Rausch L, Green C, Steinmetz K, Le Valley S, Catz P, Zaveri N, et al. Preclinical pharmacokinetic, toxicological and biomarker evaluation of SR16157, a novel dual-acting steroid sulfatase inhibitor and selective estrogen receptor modulator. Cancer Chemotherapy and Pharmacology. 2011;67(6):1341-1352

[171] Rasmussen LM, Zaveri NT, Stenvang J, Peters RH, Lykkesfeldt AE. A novel dual-target steroid sulfatase inhibitor and antiestrogen: SR 16157, a promising agent for the therapy of breast cancer. Breast Cancer Research and Treatment. 2007;106(1 Suppl):191-203

[172] Doppalapudi RS, Riccio ES, Rausch LL, Shinon JA, Lee RS, Mortelmans KE, et al. Evaluation of chemopreventive agents for genotoxic activity. Mutation Research. 2007;629(2):148-160

[173] Pison U, Shavva AG, Morozkina SN. Preparation of 6-oxa-8-alphasteroid estrogen analogues-A new group of unnatural estrogens and their use in medicine. JP Pat. Appl. JP2011503020; 2011

[174] Morozkina SN, Drozdov AS, Kovalev RA, Filatov MV, Shavva AG. Racemic 2,17 $\beta$-disulfamoyloxy-3methoxy- $8 \alpha$-estra-1,3,5(10)-triene as inhibitor of tumor cell proliferation of MCF-7. RU Pat. Appl. RU2562242; 2015
[175] Reddy DS. Neurosteroids:

Endogenous role in the human brain and therapeutic potentials. Progress in Brain Research. 2010;186:113-137

[176] Meingassner JG. Combination of a steroid sulfatase inhibitor and ascomycin. PCT Pat. Appl. WO2006097293; 2006

[177] Loumaye E, Cayron-Elizondo V, Gotteland J-P. Use of steroid sulfatase inhibitors for the treatment of preterm labor. PCT Pat. Appl. WO2010013187; 2010

[178] Potter BVL. Steroid sulphatase inhibition via aryl sulphamates: Clinical progress, mechanism and future prospects. Journal of Molecular Endocrinology. 2018;61:T233-T252 


\title{
Control of Liver Gene Expression by Sex Steroids and Growth Hormone Interplay
}

\author{
Leandro Fernández-Pérez, Mercedes de Mirecki-Garrido, \\ Carlota Recio and Borja Guerra
}

\begin{abstract}
Sex steroids have important physiological actions, which are not limited to reproductive organs, in both females and males. They exert important physiological roles, including the regulation of somatotropic-liver axis, intermediate metabolism, or gender dimorphism. This is in part because the liver is a sex steroid-responsive organ where sex steroid- and growth hormone (GH)-dependent signaling pathways connect to regulate complex gene expression networks. Sex steroids can impact liver gene expression by a direct, through hepatic estrogen receptor (ER) $\alpha$ and androgen receptor (AR), or indirect mechanisms, by modulation of pituitary GH secretion and/or interaction with the GHR-STAT5b signaling pathway. Therefore, deficiency of sex steroid- and $\mathrm{GH}$-dependent signaling pathways might cause a dramatic impact on mammalian liver physiology. In this chapter, we will focus our attention on main concepts and paradigms involved in the role and interplay between sex steroid- and GH-dependent signaling to regulate gene expression networks in the mammalian liver. A better understanding of how sex steroids and interactions with GH-STAT5b signaling pathway influence physiological and pathological states in the liver will contribute to improve clinical management of patients with disorders in body growth, development, and metabolism.
\end{abstract}

Keywords: estrogens, androgens, GH, liver, gene expression

\section{Introduction}

The liver is as sex steroid-responsive organ [1-13]. The natural estrogen, $17 \beta$-estradiol (E2), and androgens, testosterone (T)/dihydrotestosterone (DHT) have physiological actions, which are not limited to reproductive organs, in both females and males. The nonreproductive actions of sex steroids have relevance in liver physiopathology [1-7, 14-18]. The effects of E2 and T/DHT on liver gene expression can be direct, through their hepatic receptors, or indirect, by modulating growth hormone (GH) actions centrally $[1,2]$, regulating pituitary GH secretion, and, peripherally $[5,7,19,20]$, by modulating growth hormone receptor (GHR)-dependent signaling which can be exemplified by (1) E2 modulating GH actions in the liver through induction of suppressor of cytokine signaling (SOCS) 2 which in turn negatively regulates GHR signal transducer and activator of transcription (STAT) 5b signaling pathway and (2) the positive interplay between T/DHT and GH to enhance somatic growth and liver composition in men. Accordingly, deficiency of E2-ER $\alpha[4,18,19,21,22]$, 
androgen/AR [6, 7, 21-25] or GH-GHR [26-32] signaling pathways in adults causes a similar metabolic-like syndrome (i.e., fatty liver, adiposity, insulin resistance), a phenotype that might be ameliorated by E2/T or GH replacement. Therefore, the interplay between sex steroids and GH is clinically relevant because of its importance in the regulation of endocrine, metabolic, and gender-differentiated actions on the mammalian liver [33]. A better understanding of this complex sex steroid-GH interplay in physiological and pathological states will contribute to prevent health damage and improve clinical management of patients with growth, developmental, and metabolic disorders. In this review, we will summarize the role of sex steroid- and $\mathrm{GH}$-dependent signaling pathways on liver gene expression.

\section{The liver is as sex steroid-responsive organ}

Sex steroids can regulate liver gene transcription through direct and indirect mechanisms.

\subsection{Direct regulation of liver gene expression by sex steroids}

The liver is a direct target of sex steroids through several receptors and tissuespecific mechanisms [34-36]. The direct interaction between E2 and the transcription factors $E R \alpha$ and $E R \beta$ mediates the classical estrogen signaling, which is responsible for most estrogenic effects [35]. ER dimers directly bind DNA, specifically to estrogenresponsive elements located in the ER target gene-regulatory regions, followed by transcription activation. Furthermore, E2 can regulate the expression of its target genes by the interaction between ERs and other transcription factors, such as STAT5. Non-genomic mechanisms, via membrane ERs that activate downstream kinase pathways, have also been described to trigger E2-dependent effects. For instance, the orphan membrane $G$ protein-coupled receptor (GPR)-30 was shown to mediate a rapid estrogen signaling, although conflicting results on this receptor have been reported [37]. Lastly, estrogenic effects are closely related to ER tissue expression. ER $\alpha$ expression has been reported in the bone, reproductive tissues, white adipose tissue, liver, and kidney, whereas the ovary, gastrointestinal tract, lung, bladder, prostate, hematopoietic tissue, and central nervous system are the main ER $\beta$-expressing tissues. This indicates that selective ER $\alpha$ agonists might be used for treating ER $\alpha$-related liver diseases [38]. Similarly to classical E2 signaling, most of the known androgenic effects are mediated via direct interaction of T/DHT with the DNA-binding transcription factor AR which plays an important role in regulating androgen-dependent gene expression $[34,36]$. AR regulates the transcription of a variety of target genes through the interaction with different positive regulators (co-regulators) that provide tissue specificity of androgen actions. In addition, androgen/AR can signal by non-genomic mechanisms. Palmitoylation of AR determines its localization to the membrane, where it can be found in lipid raft membrane $[39,40]$. Interestingly, membrane-localized AR can modulate both rapid androgen-mediated G-protein signaling and rapid EGF receptor activation followed by Akt and MAPK signaling pathways and subsequent nuclear AR-mediated effects. T conversion into E2 by aromatase may also play a relevant role to regulate the effects of androgens on body growth and composition.

\subsection{Indirect regulation of liver gene expression by sex steroids}

Indirect mechanisms, related to the influence of sex steroids on pituitary GH secretory pattern $[1,2]$ and/or interaction with the GHR-STAT5b signaling pathway in target tissues $[5,7,19,20]$, play a relevant role to regulate the effects of sex steroids on the liver. 


\subsubsection{Sex steroids regulate the pattern of pituitary GH secretion}

Regulation of pituitary GH release depends of two hypothalamic peptides: a positive regulator, GHRH, and the inhibitory hormone somatostatin (SS) [41, 42]. The balance of these peptides is in turn, indirectly, affected by many physiological inhibitors (i.e., GH, IGF-1, glucocorticoids) and stimulators (i.e., sleep, nutrients, exercise, thyroid hormones, sex hormones) of pituitary GH secretion. The final integration of these signals occurs in the hypothalamus. Not only hypothalamic and endocrine factors but also other peripheral elements, mostly metabolic, affect pituitary GH production. These include glucose, fatty acids, amino acids, insulin, leptin, neuropeptide $\mathrm{Y}$, and ghrelin, among others, and are dependent on the metabolic condition of the organism. This is consistent with the GH role in the regulation of somatic growth and composition. A good example to explain the close relationship between GH and the metabolic status is the feedback loop among pituitary and adipose tissues. Adiposity is a powerful negative regulator of pituitary GH secretion. In contrast, GH induces fatty acid mobilization from adipose tissue to reduce adiposity, and circulating fatty acids inhibit pituitary GH secretion. On the contrary, other metabolites such as leptin (also produced in the adipose tissue) [43] and ghrelin (from the stomach) [44] stimulate pituitary GH secretion. Furthermore, sex steroids can also regulate pituitary GH secretion. It has been described that neonatal and postpubertal sex steroids regulate the hypothalamus on its generation of the gender dimorphism of the pituitary GH secretion seen in adulthood. This could explain the gender dimorphism seen in liver physiology $[1,13]$. In rodents, gender dimorphism is thought to be controlled by E2 secretion in adult females, whereas it is mediated by $\mathrm{T}$ secretion in neonatal and adult males. T neonatal exposure determines adult neuroendocrine control of the pulsatile pituitary GH secretion, which is first seen at puberty, when the GH secretion pattern is perceptible and continues throughout adulthood. In postpubertal rats, the male pituitary GH secretion pattern has been shown to be episodic with peaks every 3-4 hours and no measurable trough levels. As consequence, activation of GHR-STAT5b pathway is episodic as well, and phases with low levels of circulating $\mathrm{GH}$ are required to achieve maximal activation of STAT5b-mediated transcription. Conversely, female rat GH secretion is continuous, with higher basal levels and smaller intermittent peaks, and they show reduced STAT5b activation compared with males. Interestingly, depletion of liver-derived IGF-1 (LID mice) [45] or SOCS2 deletion [46] in male mice or exposition of adult male rats to E2 [47] causes liver feminization of some of the GH-regulated biomarkers of gender dimorphism. Therefore, maximal GHR-STAT5b activation occurs at puberty, and suppression occurs during aging or in mutants with defects in GHR signaling. Additionally, xenobiotics (i.e., chemicals, endocrine disruptors) can perturb the hypothalamopituitary-liver GH axis and disrupt GHR-dependent activation (masculinization) or suppression (feminization) of STAT5b function in the liver [48, 49]. Other factors that can affect liver STAT5b function include fasting, caloric restriction, and infections. Exposure to DHT and thyroid hormones can cause liver masculinization, whereas glucocorticoids, FGF15, and angiotensin II cause liver feminization $[47,49]$. Interestingly, liver feminization has been consistently observed in mouse models of obesity and diabetes. Finally, feminization of the male liver has been also associated with activation of constitutive androstane receptor (CAR) or peroxisome proliferator-activated receptor (PPAR) $\alpha$, two xenobiotic-responsive receptors, or increased expression of PPAR $\gamma$ but not other lipogenic transcription factors linked to the fatty liver [47-49]. Relevant, GH-activated STAT5b in the liver is also commonly altered by diverse xenobiotics and provides a linkage between chemical exposure and hepatotoxicity. 


\subsubsection{Sex steroids interact with GHR-STAT5b signaling pathway}

$\mathrm{E} 2(\mathrm{ER} \alpha)$ - and $\mathrm{T}(\mathrm{DHT}) / \mathrm{AR}$-dependent signaling might modulate liver gene expression by interacting with GHR-STAT5b signaling pathway. The level of cell surface GHRs can be influenced by transcriptional, translational, and posttranslational factors (e.g., nutritional status, endocrine context, IGF-1, developmental stage, sex steroids) which, thereby, regulate cell sensitivity to GH actions. In addition, E2 can inhibit GHR-JAK2-STAT5 signaling pathway through induction of SOCS2 and SOCS3 expression which in turn negatively regulates GHR signaling pathway in the liver [19]. Recently, we have shown that subcutaneous administration of nearly physiological doses of E2 to hypothyroid male rats dramatically influenced the hepatic transcriptional program (e.g., genes related to endocrine, metabolic, and gender-differentiated functions) in response to pulsatile (male pattern) GH administration [54]. The effects were associated with increased mRNA expression of several negative regulators of GHR-JAK2-STAT5b signaling pathway (e.g., SOCS2) [54]. It is thought that other negative regulators of JAK/STAT signaling may also contribute to the interaction between E2 and GH in the liver. Indeed, $\mathrm{ER} \alpha$ has been shown to stimulate protein inhibitor of activated STAT3 (PIAS3) expression which in turn inhibits STAT3 DNA binding. Intriguingly, as mentioned above, a direct ER-STAT5 interaction might directly control STAT5-dependent transcriptional activity in the liver [50].

Androgen-mediated signaling has shown to be a critical determinant of body composition in adult men, promoting growth of lean mass and suppressing fat deposition $[7,51]$, a phenotype that is also induced after $\mathrm{GH}$ replacement. Interestingly, the GH-IGF-1 axis has been reported to be positively involved in the growth-promoting and metabolic effects mediated by T [5]. Hence, linear growth in children with $\mathrm{GH}$ deficiency receiving GH therapy is further stimulated by androgen treatment, and GH is required for reaching whole androgen growth-promoting effect. Tincreases growth of boys with hypogonadism and those with hypopituitarism under $\mathrm{GH}$ prescription. However, T effects on somatic growth are poor in boys with hypopituitarism without concomitant GH replacement. Therefore, it is evident that T-GH interactions are pivotal on body composition, which is clearly exemplified by adult men with GH deficiency, whose lean body mass remains below average even after adequate androgen replacement. Adults with hypopituitarism that are not being treated with GH therapy do not show any effect of T on circulating IGF-1, since both hormones are required to exert an optimal effect on circulating IGF-1. Furthermore, the fact that the effects of GH treatment are more marked in men than in women confirms that $\mathrm{T}$ amplifies the anabolic effects of GH in vivo. Although the study is limited to prostate cancer, there are also evidences that T (DHT)/AR signaling interacts with the GHR-STAT5b signaling pathway [20]. In prostate cancer cells, SOCS2 expression was induced by androgens through a mechanism that required STAT5- and AR-dependent transcription. Consequently, SOCS2 inhibited GH activation of JAK2, Src, and STAT5 as well as both cell invasion and cell proliferation in vitro [20]. Thus, in addition of sex steroid regulation of pubertal growth and gender pattern of pituitary $\mathrm{GH}$ secretion, induction of negative regulators of JAK2-STAT5b signaling pathway in vivo is a very relevant mechanism that could explain, in part, how sex steroids modulate hepatic transcriptional program. However, further studies are still needed to better understand molecular interactions between sex steroids and GHR-STAT5b-dependent transcription in the liver.

\subsection{The GHR-STAT5b signaling pathway}

STAT5 proteins are expressed in many tissues and play critical roles in body growth, immune function, cellular differentiation, adipogenesis, oncogenesis, and, 
as mentioned above, gender dimorphism [26-32]. Regarding STAT5 tissue distribution, STAT5a is more prevalent in mammary tissue, while STAT5b expression is more enriched in the muscle and liver.

\subsubsection{Positive regulation of GHR-STAT5b signaling pathway}

GH activates STAT5b via GHR [52-54]. When GH interacts with a preformed dimmer of identical GHR pairs, a conformational change of GHR and the associated tyrosine kinase JAK2 molecules is displayed, exposing the catalytic domain of JAK2 [53]. Thus, through its pseudokinase domain, JAK2 adjacent molecules are activated by transphosphorylation. Activated JAK2 proteins phosphorylate tyrosine residues on the cytoplasmic domain of GHR, activating downstream JAK2-dependent and JAK2independent intracellular signaling, including, among others, STAT5b-dependent gene transcription. STAT5b phosphorylation by JAK2 results in their dissociation from the receptor, dimerization, and translocation to the nucleus where they modulate a transcriptional network of genes such as IGF-1, SOCS2, CYP2C12, or HNF6 [54-58]. In addition to tyrosine phosphorylation by JAK2, STAT5 activity is also regulated by the Ras/MAPK and the PI3K/Akt pathways. STAT5 proteins have been shown to be regulated by serine phosphorylation which appears to modulate DNA-binding affinity and contributes to STAT5 transcriptional activity in a promoter-dependent manner $[59,60]$. STAT5 can physically interact with p85, the regulatory subunit of PI3K and Gab2, which is also involved in the PI3K/Akt pathway [61]. Centrosomal P4.1-associated protein (CPAP) is a cytosolic protein that is normally associated with centrosomes, and it has been shown to physically interact with the unphosphorylated and phosphorylated forms of STAT5A/B [62]. Fyn, a non-receptor tyrosine kinase, and phosphoinositide 3-kinase enhancer A (PIKE-A) also physically interact with STAT5A, and these interactions might be relevant in adipogenesis [63]. It has been shown the adaptor protein [64], CT10 regulator of kinase-like proto-oncogene (CrKL), can form a complex with STAT5 after stimulation with some cytokines (e.g., GH, GM-CSF, EPO) and this complex can translocate to the nucleus and bind DNA to regulate gene expression $[65,66]$. Although less known than GHR, there exist several proteins that have been shown to directly associate with STAT5 to enhance its transcriptional activity. Similar to other transcription factors, STAT5 interacts with proteins in the general transcription factor machinery. This is exemplified by CREB-binding protein (CBP) and p300 which are nuclear coactivators that exhibit histone acetyltransferase activity and have been shown to play a positive role in the transcriptional activation of STAT5. There is evidence that $\mathrm{p} 300 / \mathrm{CBP}$ binds to the carboxy-terminal transactivation domain of STAT5 and that p300 is responsible for enhancing STAT5 transcriptional activity. The nuclear receptor coactivator 1 (NcoA-1), also known as steroid receptor coactivator 1 (SRC-1) is a nuclear coactivator known to coactivate various nuclear transcription factors such as STAT3, STAT6, progesterone receptor (PR), glucocorticoid receptor (GR), ER $\alpha$, thyroid hormone receptor (TR), retinoid X receptor (RXR), hepatocyte nuclear factor $\alpha(\mathrm{HNF} \alpha)$, and PPAR $\gamma$. Interestingly, chromatin immunoprecipitation assays have shown that STAT5A/NcoA-1 complex binds to a STAT5 site in the CIS, a negative regulator of cytokine signaling promoter [67].

\subsubsection{Negative regulation of GHR-STAT5b signaling}

The equilibrium between positive and negative regulators of GHR-dependent activity is of special concern because even slight imbalance may disrupt the GH activity causing serious diseases. Under physiological conditions, activation of GH-induced JAK2-STAT5b is temporary, with a peak of activation achieved within the first $30 \mathrm{~min}$ after GH stimulation, followed by an inactivation step [68]. 
This inactivation period is characterized by an inability of GH to promote maximal JAK2-STAT5 activity in the following 3-4 hours, unless GH is removed from the media. The main post-receptor inhibitors of GHR-JAK2-STAT5 pathway are: the SOCS family, protein phosphatases (PTPs), signal regulatory protein (SIRP)- $\alpha 1$, sirtuin 1 (SIRT1), and protein inhibitors of activated STAT (PIAS). In addition, GH-induced STAT5A phosphorylation and STAT5A-dependent transcription might be negatively regulated by transforming growth factor- $\beta$ (TGF $\beta$ ) [69], a cytokine that regulates cell growth, proliferation, differentiation, and death. Furthermore, several proteins that have been shown to directly associate with STAT5 can repress its transcriptional activity. This is exemplified by silencing mediator for retinoic acid receptor and thyroid hormone receptor (SMRT) which is a corepressor for various members of the nuclear receptor family. Although STATs are not member of the nuclear receptor superfamily, SMRT was found to interact with STAT5 and repress STAT5-dependent transcriptional activity [70]. Sac3 domain-containing protein (SHD1) is a protein that has been shown to have a role in mitotic progression and interacts with STAT5, and SHD1 can be induced by various cytokines and hormones, suggesting a potential role in modulating STAT5 transcriptional activity [71].

\subsection{The SOCS family}

The SOCS protein family is characterized by a specific protein structure as all of them have a SH2 domain and SOCS box domain [72, 73]. From a biological point of view, the SOCS box is an ubiquitination-related domain associated with complexes of elongins C and B, cullin-5, RING-box, and ligase E2, so SOCS proteins may act as ubiquitin E3 ligands that degrade proteins by direct interaction with them. An early step in GH-dependent signaling consists of GHR removal through endocytosis and ubiquitination mechanisms [74-78]. In line with this, SOCS2 has been reported to be essential in GHR-JAK2-STAT5b signaling negative regulation [79]. Regularly, SOCS2 protein levels are constitutively low, but GH rapidly induces its expression, with the subsequent SOCS2 binding to GHR complex, which promotes its ubiquitination and proteasomal degradation. Clinically relevant, SOCS2 negatively regulates GH-dependent control of body growth [26] and glucose and lipid homeostasis [46]. In addition, diverse cytokines, sex hormones (E2 and T), growth factors (e.g., insulin), and xenobiotics (e.g., dioxin, statins), can promote SOCS2 expression, generating a cross-talk mechanism through which multiple endo- and xenobiotics can regulate GHR-dependent activities. SOCS2 is responsible, among others, for regulation of the IGF-1 expression in the liver which is mediated by STAT5b [56, 80-83]. Experiments in mice with SOCS2 disruption also support that STAT5b is critical for $\mathrm{GH}$ regulation of somatic growth [72, 82]. In the SOCS2-deleted mice, the difference in body weight after weaning was associated with significant increase in bone length and increase in weight of most organs [80]. This phenotype was also associated with increased levels of IGF-1 mRNA expression in several organs [74, 80]. SOCS proteins can bind directly to tyrosine kinases to deactivate them but can also block docking on cytokine receptors to inhibit the activation of STAT in the JAK/STAT pathway [79]. It has been shown that SOCS7 also interacts directly with STAT5 and inhibits prolactin-, leptin-, and GH-dependent activation of STAT5 [84]. Interestingly, the oncogene PIM-1, a serine-threonine-protein kinase 1, might participate in the mechanism of the negative regulation of STAT5 activity by interacting with SOCS1 and SOCS3 [85].

\subsection{Protein phosphatases and signal regulatory proteins (SIRPs)}

As expected, tyrosine phosphatases such as PTP-1B and PTP-H1 [86] are negative regulators of the GHR-JAK2-STAT5b pathway. The absence (or inhibition) of 
these PTPs produces prolonged activation of STAT5 and STAT3, by GH. Relevant in wild-type fasted mice, the GH resistance state develops, which is manifested by disorders in somatotropic axis at the GHR level, whereas in fasted PTP-1B KO mice, despite starvation, GH resistance state does not develop. PTP-1B KO mice are characterized by increased STAT5b tyrosine phosphorylation and augmented level of IGF-1 [87, 88]. The PTP known as Src homology 2 (SH2) containing protein tyrosine phosphatase (SHP-1) was initially described in the hematopoietic system [89]. GH can activate SHP-1 and induce its translocation into the nucleus, where SHP-1 binds to STAT5b and, subsequently, participates in the termination of GH signaling in the male rat liver [90]. The SHP-2 also plays a critical role in the regulation of GHR-dependent signaling [91]. The absence of SHP-2 binding to GHR results in an increased activation of STAT5b-dependent transcription [92]. The clinical role of the SHP-2 in the regulation of the GH signal transduction is confirmed by Noonan [93] and Leopard [94] syndromes. In addition, dual-specificity phosphatases (DUSPs), a family of type-I cysteine-based protein tyrosine phosphatases that act on both tyrosine and serine/theronine residues on a substrate, are also of interest for its ability to interact with STAT5b [95]. However, further studies are required to understand the mechanism of this interaction. Finally, low molecular weight PTPs (LMW-PTPs) are phosphatases that play a role in controlling cell proliferation via the dephosphorylation of tyrosine kinase receptors and docking proteins. These PTPs are also of interest for their interactions with STAT5 and oncogenesis [96, 97]. Finally, SIRPs are glycoproteins which can bind to the SH2 domains of SHP-2 protein [98]. Particularly, SIRP $\alpha-1$ decreases $\mathrm{GH}$-induced phosphorylation and activities of STAT5, STAT3, and ERK1/2 and, therefore, acts as a negative regulator of GH-dependent signaling.

\subsection{Sirtuins}

Human sirtuins are a family (from SIRT1 to SIRT7) of nicotinamide adenine dinucleotide $(\mathrm{NAD}+)$-dependent enzymes that regulate a varied metabolic pathway [99]. SIRT1 plays a critical role in the organization and stabilization of the genome, response to stress, glucose homeostasis or cell differentiation, cell survival, inflammation, mitochondrial biogenesis, and oxidative damage. Interestingly, SIRT1 inhibits GH-induced IGF-1 mRNA expression in the liver, decreases lysine acetylation on STAT5, and inhibits the GH-induced tyrosine phosphorylation [100]. SIRT1 might be involved in GH resistance state. In fasted mice, SIRT1 protein level was increased, and SIRT1 inhibition restored lysine acetylation of STAT5 and STAT5 phosphorylation to basal levels, which reversed the GH resistance state [100]. The inhibitory effect of SIRT1 has been also observed on STAT3 protein activity in the liver. Resveratrol, an estrogenic/antiestrogenic stilbene and stimulator of SIRT1, also caused inhibition of STAT5 and STAT3 activities [101-104].

\subsection{Protein inhibitors of activated STAT (PIAS)}

PIAS proteins play an important role in the modulation of multiples signaling pathways which include to the AR-mediated transcription $[105,106]$. STAT protein may be modulated by PIAS proteins in varied ways: (1) the interaction of PIASs with STATs may be type-dependent (e.g., PIAS1-STAT1, PIAS3-STAT3); (2) the PIASs can inhibit STAT-induced gene expression by DNA-binding inhibition (e.g., PIAS1STAT1) or without DNA-binding inhibition (e.g., PIAS4-STAT1); and (3) PIAS proteins are expressed in different tissues. Relevant, intranuclear prolactin/cyclophilin B complex might act as a transcriptional inducer by interacting directly with STAT5, resulting in the removal of the PIAS3, thereby enhancing STAT5 DNA-binding 
activity and prolactin-induced STAT5-dependent gene expression [107]. However, the role of PIAS proteins in somatotropic-liver axis has not been thoroughly investigated.

\subsection{STAT5 interacts with Oct-1 to regulate cell cycle}

Cyclin D1 is involved in regulation of the cell cycle and is a STAT5 target gene [108]. Octamer-binding protein 1 (Oct-1) is a transcription factor ubiquitously expressed in the nucleus that contains POU (pituitary-specific, octomer transcription factor, Unc-86) domain, a DNA-binding domain that recognizes the octamer motif. Oct-1 physically interacts with STAT5A in the nucleus, and this interaction is necessary for activating the cyclin D1 promoter and regulating D1 expression.

\subsection{STAT5 associates with steroid receptors}

PR and GR physically interact with STAT5. PR interacts with STAT5A in the cell nucleus, and STAT5A functions as a coactivator in the regulation of several PR target genes (i.e., RANKL, Wnt4, Areg) [109]. The GR has been shown to physically interact with both STAT5A and STAT5B in a variety of cell types including mammary gland, adipocytes, and hepatocytes. GR acts as a coactivator of STAT5 during mammary gland and somatotropic-liver axis development [110, 111]. Interestingly, GR acts as a positive regulator (coactivator) for STAT5b transcriptional activity in the promotion of body growth and sexual maturation. In fact, mice with inactive GR, specifically in the liver, have impaired body growth, suggesting the importance of GR in hepatocytes for GH-dependent postnatal growth. In addition, genes whose expression was similarly altered by GR and STAT5 deletions in mice included male-predominant genes, GH-responsive genes, steroid dehydrogenases, ribosomal protein genes, or IGF-1 and ASL, two genes which are involved in promoting body growth and gender dimorphism. In addition to GR acting as a positive activator of STAT5 transcriptional regulation, STAT5 has a role in repressing GR-mediated gene transcription $[112,113]$.

\subsection{Epigenetic modulation of STAT5 transcriptional activity: a cross talk with xenobiotics}

Finally, STAT5-dependent gene expression might also be regulated by epigenetic mechanisms [114-116]. Lysine-specific demethylase 1 (LSD1) and histone deacetylase 3 (HDAC3) are epigenetic modifiers that are typically associated with the modulation of histone activity. Nevertheless, the biological impact of the LSD1/ HDAC3/STAT5A interaction network remains unclear, and further studies are required in order to elucidate the function of these interactions [117]. Enhancer of zeste homolog 2 (EZH2) is a histone-lysine N-methyltransferase enzyme involved in the methylation of DNA, and studies in different tissues have shown that EZH2 can also modulate several activities of STAT5 [118].

\section{STAT5b in liver physiology}

Target disruption or mutation of the GHR-JAK2-STAT5b signaling pathway together with clinical studies of GH-resistant mutants has shown that this pathway is a key in GH regulation of target genes associated with postnatal body growth, lipid and glucose metabolism, gender dimorphism, and liver pathophysiology (e.g., fatty liver, insulin resistance, fibrosis, hepatocellular carcinoma) [26-32]. 


\subsection{Postnatal body growth}

GH modulates postnatal growth [42]. The liver is the main source of circulating IGF-1, and STAT5b directly controls GH-dependent transcription of IGF-1 [26]. How GH treatment is administrated determines $\mathrm{GH}$ actions on the liver. In rodents, it has been reported that intermittent (male pattern) $\mathrm{GH}$ administration more potently stimulates body growth rate, IGF-1 expression, and STAT5b activity in the liver than continuous (female pattern) GH administration. However, GH is more efficient than IGF-1 since GH triggers additional growth independent of IGF-1. As pointed above, not only STAT5b but also other transcription factors that interact with STAT5b can influence body growth, including GR, a critical coactivator of STAT5b in the liver [119], or ER, which interacts with E2 and STAT5 [50]. Besides endocrine actions, paracrine effects of STAT5 in GH activity on muscle have been described, since a reduction of IGF-1 transcripts in the muscle and a loss of mass in muscle-specific deletion of STAT5a/b were reported [120].

\subsection{Lipid and glucose metabolism}

Energy/fuel metabolism, and particularly lipid metabolism, is the main metabolic process affected by GH status [26, 47, 121, 122]. GH promotes protein synthesis and inhibits protein degradation in muscle, bone, and other large tissues, thereby blocking glucose and amino acid catabolism and placing lipids as the main source of energy. GH exerts these actions by inhibiting insulin actions and leading fatty acid mobilization from adipose tissue and liver [26, 27]. In adipose tissue, GH poses lipolytic effects and reduces fat mass. This is especially evident in individuals that show an excess of fat accumulated during periods of GH deficiency [26-28]. Furthermore, GH displays triglyceride synthesis and secretion in the liver, and, besides increasing lipogenesis (e.g., SREBP1), GH inhibits PPAR $\alpha$ expression and reduces lipid oxidation $[47,123]$. In the skeletal muscle, $\mathrm{GH}$ drives triglyceride uptake and lipid oxidation, effects that can be reverted by external factors such as nutrition, exercise, or sex steroid hormones. In adulthood, GH can unleash a metabolic syndrome (i.e., increased visceral adiposity, fatty liver, decreased muscle mass, metabolic disturbances) that can be ameliorated by GH replacement therapy. In rodents and humans with fatty liver and adiposity, an ineffective GHR-JAK2STAT5 signaling has been reported, which is attributed to increased lipogenesis and reduced triglyceride secretion, as well as lowered lipolysis [28, 29, 124]. In fact, it has been shown that STAT5b-deleted male mice become obese in later life [125] and that deletion of STAT5b in a mature human is associated with obesity [126]. In contrast, ablation of SOCS2, with subsequent increased STAT5 signaling, was shown to protect mice from high-fat diet-induced liver steatosis [46]. These evidences highlight two physiological aspects of GHR-STAT5b signaling: (a) STAT5b is essential in the regulation of key enzymes or genes otherwise involved in lipid and energy balance. Clinically relevant is that $\mathrm{GH}$ anti-obesity actions increase with the male pattern of pituitary GH secretion because of pulsatile STAT5 signaling and (b) absent GHR signaling, and therefore reduced STAT5 activation, provokes the fatty liver even with normal plasma levels of free fatty acids and minimal adiposity. Interestingly, agonists of liver X receptor (LXR), which cause hepatic steatosis [127], can inhibit GH-STAT5 activation through the induction of sterol regulatory element binding protein 1 (SREBP1) [128]. SREBP1, a LXR target gene, downregulates STAT5b gene transcription and stimulates STAT5b protein degradation. These findings highlight the molecular interactions of LXR with GH-STAT5 signaling in the liver. 
$\mathrm{GH}$ activates the production of glucose in the liver by promoting glycogenolysis; however, GH can exert either a stimulatory or no effect on gluconeogenesis, due to $\mathrm{GH}$ antagonism of insulin action that triggers hepatic/systemic insulin resistance [27]. Furthermore, IGF-1 has an important role on carbohydrate metabolism and may increase insulin sensitivity by suppressing GH release. Therefore, activation of IGF-1 signaling increases the degree of complexity in understanding the molecular mechanisms involved in $\mathrm{GH}$-induced insulin resistance in vivo. GHRKO and GH-deficient mice show improved insulin sensitivity and upregulated hepatic insulin signaling, thereby suggesting that GH locally antagonizes insulin signaling in the liver [129]. However, human GH gene overexpression has been shown to increase basal hepatic glucose uptake and glycogen burden in rats [130]. $\mathrm{GH}$-induced insulin resistance may emerge from the increased mobilization of free fatty acids from peripheral adipose tissue. This can be affecting liver insulin sensitivity, leading to insulin resistance and upregulation of gluconeogenic genes (e.g., glucose-6-phosphatase, phosphoenolpyruvate carboxykinase), essential to glucose homeostasis in the liver. Intriguingly, LID mice have been shown to present a $75 \%$ reduction in circulating IGF-1 levels, three- to fourfold increase in circulating $\mathrm{GH}$ levels, and insulin resistance, without significant enhanced circulating free fatty acid levels. This suggested a possible local cross talk between $\mathrm{GH}$ and insulin signaling systems within the hepatocyte. Additionally, crossbreeding between LID mice and GH transgenic mice resulted in significantly increased serum free fatty acid levels and improved insulin sensitivity due to higher glucose uptake in hepatic, skeletal muscle, and adipose tissues [131]. Besides free fatty acids, the SOCS family of proteins, whose expression is induced by both GH and insulin in the liver, has also been suggested to contribute to insulin resistance $[79,128]$. Recently, we have reported that SOCS2 deletion protected mice against the fatty liver, but, paradoxically, worsened insulin resistance was observed in high-fat dietfed mice [46]. In contrast, SOCS2 deletion was shown to protect adult male mice against streptozotocin-induced type I diabetes [132].

\subsection{STAT5b is a master regulator for "liver sexuality"}

Gender dimorphism in the mammalian liver contributes to gender differences in body growth, intermediate metabolism, and steroid and xenobiotic compound metabolism. Many sex-dependent liver genes are regulated by sex differences in pituitary GH secretion, with STAT5b, proposed to mediate signaling by the pulsatile, male plasma GH profile. Most of the gender dimorphism in the liver can be explained by the female-specific pattern of pituitary gh secretion, through the induction and suppression of female- and male-predominant transcripts, respectively. The 20-30\% of rodent hepatic genes have a sex-specific expression pattern. Genome-wide screens of gene expression have shown that several families of hepatic genes involved in endoand xenobiotic metabolism and metabolic functions (e.g., lipid metabolism) are dependent on GH- and sex-dependent regulation. Moreover, other hepatic transcripts that encode plasma proteins, enzymes, transcription factors, and receptors and are involved in the metabolism of proteins, carbohydrates, or lipids have been found to be up- and/or downregulated by the different patterns of GH or sex steroid activity $[47,55]$. A consensus exists that the response to sex-different pattern of pituitary $\mathrm{GH}$ secretion is the major cause of gender dimorphism in the liver. Large-scale gene expression study has been conducted using male and female mice, wild type and STAT5b inactivated, to characterize sex differences in liver gene expression and their dependence on STAT5B $[26,55,133,134]$. Total disruption of STAT5b triggers loss of sexually dimorphic body growth in mice, as evidenced in affected male mice with reduced size (comparable with female size) and female mice unaffected. 
Furthermore, a 30-50\% reduction in circulating IGF-1 was found in affected male, but not in female mice. Nevertheless, the combined interruption of STAT5a and STAT5b significantly reduced body weight gain in female mice and repressed body growth in male mice more significantly than in male STAT5b null mice, which resemble both GH- or GHR-deficient mice. These findings confirmed the importance of STAT5b in male-specific body growth while exhibiting that STAT5a equally regulates body growth in both sexes. STAT5b is crucial for sex-dependent liver gene expression, a characteristic of approximately $4 \%$ of the genome. In male mice, male-predominant liver gene expressions are positively regulated by STAT5b or STAT5b-dependent factors, whereas female-predominant liver genes are repressed in a STAT5b-dependent manner. Remarkably, a number of the STAT5b-dependent male genes encode transcriptional repressors; these may include direct STAT5b target genes that repress female-predominant genes in the male liver. Several female-predominant repressors show enhanced expression in STAT5b-deficient male mice; these may contribute to the major loss of male gene expression found in the absence of STAT5b. Thus, STAT5b is a key player in this scenario, and it is responsible for the masculinization of the male liver [55, 125]. Conversely, other transcription factors (e.g., HNF6, HNF3 $\beta$ ) are more efficiently activated in the female liver or by the continuous $\mathrm{GH}$ administration [135, 136]. In addition, SREBP1c induction, as well as hepatic triglyceride synthesis and VLDL secretion, and PPAR $\alpha$ inhibition can be observed in the liver after continuous $\mathrm{GH}$ administration $[47,123]$. However, it is likely that other factors are behind some sex differences in the liver. Potential mechanisms that could contribute to this "liver sexuality" are the pituitary-independent effects of sex steroids through interaction with GH-JAK2-STAT5 signaling pathway in the liver.

\section{Sex steroids in liver physiology}

The transcriptional program regulated by E2/ER $\alpha$ - and T(DHT)/AR-dependent signaling is linked to body growth and composition, drug-induced hepatotoxicity, liver growth, hepatic carcinogenesis, or even control of fertility [3, 4, 6, 7, 14-17, 23]. However, the specific roles of altered androgen/AR signaling dysfunctions, as well as its influence on GHR-dependent signaling, in the pathophysiology of metabolic phenotypes in the liver remain, in comparison with E2/ER $\alpha$ signaling, largely unknown. Conversely, the influence of JAK2 on ER $\alpha / A R$-dependent transcription might also play a central role in the regulation of liver physiology and suggests a more complex level of cross talk between E2/ER $\alpha$ - or T/AR-dependent signaling and GHR in the liver [137].

\subsection{Body growth and composition}

The impact of sex steroids on body growth and composition is complex $[4,5,19$, 138]. Increased pubertal growth velocity associated with enhanced GH secretion has generally been attributed to T secretion in boys and to E2 or adrenal androgen secretion in girls. However, recent evidences support that E2 may be the main hormone promoting pubertal growth spurt in both sexes $[139,140]$. Intriguingly, the lack of E2/ER $\alpha$-dependent signaling, but not of ER $\beta$, mediates key effects of estrogens in the skeleton of male mice during growth and maturation. A similar phenotype to ER $\alpha$ null mice can be found in aromatase-deficient (ArKO) male rats, where T cannot produce estrogens. Remarkably, E2 can retrieve skeletal growth rates in the absence of GHR (i.e., GHRKO mice), which is associated with an elevated hepatic and serum levels of IGF-1. This provides a novel mechanism of hepatic IGF-1 production, independent of GHR [139]. In addition, E2 can induce IGF-1 gene expression in the hypothyroid male rat liver, accompanied by low or 
undetectable levels of circulating GH [47]. Gender-related differences in body composition during pubertal growth are thought to be partially mediated by sex steroids through GH-IGF-1 axis modulation. Oral E2 administration to postmenopausal women was shown to decrease circulating IGF-1 levels and increase GH expression, whereas transdermal E2 application was reported to elevate both GH secretion and IGF-1 concentrations [141]. Likewise, oral administration of pharmacological doses of estrogen to hypopituitary patients suppressed GH-regulated endocrine and metabolic effects (i.e., circulating IGF-1 levels, lipid oxidation, and protein synthesis). These effects on metabolism and body composition are attenuated by transdermal administration which suggests that these route-dependent effects are consequence of hepatic first pass effect of oral estrogen leading to direct inhibition of GHR-JAK2-STAT5-IGF-1 signaling pathway. This inhibition might be explained by E2 induction of SOCS2 and SOCS3 which are negative regulators of GHR-JAK2-STAT5b signaling in the liver [19]. E2 modulation of GH signaling is also exemplified by GH treatment inducing a greater increase in lean mass and decrease in fat mass or a greater increase in indices of bone turnover and in bone mass, in GH-deficient male than female patients $[142,143]$.

\subsection{Lipid and glucose metabolism}

Gender dimorphism also affects lipid and glucose metabolism [21, 22, 24]. In human and rodents, E2 physiologically mediates lipid and glucose metabolism. In fact, deficiency of E2/ER $\alpha$ signaling can trigger a metabolic syndrome-like phenotype (i.e., fatty liver, adiposity, insulin resistance) $[18,21,144]$. It has been shown that postmenopausal women are more prone to develop metabolic syndrome than premenopausal women. ER $\alpha$ deficiency or reduced levels of aromatase activity have been reported to promote the development of visceral adiposity, insulin resistance, and hyperinsulinemia both in male humans and mice. In ER $\alpha \mathrm{KO}$ and ArKO mice, this metabolic syndrome-like phenotype can be reverted by E2 treatment. The favorable effect of E2 in lipid and glucose homeostasis stabilization is also found in $\mathrm{ob} / \mathrm{ob}$ and high-fat diet-fed mice, models of obesity and type 2 diabetes. Treatment of ob/ob mice with PPT has been shown to improve glucose tolerance and insulin sensitivity, thus confirming the key role that $E R \alpha$ plays in the control of glucose homeostasis. Estrogenic signaling via GPR-30 has also been connected with glucose homeostasis and insulin production. ER $\alpha$ mainly controls antilipogenesis, reduction of adiposity, and improvement of insulin sensitivity, whereas ER $\beta$ may be detrimental for the maintenance of normal glucose and lipid homeostasis. In ER $\alpha \mathrm{KO}$ mice, insulin resistance, accompanied by increased lipid content and hepatic glucose production, is mainly localized to the liver. Surprisingly, when hepatic ER $\alpha$ was selectively ablated (LERKO mice), mice did not restore the observed ER $\alpha$ KO mice phenotype (i.e., adiposity, glucose intolerance, insulin resistance), even when challenged with a high-fat diet. This suggests that unidentified compensatory mechanisms may be arising or that hepatic insulin resistance occurs as a secondary effect upon ablation of E2 signaling in other cell types. Intriguingly, selective ablations of ER $\alpha$ in the hypothalamic brain region or in hematopoietic/myeloid cells evoke increased body weight and reduced glucose tolerance. The antilipogenic effects of E2 in the liver are partially a result of the activation of PPAR $\alpha$ - and the inhibition of LXR $\alpha$-dependent signaling pathways, with subsequent increased fatty acid oxidation and inhibition of lipogenic genes (e.g., SREPB1c, Apo E) [47]. Activation of LXR $\alpha$-dependent signaling enhances triglyceride accumulation in the liver. In contrast, E2/ ER $\alpha$ signaling suppresses lipogenic pathway expression and the fatty liver induced by LXR activation [38]. Similar to E2/ER $\alpha$ deficiency, reduced androgen/AR signaling is associated with a metabolic syndrome-like phenotype 
(i.e., truncal adiposity, fatty liver, increased triglycerides/cholesterol, reduced HDL, insulin resistance type 2 diabetes), and this is improved after $T$ replacement therapy $[6,25]$. Nevertheless, the specific role of the androgen/AR signaling in liver metabolism regulation is still largely understood. Tissue-specific AR signaling has been shown to be involved in the regulation of lipid metabolism (i.e., inhibits lipogenesis, prevents liver steatosis) and promote anabolic growth in peripheral tissues [25]. Deletion of AR (ARKO) causes late-onset obesity in male mice, whereas the liver-specific ARKO (LARKO) exhibits increased insulin resistance and steatosis, with decreased $\beta$-oxidation, upon high-fat diet. Clinically relevant, high insulin resistance and impaired glucose tolerance have also been revealed in men with $\mathrm{T}$ deficiency [6]. Furthermore, some AR polymorphisms with reduced AR activity are connected to an excess of body fat and fat distribution pattern in both sexes [36]. Remarkably, T treatment diminishes visceral fat and improves nonalcoholic fatty liver disease in mice and human males [6, 23-25]. However, most E2/ER $\alpha$ actions that regulate body weight and lipid/glucose metabolism equally affect both female and male, thus suggesting that T aromatization in E2, via ER $\alpha$, might also contribute to energy homeostasis in males. In summary, reduced E2/ER $\alpha$ or T/AR signaling is associated with metabolic disorders, including metabolic syndromelike phenotype with adiposity and hepatic steatosis, which resembles deficiency of GHR-JAK2-STAT5 signaling. Notably, these metabolic disorders can be partially prevented or ameliorated, by E2/T and/or GH replacement therapies, thus suggesting that these hormones control overlapping cellular networks related with physiological control of lipid and glucose homeostasis.

\section{Conclusions}

Estrogen/ER $\alpha$-dependent signaling and androgen/AR-dependent signaling are essential components in liver physiology and pathology in both male and female. Both direct and indirect actions of sex steroids in the liver are physiologically and therapeutically relevant. Particularly relevant are sex hormone interactions with GH-regulated endocrine (e.g., IGF-1), metabolic (e.g., lipid and glucose metabolism), and gender dimorphism (e.g., endo- and xenobiotic metabolism) functions in the liver. Therefore, the pituitary (GH)-gonadal (E2 and T)-liver axis is relevant in physiology and pathophysiology in mammals. Additionally, the endocrine and metabolic consequences of long-term exposition to compounds derived from sex hormones and their influence on the pituitary-liver axis need to be further understood. Thus, going in-depth in the study of this complex interaction in both physiological and pathological states may contribute to prevent health damage and ameliorate clinical outcome of patients with growth, developmental, and metabolic disorders.

\section{Acknowledgements}

We thank all the authors who contributed to the understanding of the cross talk between sex hormones and GH signaling in the liver. We apologize to those whose work deserves to be cited but unfortunately are not quoted because of space restriction. The research program in the author's lab was supported by grants-in-aid from the Spanish Ministry of Economy and Competitiveness (MINECO) with the funding of the European Regional Development Fund-European Social Fund (SAF201565113-C2-2-R), Canary Islands Government (ACIISI PI2010), and Alfredo Martin Reyes Foundation (Arehucas)-FICIC. 


\section{Conflict of interest}

The authors declare that the research was conducted in the absence of any commercial or financial relationships that could be construed as a potential conflict of interest.

\section{Author details}

Leandro Fernández-Pérez*, Mercedes de Mirecki-Garrido, Carlota Recio and Borja Guerra

Institute for Research in Biomedicine and Health (IUIBS), University of Las Palmas de Gran Canaria (ULPGC), Las Palmas de Gran Canaria, Spain

*Address all correspondence to: leandrofco.fernandez@ulpgc.es

\section{IntechOpen}

(C) 2019 The Author(s). Licensee IntechOpen. This chapter is distributed under the terms of the Creative Commons Attribution License (http://creativecommons.org/licenses/ by/3.0), which permits unrestricted use, distribution, and reproduction in any medium, provided the original work is properly cited. (cc) BY 


\section{References}

[1] Mode A, Gustafsson JA. Sex and the liver-A journey through five decades. Drug Metabolism Reviews. 2006;38:197-207

[2] Waxman DJ, Holloway MG. Sex differences in the expression of hepatic drug metabolizing enzymes. Molecular Pharmacology. 2009;76:215-228

[3] Loria P, Carulli L, Bertolotti M, Lonardo A. Endocrine and liver interaction: The role of endocrine pathways in NASH. Nature Reviews Gastroenterology \& Hepatology. 2009;6:236-247

[4] Mauvais-Jarvis F, Clegg DJ, Hevener AL. The role of estrogens in control of energy balance and glucose homeostasis. Endocrine Reviews. 2013;34:309-338

[5] Birzniece V, Meinhardt UJ, Umpleby MA, Handelsman DJ, Ho KK. Interaction between testosterone and growth hormone on whole-body protein anabolism occurs in the liver. The Journal of Clinical Endocrinology and Metabolism. 2011;96:1060-1067

[6] Rao PM, Kelly DM, Jones TH. Testosterone and insulin resistance in the metabolic syndrome and T2DM in men. Nature Reviews Endocrinology. 2013;9:479-493

[7] Birzniece V. Hepatic actions of androgens in the regulation of metabolism. Current Opinion in Endocrinology, Diabetes, and Obesity. 2018;25:201-208

[8] Wauthier V, Sugathan A, Meyer RD, Dombkowski AA, Waxman DJ. Intrinsic sex differences in the early growth hormone responsiveness of sex-specific genes in mouse liver. Molecular Endocrinology. 2010;24:667-678

[9] Zheng D, Wang X, Antonson P, Gustafsson JA, Li Z. Genomics of sex hormone receptor signaling in hepatic gender dimorphism. Molecular and Cellular Endocrinology. 2018;471:33-41

[10] Cvitanovic Tomas T, Urlep Z, Moskon M, Mraz M, Rozman D. Liver sex computational model: Sexual aspects in hepatic metabolism and abnormalities. Frontiers in Physiology. 2018;9:360

[11] Shen M, Shi H. Sex hormones and their receptors regulate liver energy homeostasis. International Journal of Endocrinology. 2015;2015:294278

[12] Torre D, Lolli F, Ciana P, Maggi A. Gender dimorphism and estrogen action in mouse liver. Advances in Experimental Medicine and Biology. 2017;1043:141-151

[13] Das RK, Banerjee S, Shapiro BH. Growth hormone: A newly identified developmental organizer. The Journal of Endocrinology. 2017;232:377-389

[14] Fisher B, Gunduz N, Saffer EA, Zheng S. Relation of estrogen and its receptor to rat liver growth and regeneration. Cancer Research. 1984;44:2410-2415

[15] Henriquez-Hernandez LA, FloresMorales A, Santana-Farre R, Axelson M, Nilsson P, Norstedt G, et al. Role of pituitary hormones on 17alphaethinylestradiol-induced cholestasis in rat. The Journal of Pharmacology and Experimental Therapeutics. 2007;320:695-705

[16] Bigsby RM, Caperell-Grant A. The role for estrogen receptor-alpha and prolactin receptor in sex-dependent DEN-induced liver tumorigenesis. Carcinogenesis. 2011;32(8):1162-1166

[17] Della Torre S, Rando G, Meda C, Stell A, Chambon P, Krust A, et al. Amino acid-dependent activation 
of liver estrogen receptor alpha integrates metabolic and reproductive functions via IGF-1. Cell Metabolism. 2011;13:205-214

[18] Jones ME, Boon WC, McInnes K, Maffei L, Carani C, Simpson ER.

Recognizing rare disorders: Aromatase deficiency. Nature Clinical Practice Endocrinology \& Metabolism.

2007;3:414-421

[19] Leung KC, Johannsson G, Leong GM, Ho KK. Estrogen regulation of growth hormone action. Endocrine Reviews. 2004;25:693-721

[20] Iglesias-Gato D, Chuan YC, Wikstrom P, Augsten S, Jiang N, Niu Y, et al. SOCS2 mediates the cross talk between androgen and growth hormone signaling in prostate cancer. Carcinogenesis. 2014;35:24-33

[21] Ribas V, Nguyen MT, Henstridge DC, Nguyen AK, Beaven SW, Watt MJ, et al. Impaired oxidative metabolism and inflammation are associated with insulin resistance in ERalpha-deficient mice. American Journal of Physiology. Endocrinology and Metabolism. 2010;298:

E304-E319

[22] Hedrington MS, Davis

SN. Gender dimorphism in glucose and lipid metabolism during fasting, hypoglycemia, and exercise. Frontiers in Endocrinology. 2015;6:61

[23] Kaufman JM, Vermeulen A. The decline of androgen levels in elderly men and its clinical and therapeutic implications. Endocrine Reviews. 2005;26:833-876

[24] Mauvais-Jarvis F. Estrogen and androgen receptors: Regulators of fuel homeostasis and emerging targets for diabetes and obesity. Trends in Endocrinology and Metabolism. 2011;22:24-33
[25] Yu IC, Lin HY, Sparks JD, Yeh S, Chang C. Androgen receptor roles in insulin resistance and obesity in males: The linkage of androgen-deprivation therapy to metabolic syndrome. Diabetes. 2014;63:3180-3188

[26] Lichanska AM, Waters MJ. How growth hormone controls growth, obesity and gender dimorphism. Trends in Genetics. 2008;24:41-47

[27] Vijayakumar A, Yakar S, Leroith D. The intricate role of growth hormone in metabolism. Frontiers in Endocrinology. 2011;2:32

[28] Barclay JL, Nelson CN, Ishikawa M, Murray LA, Kerr LM, McPhee TR, et al. GH-dependent STAT5 signaling plays an important role in hepatic lipid metabolism. Endocrinology. 2011;152:181-192

[29] Sos BC, Harris C, Nordstrom SM, Tran JL, Balazs M, Caplazi P, et al. Abrogation of growth hormone secretion rescues fatty liver in mice with hepatocyte-specific deletion of JAK2. The Journal of Clinical Investigation. 2011;121:1412-1423

[30] Fan Y, Fang X, Tajima A, Geng X, Ranganathan S, Dong H, et al. Evolution of hepatic steatosis to fibrosis and adenoma formation in liver-specific growth hormone receptor knockout mice. Frontiers in Endocrinology. 2014;5:218

[31] Sperling MA. Traditional and novel aspects of the metabolic actions of growth hormone. Growth Hormone \& IGF Research. 2016;26:69-75

[32] Zhu WF, Tang SJ, Shen Z, Wang YM, Liang L. Growth hormone reverses dyslipidemia in adult offspring after maternal undernutrition. Scientific Reports. 2017;7:6038

[33] Fernandez-Perez L, de MireckiGarrido M, Guerra B, Diaz M, 
Diaz-Chico JC. Sex steroids and growth hormone interactions. Endocrinología y Nutrición. 2016;63:171-180

[34] Song CS, Rao TR, Demyan WF, Mancini MA, Chatterjee B, Roy AK. Androgen receptor messenger ribonucleic acid (mRNA) in the rat liver: Changes in mRNA levels during maturation, aging, and calorie restriction. Endocrinology. 1991;128:349-356

[35] Heldring N, Pike A, Andersson S, Matthews J, Cheng G, Hartman J, et al. Estrogen receptors: How do they signal and what are their targets. Physiological Reviews. 2007;87:905-931

[36] Pihlajamaa P, Sahu B, Janne OA. Determinants of receptor- and tissuespecific actions in androgen signaling. Endocrine Reviews. 2015;36:357-384

[37] Sousa C, Ribeiro M, Rufino AT, Leitao AJ, Mendes AF. Assessment of cell line competence for studies of pharmacological GPR30 modulation. Journal of Receptor and Signal Transduction Research. 2017;37:181-188

[38] Han SI, Komatsu Y, Murayama A, Steffensen KR, Nakagawa Y, Nakajima Y, et al. Estrogen receptor ligands ameliorate fatty liver through a nonclassical estrogen receptor/liver $\mathrm{X}$ receptor pathway in mice. Hepatology. 2014;59:1791-1802

[39] Pedram A, Razandi M, Deschenes RJ, Levin ER. DHHC-7 and -21 are palmitoylacyltransferases for sex steroid receptors. Molecular Biology of the Cell. 2012;23:188-199

[40] Pedram A, Razandi M, Sainson RC, Kim JK, Hughes CC, Levin ER. A conserved mechanism for steroid receptor translocation to the plasma membrane. The Journal of Biological Chemistry. 2007;282:22278-22288
[41] Kaplan SA, Cohen P. The somatomedin hypothesis 2007: 50 years later. The Journal of Clinical Endocrinology and Metabolism. 2007;92:4529-4535

[42] Le Roith D, Bondy C, Yakar S, Liu JL, Butler A. The somatomedin hypothesis: 2001. Endocrine Reviews. 2001;22:53-74

[43] Tannenbaum GS, Gurd W, Lapointe M. Leptin is a potent stimulator of spontaneous pulsatile growth hormone $(\mathrm{GH})$ secretion and the $\mathrm{GH}$ response to $\mathrm{GH}$-releasing hormone. Endocrinology. 1998;139:3871-3875

[44] Pradhan G, Samson SL, Sun Y. Ghrelin: Much more than a hunger hormone. Current Opinion in Clinical Nutrition and Metabolic Care. 2013;16:619-624

[45] Ohlsson C, Mohan S, Sjogren K, Tivesten A, Isgaard J, Isaksson O, et al. The role of liver-derived insulin-like growth factor-I. Endocrine Reviews. 2009;30:494-535

[46] Zadjali F, Santana-Farre R, Vesterlund M, Carow B, MireckiGarrido M, Hernandez-Hernandez I, et al. SOCS2 deletion protects against hepatic steatosis but worsens insulin resistance in high-fatdiet-fed mice. The FASEB Journal. 2012;26:3282-3291

[47] Fernandez-Perez L, Santana-Farre R, de Mirecki-Garrido M, Garcia I, Guerra B, Mateo-Diaz C, et al. Lipid profiling and transcriptomic analysis reveals a functional interplay between estradiol and growth hormone in liver. PLoS One. 2014;9:e96305

Oshida K, Waxman DJ, Corton JC. Chemical and hormonal effects on STAT5b-dependent gender dimorphism of the liver transcriptome. PLoS One. 2016;11:e0150284 
[48] Oshida K, Vasani N, Waxman DJ, Corton JC. Disruption of STAT5bregulated gender dimorphism of the liver transcriptome by diverse factors is a common event. PLoS One. 2016;11:e0148308

[49] Bjornstrom L, Sjoberg M.

Mechanisms of estrogen receptor signaling: Convergence of genomic and nongenomic actions on target genes. Molecular Endocrinology. 2005;19:833-842

[50] Gibney J, Wolthers T, Johannsson G, Umpleby AM, Ho KK. Growth hormone and testosterone interact positively to enhance protein and energy metabolism in hypopituitary men. American Journal of Physiology. Endocrinology and Metabolism. 2005;289:E266-E271

[51] Hennighausen L, Robinson GW. Interpretation of cytokine signaling through the transcription factors STAT5A and STAT5B. Genes \& Development. 2008;22:711-721

[52] Brooks AJ, Waters MJ. The growth hormone receptor: Mechanism of activation and clinical implications. Nature Reviews Endocrinology. 2010;6:515-525

[53] Carter-Su C, Schwartz J, Argetsinger LS. Growth hormone signaling pathways. Growth Hormone \& IGF Research. 2016;28:11-15

[54] Waxman DJ, O'Connor C. Growth hormone regulation of sex-dependent liver gene expression. Molecular Endocrinology. 2006;20:2613-2629

[55] Vidal OM, Merino R, Rico-Bautista E, Fernandez-Perez L, Chia DJ, Woelfle J, et al. In vivo transcript profiling and phylogenetic analysis identifies suppressor of cytokine signaling 2 as a direct signal transducer and activator of transcription $5 \mathrm{~b}$ target in liver. Molecular Endocrinology.

2007;21:293-311
[56] Waxman DJ, Celenza JL. Gender dimorphism of hepatic gene expression: Novel biological role of KRAB zinc finger repressors revealed. Genes \& Development. 2003;17:2607-2613

[57] Cesena TI, Cui TX, Piwien-Pilipuk G, Kaplani J, Calinescu AA, Huo JS, et al. Multiple mechanisms of growth hormone-regulated gene transcription. Molecular Genetics and Metabolism. 2007;90:126-133

[58] Park SH, Yamashita H, Rui H, Waxman DJ. Serine phosphorylation of GH-activated signal transducer and activator of transcription $5 a$ (STAT5a) and STAT5b: Impact on STAT5 transcriptional activity. Molecular Endocrinology. 2001;15:2157-2171

[59] Clark DE, Williams CC, Duplessis TT, Moring KL, Notwick AR, Long W, et al. ERBB4/HER4 potentiates STAT5A transcriptional activity by regulating novel STAT5A serine phosphorylation events. The Journal of Biological Chemistry. 2005;280:24175-24180

[60] Rosa Santos SC, Dumon S, Mayeux P, Gisselbrecht S, Gouilleux F. Cooperation between STAT5 and phosphatidylinositol 3-kinase in the IL-3-dependent survival of a bone marrow derived cell line. Oncogene. 2000;19:1164-1172

[61] Peng B, Sutherland KD, Sum EY, Olayioye M, Wittlin S, Tang TK, et al. CPAP is a novel stat5interacting cofactor that augments stat5-mediated transcriptional activity. Molecular Endocrinology. 2002;16:2019-2033

[62] Wei H, Wang S, Chen Q, Chen Y, Chi X, Zhang L, et al. Suppression of interferon lambda signaling by SOCS-1 results in their excessive production during influenza virus infection. PLoS Pathogens. 2014;10:e1003845 
[63] Lee J, Seong S, Kim JH, Kim K, Kim I, Jeong BC, et al. STAT5 is a key transcription factor for IL-3-mediated inhibition of RANKL-induced osteoclastogenesis. Scientific Reports. 2016;6:30977

[64] Ota J, Kimura F, Sato K, Wakimoto N, Nakamura Y, Nagata N, et al. Association of CrkL with STAT5 in hematopoietic cells stimulated by granulocyte-macrophage colonystimulating factor or erythropoietin. Biochemical and Biophysical Research Communications. 1998;252:779-786

[65] Ozaki K, Oda A, Wakao H, Rhodes J, Druker BJ, Ishida A, et al. Thrombopoietin induces association of Crkl with STAT5 but not STAT3 in human platelets. Blood. 1998;92:4652-4662

[66] Litterst CM, Kliem S, Marilley D, Pfitzner E. NCoA-1/SRC-1 is an essential coactivator of STAT5 that binds to the FDL motif in the alpha-helical region of the STAT5 transactivation domain. The Journal of Biological Chemistry. 2003;278:45340-45351

[67] Flores-Morales A, Greenhalgh CJ, Norstedt G, Rico-Bautista E. Negative regulation of growth hormone receptor signaling. Molecular Endocrinology. 2006;20:241-253

[68] Hosui A, Kimura A, Yamaji D, Zhu BM, Na R, Hennighausen L. Loss of STAT5 causes liver fibrosis and cancer development through increased TGF- $\{$ beta $\}$ and STAT3 activation. The Journal of Experimental Medicine. 2009;206:819-831

[69] Nakajima H, Brindle PK, Handa M, Ihle JN. Functional interaction of STAT5 and nuclear receptor co-repressor SMRT: Implications in negative regulation of STAT5-dependent transcription. The EMBO Journal. 2001;20:6836-6844
[70] Nakajima H, Tamura T, Ito M, Shibata F, Kuroda K, Fukuchi Y, et al. SHD1 is a novel cytokine-inducible, negative feedback regulator of STAT5dependent transcription. Blood. 2009;113:1027-1036

[71] Linossi EM, Babon JJ, Hilton DJ, Nicholson SE. Suppression of cytokine signaling: The SOCS perspective. Cytokine \& Growth Factor Reviews. 2013;24:241-248

[72] Kazi JU, Kabir NN, Flores-Morales A, Ronnstrand L. SOCS proteins in regulation of receptor tyrosine kinase signaling. Cellular and Molecular Life Sciences. 2014;71:3297-3310

[73] Greenhalgh CJ, Rico-Bautista E, Lorentzon M, Thaus AL, Morgan PO, Willson TA, et al. SOCS2 negatively regulates growth hormone action in vitro and in vivo. The Journal of Clinical Investigation. 2005;115:397-406

[74] Strous GJ, van Kerkhof P, Govers R, Rotwein P, Schwartz AL. Growth hormone-induced signal transduction depends on an intact ubiquitin system. The Journal of Biological Chemistry. 1997;272:40-43

[75] van Kerkhof P, Sachse M, Klumperman J, Strous GJ. Growth hormone receptor ubiquitination coincides with recruitment to clathrin-coated membrane domains. The Journal of Biological Chemistry. 2001;276:3778-3784

[76] van Kerkhof P, Putters J, Strous GJ. The ubiquitin ligase SCF (betaTrCP) regulates the degradation of the growth hormone receptor. The Journal of Biological Chemistry. 2007;282:20475-20483

[77] Slotman JA, da Silva Almeida AC, Hassink GC, van de Ven RH, van Kerkhof P, Kuiken HJ, et al. Ubc13 and $\mathrm{COOH}$ terminus of Hsp70-interacting protein (CHIP) are required for growth 
hormone receptor endocytosis. The Journal of Biological Chemistry. 2012;287:15533-15543

[78] Rico-Bautista E, Flores-Morales A, Fernandez-Perez L. Suppressor of cytokine signaling (SOCS) 2, a protein with multiple functions. Cytokine \& Growth Factor Reviews. 2006;17:431-439

[79] Metcalf D, Greenhalgh CJ, Viney E, Willson TA, Starr R, Nicola NA, et al. Gigantism in mice lacking suppressor of cytokine signalling-2. Nature. 2000;405:1069-1073

[80] Leroith D, Nissley P. Knock your SOCS off! The Journal of Clinical Investigation. 2005;115:233-236

[81] Greenhalgh CJ, Bertolino P, Asa SL, Metcalf D, Corbin JE, Adams TE, et al. Growth enhancement in suppressor of cytokine signaling 2 (SOCS-2)-deficient mice is dependent on signal transducer and activator of transcription $5 \mathrm{~b}$ (STAT5b). Molecular Endocrinology. 2002;16:1394-1406

[82] Vesterlund M, Zadjali F, Persson T, Nielsen ML, Kessler BM, Norstedt G, et al. The SOCS2 ubiquitin ligase complex regulates growth hormone receptor levels. PLoS One. 2011;6:e25358

[83] Martens N, Uzan G, Wery M, Hooghe R, Hooghe-Peters EL, Gertler A. Suppressor of cytokine signaling 7 inhibits prolactin, growth hormone, and leptin signaling by interacting with STAT5 or STAT3 and attenuating their nuclear translocation. The Journal of Biological Chemistry. 2005;280:13817-13823

[84] Peltola KJ, Paukku K, Aho TL, Ruuska M, Silvennoinen O, Koskinen PJ. Pim-1 kinase inhibits STAT5-dependent transcription via its interactions with SOCS1 and SOCS3. Blood. 2004;103:3744-3750
[85] Pasquali C, Curchod ML, Walchli S, Espanel X, Guerrier M, Arigoni F, et al. Identification of protein tyrosine phosphatases with specificity for the ligand-activated growth hormone receptor. Molecular Endocrinology. 2003;17:2228-2239

[86] Escriva F, Gonzalez-Rodriguez A, Fernandez-Millan E, Rondinone CM, Alvarez C, Valverde AM. PTP1B deficiency enhances liver growth during suckling by increasing the expression of insulin-like growth factor-I. Journal of Cellular Physiology. 2010;225:214-222

[87] Owen C, Lees EK, Mody N, Delibegovic M. Regulation of growth hormone induced JAK2 and mTOR signalling by hepatic protein tyrosine phosphatase 1B. Diabetes \& Metabolism. 2015;41:95-101

[88] Yi TL, Cleveland JL, Ihle JN. Protein tyrosine phosphatase containing $\mathrm{SH} 2$ domains: Characterization, preferential expression in hematopoietic cells, and localization to human chromosome 12p12-p13. Molecular and Cellular Biology. 1992;12:836-846

[89] Ram PA, Waxman DJ. Interaction of growth hormone-activated STATs with $\mathrm{SH} 2$-containing phosphotyrosine phosphatase SHP-1 and nuclear JAK2 tyrosine kinase. The Journal of Biological Chemistry. 1997;272:17694-17702

[90] Qu CK. The SHP-2 tyrosine phosphatase: Signaling mechanisms and biological functions. Cell Research. 2000;10:279-288

[91] Stofega MR, Herrington J, Billestrup N, Carter-Su C. Mutation of the SHP-2 binding site in growth hormone $(\mathrm{GH})$ receptor prolongs $\mathrm{GH}$-promoted tyrosyl phosphorylation of GH receptor, JAK2, and STAT5B. Molecular Endocrinology. 2000;14:1338-1350 
[92] Tartaglia M, Kalidas K, Shaw A, Song X, Musat DL, van der Burgt I, et al. PTPN11 mutations in Noonan syndrome: Molecular spectrum, genotype-phenotype correlation, and phenotypic heterogeneity.

American Journal of Human Genetics. 2002;70:1555-1563

\section{[93] Ogata T, Yoshida R. PTPN11} mutations and genotype-phenotype correlations in Noonan and LEOPARD syndromes. Pediatric Endocrinology Reviews. 2005;2:669-674

[94] Wu TH, Lee HT, Lai CC, Yang AH, Loong CC, Wang HK, et al. Suppressor of cytokine signaling (SOCS) 1 is downregulated in renal transplant recipients with rejection. Transplant Immunology. 2016;38:54-59

[95] Schiffer JM, Malmstrom RD, Parnell J, Ramirez-Sarmiento C, Reyes J, Amaro RE, et al. Model of the ankyrin and SOCS box protein, ASB9, E3 ligase reveals a mechanism for dynamic ubiquitin transfer. Structure. 2016;24:1248-1256

[96] Ghazawi FM, Faller EM, Parmar P, El-Salfiti A, MacPherson PA. Suppressor of cytokine signaling (SOCS) proteins are induced by IL-7 and target surface CD127 protein for degradation in human CD8 T cells. Cellular Immunology. 2016;306-307:41-52

[97] Kharitonenkov A, Chen Z, Sures I, Wang H, Schilling J, Ullrich A. A family of proteins that inhibit signaling through tyrosine kinase receptors.

Nature. 1997;386:181-186

[98] Heinrich PC, Behrmann I, Haan S, Hermanns HM, Muller-Newen G, Schaper F. Principles of interleukin (IL)-6-type cytokine signalling and its regulation. The Biochemical Journal. 2003;374:1-20

[99] Yamamoto M, Iguchi G, Fukuoka H, Suda K, Bando H, Takahashi M, et al.
SIRT1 regulates adaptive response of the growth hormone--insulin-like growth factor-I axis under fasting conditions in liver. Proceedings of the National Academy of Sciences of the United States of America. 2013;110:14948-14953

[100] Borra MT, Smith BC, Denu JM. Mechanism of human SIRT1 activation by resveratrol. The Journal of Biological Chemistry. 2005;280:17187-17195

[101] Cote CD, Rasmussen BA, Duca FA, Zadeh-Tahmasebi M, Baur JA, Daljeet M, et al. Resveratrol activates duodenal Sirt1 to reverse insulin resistance in rats through a neuronal network. Nature Medicine. 2015;21:498-505

[102] Hou X, Rooklin D, Fang H, Zhang Y. Resveratrol serves as a protein-substrate interaction stabilizer in human SIRT1 activation. Scientific Reports. 2016;6:38186

[103] Li Y, Zhu W, Li J, Liu M, Wei M. Resveratrol suppresses the STAT3 signaling pathway and inhibits proliferation of high glucose-exposed HepG2 cells partly through SIRT1.

Oncology Reports. 2013;30:2820-2828

[104] Gross M, Liu B, Tan J, French FS, Carey M, Shuai K. Distinct effects of PIAS proteins on androgen-mediated gene activation in prostate cancer cells. Oncogene. 2001;20:3880-3887

[105] Chen WC, Chen YM, Huang CC, Tzeng YD. Dehydroepiandrosterone supplementation combined with whole-body vibration training affects testosterone level and body composition in mice. International Journal of Medical Sciences. 2016;13:730-740

[106] Rycyzyn MA, Clevenger CV. The intranuclear prolactin/cyclophilin B complex as a transcriptional inducer. Proceedings of the National Academy of Sciences of the United States of America. 2002;99:6790-6795 
[107] Matsumura I, Kitamura T, Wakao H, Tanaka H, Hashimoto K, Albanese C, et al. Transcriptional regulation of the cyclin $\mathrm{D} 1$ promoter by STAT5: Its involvement in cytokine-dependent growth of hematopoietic cells. The EMBO Journal. 1999;18:1367-1377

[108] Stoecklin E, Wissler M, Schaetzle D, Pfitzner E, Groner B. Interactions in the transcriptional regulation exerted by Stat 5 and by members of the steroid hormone receptor family. The Journal of Steroid Biochemistry and Molecular Biology. 1999;69:195-204

[109] Stocklin E, Wissler M, Gouilleux F, Groner B. Functional interactions between Stat 5 and the glucocorticoid receptor. Nature. 1996;383:726-728

[110] Engblom D, Kornfeld JW, Schwake L, Tronche F, Reimann A, Beug H, et al. Direct glucocorticoid receptor-Stat5 interaction in hepatocytes controls body size and maturation-related gene expression. Genes \& Development. 2007;21:1157-1162

[111] Feng ZP, Chandrashekaran IR, Low A, Speed TP, Nicholson SE, Norton RS. The N-terminal domains of SOCS proteins: A conserved region in the disordered N-termini of SOCS4 and 5. Proteins. 2012;80:946-957

[112] Whiting RJ, Payne CJ, Satiaputra J, Kucera N, Qiu TW, Irtegun S, et al. Targeting Lyn tyrosine kinase through protein fusions encompassing motifs of Cbp (Csk-binding protein) and the SOCS box of SOCS1. The Biochemical Journal. 2012;442:611-620

[113] Lau-Corona D, Suvorov A, Waxman DJ. Feminization of male mouse liver by persistent growth hormone stimulation: Activation of sex-biased transcriptional networks and dynamic changes in chromatin states. Molecular and Cellular Biology. 2017;37(19):pii: e00301-pii: e00317
[114] Wingelhofer B, Neubauer HA, Valent P, Han X, Constantinescu SN, Gunning PT, et al. Implications of STAT3 and STAT5 signaling on gene regulation and chromatin remodeling in hematopoietic cancer. Leukemia. 2018;32:1713-1726

[115] Zhang Q, Wang HY, Liu X, Wasik MA. STAT5A is epigenetically silenced by the tyrosine kinase NPM1ALK and acts as a tumor suppressor by reciprocally inhibiting NPM1ALK expression. Nature Medicine. 2007;13:1341-1348

[116] Nanou A, Toumpeki C, Lavigne MD, Lazou V, Demmers J, Paparountas T, et al. The dual role of LSD1 and HDAC3 in STAT5-dependent transcription is determined by protein interactions, binding affinities, motifs and genomic positions. Nucleic Acids Research. 2017;45:142-154

[117] Yoo KH, Oh S, Kang K, Hensel T, Robinson GW, Hennighausen L. Loss of EZH2 results in precocious mammary gland development and activation of STAT5-dependent genes. Nucleic Acids Research. 2015;43:8774-8789

[118] Mueller KM, Themanns M, Friedbichler K, Kornfeld JW, Esterbauer $\mathrm{H}$, Tuckermann JP, et al. Hepatic growth hormone and glucocorticoid receptor signaling in body growth, steatosis and metabolic liver cancer development. Molecular and Cellular Endocrinology. 2012;361:1-11

[119] Klover P, Hennighausen L. Postnatal body growth is dependent on the transcription factors signal transducers and activators of transcription $5 \mathrm{a} / \mathrm{b}$ in muscle: A role for autocrine/paracrine insulin-like growth factor I. Endocrinology. 2007;148:1489-1497

[120] LeRoith D, Yakar S. Mechanisms of disease: Metabolic effects of growth hormone and insulin-like growth 
factor 1. Nature Clinical Practice. Endocrinology \& Metabolism.

2007;3:302-310

[121] Baik M, Yu JH, Hennighausen L. Growth hormone-STAT5 regulation of growth, hepatocellular carcinoma, and liver metabolism. Annals of the New York Academy of Sciences. 2011;1229:29-37

[122] Tollet-Egnell P, Parini P, Stahlberg N, Lonnstedt I, Lee NH, Rudling M, et al. Growth hormonemediated alteration of fuel metabolism in the aged rat as determined from transcript profiles. Physiological Genomics. 2004;16:261-267

[123] List EO, Sackmann-Sala L, Berryman DE, Funk K, Kelder B, Gosney ES, et al. Endocrine parameters and phenotypes of the growth hormone receptor gene disrupted (GHR-/-) mouse. Endocrine Reviews. 2011;32:356-386

[124] Udy GB, Towers RP, Snell RG, Wilkins RJ, Park SH, Ram PA, et al. Requirement of STAT5b for gender dimorphism of body growth rates and liver gene expression. Proceedings of the National Academy of Sciences of the United States of America. 1997;94:7239-7244

[125] Vidarsdottir S, Walenkamp MJ, Pereira AM, Karperien M, van Doorn J, van Duyvenvoorde HA, et al. Clinical and biochemical characteristics of a male patient with a novel homozygous STAT5b mutation. The Journal of Clinical Endocrinology and Metabolism. 2006;91:3482-3485

[126] Hong C, Tontonoz P. Liver

$\mathrm{X}$ receptors in lipid metabolism: Opportunities for drug discovery. Nature Reviews Drug Discovery. 2014;13:433-444

[127] Zadjali F, Santana-Farre R, Mirecki-Garrido M, Ellis E, Norstedt G, Fernandez-Perez L, et al. Liver X receptor agonist downregulates growth hormone signaling in the liver. Hormone Molecular Biology and Clinical Investigation. 2011;8:471-478

[128] Dominici FP, Turyn D. Growth hormone-induced alterations in the insulin-signaling system. Experimental Biology and Medicine. 2002;227:149-157

[129] Cho Y, Ariga M, Uchijima Y, Kimura K, Rho JY, Furuhata Y, et al. The novel roles of liver for compensation of insulin resistance in human growth hormone transgenic rats. Endocrinology. 2006;147:5374-5384

[130] Yakar S, Setser J, Zhao H, Stannard B, Haluzik M, Glatt V, et al. Inhibition of growth hormone action improves insulin sensitivity in liver IGF1-deficient mice. The Journal of Clinical Investigation. 2004;113:96-105

[131] Alkharusi A, Mirecki-Garrido M, Ma Z, Zadjali F, Flores-Morales A, Nystrom T, et al. Suppressor of cytokine signaling 2 (SOCS2) deletion protects against multiple low dose streptozotocin-induced type 1 diabetes in adult male mice. Hormone Molecular Biology and Clinical Investigation. 2016;26:67-76

[132] Davey HW, Wilkins RJ, Waxman DJ. STAT5 signaling in sexually dimorphic gene expression and growth patterns. American Journal of Human Genetics. 1999;65:959-965

[133] Chia DJ. Minireview: Mechanisms of growth hormone-mediated gene regulation. Molecular Endocrinology. 2014;28:1012-1025

[134] Lahuna O, Fernandez L, Karlsson H, Maiter D, Lemaigre FP, Rousseau GG, et al. Expression of hepatocyte nuclear factor 6 in rat liver is sex-dependent and regulated by growth hormone. Proceedings of the National Academy of Sciences of the United States of America. 1997;94:12309-12313 
[135] Lahuna O, Rastegar M, Maiter D, Thissen JP, Lemaigre FP, Rousseau GG. Involvement of STAT5 (signal transducer and activator of transcription 5) and HNF-4 (hepatocyte nuclear factor 4) in the transcriptional control of the hnf6 gene by growth hormone. Molecular Endocrinology. 2000;14:285-294

[136] Gupta N, Mayer D. Interaction of JAK with steroid receptor function. JAKSTAT. 2013;2:e24911

[137] Birzniece V. Gonadal steroids and body composition, strength, and sexual function in men. The New England Journal of Medicine. 2013;369:2455

[138] Venken K, Schuit F, Van Lommel L, Tsukamoto K, Kopchick JJ, Coschigano $\mathrm{K}$, et al. Growth without growth hormone receptor: Estradiol is a major growth hormone-independent regulator of hepatic IGF-I synthesis. Journal of Bone and Mineral Research. 2005;20:2138-2149

[139] Meinhardt UJ, Ho KK. Regulation of growth hormone action by gonadal steroids. Endocrinology and Metabolism Clinics of North America. 2007;36:57-73

[140] Weissberger AJ, Ho KK, Lazarus L. Contrasting effects of oral and transdermal routes of estrogen replacement therapy on 24-hour growth hormone $(\mathrm{GH})$ secretion, insulin-like growth factor I, and GH-binding protein in postmenopausal women. The Journal of Clinical Endocrinology and Metabolism. 1991;72:374-381

[141] Burman P, Johansson AG, Siegbahn A, Vessby B, Karlsson FA. Growth hormone (GH)-deficient men are more responsive to $\mathrm{GH}$ replacement therapy than women. The Journal of Clinical Endocrinology and Metabolism. 1997;82:550-555

[142] Huang DS, O’Sullivan AJ. Shortterm oral oestrogen therapy dissociates the growth hormone/insulin-like growth factor-I axis without altering energy metabolism in premenopausal women. Growth Hormone \& IGF Research. 2009;19:162-167

[143] Xu Y, Nedungadi TP, Zhu L, Sobhani N, Irani BG, Davis KE, et al. Distinct hypothalamic neurons mediate estrogenic effects on energy homeostasis and reproduction. Cell Metabolism. 2011;14:453-465 


\title{
Role of Androgens in Cardiovascular Diseases in Men: A Comprehensive Review
}

\author{
Dilip Mukherjee, Koushik Sen, Shreyasi Gupta, \\ Piyali Chowdhury, Suravi Majumder and Payel Guha
}

\begin{abstract}
The present knowledge on the androgens role in cardiovascular physiology is not fully completed. It remains unclear whether low serum testosterone concentrations in men are an independent risk factor for cardiovascular diseases (CVDs) or a marker of the presence of CVD. However, we demonstrated that endogenous testosterone levels may be implicated in CVDs. Androgens role in modulating cardiovascular function is one of the highest importances, given that its deficiency is strongly associated with hypertension, atherosclerosis, diabetes, obesity, and cardiac hypertrophy. Although significant and independent association between testosterone levels and cardiovascular events in elderly men have not been confirmed in large prospective studies, cross-sectional studies, however, suggested that low testosterone levels in elderly men are associated with CVDs. The results of androgen therapy are not also conclusive. Perhaps, the effects of testosterone treatment of cardiovascular mortality and morbidity have not been extensively examined in control studies. Data on male animal experimentation of the effect of testosterone replacement therapy are either neutral or beneficial on the development of atherosclerosis. Since circulatory androgen levels modulation is expected to cause many other side effects, it seems to be essential to develop a strategy to target androgen receptor for better treating the CVDs.
\end{abstract}

Keywords: testosterone, miocardial infarction, men, lipid profile, ROS

\section{Introduction}

Cardiovascular diseases (CVDs) refers to a class of diseases that involve the heart and/or blood vessels and still the highest leading cause of death in developed and developing countries with earlier onset and possibly of greater mortality risk seen in males compared to females. Approximately 17.5 million people died from CVDs in 2012 representing 31\% of all global deaths. It is anticipated that by 2030, the number of death due to CVDs will be reach to more than 23.6 million [1]. Since male gender is one of the risk factors for premature coronary artery disease, stroke, peripheral vascular disease, and heart failure, androgens have often been considered as a cause underlying this male disadvantage $[2,3]$. Androgens, mainly 
testosterone, may also play in cardiovascular morbidity and mortality by modulating the risk factors of atherosclerosis and vascular functions, lesions to cerebral and peripheral arterial vessel and myocardial infarction leading to heart failure in male [4].

A recent perspective study reveals that testosterone levels in men decline gradually with increasing age and this caused a dramatic increase in the incidence of CVDs [5, 6], but the mechanism of age-related cardiovascular performance remains to be completely understood. However, a protective role of androgen for CVDs in men has been reported and its deficiency may increase the significant risk factor for CVDs. Moreover, controversy also exists whether this age-associated decline in testosterone level is a natural physiologic processes or combination of co-morbidities and life-style choices [7]. With the prospects of much wider therapeutic approaches of testosterone on CVDs, it has become increasingly important to address whether testosterone treatment might increase the risk of severity of CVDs. Considering the importance of therapeutic use of testosterone as have been reflected in several recent studies, it is important to address the issue in a more critical way.

\section{Cardiovascular diseases: types and risk factors}

CVDs refer to any dysfunctional condition of the heart or the blood vessels (arteries, veins, and capillaries). Coronary heart disease (CHD) and stroke are two fundamental components of CVDs [8]. CVDs can be classified in eight major groups. These are: stroke-disruption of the blood supply to the brain either from blockage or from rupture of blood vessels; CHD-disease of blood vessels, transporting blood to the heart muscle; rheumatic heart disease-caused due to rheumatic fever by streptococcal bacteria when heart muscles and valves are damaged; congenital heart disease-structural malformation of heart; aortic aneurysm-dilation and rupture of aorta; peripheral arterial disease-disease of the arteries that supply blood to arms and legs; deep venous thrombosis and pulmonary embolism-blood clot in leg veins, which can dislodge and move to heart and brain; and other CVDs- tumors of the heart, vascular tumor of the brain, disorder of the heart muscle lining etc.

Risk factors can be categorized as modifiable and non-modifiable risk factors. Modifiable risk factors include; high blood pressure, abnormal blood lipids, tobacco use, physical inactivity, obesity, unhealthy diets, and diabetes mellitus. Non-modifiable risk factors are advancing age, hereditary or family history, gender, and race.

\section{Testosterone and its function}

Testosterone, a C19 androgen, is the most vital circulating androgens both in male and female. In men, it is mainly synthesized in the testes and a small amount is also derived from adrenal cortex. Testosterone is essential for male sexual differentiation, development and normal function of male reproductive organs, and maintenance of secondary sexual characters. In addition, testosterone promotes many other physiological processes like bone formation, growth of muscle, hair growth, body composition, and erythropoiesis and decreased the risk of osteoporosis [9]. In normal adult men, testosterone concentration ranges between 241 and $827 \mathrm{ng} / \mathrm{dl}$ [10]. Secretion of testosterone varies with circadian rhythm. 
Circulating testosterone is mainly bound to sex hormone binding globulin (SHBG) and albumin and only $1-2 \%$ remains as unbound form.

In target cells, testosterone binds to the intracellular androgen receptors (ARs) or is converted to dihydrotestosterone (DHT) catalyzed by $5 \alpha$-reductase, which then binds to AR. In some target tissues, testosterone is converted to estrogens by cytochrome P450 aromatase enzyme and estrogens then bind to estrogen receptors. Both androgen and estrogen receptors act as transcription factors and mediate genomic effects [11]. In addition, various in vitro and in vivo studies have shown that testosterone and its derivatives can affect cellular processes in a non-genomic fashion [12]. Testosterone has been shown to regulate cell to cell ion exchange via gap junction in Sertoli cells and cardiac cells in young rats [13]. Testosterone also promotes vasoconstriction $[14,15]$ and rapid rise of $\mathrm{Ca}^{2+}$ in cultured cardiomyocytes by $\mathrm{PLC} / \mathrm{IP}_{3}$-dependent mechanism [16].

\section{Circulatory levels of testosterone and CVDs}

Association of blood testosterone levels and incidence of CVDs in men with increasing age is based mainly on observational studies and the main disadvantages of such type of studies are the extremely variable endpoints of CVDs, heterogeneous study groups, and diverse selection criteria. A continuous study for months to several years on a particular study group of CVD patient is very difficult for various reasons. Importantly, patients in these study groups are mostly in medications or modified their life style. Moreover, selection of poorly-matched controls and timing of blood sampling are not always standardized for diurnal variation of hormone levels. All these factors have a serious impact to draw a definite conclusion. However, taking all these into consideration, recently, we investigated the relationship between serum total testosterone levels and lipid profiles as well as fasting blood glucose (FBG) levels in elderly men with angiographically confirmed CVDs from two thickly populated and socio-economically backward districts; Nadia and Murshidabad of West Bengal, India. We observed that relationship between sex hormones, lipid profiles and FBG levels of CVD patients is strikingly different from men with no CVDs of similar age group [17]. Considering the previous observational studies along with our study, we presented a comprehensive idea on the relationship between serum testosterone levels and CVDs globally.

In normal men of developed countries, the overall incidence of testosterone deficiency increases with age and approximately one half a million new cases of testosterone deficiency are expected in men aged 40-90 years old (Figure 1) [18]. An independent effect of age on serum testosterone in a study of 890 men has also been demonstrated [19]. Prevalence of testosterone deficiency in men aged $>45$ years is approximately $38.7 \%$ based on total testosterone (T) levels and about $36.3 \%$ based on bio-available or free $\mathrm{T}$ [20]. They have documented that major risk factors such as obesity, diabetes, hypertension, hyperlipidaemia, prostate disease, and asthma or chronic obstructive pulmonary disease are responsible for low testosterone levels in men compared without such conditions. A schematic representation of the association of testosterone and cardiovascular risk factors is depicted in Figure 2. It has been reported that low testosterone levels are associated with increased death from CVDs [21]. Whereas, for a long time prospective studies failed to find significant association between testosterone levels and risk of cardiovascular events in middle aged men [22, 23]. However, a study of osteoporotic fractures in elderly men of Sweden reported that high serum testosterone level is associated with reduced risk of cardiovascular events [24]. This is consistent with the influence of testosterone levels on multiple risk factors such as obesity, diabetes, blood 


\section{Child}

(100-110ng/dl)
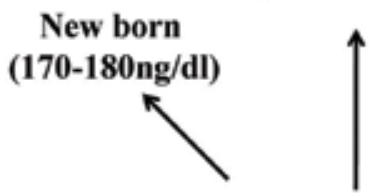

Adolescence

(170-180ng/dl)

Normal range of

Male age 70

testosterone in

$(500-600 \mathrm{ng} / \mathrm{dl})$

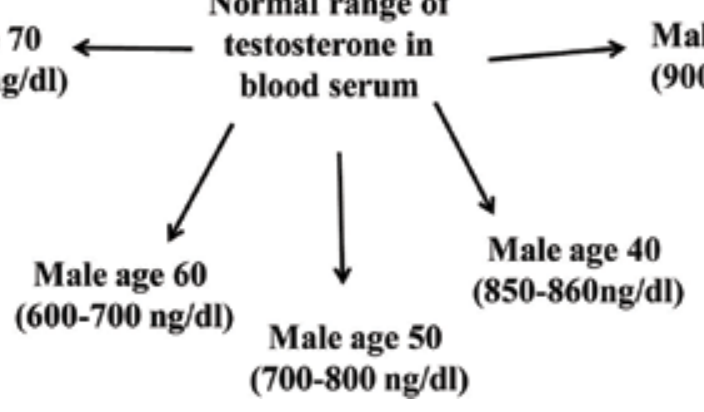

Male age 20-30

(900-1000ng/dl)

\section{Male age 40}

Male age 60
$600-700 \mathrm{ng} / \mathrm{dI})$

$(700-800 \mathrm{ng} / \mathrm{dl})$

Figure 1.

Testosterone levels in men at different ages of life.

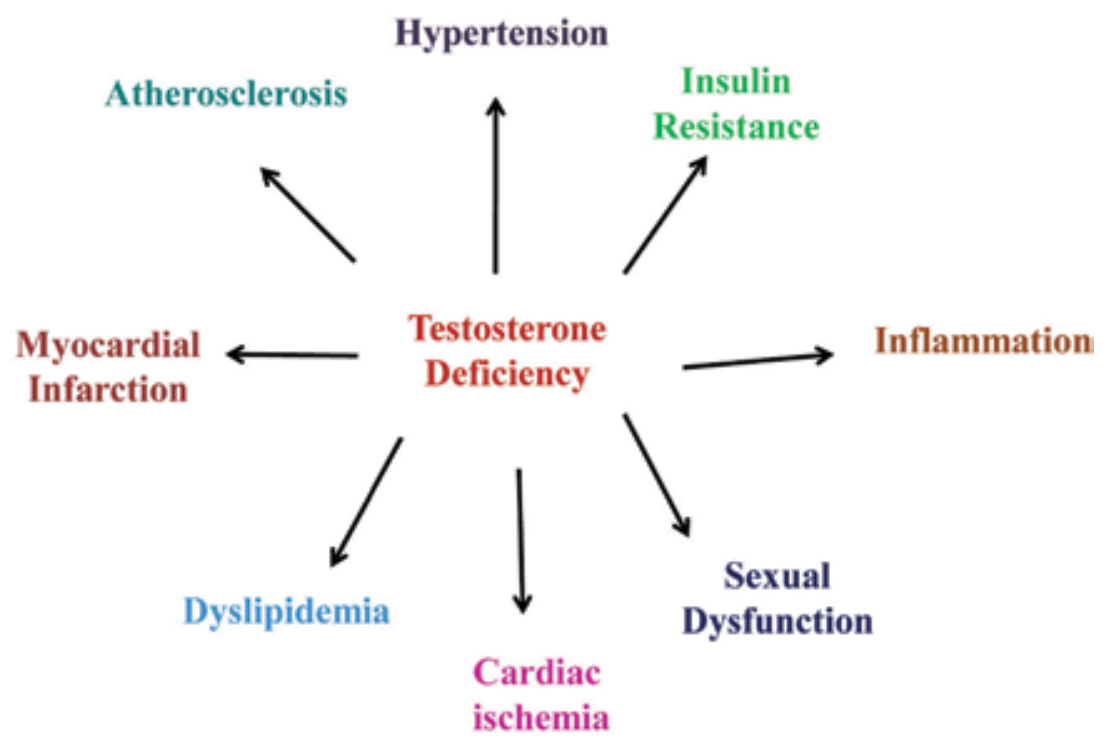

Figure 2.

Association of testosterone deficiency and cardiovascular risk factors.

pressure, and carotid atherosclerosis $[25,26]$. A recent meta-analysis showed that low testosterone levels predicted risk for CVDs in elderly men but not middle-aged men [27]. Interestingly, using data from the French Three-City prospective cohort study (3650 men aged $>65$ years) after adjustment for cardiovascular risk factors, a $\mathrm{J}$-shaped association between plasma total testosterone and incidence of ischemic arterial disease (IAD) in elderly men has been reported [28]. They have suggested that both high and low plasma testosterone levels are associated with an increased risk of arterial ischemic events in elderly men and an optimal range of testosterone levels may confer protection against cardiovascular events. In a recent study, Kelly and Jones [29] observed that testosterone replacement in men diagnosed with hypogonadism shown to be a beneficial effect on several cardiovascular risk factors, cardiac ischemia, functional exercise capacity, and mortality. 


\section{Association of various risk factors with CVD}

\subsection{Role of lipids in CVD}

It has long been established that lipids play a central role in the initiation and progression of CVDs [30-32]. Dyslipidemia comprises the abnormalities of lipid profiles characterized by high levels of total cholesterol (TC), triglyceride (TG), low density lipoprotein (LDL), and very low density lipoprotein (VLDL) along with low levels of high density lipoprotein (HDL) that contributes to the development of atherosclerosis [33]. In older men, reduced testosterone levels are associated with adverse profiles of lipids. Low testosterone level is associated with high TC, high LDL $[34,35]$, and high TG $[36,37]$. Hypo-gonadal men exhibit abdominal or central adiposity $[38,39]$. This finding has led to conclude that all parameters of lipid profile except HDL might be more strongly associated with CVD risk, whereas some investigators reported a negative correlation between HDL and CVD [40, 41]. A strong inverse correlation between body fat and testosterone level is also observed [42]. Higher mass of visceral adipose tissue is inversely correlated with bio-available testosterone [43]. In an epidemiological study from our laboratory, we studied the relationship between serum total testosterone levels and lipid profiles in male patients ranging the age group between 40 and 70 years with angiographically proven CVDs from Nadia and Murshidabad district of West Bengal, India and compared the data with normal men with no CVD history. We observed a significantly low serum total testosterone levels in CVD patient group compared to normal group and further demonstrated a significant negative association between serum total testosterone and TC, TG, LDL, and VLDL among CVDs patients. However, a significant positive correlation between serum total testosterone and HDL was observed [17]. Thus, in these two districts of West Bengal, low levels of serum total testosterone in elderly men are associated with CVD that appear together with an atherogenic lipid milieu that may be involved in pathogenesis of CVD. The molecular mechanism of sex hormone-induced changes in the serum lipid profile is incompletely understood [33]. However, there are evidence from animals, cell, and clinical studies that testosterone controls the expression of important regulatory protein involved in lipid and cholesterol metabolism namely, apolipoprotein A-1

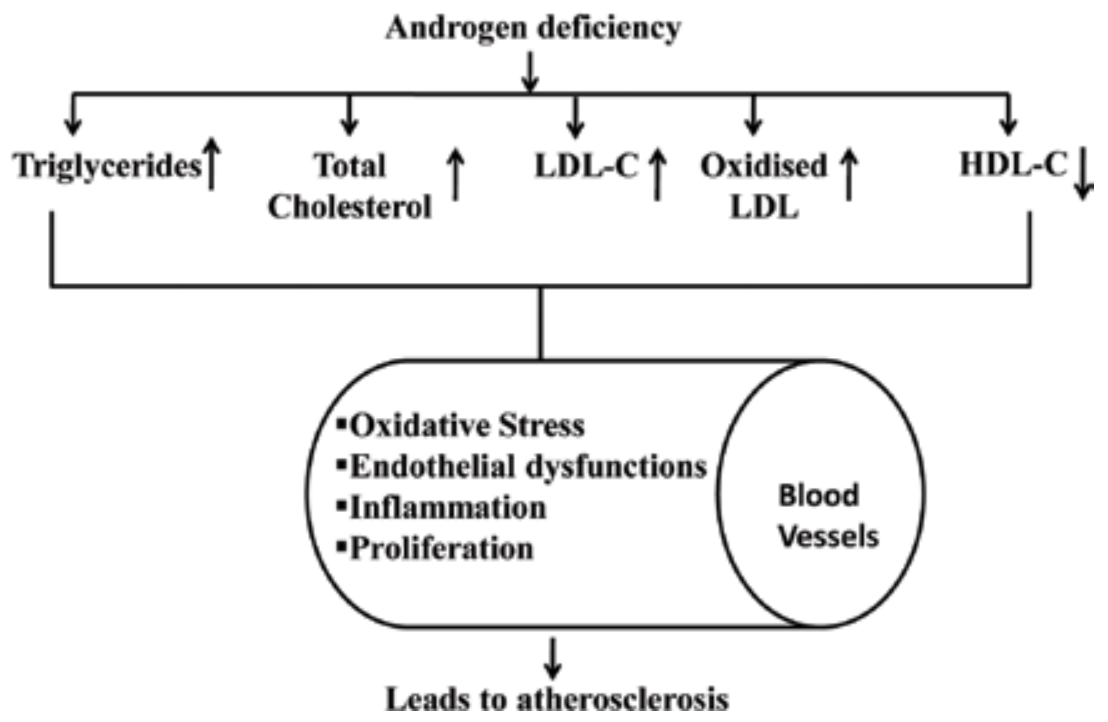

Figure 3.

Changes in lipid profile due to androgen deficiency, leading to atherosclerosis. 
(apoA1) [44, 45], and scavenger receptor class B type 1 (SRB1) [46-48]. The major component of HDL is apoA1, which is secreted by the liver in lipid free or minimally lipidated form [44]. The interaction between apoA1 and lipid transfer ABCA1 present in the peripheral tissues results in the formation of minimally lipidated apoA1, which through a series of steps is converted to discoid shaped pre-HDL. This does not possess atheroprotective properties [45]. In addition to apoA1 and SRB1, lipoprotein modifying enzymes are also critical in maintenance of serum lipid homeostasis. One of the most important lipoprotein modifying enzymes is lipoprotein lipase (LPL), present on the endothelial cell surface [49]. Other enzymes are lecithin-cholesterol-acyl-transferase (LCAT) which esterifies the free cholesterol of HDL and cholesterol ester transferase protein (CETP), which mediates the exchange of cholesterol ester between HDL and LDL [44]. Testosterone might promote the expression of SRB1 receptor and facilitate the selective uptake of HDL, thereby exerting an antiatherogenic role [50]. A schematic association of testosterone deficiency and atherogenic lipid profile is depicted in Figure 3.

\section{Relationship between low testosterone levels and cardiovascular risk factors}

\subsection{Role of androgens in hypertension}

Hypertension is one of the major risk factors for developing CVDs leading to atherosclerosis and sudden cardiac death. Studies with human reveal that hypertension is more prevalent and occurs earlier in men than in women [51, 52]. Sexual dimorphism in blood pressure develops and is maintained until the age of 60 years [53-55]. Epidemiological data further indicate that women older than 60 years, show gradual increase in systolic blood pressure over a period of 5-20 years, until hypertension is highly prevalent in women as in men [55-57]. In hypertensive patients, treatment with antihypertensive drugs can reduce sexual activity and blood concentrations of testosterone $[58,59]$. However, treatment of androgen to such patients found to exacerbate hypertension and increase the risk of CVDs [60-62]. There is also higher incidence of hypertension in individual with reduced free testosterone [63].

In animal studies, all major mouse and rat models (noncastrated, castrated, and anti-androgen treated) potential role for androgen in the pathogenesis of hypertension have been documented $[55,64]$. In mice, castration and subsequent treatment with testosterone at high dose produce the onset of hypertension and further observed that this effect is mediated by androgen receptor [65]. Long back, it was found that $t f m \mathrm{X}$ chromosome (including a mutated non-functional AR) rats and castrated rats have lower blood pressure than intact control rats, suggesting that androgen/AR signaling pathway might be involved in hypertension [66]. Thus, androgen-AR signaling pathway appears to be involved in the regulation of hypertension in men and as androgen level reduce with increasing age this might have a deleterious effect on the development of hypertension. Antiandrogen treatment might be able to suppress hypertension. Moreover, some recent studies using AR knockout mice in selective cells suggest that AR in individual cell types may have independent role in the development of hypertension $[67,68]$.

\subsection{Testosterone association in type 2 diabetes and insulin resistance, a risk factor of CVD}

Low level of testosterone is associated with type 2 diabetes mellitus (T2DM) irrespective of age, race, and obesity [69-72]. High plasma testosterone level is 
associated with reduced risk of developing T2DM [73]. Insulin resistance is the most common hyperglycemic condition and hallmark of T2DM [74]. It is a state where target cells are not responding to normal levels of circulating insulin leading to development of T2DM [75, 76]. An inverse relationship between total testosterone concentration and insulin resistance has also been reported in men [77, 78]. Clinical trials have demonstrated that testosterone administration improved insulin sensitivity, reduced glycaemia, and heart failure progression in men [79].

Cohort studies from Farmingham, Heart Study, EMAS, and Osteoporotic Fractures in Men study [80] and Western Australian Health in Men Study [81] reported that men with T2DM have lower testosterone levels compared with men without T2DM. In fact, different earlier studies showed that men with T2DM have $30-40 \%$ lower circulatory testosterone levels than that of healthy men [82-84]. In a study of 3156 men from various ethnic backgrounds, aged 45-84 years and after adjusting for age, ethnicity, BMI, it has been shown that T2DM and FBG levels are inversely associated with total testosterone concentration [70]. In a recent study with elderly male patients (40-70 years of age) of two district of West Bengal, we observed a highly significant negative correlation between serum total testosterone and FBG levels in CVD patients compared with non-CVD patients of same locality [17]. Our results further indicate that low levels of serum total testosterone might have role in the development of hyperglycemia as evidenced from high FBG levels in elderly men. Moreover, a recent study demonstrated that insulin resistance, hyperinsulinemia, and associated hyperglycemia can promote the development of specific form of cardio-morphopathy, which is independent of coronary artery disease and hypertension and a major cause of morbidity and mortality in developed countries [85]. It is characterized by myocardial insulin signaling, mitochondrial dysfunction, activation of sympathetic nervous system, activation of renin-angiotensin-aldosterone system, and male adaptive immune responses [86]. These patho-physiological changes result in oxidative stress, fibrosis, hypertrophy, cardiac diastolic dysfunction, and eventually systemic heart failure [87].

Association of testosterone deficiency with hyperglycemia has also been observed in animal model [88]. It has been demonstrated that castration-induced testosterone deficiency not only enhanced the hepatic gluconeogenesis but also decreased extra-hepatic insulin sensitivity in aged male rats [89]. Unpublished data from our laboratory also demonstrate that castration in adult male mice is followed by an increase in FBG level compared to sham operated control group and this increase in serum FBG levels was reversed after treatment with testosterone.

The mechanism linking androgen with T2DM and insulin receptor is not fully understood. Testosterone administration up-regulate the expression of GLUT-4, insulin receptor substrate-1 (IRS-1) in cultured adipocytes, and skeletal muscle cells [90]. Another study showed that testosterone promotes AKT and PKC phosphorylation, the major mediator of insulin receptor signaling, which regulate GLUT-4 translocation (Figure 4) [91]. The beneficial effects of testosterone on diabetes through increasing the metabolic rate in muscle promoting gain of energy from adipose tissue resulting decreased fat mass concentration has also been reported [92]. In vitro study of murine model also demonstrated that testosterone administration reduces $\beta$ cell apoptosis [93], whereas, testosterone deficiency promote elevation of the expression of RBP4, which increases insulin resistance [94]. On the contrary, several studies demonstrate a non-positive correlation between testosterone supplementation and heart failure. Several clinical trials led to propose that testosterone supplementation at physiological doses could be a treatment for men with metabolic syndrome and heart failure [95]. 


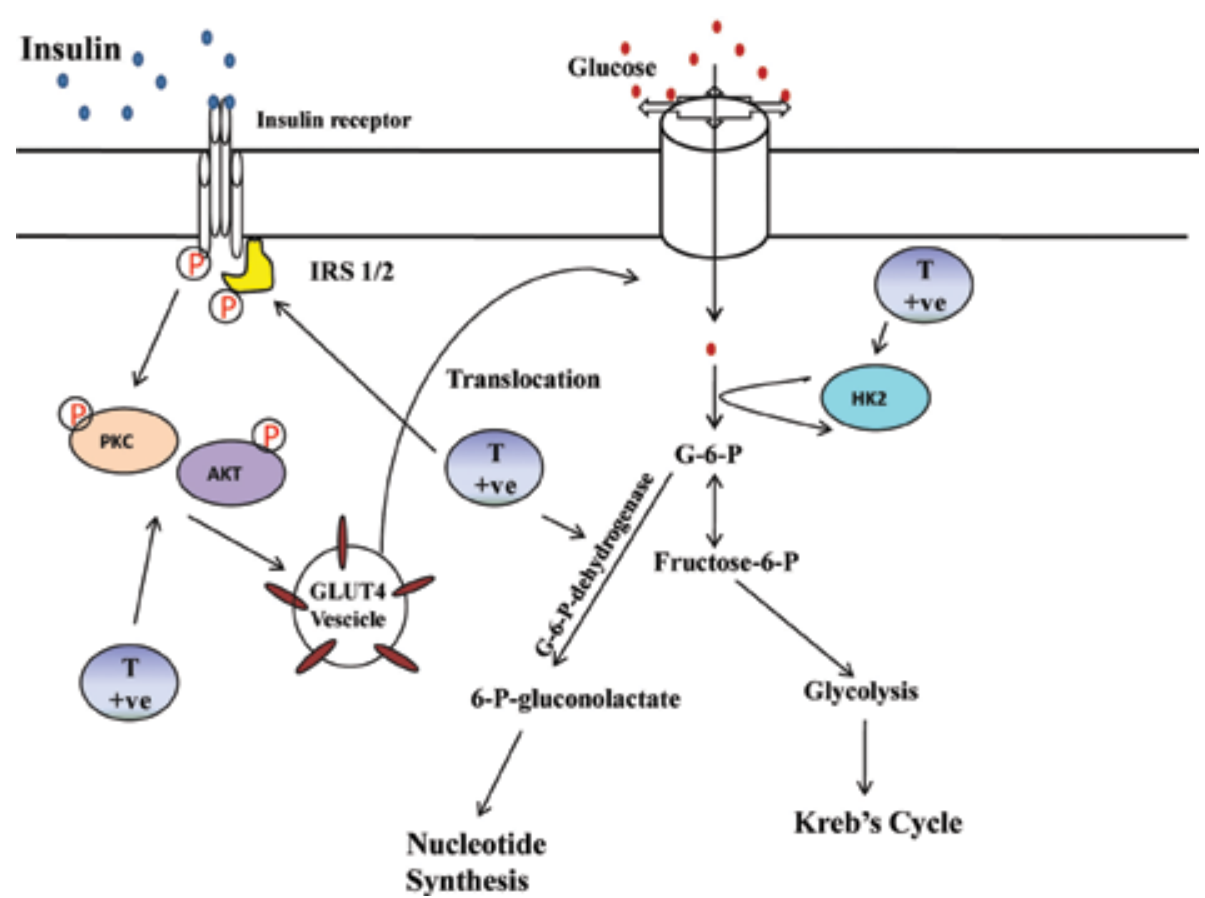

Figure 4.

Proposed mechanism of action of testosterone on cellular IRS activation leading to glucose homeostasis. Testosterone increases GLUT4 expression and membrane translocation which increases cellular uptake and utilization of glucose. Abbreviations: GLUT4, glucose transporter 4; G6P, glucose-6-phosphate; HK2, hexokinase 2; IRS, insulin receptor substrate; $T+v e$ indicates targets or activity increased by testosterone PKC and $A K T$.

\subsection{Testosterone and vascular inflammation}

It is now well accepted that atherosclerosis is a chronic inflammatory disease. Individuals with hyperlipidaemia and signs of systemic inflammation develop atherosclerosis, with specific defects in lipid processing and immune activity consequentially occurring at the vessel wall. It is known that the activation of endothelial cells promotes the adhesion of leukocytes to the blood vessel wall as an early atherogenic event leading to increased vascular permeability for not only the inflammatory leukocytes, but also the circulating lipid components, such as LDL [96]. It has been suggested from observational studies that many pro-inflammatory cytokines like interleukin $1 \beta$ (IL-1 $\beta$ ), IL 6, TNF- $\alpha$, C-reactive protein (CRP), and serum testosterone levels are inversely related in patients with CVDs and T2DM [97-99]. These inflammatory cytokines are known to modulate lipid metabolism, endothelial functions, and atherosclerosis [100]. Testosterone has been reported to reduce the levels of TNF- $\alpha$ and elevated circulating anti-inflammatory IL-10 $[101,102]$ and circulating CRP [102] in hypogonadal men with CVDs. In vitro studies also support the protective effect of testosterone supplementation on atherosclerosis, but the mechanism is not fully known $[103,104]$.

\section{Testosterone deficiency and vascular functions}

A negative correlation between testosterone and hypertension has already been discussed. In a subpopulation study of 206 aged males, it was shown that serum testosterone level is an independent negative predictor for developing arterial 
stiffness and this association remained after adjusting for the other risk factors [105]. Carotid-intima media thickness (IMT) is a marker for CVDs [106]. The relationship among the progression of carotid-IMT, atherosclerotic plaque formation, and total testosterone was investigated and an inverse relationship between this hormone and atherosclerotic plaque formation was observed. This study also reported for a positive co-relation between carotid-IMT and atherosclerosis [107]. Men with low serum testosterone level exhibit higher IMT compared to normal control [108-110]. Long term testosterone administration reduced carotid-IMT in men with CVDs [111, 112]. Animal models also demonstrated that castration or hypogonadism in mice or rabbits fed a pro-artherogenic diet results in increased atherosclerosis and testosterone supplementation inhibits plaque formation [113]. The cellular and molecular mechanism by which testosterone induced IMT is little understood. Other studies, however, have shown that testosterone may reduce IMT by down regulating the inflammatory response or acting as a regulator of apoptosis or increasing vascular smooth muscle cell stability [7].

Endothelial cells play an important role in atherosclerosis, regulation of vascular tone and forming a barrier that regulates the uptake of cells and macromolecules into the vessel wall [114]. Clinical evidence suggests a link between testosterone deficiency and endothelial dysfunction [115-117]. Flow-mediated dilation (FMD), which represents endothelial dysfunction is decreased in men with testosterone deficiency and increased after exogenous administration of the steroid [118, 119]. Testosterone can exert direct effects on various cells of vascular wall by activation of androgen receptor or by non-genomic effects on plasma-membrane receptors and channels [114]. Testosterone can modulate calcium flux by mechanism that is independent of androgen and estrogen receptors in macrophages and endothelial cells [120]. Androgen receptors are expressed in endothelial cells, smooth muscle cells, and cardiomyocytes and all of these are relevant to atherosclerosis and heart failure [121]. It has also been demonstrated that testosterone may improve endothelial function through modulation of nitric oxide (NO) release. Endotheliumproduced NO plays a variety of roles in vascular function maintenance like vasodilatation, inhibition of cell death, and platelet aggregation [96, 122].

\section{Role of androgens in cardiac hypertrophy}

Cardiac growth can be divided into two categories: normal growth in the developmental process and cardiac hypertrophy induced by hemodynamic overload. Since cardiomyocytes are terminally differentiated and lost their ability to multiply soon after birth, they respond to increased workload by an increase in cell size (hypertrophy), not by an increase in cell number (hyperplasia). Cardiac hypertrophy is prevalent in men with hypertension and recognized as an independent risk factor for congestive heart failure and sudden cardiac death [123]. The most impressive evidence of the effect of androgens on heart is the case of highly conditioned athletes, who died by sudden cardiac death. Examination of such death indicated anatomical abnormalities in heart, known as hypertrophy-cardiac myopathy [124]. Since, the net weight of heart is increased as a result of individual cardio-myocyte, the cardiac hypertrophy is assessed as heart weight to body weight ratio and left ventricular hypertrophy $(\mathrm{LVH})$. LVH is the most potent predictor of adverse cardiovascular outcomes in hypertensive populations and is independent risk factors for coronary heart disease, sudden death, heart failure, and stroke. Clinically LVH is diagnosed by evaluating ventricular functions, such as left ventricular ejection fraction, left ventricular shortening fraction, end-systolic, and enddiastolic volume by electro physiological studies. Although directly related to 
systolic blood pressure, other factors including age, sex, race, body mass index, and stimulation of renin-angiotensin-aldosterone system and sympathetic nervous system play an important role of pathogenesis of LVH. LVH is associated both with hypertension and increased cardiovascular morbidity and mortality [125], and it has been suggested that testosterone could be influential in modulating left ventricular mass [126]. Low level of testosterone in male is associated with high blood pressure and left ventricular mass [127]. Interestingly, this association is mediated through obesity. Very recently, it has also been suggested that testosterone can induce hypertrophy in rat heart, which is independent of exposure duration [128].

A central link for the development of skeletal muscle hypertrophy is the activation of mammalian target of rapamycin (mTOR) [129, 130], which also have been reported in testosterone-induced cardiomyocyte hypertrophy [131]. Both type I and type II skeletal muscle fibers have shown to respond in testosterone treatment increasing muscle mass, cross-sectional areas (CSA), and satellite cell number after hormone administration [132]. Testosterone and its synthetic cognates have been used both clinically and illicitly to increase muscle mass [133]. However, the cellular mechanism explaining these effects is not completely understood. Different cellular and molecular mechanisms are shown to be involved in skeletal muscle hypertrophy induced by testosterone, including promotion of nuclear accretion, entry of satellite cells into cell cycle [132-134], and activation of intracellular androgen receptor [135]. Besides regulating gene expression via AR, testosterone also produces fast, non-transcriptional responses involving membrane-linked signal transduction pathways [12]. A rapid non-genomic action exerted via G-protein coupled receptor, intracellular calcium increases, and extracellular signal regulated kinase $1 / 2$ (ERK 1/2) activation has been described for the action of testosterone in skeletal myotubes [136]. Recently, a cellular lineage of myoblast, which lack the classical AR (L6 myoblast), testosterone has shown to promote the proliferation and differentiation of L6 cell via G-protein coupled receptor [137]. Altogether, these data suggest that in men testosterone, increased cardiac hypertrophy and aside from classical mechanism of action of testosterone, non-classical actions are also implicated in development of cardiac hypertrophy.

\section{Testosterone replacement therapy in CVD patients}

Testosterone replacement therapy (TRT) is increasingly promoted and suggested to be a possible curative way for the adverse effect of low testosterone on CVDs in elderly men. Whereas, the effectiveness of TRT in hypogonadal men has been shown to be effective in alleviating the symptoms of fatigue, sexual dysfunction, depression, decreased bone density, decreased muscle mass, among others [138-141], uncertainties remain with respect to cardiovascular safety for its use. In 2004, a committee on assessing the need for clinical trial of testosterone replacement therapy by Institute of Medicine (IOM) in a review concluded largely based on placebo control trials and show that there is no clear evidence on benefit of the heath outcome examined. In fact, no positive effect of TRT on cardiovascular events was observed [142-144]. Observational studies evaluating the cardiovascular safety of TRT in men have also generated inconsistent results $[145,146]$. An independent review conducted by European Medicines Agency (EMA) also found a lack of consistent evidence for TRT increasing cardiovascular risks (European Medicines Agency (EMA)), 2015 [147]. Very recently, in systematically review and meta-analysis by various authors did not find any significant association between exogeneous testosterone treatment and myocardial infarction, stroke or morbidity of randomized control trials [148, 149]. But, a recent study demonstrated that testosterone treatment in men with low 
endogenous testosterone shows improved survival rate in CVD patients [150]. Physiological replacement of testosterone has been shown to decrease cholesterol level and LDL concentration in men $[101,151]$. Studies on the effect of TRT on HDL concentration yielded conflicting result with either a decrease [152] or no changes $[102,153]$. Other investigators observed an increase in concentration of HDL level after testosterone administration [154]. In a recent study on the effects of TRT on lipid metabolism in hypogonadal men with T2DM, it has been hypothesized that because the relationship between lipid metabolism and artherosclerosis are unequivocal, TRT, which ameliorates lipid metabolism, may decrease the morbidity and mortality of CVD in hypogonadal men with T2DM by preventing atherogenesis [155]. Data from randomized placebo-controlled trials (RCTs) suggest that treatment with testosterone is not effective in reducing CV risk; however, when TRT is correctly applied, it is not associated with an increase in CV risk and it may have beneficial effects in sub-population [156]. On the contrary, available reports indicated that TRT is positively correlated with increased cardiovascular risk [157]. It has been reported that those who are under TRT showed increased risk of CVDs $[158,159]$. A systemic review and meta-analysis of the effect of testosterone therapy on cardiovascular events showed that testosterone increases cardiovascular related events among men. The risk of TRT was particularly marked in trials [160].

\section{Effects of testosterone on myocardial infarction}

The myocardial cells undergo a dynamic repair process after myocardial infarction (MI), which is also regulated by hormonal factors and characterized by removal of necrotic tissue and chamber dilatation for so-called "cardiac remodeling" [161]. Recent cohort studies and meta-analyses of randomized clinical trials reported that testosterone therapy is associated with an increased risk of MI, ischemic stroke, and overall mortality $[157,159]$. Supplemental testosterone treatment dramatically increased cardiac rupture and mortality in female mice with or without ovariectomy, whereas castration significantly decreased both the events in males [160]. This indicates role of testosterone is sex specific and even hypotesteronemic condition is good for MI associated cardiac remodeling. Findings suggest that testosterone may adversely affect myocardial healing and early remodeling during the acute phase of MI, causing the observed "gender difference." However, this is highly controversial and association between testosterone therapies and cardiovascular disease is complex and need more dose-specific and time-specific statistical analyses and molecular studies to conclude that whether TRT is beneficial or not.

\section{Conclusion}

For last two decades, androgens have attracted significant interest in explaining the gender difference in CVDs. Although, strong evidences show that testosterone is associated with prevalence of CVDs and affects several key cardiovascular risk factors and increase the risk of cardiovascular mortality, significant independent association between androgen levels and cardiovascular events in men have not been confirmed in large prospective studies. Effects of testosterone therapy on cardiovascular mortality have not also been definitely confirmed in prospective controlled studies. Testosterone administration in men and animal induces both beneficial and deleterious effects on cardiovascular risk factors. Further research in this field is necessary to know the real cardiovascular effects of androgen and to understand the role of androgen in therapeutic applications in CVDs. 


\section{Author details}

Dilip Mukherjee*, Koushik Sen, Shreyasi Gupta, Piyali Chowdhury, Suravi Majumder and Payel Guha Department of Zoology, Kalyani University, Nadia, West Bengal, India

*Address all correspondence to: dilipmukher@rediffmail.com

\section{IntechOpen}

(C) 2020 The Author(s). Licensee IntechOpen. This chapter is distributed under the terms of the Creative Commons Attribution License (http://creativecommons.org/licenses/ by/3.0), which permits unrestricted use, distribution, and reproduction in any medium, provided the original work is properly cited. (cc) BY 


\section{References}

[1] Mozaffarian D, Benjamin EJ, Go AS, Arnett DK, Blaha MJ, Cushman M, et al. Heart disease and stroke statistics2016 update: A report from the American Heart Association. Circulation. 2015;1:CIR350

[2] Kaufman JM, Vermeulen A. The decline of androgen levels in elderly men and its clinical and therapeutic implications. Endocrine Reviews. 2005; 26(6):833-876

[3] Banos G, Guarner V, Perez-Torres I. Sex steroid hormones, cardiovascular diseases and the metabolic syndrome. Cardiovascular \& Hematological Agents in Medicinal Chemistry (Formerly Current Medicinal ChemistryCardiovascular \& Hematological Agents). 2011;9(3):137-146

[4] Snyder PJ, Bhasin S, Cunningham GR, Matsumoto AM, Stephens-Shields AJ, Cauley JA, et al. Effects of testosterone treatment in older men. New England Journal of Medicine. 2016;374(7):611-624

[5] Lakatta EG, Levy D. Arterial and cardiac aging: Major shareholders in cardiovascular disease enterprises: Part I: Aging arteries: A "set up" for vascular disease. Circulation. 2003;107(1): 139-146

[6] Ayaz O, Howlett SE. Testosterone modulates cardiac contraction and calcium homeostasis: Cellular and molecular mechanisms. Biology of Sex Differences. 2015;6(1):9. DOI: 10.1186/ s13293-015-0027-9

[7] Oskui PM, French WJ, Herring MJ, Mayeda GS, Burstein S, Kloner RA. Testosterone and the cardiovascular system: A comprehensive review of the clinical literature. Journal of the American Heart Association. 2013;2(6): e000272
[8] Mackay J. The atlas of heart disease and stroke. World Health Organization. 2004:18-25

[9] Matsumoto AM, Bremner WJ. Testicular disorders. In: Melmed S, Polonsky K, Larsen P, Kronenberg, editors. Williams Textbook of Endocrinology. 12th ed. Philadelphia: Elsevier; 2011. pp. 689-777

[10] Seth M, Sachdeva A, Sahary P, Seth S, Madaan H. Relationship of testosterone levels in males with coronary heart disease. International Journal of Pharmacology and Biosciences. 2011;2(2):B-566-B-570

[11] Falkenstein E, Tillmann HC, Christ M, Feuring M, Wehling M. Multiple actions of steroid hormonesA focus on rapid, nongenomic effects. Pharmacological Reviews. 2000;52(4): 513-556

[12] Foradori CD, Weiser MJ, Handa RJ. Non-genomic actions of androgens. Frontiers in Neuroendocrinology. 2008; 29(2):169-181

[13] Pluciennik F, Verrecchia F, Bastide B, Herve JC, Joffre M, Deleze J. Reversible interruption of gap junctional communication by testosterone propionate in cultured Sertoli cells and cardiac myocytes. The Journal of Membrane Biology. 1996; 149(3):169-177

[14] Masuda A, Mathur R, Halushka PV. Testosterone increases thromboxane A2 receptors in cultured rat aortic smooth muscle cells. Circulation Research. 1991; 69(3):638-643

[15] Schrör K, Morinelli TA, Masuda A, Matsuda K, Mathur RS, Halushka PV. Testosterone treatment enhances thromboxane A2 mimetic induced coronary artery vasoconstriction in 
guinea pigs. European Journal of Clinical Investigation. 1994;24(S1):50-52

[16] Vicencio JM, Ibarra C, Estrada M, Chiong M, Soto D, Parra V, et al. Testosterone induces an intracellular calcium increase by a nongenomic mechanism in cultured rat cardiac myocytes. Endocrinology. 2006;147(3): 1386-1395

[17] Chowdhury P, Sen K, Gupta S, Majumder S, Guha P, Chakraborty A, et al. Association of endogenous testosterone with lipid and blood glucose profiles in elderly men with angiographically proven cardiovascular disease of Nadia and Murshidabad District, West Bengal. Proceedings of the Zoological Society. Springer Nature. 2018;71:48-55

[18] Araujo AB, O’donnell AB, Brambilla DJ, Simpson WB, Longcope C, Matsumoto AM, et al. Prevalence and incidence of androgen deficiency in middle-aged and older men: Estimates from the Massachusetts Male Aging Study. The Journal of Clinical Endocrinology \& Metabolism. 2004;89(12):5920-5926

[19] Harman SM, Metter EJ, Tobin JD, Pearson J, Blackman MR. Longitudinal effects of aging on serum total and free testosterone levels in healthy men. The Journal of Clinical Endocrinology \& Metabolism. 2001;86(2):724-731

[20] Mulligan K, Zackin R, Von Roenn JH, Chesney MA, Egorin MJ, Sattler FR, et al. Testosterone supplementation of megestrol therapy does not enhance lean tissue accrual in men with human immunodeficiency virus-associated weight loss: A randomized, double-blind, placebocontrolled, multicenter trial. The Journal of Clinical Endocrinology \& Metabolism. 2006;92(2):563-570

[21] Hyde Z, Norman PE, Flicker L, Hankey GJ, Almeida OP, McCaul KA, et al. Low free testosterone predicts mortality from cardiovascular disease but not other causes: The Health in Men Study. The Journal of Clinical Endocrinology \& Metabolism. 2012; 97(1):179-189

[22] Yarnell JW, Beswick AD, Sweetnam PM, Riad-Fahmy D.

Endogenous sex hormones and ischemic heart disease in men. The Caerphilly prospective study. Arteriosclerosis, Thrombosis, and Vascular Biology. 1993;13(4):517-520

[23] Ärnlöv J, Pencina MJ, Amin S, Nam BH, Benjamin EJ, Murabito JM, et al. Endogenous sex hormones and cardiovascular disease incidence in men. Annals of Internal Medicine. 2006; 145(3):176-184

[24] Ohlsson C, Barrett-Connor E, Bhasin S, Orwoll E, Labrie F, Karlsson MK, et al. High serum testosterone is associated with reduced risk of cardiovascular events in elderly men: The MrOS (Osteoporotic Fractures in Men) study in Sweden. Journal of the American College of Cardiology. 2011; 58(16):1674-1681

[25] Yeap BB. Are declining testosterone levels a major risk factor for ill-health in aging men? International Journal of Impotence Research. 2009;21(1):24-36

[26] Soisson V, Brailly-Tabard S, Empana JP, Féart C, Ryan J, Bertrand M, et al. Low plasma testosterone and elevated carotid intima-media thickness: Importance of low-grade inflammation in elderly men. Atherosclerosis. 2012; 223(1):244-249

[27] Ruige JB, Mahmoud AM, De Bacquer D, Kaufman JM. Endogenous testosterone and cardiovascular disease in healthy men: A meta-analysis. Heart. 2011;97(11):870-875

[28] Soisson V, Brailly-Tabard S, Helmer C, Rouaud O, Ancelin ML, 
Zerhouni C, et al. A J-shaped association between plasma testosterone and risk of ischemic arterial event in elderly men: The French 3C cohort study. Maturitas. 2013;75(3):282-288

[29] Kelly DM, Jones TH. Testosterone and cardiovascular risk in men. In: Cardiovascular Issues in Endocrinology. Vol. 43. Basel, Switzerland: Karger Publishers; 2014. pp. 1-20

[30] Ginsberg HN. Lipoprotein metabolism and its relationship to atherosclerosis. The Medical Clinics of North America. 1994;78(1):1-20

[31] Glew RH, Kassam HA, Bhanji RA, Okorodudu A, VanderJagt DJ. Serum lipid profiles and risk of cardiovascular disease in three different male populations in northern Nigeria. Journal of Health, Population and Nutrition. 2002;1:166-174

[32] Chrysohoou C, Panagiotakos DB, Pitsavos C, Kosma K, Barbetseas J, Karagiorga M, et al. Distribution of serum lipids and lipoproteins in patients with beta thalassaemia major; an epidemiological study in young adults from Greece. Lipids in Health and Disease. 2004;3(1):3

[33] Traish AM, Abdou R, Kypreos KE. Androgen deficiency and atherosclerosis: The lipid link. Vascular Pharmacology. 2009;51(5-6):303-313

[34] Simon D, Charles MA, Nahoul K, Orssaud G, Kremski J, Hully V, et al. Association between plasma total testosterone and cardiovascular risk factors in healthy adult men: The Telecom Study. The Journal of Clinical Endocrinology \& Metabolism. 1997; 82(2):682-685

[35] Barud W, Palusiński R, Bełtowski J, Wójcicka G. Inverse relationship between total testosterone and antioxidized low density lipoprotein antibody levels in ageing males. Atherosclerosis. 2002;164(2):283-288

[36] Mäkinen JI, Perheentupa A, Irjala K, Pöllänen P, Mäkinen J, Huhtaniemi I, et al. Endogenous testosterone and serum lipids in middle-aged men. Atherosclerosis. 2008;197(2):688-693

[37] Akishita M, Fukai S, Hashimoto M, Kameyama Y, Nomura K, Nakamura T, et al. Association of low testosterone with metabolic syndrome and its components in middle-aged Japanese men. Hypertension Research. 2010; 33(6):587

[38] Haffner SM, Mykkänen L, Valdez RA, Katz MS. Relationship of sex hormones to lipids and lipoproteins in nondiabetic men. The Journal of Clinical Endocrinology \& Metabolism. 1993; 77(6):1610-1615

[39] Couillard C, Gagnon J, Bergeron J, Leon AS, Rao DC, Skinner JS, et al. Contribution of body fatness and adipose tissue distribution to the age variation in plasma steroid hormone concentrations in men: The HERITAGE Family Study 1. The Journal of Clinical Endocrinology \& Metabolism. 2000; 85(3):1026-1031

[40] Gordon DJ, Probstfield JL, Garrison RJ, Neaton JD, Castelli WP, Knoke JD, et al. High-density lipoprotein cholesterol and cardiovascular disease. Four prospective American studies. Circulation. 1989; 79(1):8-15

[41] Barter P, Gotto AM, LaRosa JC, Maroni J, Szarek M, Grundy SM, et al. HDL cholesterol, very low levels of LDL cholesterol, and cardiovascular events. New England Journal of Medicine. 2007; 357(13):1301-1310

[42] Kapoor D, Malkin CJ, Channer KS, Jones TH. Androgens, insulin resistance and vascular disease in men. Clinical Endocrinology. 2005;63(3):239-250 
[43] Nielsen TL, Hagen C, Wraae K, Brixen K, Petersen PH, Haug E, et al. Visceral and subcutaneous adipose tissue assessed by magnetic resonance imaging in relation to circulating androgens, sex hormone-binding globulin, and luteinizing hormone in young men. The Journal of Clinical Endocrinology \& Metabolism. 2007; 92(7):2696-2705

[44] Rader DJ. High-density lipoproteins and atherosclerosis. The American Journal of Cardiology. 2002;90(8):62-70

[45] Zannis VI, Kypreos KE, Chroni A, Kardassis D, Zanni EE. Lipoproteins and atherogenesis. Molecular Mechanisms of Atherosclerosis. 2004;8:111-174

[46] Liu B, Krieger M. Highly purified scavenger receptor class B, type I reconstituted into phosphatidylcholine/ cholesterol liposomes mediates high affinity high density lipoprotein binding and selective lipid uptake. Journal of Biological Chemistry. 2002;277(37): 34125-34135

[47] Isidori AM, Giannetta E, Greco EA, Gianfrilli D, Bonifacio V, Isidori A, et al. Effects of testosterone on body composition, bone metabolism and serum lipid profile in middle-aged men: A meta-analysis. Clinical Endocrinology. 2005;63(3):280-293

[48] Haring R, Baumeister SE, Völzke H, Dörr M, Felix SB, Kroemer HK, et al. Prospective association of low total testosterone concentrations with an adverse lipid profile and increased incident dyslipidemia. European Journal of Cardiovascular Prevention \& Rehabilitation. 2011;18(1):86-96

[49] Beigneux AP, Franssen R, Bensadoun A, Gin P, Melford K, Peter J, et al. Chylomicronemia with a mutant GPIHBP1 (Q115P) that cannot bind lipoprotein lipase. Arteriosclerosis, Thrombosis, and Vascular Biology. 2009;29(6):956-962
[50] Langer C, Gansz B, Goepfert C, Engel T, Uehara Y, von Dehn G, et al. Testosterone up-regulates scavenger receptor BI and stimulates cholesterol efflux from macrophages. Biochemical and Biophysical Research Communications. 2002;296(5): 1051-1057

[51] Wiinberg N, Høegholm A, Christensen HR, Bang LE, Mikkelsen KL, Nielsen PE, et al. 24-h ambulatory blood pressure in 352 normal Danish subjects, related to age and gender. American Journal of Hypertension. 1995;8(10):978-986

\section{[52] Egan BM, Zhao Y, Axon RN. US} trends in prevalence, awareness, treatment, and control of hypertension, 1988-2008. JAMA. 2010;303(20): 2043-2050

[53] Himmelmann A, Svensson A, Hansson L. Influence of sex on blood pressure and left ventricular mass in adolescents: The Hypertension in Pregnancy Offspring Study. Journal of Human Hypertension. 1994;8(7): 485-490

[54] Burt VL, Whelton P, Roccella EJ, Brown C, Cutler JA, Higgins M, et al. Prevalence of hypertension in the US adult population: Results from the Third National Health and Nutrition Examination Survey, 1988-1991.

Hypertension. 1995;25(3):305-313

[55] Wilson C, Maass R, Estrada M. Cardiovascular effects of androgens. In: Akin F, editor. Basic and Clinical Endocrinology Up-to-Date 2011. Rijeka: IntechOpen. ISBN: 978-953-307-340-8.

Available from: http://www.intechopen. $\mathrm{com} /$ books/basic-and-clinical-endoc rinology-up-to-date/cardiovasculareffects-ofandrogens

[56] Stamler J, Stamler R, Riedlinger WF, Algera G, Roberts RH. Hypertension screening of 1 million Americans: Community hypertension evaluation 
clinic (CHEC) program, 1973 through 1975. JAMA. 1976;235(21):2299-2306

[57] Kienitz T, Quinkler M. Testosterone and blood pressure regulation. Kidney and Blood Pressure Research. 2008; 31(2):71-79

[58] Suzuki H, Tominaga T, Kumagai H, Saruta T. Effects of first-line antihypertensive agents on sexual function and sex hormones. Journal of Hypertension. Supplement: Official Journal of the International Society of Hypertension. 1988;6(4):S649-S651

[59] Fogari R, Corradi L, Marasi G, Zoppi A, Mugellini A, Banderali A, et al. I007: Sexual activity and testosterone levels in hypertensive males. American Journal of Hypertension. 2000;13(S2): $278 \mathrm{~A}$

[60] Tangredi JF, Buxton IL. Hypertension as a complication of topical testosterone therapy. Annals of Pharmacotherapy. 2001;35(10): 1205-1207

[61] Reckelhoff JF, Yanes LL, Iliescu R, Fortepiani LA, Granger JP. Testosterone supplementation in aging men and women: Possible impact on cardiovascular-renal disease. American Journal of Physiology-Renal Physiology. 2005;289(5):F941-F948

[62] Cheung KK, Luk AO, So WY, Ma RC, Kong AP, Chow FC, et al. Testosterone level in men with type 2 diabetes mellitus and related metabolic effects: A review of current evidence. Journal of Diabetes Investigation. 2015; 6(2):112-123

[63] Fogari R, Preti P, Zoppi A, Fogari E, Rinaldi A, Corradi L, et al. Serum testosterone levels and arterial blood pressure in the elderly. Hypertension Research. 2005;28(8):625-630

[64] Reckelhoff JF, Granger JP. Role of androgens in mediating hypertension and renal injury. Clinical and Experimental Pharmacology and Physiology. 1999;26(2):127-131

[65] Dubey RK, Oparil S, Imthurn B, Jackson EK. Sex hormones and hypertension. Cardiovascular Research. 2002;53(3):688-708

[66] Ely DL, Salisbury R, Hadi D, Turner M, Johnson ML. Androgen receptor and the testes influence hypertension in a hybrid rat model. Hypertension. 1991;17:1104-1110

[67] Wang C, Nieschlag E, Swerdloff R, Behre HM, Hellstrom WJ, Gooren LJ, et al. Investigation, treatment, and monitoring of late-onset hypogonadism in males: ISA, ISSAM, EAU, EAA, and ASA recommendations. European Journal of Endocrinology. 2008;159(5):507-514

[68] Lin TH, Yeh S, Chang C. Tissuespecific knockout of androgen receptor in mice. In: Androgen Action. Totowa, New Jersey, USA: Humana Press; 2011. pp. 275-293

[69] Rhoden EL, Ribeiro EP, Teloken C, Souto CA. Diabetes mellitus is associated with subnormal serum levels of free testosterone in men. BJU International. 2005;96(6):867-870

[70] Selvin E, Feinleib M, Zhang L, Rohrmann S, Rifai N, Nelson WG, et al. Androgens and diabetes in men: Results from the Third National Health and Nutrition Examination Survey (NHANES III). Diabetes Care. 2007; 30(2):234-238

[71] Colangelo LA, Ouyang P, Liu K, Kopp P, Golden SH, Dobs AS, et al.

Association of endogenous sex hormones with diabetes and impaired fasting glucose in men: The MultiEthnic Study of Atherosclerosis. Diabetes Care. 2009;32(6):1049-1051

[72] Corona G, Monami M, Rastrelli G, Aversa A, Sforza A, Lenzi A, et al. 
Type 2 diabetes mellitus and testosterone: A meta-analysis study. International Journal of Andrology. 2011;34:528-540

[73] Ding EL, Song Y, Malik VS, Liu S. Sex differences of endogenous sex hormones and risk of type 2 diabetes: A systematic review and meta-analysis. JAMA. 2006;295(11):1288-1299

[74] DeFronzo RA. Insulin resistance, lipotoxicity, type 2 diabetes and atherosclerosis: The missing links. The Claude Bernard Lecture 2009. Diabetologia. 2010;53(7):1270-1287

[75] Mlinar B, Marc J, Janež A, Pfeifer M. Molecular mechanisms of insulin resistance and associated diseases. Clinica Chimica Acta. 2007;375(1-2):20-35

[76] Grossmann M, Gianatti EJ, Zajac JD. Testosterone and type 2 diabetes. Current Opinion in Endocrinology, Diabetes and Obesity. 2010;17(3): 247-256

[77] Pitteloud N, Hardin M, Dwyer AA, Valassi E, Yialamas M, Elahi D, et al. Increasing insulin resistance is associated with a decrease in Leydig cell testosterone secretion in men. The Journal of Clinical Endocrinology \& Metabolism. 2005;90(5):2636-2641

[78] Osuna CJA, Gomez-Perez R, ArataBellabarba G, Villaroel V. Relationship between BMI, total testosterone, sex hormone-binding-globulin, leptin, insulin and insulin resistance in obese men. Archives of Andrology. 2006; 52(5):355-361

[79] Cook NL, Romashkan S. Why do we need a trial on the effects of testosterone therapy in older men? Clinical Pharmacology \& Therapeutics. 2011; 89(1):29-31

[80] Bhasin S, Jasjua GK, Pencina M, D'agostino R, Coviello AD, Vasan RS, et al. Sex hormone-binding globulin, but not testosterone, is associated prospectively and independently with incident metabolic syndrome in men: The Framingham Heart Study. Diabetes Care. 2011;34(11):2664-2670

[81] Yeap BB, Araujo AB, Wittert GA. Do low testosterone levels contribute to ill-health during male ageing? Critical Reviews in Clinical Laboratory Sciences. 2012;49(5-6):168-182

[82] Dhindsa S, Prabhakar S, Sethi M, Bandyopadhyay A, Chaudhuri A, Dandona P. Frequent occurrence of hypogonadotropic hypogonadism in type 2 diabetes. The Journal of Clinical Endocrinology \& Metabolism. 2004; 89(11):5462-5468

[83] Kapoor D, Clarke S, Stanworth R, Channer KS, Jones TH. The effect of testosterone replacement therapy on adipocytokines and C-reactive protein in hypogonadal men with type 2 diabetes. European Journal of Endocrinology. 2007;156(5):595-602

[84] Grossmann M, Thomas MC, Panagiotopoulos S, Sharpe K, MacIsaac RJ, Clarke S, et al. Low testosterone levels are common and associated with insulin resistance in men with diabetes. The Journal of Clinical Endocrinology \& Metabolism. 2008; 93(5):1834-1840

[85] Jia G, DeMarco VG, Sowers JR. Insulin resistance and hyperinsulinaemia in diabetic cardiomyopathy. Nature Reviews Endocrinology. 2016;12(3):144-153

[86] Isfort M, Stevens SC, Schaffer S, Jong CJ, Wold LE. Metabolic dysfunction in diabetic cardiomyopathy. Heart Failure Reviews. 2014;19(1):35-48

[87] Dhalla NS, Takeda N, RodriguezLeyva D, Elimban V. Mechanisms of subcellular remodeling in heart failure 
due to diabetes. Heart Failure Reviews. 2014;19(1):87-99

[88] Muthusamy T, Murugesan P, Balasubramanian K. Sex steroids deficiency impairs glucose transporter 4 expression and its translocation through defective Akt phosphorylation in target tissues of adult male rat. Metabolism. 2009;58(11):1581-1592

[89] Xia F, Xu X, Zhai H, Meng Y, Zhang H, Du S, et al. Castration-induced testosterone deficiency increases fasting glucose associated with hepatic and extra-hepatic insulin resistance in adult male rats. Reproductive Biology and Endocrinology. 2013;11(1): Article No. 106

[90] Chen X, Li X, Huang HY, Lin JF. Effects of testosterone on insulin receptor substrate- 1 and glucose transporter 4 expression in cells sensitive to insulin. Zhonghua Yi Xue Za Zhi. 2006;86(21):1474-1477

[91] Sato K, Iemitsu M, Aizawa K, Ajisaka R. Testosterone and DHEA activate the glucose metabolism-related signaling pathway in skeletal muscle. American Journal of PhysiologyEndocrinology and Metabolism. 2008; 294(5):E961-E968

[92] Kelly DM, Jones TH. Testosterone: A metabolic hormone in health and disease. Journal of Endocrinology. 2013; 217:R25-R45

[93] Palomar-Morales M, Morimoto S, Mendoza-Rodríguez CA, Cerbón MA. The protective effect of testosterone on streptozotocin-induced apoptosis in $\beta$ cells is sex specific. Pancreas. 2010; 39(2):193-200

[94] McInnes KJ, Smith LB, Hunger NI, Saunders PT, Andrew R, Walker BR. Deletion of the androgen receptor in adipose tissue in male mice elevates retinol binding protein 4 and reveals independent effects on visceral fat mass and on glucose homeostasis. Diabetes. 2012;61(5):1072-1081

[95] Pugh PJ, English KM, Jones TH, Channer KS. Testosterone: A natural tonic for the failing heart? QJM. 2000; 93(10):689-694

[96] Kelly DM, Jones TH. Testosterone: A vascular hormone in health and disease. Journal of Endocrinology. 2013; 217:R47-R71

[97] Yang Q, Graham TE, Mody N, Preitner F, Peroni OD, Zabolotny JM, et al. Serum retinol binding protein 4 contributes to insulin resistance in obesity and type 2 diabetes. Nature. 2005;436(7049):356-362

[98] Maggio M, Basaria S, Ble A, Lauretani F, Bandinelli S, Ceda GP, et al. Correlation between testosterone and the inflammatory marker soluble interleukin- 6 receptor in older men. The Journal of Clinical Endocrinology \& Metabolism. 2006;91(1):345-347

[99] Nettleship JE, Pugh PJ, Channer KS, Jones $\mathrm{T}$, Jones RD. Inverse relationship between serum levels of interleukin-1 $\beta$ and testosterone in men with stable coronary artery disease. Hormone and Metabolic Research. 2007;39(05): 366-371

[100] Watkins LR, Hutchinson MR, Johnston IN, Maier SF. Glia: Novel counter-regulators of opioid analgesia. Trends in Neurosciences. 2005;28(12): 661-669

[101] Malkin CJ, Pugh PJ, Jones RD, Kapoor D, Channer KS, Jones TH. The effect of testosterone replacement on endogenous inflammatory cytokines and lipid profiles in hypogonadal men. The Journal of Clinical Endocrinology \& Metabolism. 2004;89(7):3313-3318

[102] Malkin CJ, Pugh PJ, Morris PD, Kerry KE, Jones RD, Jones TH, et al. Testosterone replacement in 
hypogonadal men with angina improves ischemic threshold and quality of life. Heart. 2004;90(8):871-876

[103] Haider A, Gooren LJ, Padungtod P, Saad F. Improvement of the metabolic syndrome and of non-alcoholic liver steatosis upon treatment of hypogonadal elderly men with parenteral testosterone undecanoate. Experimental and Clinical Endocrinology \& Diabetes. 2010; 118(03):167-171

[104] Nathan L, Shi W, Dinh H, Mukherjee TK, Wang X, Lusis AJ, et al. Testosterone inhibits early atherogenesis by conversion to estradiol: Critical role of aromatase. Proceedings of the National Academy of Sciences. 2001;98(6):3589-3593

[105] Hougaku H, Fleg JL, Najjar SS, Lakatta EG, Harman SM, Blackman MR, et al. Relationship between androgenic hormones and arterial stiffness, based on longitudinal hormone measurements. American Journal of Physiology-Endocrinology and Metabolism. 2006;290(2):E234-E242

[106] Mäkinen J, Järvisalo MJ, Pöllänen P, Perheentupa A, Irjala K, Koskenvuo $\mathrm{M}$, et al. Increased carotid atherosclerosis in andropausal middleaged men. Journal of the American College of Cardiology. 2005;45(10): 1603-1608

[107] Vikan T, Johnsen SH, Schirmer H, Njølstad I, Svartberg J. Endogenous testosterone and the prospective association with carotid atherosclerosis in men: The Tromsø study. European Journal of Epidemiology. 2009;24(6): 289-295

[108] Van den Beld AW, Bots ML, Janssen JA, Pols HA, Lamberts SW, Grobbee DE. Endogenous hormones and carotid atherosclerosis in elderly men. American Journal of Epidemiology. 2003;157(1):25-31
[109] Fukui M, Kitagawa Y, Ose H, Hasegawa G, Yoshikawa T, Nakamura N. Role of endogenous androgen against insulin resistance and athero-sclerosis in men with type 2 diabetes. Current Diabetes Reviews. 2007;3(1):25-31

[110] Fu L, Gao QP, Shen JX.

Relationship between testosterone and indexes indicating endothelial function in male coronary heart disease patients. Asian Journal of Andrology. 2008;10(2): 214-218

[111] Mathur A, Malkin C, Saeed B, Muthusamy R, Jones TH, Channer K. Long-term benefits of testosterone replacement therapy on angina threshold and atheroma in men. European Journal of Endocrinology. 2009;161(3):443-449

[112] Zitzmann M, Vorona E, Wenk M, Saad F, Nieschlag E. Testosterone administration decreases carotid artery intima media thickness as a marker of impaired vascular integrity in middleaged overweight men: 61 . Journal of Men's Health. 2009;6(3):243

[113] von Eckardstein A, Wu FC. Testosterone and atherosclerosis. Growth Hormone \& IGF Research. 2003;13:S72-S84

[114] Lu YL, Kuang L, Zhu H, Wu H, Wang XF, Pang YP, et al. Changes in aortic endothelium ultrastructure in male rats following castration, replacement with testosterone and administration of $5 \alpha$-reductase inhibitor. Asian Journal of Andrology. 2007;9(6):843-847

[115] Miller VM, Mulvagh SL. Sex steroids and endothelial function: Translating basic science to clinical practice. Trends in Pharmacological Sciences. 2007;28(6):263-270

[116] Foresta C, Zuccarello D, De Toni L, Garolla A, Caretta N, Ferlin A. 
Androgens stimulate endothelial progenitor cells through an androgen receptor-mediated pathway. Clinical Endocrinology. 2008;68(2):284-289

[117] Ong PJ, Patrizi G, Chong WC, Webb CM, Hayward CS, Collins P. Testosterone enhances flow-mediated brachial artery reactivity in men with coronary artery disease. American Journal of Cardiology. 2000;85(2): 269-272

[118] Akishita M, Hashimoto M, Ohike Y, Ogawa S, Iijima K, Eto M, et al. Low testosterone level is an independent determinant of endothelial dysfunction in men. Hypertension Research. 2007;30(11):1029-1034

[119] Rubio-Gayosso I, Garcia-Ramirez $\mathrm{O}$, Gutierrez-Serdan R, GuevaraBalcazar G, Muñoz-García O, MoratoCartajena $\mathrm{T}$, et al. Testosterone inhibits bradykinin-induced intracellular calcium kinetics in rat aortic endothelial cells in culture. Steroids. 2002;67(5): 393-397

[120] Wu FC, von Eckardstein A. Androgens and coronary artery disease. Endocrine Reviews. 2003;24(2):183-217

[121] Traish AM. Adverse health effects of testosterone deficiency (TD) in men. Steroids. 2014;88:106-116

[122] Neyses L, Pelzer T. The biological cascade leading to cardiac hypertrophy. European Heart Journal. 1995;16:8-11

[123] Maron BJ, Epstein SE. Hypertrophic cardiomyopathy: Recent observations regarding the specificity of three hallmarks of the disease:

Asymmetric septal hypertrophy, septal disorganization and systolic anterior motion of the anterior mitral leaflet. The American Journal of Cardiology. 1980; 45(1):141-154

[124] Levy D, Garrison RJ, Savage DD, Kannel WB, Castelli WP. Prognostic implications of echocardiographically determined left ventricular mass in the Framingham Heart Study. New England Journal of Medicine. 1990;322(22): 1561-1566

[125] Hayward CS, Webb CM, Collins P. Effect of sex hormones on cardiac mass. The Lancet. 2001;357(9265):1354-1356

[126] Svartberg J, von Muhlen D, Schirmer H, Barrett-Connor E, Sundfjord J, Jorde R. Association of endogenous testosterone with blood pressure and left ventricular mass in men. The Tromso Study. European Journal of Endocrinology. 2004;150(1): 65-71

[127] Pirompol P, Teekabut V, Weerachatayanukul W, Bupha-Intr T. Supra-physiological dose of testosterone induces pathological cardiac hypertrophy. Journal of Endocrinology. 2016;229:13-23

[128] Miyazaki M, Esser KA. Cellular mechanisms regulating protein synthesis and skeletal muscle hypertrophy in animals. Journal of Applied Physiology. 2009;106(4): 1367-1373

[129] Fry CS, Drummond MJ, Glynn EL, Dickinson JM, Gundermann DM, Timmerman KL, et al. Aging impairs contraction-induced human skeletal muscle mTORC1 signaling and protein synthesis. Skeletal Muscle. 2011;1(1):11

[130] Altamirano F, Oyarce C, Silva P, Toyos M, Wilson C, Lavandero S, et al. Testosterone induces cardiomyocyte hypertrophy through mammalian target of rapamycin complex 1 pathway. Journal of Endocrinology. 2009;202(2): 299-307

[131] Sinha-Hikim I, Cornford M, Gaytan H, Lee ML, Bhasin S. Effects of testosterone supplementation on skeletal muscle fiber hypertrophy and satellite cells in community-dwelling 
older men. The Journal of Clinical Endocrinology \& Metabolism. 2006; 91(8):3024-3033

[132] Favier FB, Benoit H, Freyssenet D. Cellular and molecular events controlling skeletal muscle mass in response to altered use. Pflügers ArchivEuropean Journal of Physiology. 2008; 456(3):587-600

[133] Sinha-Hikim I, Artaza J, Woodhouse L, Gonzalez-Cadavid N, Singh AB, Lee MI, et al. Testosteroneinduced increase in muscle size in healthy young men is associated with muscle fiber hypertrophy. American Journal of Physiology-Endocrinology and Metabolism. 2002;283(1):E154E164

[134] Kadi F. Cellular and molecular mechanisms responsible for the action of testosterone on human skeletal muscle. A basis for illegal performance enhancement. British Journal of Pharmacology. 2008;154(3):522-528

[135] Estrada M, Espinosa A, Müller M, Jaimovich E. Testosterone stimulates intracellular calcium release and mitogen-activated protein kinases via a $\mathrm{G}$ protein-coupled receptor in skeletal muscle cells. Endocrinology. 2003; 144(8):3586-3597

[136] Fu R, Liu J, Fan J, Li R, Li D, Yin J, et al. Novel evidence that testosterone promotes cell proliferation and differentiation via $G$ protein-coupled receptors in the rat $\mathrm{L} 6$ skeletal muscle myoblast cell line. Journal of Cellular Physiology. 2012;227(1):98-107

[137] Tsitouras PD, Martin CE, Harman SM. Relationship of serum testosterone to sexual activity in healthy elderly men. Journal of Gerontology. 1982;37(3):288-293

[138] Schweiger U, Deuschle M, Weber B, Korner A, Lammers CH, Schmider J, et al. Testosterone, gonadotropin, and cortisol secretion in male patients with major depression. Psychosomatic Medicine. 1999;61: 292-296

[139] Stepan JJ, Lachman M, Zvěřina J, Pacovský V, Baylink DJ. Castrated men exhibit bone loss: Effect of calcitonin treatment on biochemical indices of bone remodeling. The Journal of Clinical Endocrinology \& Metabolism. 1999; 69(3):523-527

[140] Baumgartner RN, Waters DL, Gallagher D, Morley JE, Garry PJ. Predictors of skeletal muscle mass in elderly men and women. Mechanisms of Ageing and Development. 1999;107(2): 123-136

[141] Calof OM, Singh AB, Lee ML, Kenny AM, Urban RJ, Tenover JL, et al. Adverse events associated with testosterone replacement in middleaged and older men: A meta-analysis of randomized, placebo-controlled trials. The Journals of Gerontology Series A: Biological Sciences and Medical Sciences. 2005;60(11):1451-1457

[142] Haddad RM, Kennedy CC, Caples SM, Tracz MJ, Boloña ER, Sideras K, et al. Testosterone and cardiovascular risk in men: A systematic review and meta-analysis of randomized placebo-controlled trials. Mayo Clinic Proceedings. 2007;82(1):29-39

[143] Fernández-Balsells MM, Murad MH, Lane M, Lampropulos JF, Albuquerque F, Mullan RJ, et al. Adverse effects of testosterone therapy in adult men: A systematic review and meta-analysis. The Journal of Clinical Endocrinology \& Metabolism. 2010; 95(6):2560-2575

[144] Vigen R, O’Donnell CI, Barón AE, Grunwald GK, Maddox TM, Bradley SM, et al. Association of testosterone therapy with mortality, myocardial infarction, and stroke in men with low testosterone levels. JAMA. 2013;310(17):1829-1836 
[145] Sharma R, Oni OA, Chen G, Sharma M, Dawn B, Sharma R, et al. Association between testosterone replacement therapy and the incidence of DVT and Pulmonary embolism: A retrospective cohort study of the veterans administration database. Chest. 2016;150(3):563-571

[146] European Medicines Agency. No consistent evidence of an increased risk of heart problems with testosterone medicines. 2014. Available from: http:// www.ema.europa.eu/docs/en_GB/doc ument_library/Referrals_document/Te stosterone_31/Position_provided_by_ CMDh/WC500177617.Pdf

[147] Alexander GC, Iyer G, Lucas E, Lin D, Singh S. Cardiovascular risks of exogenous testosterone use among men: A systematic review and meta-analysis. The American Journal of Medicine. 2017;130(3):293-305

[148] Loo SY, Chen BY, Yu OHY, Azoulay L, Renoux C. Testosterone replacement therapy and the risk of stroke in men: A systematic review. Maturitas. 2017;106:31-37

[149] Shores MM, Smith NL, Forsberg CW, Anawalt BD, Matsumoto AM. Testosterone treatment and mortality in men with low testosterone levels. The Journal of Clinical Endocrinology \& Metabolism. 2012;97(6):2050-2058

[150] Muraleedharan V, Ranjan N, Rolfe C, Jones TH. The effect of testosterone undecanoate on cardiovascular risk factors in men with hypogonadism in clinical practice. Endocrine Reviews. 2010;31(3). Issue 3 Supplement

[151] Bagatell CJ, Heiman JR, Matsumoto AM, Rivier JE, Bremner WJ. Metabolic and behavioral effects of high-dose, exogenous testosterone in healthy men. The Journal of Clinical Endocrinology \& Metabolism. 1994; 79(2):561-567
[152] Kapoor D, Goodwin E, Channer KS, Jones TH. Testosterone replacement therapy improves insulin resistance, glycaemic control, visceral adiposity and hypercholesterolaemia in hypogonadal men with type 2 diabetes. European Journal of Endocrinology. 2006;154(6):899-906

[153] Zitzmann M, Nieschlag E. Androgen receptor gene CAG repeat length and body mass index modulate the safety of long-term intramuscular testosterone undecanoate therapy in hypogonadal men. The Journal of Clinical Endocrinology \& Metabolism. 2007;92(10):3844-3853

[154] Zhang KS, Zhao MJ, An Q Jia YF, $\mathrm{Fu} \mathrm{LL}, \mathrm{Xu} \mathrm{JF}$, et al. Effects of testosterone supplementation therapy on lipid metabolism in hypogonadal men with T2 DM: A meta-analysis of randomized controlled trials.

Andrology. 2018;6(1):37-46

[155] Corona G, Rastrelli G, Di

Pasquale G, Sforza A, Mannucci E, Maggi M. Testosterone and cardiovascular risk: Meta-analysis of interventional studies. The Journal of Sexual Medicine. 2018;15(6):820-838

[156] Finkle WD, Greenland S, Ridgeway GK, Adams JL, Frasco MA, Cook MB, et al. Increased risk of nonfatal myocardial infarction following testosterone therapy prescription in men. PloS One. 2014;9(1):e85805

[157] Basaria S, Coviello AD, Travison TG, Storer TW, Farwell WR, Jette AM, et al. Adverse events associated with testosterone administration. New England Journal of Medicine. 2010;363(2):109-122

[158] Xu L, Freeman G, Cowling BJ, Schooling CM. Testosterone therapy and cardiovascular events among men: A systematic review and meta-analysis of placebo-controlled randomized trials. BMC Medicine. 2013;11(1):108 
[159] Bouchardy B, Majno G.

Histopathology of early myocardial

infarcts: A new approach. The American

Journal of Pathology. 1974;74(2):301

[160] Knowlton KU, Chien KR.

Inflammatory pathways and cardiac

repair: The affliction of infarction.

Nature Medicine. 1999;5(10):1122

[161] Cavasin MA, Sankey SS, Yu AL, Menon S, Yang XP. Estrogen and testosterone have opposing effects on chronic cardiac remodeling and function in mice with myocardial infarction. American Journal of Physiology-Heart and Circulatory Physiology. 2003;284(5):H1560-H1569 


\title{
Steroid-Based Supramolecular Systems and their Biomedical Applications: Biomolecular Recognition and Transportation
}

\author{
Ruilong Sheng
}

\begin{abstract}
In this chapter, the biomedical application of steroid-based compounds at "beyond the molecule"-supramolecular level—is reviewed. The renewable and economic natural steroid compounds could be employed as building blocks in the design and construction of steroid-based supramolecular systems. The specific physicochemical features (size, shape, topology, hydrophobicity, chemical modifiability, etc.) and biological properties (biocompatibility, biodegradability, bioaffinity, etc.) could be integrated into functional supramolecular systems by chemical synthesis, modification and intermolecular interactions (such as hydrogen bonding, $\pi-\pi$ stacking, van der Waals forces, inclusion interactions, chiral interactions, electrostatic interactions, and so on). The steroid-based (supra)molecules could be employed for molecular recognition and/or be self-assembled into various functional supramolecular assemblies for biomedical applications. The specific physicochemical and biological properties, good biocompatibility, and biological activity endow the steroid-based supramolecular systems good feasibility to be employed in biomolecular recognition/sensing and biomolecular transportation (gene/drug delivery). The examples in this chapter are exemplificative of the transformation of natural steroid-based compounds into functional steroid-based supramolecular systems through molecular and supramolecular engineering technology, moreover, which may inspire the systematic study of natural product-based supramolecular (nano)materials toward future pharmaceutical and biomedical industry.
\end{abstract}

Keywords: steroid, supramolecular, biomolecular recognition, biomolecular transportation, gene delivery, drug delivery

\section{Introduction}

Transformation of renewable and biocompatible natural products [1] into a variety of molecular building blocks to construct functional molecular systems and then following the molecular assembly processes to create new functional materials has been highly focused for nurturing the sustainable development. Steroids, a large natural lipid family known as "keys of life," played vital roles including membrane formation, hormone metabolism, and cell signal transduction in organelles. Some steroidal compounds possess special physicochemical features 
Renewable Natural Steroid Compounds

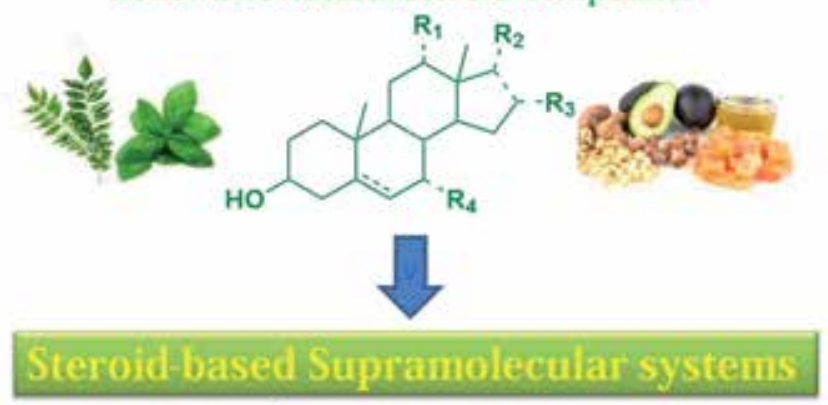

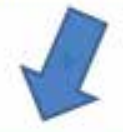

(Bio)molecular Recognition

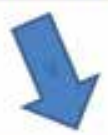

(Bio)molecular Transportation

Figure 1.

Steroid-based supramolecular systems for biomolecular recognition and biomolecular transportation.

such as hydrophobicity, rigidity, mesogenic behaviors, and so on, which made them the functional building blocks for the construction of supramolecular architectures [2] and soft nanomatters toward biomaterial application [3].

In general, the functions of supramolecules mainly cover molecular recognition, molecular transportation, and molecular catalysis [4]. Molecular recognition is a fundamental process that integrates molecular information (size, shape, charge, etc.) by interacting (host) molecules with certain (guest) molecular species [5]. Molecular transportation is the use of supramolecules to translocate bounded/ loaded molecular species (such as anions [6]) through membranes (especially cell membranes [7]), which could be coupled with chemical potentials [8]. Biomolecular recognition (detecting/sensing of certain biomolecules) and biomolecular transportation (administration/delivery of bioactive molecules into the cells/organs) have been regarded as two important fields in biomedical-orientated supramolecular (medicinal) chemistry [9]. The steroid-based supramolecular systems could be divided into two groups according to their function: (1) steroidbased supramolecular system for biomolecular recognition and (2) steroid-based supramolecular system for biomolecular transportation (Figure 1).

\section{Steroid-based supramolecular system for biomolecular recognition}

Recognition/sensing of biomedically important substances such as specific ions (cations/anions), nucleic acids, peptides, proteins/enzymes, volatile bioorganic molecules, biometabolites, as well as tumor biomarkers is very essential for the deep understanding of biochemical mechanisms. Earlier analytical tools, including chemiluminescence, amperometry, electrochemistry, spectrophotometry, highperformance liquid chromatography, etc., have been developed for the detection of biomedically important substances. However, these traditional methods have some drawbacks such as requirement of expensive instruments and complicated pre-treatment processes, which largely restricted their practical application. Rapid development of artificial molecular receptors or molecular sensors may provide powerful tools for the recognition/sensing of chemical species/analytes, which can be attributed to their advantages of easy-to-manipulate, high-sensitivity, fastresponse, high-temporal, and spatial resolution [5]. 
Steroid-Based Supramolecular Systems and their Biomedical Applications: Biomolecular... DOI: $h$ ttp://dx.doi.org/10.5772/intechopen.86752

\subsection{Steroid-based macrocyclic molecular receptors}

Artificial/synthetic macrocyclic molecular receptors are important supramolecular architectures, which can be used as a host molecule to recognition-specific guest molecules [10]. They can also be used to mimic complex biological hostguest systems, e.g., cell surface receptors, nuclear receptors, as well as enzymes for substrate recognition. Typical macrocyclic molecular receptors bind guest molecules inside their designated cavity. During the past decades, many steroids were developed to construct molecular receptors. Among them, bile acids, a family of molecules with facial amphiphilicity, specific molecular chirality, and multiple reactive sites (hydroxyl and carboxylic acid groups), are often employed as molecular skeletons/scaffolds in the construction of supramolecular architectures for molecular recognition $[11,12]$.

In an early work, Davis et al. synthesized a neutral and lipophilic system from the steroid cholic acid (Figure 2). It forms 1:1 complexes with fluoride, chloride, and bromide ions and shows good discrimination of $\mathrm{Cl}^{-}>\mathrm{Br}^{-}>\mathrm{I}^{-}$[13]. In this work, the anion recognition process was carried out in organic solvents.

Also for anion recognition, more recently Peng et al. synthesized cholate-based cage amphiphilic systems with combination of structural rigidity and flexibility. These cage compounds with extending and bridging three polar chains were prepared by click reaction. The connecting chains composed of oligo(ethylene glycol) units or chains containing 1,2,3-triazole units to present flexibility, for example, a model compound (triazole 21a), could recognize halide anions with a binding sequence of $\mathrm{Cl}^{-}>\mathrm{Br}^{-}>\mathrm{I}^{-} \sim \mathrm{F}^{-}$, which makes them potential anions receptors/ sensors [14].

Recently, steroid-based macrocyclic molecular receptors with the combination of multifunctions (e.g., chiral recognition-optical properties) emerged as a new trend of research. In this context, Wu et al. synthesized a deoxycholic acid-based macrocycle receptor CDTB, which selectively recognized $\mathrm{Hg}^{2+}$ involving 1,2,3-triazole motifs as binding sites. The as-formed [CDTB. $\mathrm{Hg}^{2+}$ ] complex could be used to perform enantioselective recognition of amino acids (especially cysteine) in aqueous solution (Figure 3), leading to difference in fluorescence enhancement of the chiral BINOL macrocyclic structure at $\sim 358 \mathrm{~nm}$. This research provided cascade recognition of chiral amino acids and bestows the future design of steroid-based dual-functional macrocyclic molecular receptor models for chiral natural product discrimination/recognition [15].

Although some progresses had been made in this field, the synthesis of steroidbased macrocyclic molecular receptors is still mainly focused on the mono steroidcontaining macrocyclics and $\mathrm{C}_{2}$-symmetric macrocyclics; the facile and low-cost

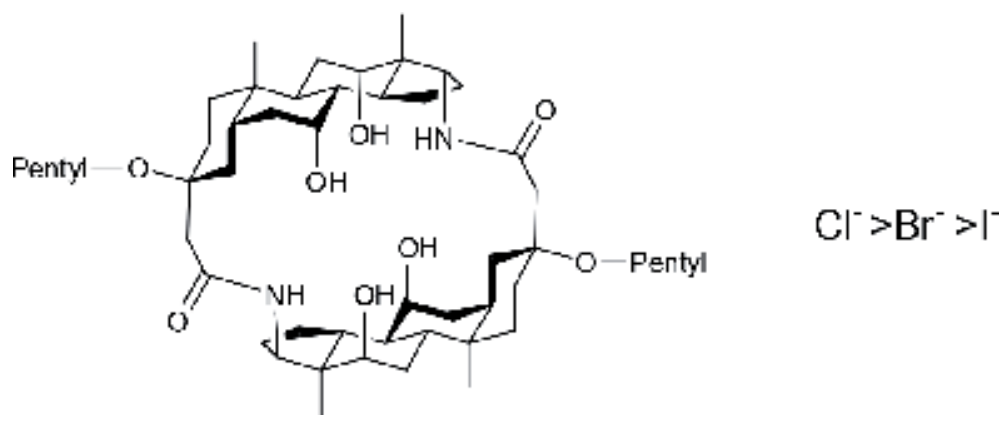

Figure 2.

Cholic acid-based macrocyclic receptor for halides $\mathrm{Cl}^{-}, \mathrm{Br}^{-}$, and $\mathrm{I}^{-}$recognition. 


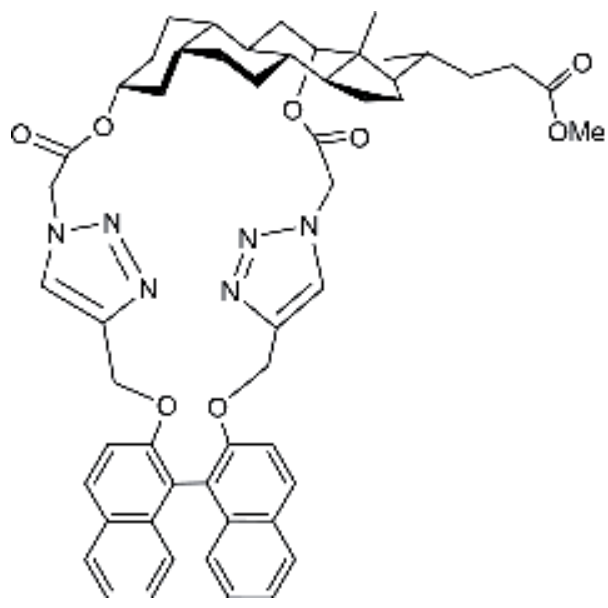<smiles>[R]C(N)C(=O)O</smiles>

Figure 3.

Cholic acid-BINOL-based fluorescent macrocyclic receptor for chiral amino acid recognition.

preparation of macrocyclics need to be developed. Notably, the steroid-based macrocyclics with higher-order symmetric elements (such as $\mathrm{C}_{3}, \mathrm{C}_{4}, \mathrm{D}_{\mathrm{xh}}$, etc.), modifiable and derivable sites, various topological diversities [16], as well as chiral/ asymmetric features (giant chiral macrocyclics) are rare. Moreover, for practical application, the functionalities (such as optical, radioactive, paramagnetic, etc.) of the steroid-based macrocyclic molecular receptors need to be largely expanded.

\subsection{Steroid-based molecular clefts/tweezers}

Another type of artificial/synthetic molecular receptors is open-structured molecular clefts/tweezers, which can recognize guest molecules by forming a sandwich-type structure through $\pi-\pi$ stacking, hydrogen bonding, and/or ionic and electrostatic interactions. For the recognition of aromatic molecules, the arms of the molecular clefts/tweezers were generally designated to be aromatic and with special geometrical arrangements. Taking the advantages of low cost, head-tail-modifiable molecular groups, rigidity, chemically different hydroxyl groups, unique amphiphilicity, and natural chiral microenvironment, bile acids and their derivatives are mostly employed to construct steroid-based molecular clefts/tweezers [17].

For the steroid-based molecular clefts/tweezers toward anion recognition, acidic amide groups (such as $\mathrm{NH}$ in ureas or thioureas) were always used to achieve higher affinities [17]. In this context, Davis et al. constructed anion receptor by placing squaramide groups in axial positions at the hydroxyl groups of steroid (cholic acid) skeleton, which could fix the NH groups on squaramide at certain locations for cooperatively bind anions (Figure 4). By using the steroid-squaramide receptor, anions $\mathrm{Cl}^{-}$and $\mathrm{AcO}^{-}$could be transferred from water to organic solvent by liquidphase extraction. The binding constants of the steroid-squaramide receptor to $\mathrm{Cl}^{-}$ and $\mathrm{AcO}^{-}$of tetraethylammonium salts exceeding $10^{14} \mathrm{M}^{-1}$ in chloroform solution have been measured. The results indicated that these anion receptors might serve as transmembrane anion carriers or artificial cell surface receptors for biomedical application [18].

The synthesized molecular tweezers for small biomolecule recognition mainly have charge-bearing moieties/groups such as carboxylic acids and amine/guanine groups. As an example, Rao et al. have designed and synthesized a bile acid-based molecular tweezer with two carboxylic acid groups attached to the C-3 and C-12 
hydroxyl groups, which could complex 9-N-butyladenine and biotin methyl ester [19] by $\pi-\pi$ and electrostatic interactions along with restricted rotation effects

(Figure 5). Notably, the sensitivity and selectivity of this kind of receptors are not high enough to distinguish biomolecules with similar structures. To design highly selective molecular tweezers, a possible strategy is to mimic the microchemical environment of protein (or sugar) domains responsible for enzyme-substrate recognition or cell receptor-ligand interactions [4].

For chiral amino acid recognition, Davis et al. [20] prepared guanidiniumbearing steroidal molecular tweezers, which could recognize and extract $N$-acetylamino acids (Figure 6) from aqueous solution into the organic phase $\left(\mathrm{CHCl}_{3}\right)$ by electrostatic interactions between guanidinium moiety and carboxylic acid groups, with enantiomeric excesses (ee\%) of about $80 \%$ [21]. In general, the association constant for these acceptors should be around $\sim 10^{-4}-10^{-5}$.

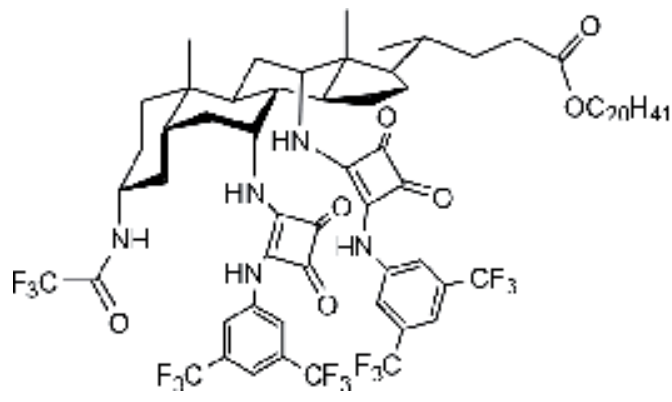

Figure 4.

Cholic acid-squaramide conjugates as a molecular tweezer for anions $\mathrm{Cl}^{-}$and $\mathrm{AcO}^{-}$recognition.

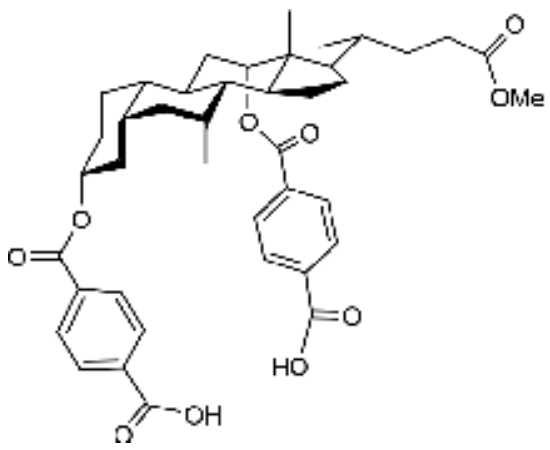<smiles>Nc1ncnc2c1ncn2Cc1ccccc1</smiles><smiles>CO[14CH2][14CH2][14C@@]1(C)SC[C@@H]2NC(=O)N[C@H]21</smiles>

Figure 5.

Cholic acid-based molecular tweezer for $N$-butyladenine and biotin methyl ester recognition.

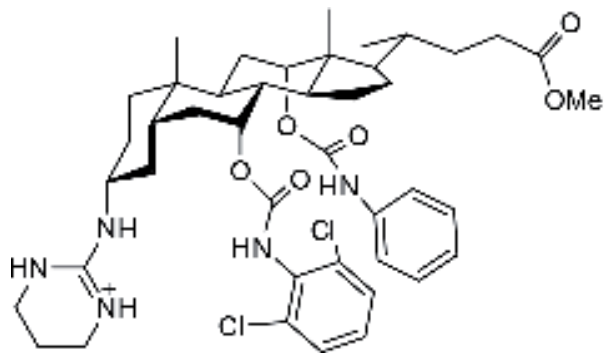<smiles>[R]C(NCCCC)C(=O)O</smiles>

Figure 6.

Cholic acid-guanidinium molecular tweezer for $N$-acetyl-amino acid recognition. 
Bile acid-based receptors containing 2,6-diaminopyridine and the dioctylamide of 2,6-diaminopyridine were also used to bind 7,8-dimethyl flavin analogues. The association constants increased with increasing electron-donating capacity of the substituents at the 7 and 8 positions of the flavin analogues [22].

To our knowledge, up to date, the molecular recognition of the steroid-based molecular tweezers mainly focuses on several simple molecules including anions, nucleosides, and amino acids. Their recognition properties toward more biomolecular analytes/substrates (such as oligosaccharides, peptides, biometabolites, as well as pharmaceuticals) need to be continuously explored. Further improvements on the sensitivity and selectivity, possibility to perform quantitative detection/ recognition, increasing signal-noise ratios, as well as developing portable in situ test $\mathrm{kit} / \mathrm{membrane}$ also need to be taken into consideration. Notably, the cell biological behaviors such as uptake, metabolism, and pharmacological applications of these steroid molecular tweezers are far from being understood. Moreover, the emergence of natural compound such as coumarin [23-25]-based fluorescent molecular receptors/sensors may inspire further development of steroid-based multichannel molecular receptors [4].

\section{Steroid-based supramolecular system for biomolecular transportation}

Transportation/delivery technology of biomolecular species (especially therapeutic agents) across cell membranes and other biological barriers emerged and rapidly developed as a pivotal area in pharmaceutical and clinical biomedicine, since many biological barriers prevent the implementation of clinically effective therapeutic agents (e.g., genes, antitumor drugs, cell signal inhibitors, neuron modulators, etc.). Therefore, developing functional therapeutic (gene/drug) transportation/delivery systems with the merit of low cost, facile-to-prepare, high storage stability, low cytotoxicity, high gene/drug-loading/delivery capacity, as well as controllable releasing/targeting features has attracted much attention in recent years [26-32].

\subsection{Steroid-based supramolecular system for gene delivery}

Using renewable and biocompatible natural-based resources to construct supramolecular biomaterials has attracted great attentions in recent years. As a hot spot in biomaterial research, developing new cationic lipids as non-viral gene (DNA, oligo DNA, SiRNA, etc.) carriers toward gene therapy has been achieved increasing attentions in the past few decades $[33,34]$. An ideal lipid gene carrier should be highly biocompatible [35] and could efficiently load and release therapeutic gene substances [36] into target cells. In this context, recent researches revealed that the introduction of some steroidal hydrophobic molecules in gene carriers could enhance gene loading capacity and delivery efficiency [37], improve estrogen receptor (ER) affinity [38], lower cytotoxicity and membrane disruption [39], and so on, making the steroid-based cationic amphiphiles/lipids promising candidates for gene delivery/transfection (Figure 7).

Among the steroid compounds, cholesterol was the most commonly used steroidal compounds in the construction of functional gene/drug [40] carriers. As an example, Bhattacharya and Bajaj developed a series of cholesterol cationic lipids [41] and gemini-lipids [42-46] with remarkably high gene transfection efficiency and transfected p53-EGFP-C3 plasmid DNA to induce tumor apoptosis [47]. In another example, Rana et al. [48] prepared some cholesterol-hybridized cationic lipids with enhanced SiRNA delivery efficiencies and lower cytotoxicity. 
In addition, Zenkova et al. [49-51] disclosed a series of cholesterol cationic lipids modified with heterocyclic (pyridine, methylimidazole, etc.) or polyamine headgroups having low cytotoxicity and high transfection efficiency, and some cholesterol-based cationic glucosidal lipids also have similar properties [52].

In our earlier work, we prepared a series of bioreduction-responsive cholesterol disulfide cationic (CHOSS) lipids [53], which possessed low cytotoxicity, high pDNA transfection efficiency, as well as perinucleic localization effect (Figure 8). Afterward, we studied the structure-gene transfection relationship of some cholesterol-based cationic lipids bearing versatile amino acid headgroups and chemical linkage bonds [54], and it was found that the physicochemical features and gene transfection-related properties of the cholesterol-based lipids relied greatly on the cationic headgroups [54].

Besides cholesterol, some other steroidal compounds such as diosgenin (a phytosteroid sapogenin used in the preparation of different steroids, e.g., cortisone), bile acids, etc. were employed to construct lipid gene carriers. As an example, Regen et al. developed a series of "molecular umbrella" amphiphiles [55] and disulfidecontaining bile acid-SiRNA conjugates [56] for intracellular SiRNA delivery. In addition, Yi et al. [57-59] synthesized some diosgenin-based cyclen cationic lipids with the merit of low cytotoxicity and high transfection efficiency. In a previous work, we also synthesized some cholesterol and lithocholate-derived cationic lipids via CuAAC "click" approach and disclosed that their gene transfection efficiency relied greatly on the steroid structures [60].

It has been known that the endocytosis mechanism greatly affects the intracellular gene transfection efficacy and subcellular distribution of gene carriers [61]. For the endocytosis pathways of steroid-containing gene carriers, only a few cases were

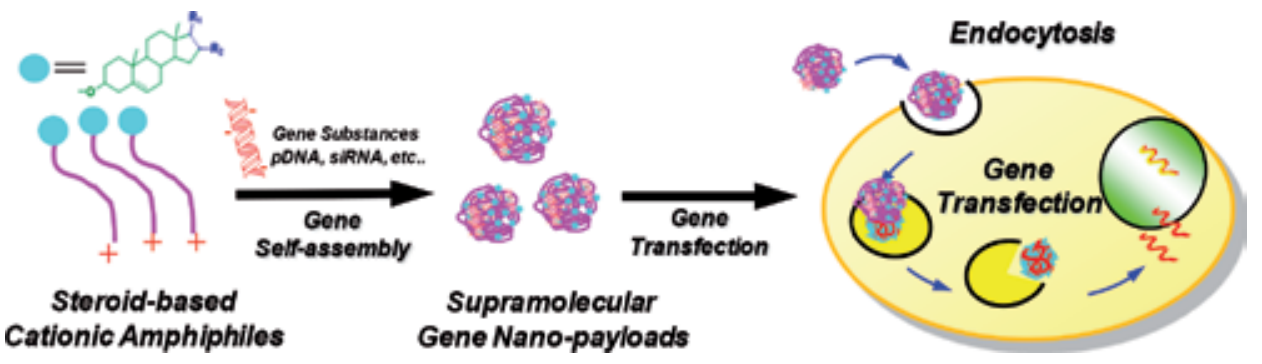

Figure 7.

Steroid-based cationic amphiphiles/lipids for gene delivery/transfection.

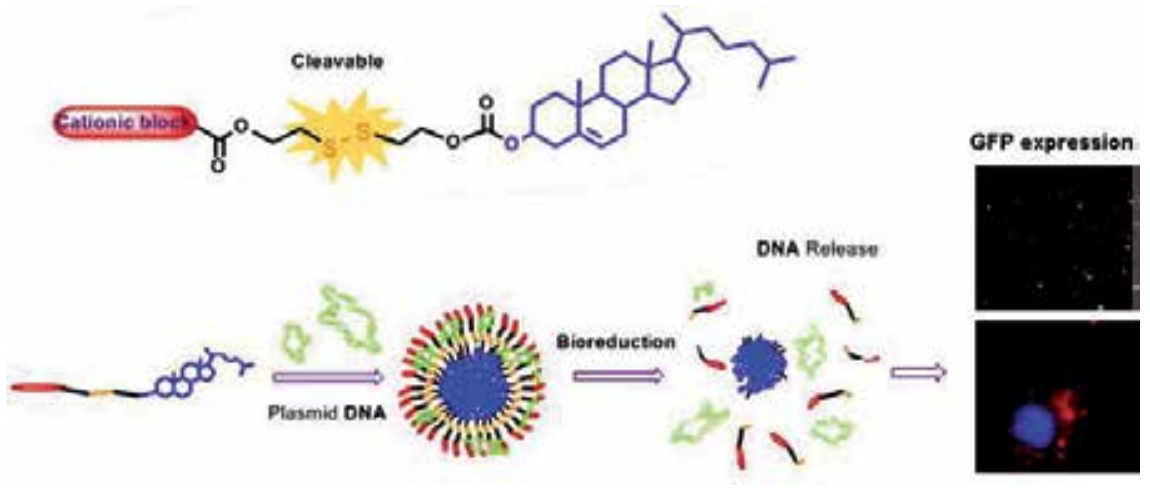

Figure 8.

Bioreduction-responsive cholesterol-based disulfide cationic lipids/pDNA supramolecular payloads as efficient gene delivery carriers. 
investigated. In this context, Bae et al. [62] found that clathrin-mediated endocytosis is the dominant pathway for cholesterol-based (CHOL-E) liposomes. On the other hand, Pozzi et al. [63] disclosed that macropinocytosis is the only endocytosis pathway of a cholesterol cationic lipid (DC-Chol) containing multicomponent envelope-type nanoparticle system (MENS). Besides, Jeong et al. [64] disclosed that clathrin, caveolae, and pinocytosis pathways are involved in the cellular uptake mechanism of hydrophobic $5 \beta$-cholanic acid containing glycol chitosan (HGC) nanoparticles.

In a recent work, our research team successfully prepared a series of steroidbased cationic lipids by integrating various hydrophobic steroid skeletons with $(l-)$-arginine headgroups via a facile and efficient synthetic approach. We found that the plasmid DNA (pDNA)-binding affinity of the steroid-based cationic lipids, average particle sizes, surface potentials, morphologies, as well as stability of the steroid-based cationic lipids/pDNA lipoplexes depend largely on the steroid skeletons. Cellular evaluation results revealed that cytotoxicity and gene transfection efficiency of the steroid-based cationic lipids in H1299 and HeLa cells strongly relied on the steroid. Interestingly, the steroid lipids/pDNA lipoplexes seemed to enter H1299 cells mainly through caveolae- and lipid-raft-mediated endocytosis pathways, and an intracellular trafficking route of "lipid-raft-mediated endocytosis $\rightarrow$ lysosome $\rightarrow$ cell nucleic localization" was accordingly proposed (Figure 9). The study provided possible approach for developing high-performance steroid-based lipid gene carriers, in which the cytotoxicity, gene transfection capability, endocytosis pathways, as well as intracellular trafficking/localization manners could be tuned/controlled by introducing proper steroid skeletons/hydrophobes. Noteworthy, among the lipids, Cho-Arg showed remarkably high gene transfection efficacy even under high serum concentration (50\% FBS), making it an efficient gene transfection agent for practical application [65].

Although many remarkable achievements have been made in the steroid-based gene delivery systems, the working performance such as biocompatibility, gene transfection efficiency, serum compatibility, cell membrane permeability, as well as the in vivo transfection of the most of steroid-based gene carriers were still far from their maximum value, especially far below from their natural virus (adenovirus, SV40, etc.) counterparts. The correlation between steroid-based molecular structures and their transfection efficiency is not well known, and, notably, the correlation between molecular structures and endocytosis pathways, endonucleasis gateways, and intracellular trafficking and subcellular targeting/localization for the most of steroid-based gene delivery systems still remains unclear. Elucidating these correlations may offer new routes to further design steroid-based supramolecular systems with "endocytosis pathway selection" and "subcellular organelle targeting/localization" features.

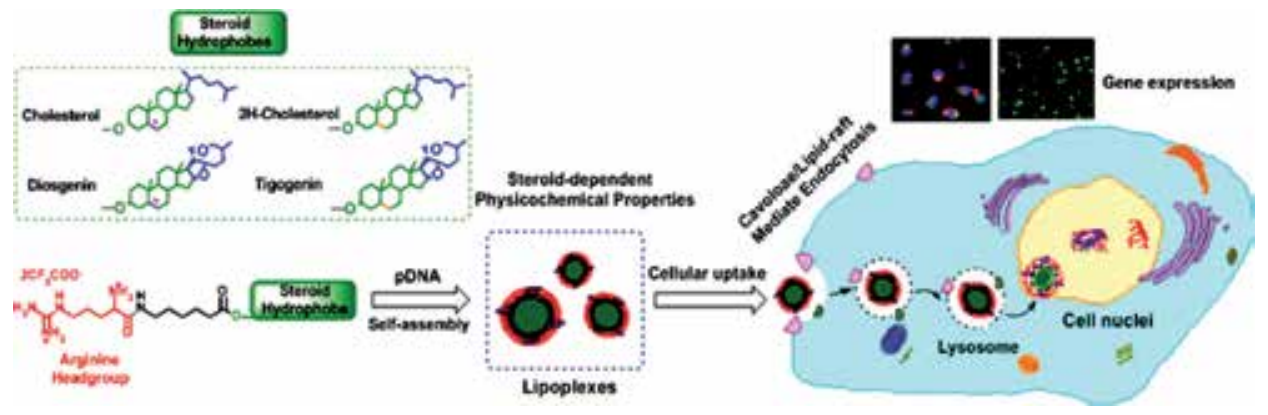

Figure 9.

Steroid-based cationic lipids/pDNA supramolecular payloads as efficient gene delivery carriers and the caveolae/lipid-raft-mediated cellular uptake pathway. 
Moreover, to achieve combo-chemotherapy and high theranostic performance, remote [66] factors (e.g., near-infrared light, ultrasonic, X-ray, or $\gamma$-ray) —induced controllable gene releasing and (optical and radioactive) imaging agents—which incorporated steroid-based supramolecular gene carriers need to be taken into consideration. For future research, we envisioned that "smart" features such as enzymeresponsive [67], self-programmable [68], self-replicable, as well as self-evolution technology could be implemented on the steroid-based supramolecular gene carriers by designing/optimizing the steroid-based molecular structures or supramolecular architectures through molecular or supramolecular engineering approaches.

\subsection{Steroid-based supramolecular system for small molecule/drug delivery}

Similar to gene delivery, controllable delivering of small molecules, including drugs and other bioactive compounds by steroid-based supramolecular systems, is another important field. Some steroids such as bile acids and diosgenin were utilized to prepare drug delivery carriers. In an early study, Regen et al. developed some cholic acid-based molecular umbrellas, which were utilized to transport small biomolecules such as adenosine 5-triphosphate (ATP) [69], glutathione (GSH) [70], as well as an oligonucleotide (S-dT16) [71] across phospholipid bilayer membranes prepared from 1-palmitoyl-2-oleoyl-sn-glycero-3-phosphocholine and 1-palmitoyl-2-oleoyl-sn-glycero-3-phosphatidylglycerol.

To improve the hydrophilic, long-retention/stealth effect, and biocompatibility, polyethylene glycol (PEG) was often introduced to steroid scaffolds [72]. In fact, PEGylated bile acids were synthesized to further prepare self-emulsifying drug delivery systems (SEDDSs), which could enhance the solubility and absorption of poor water-soluble antitumor agent (doxorubicin [73]) or antibiotics (itraconazole [74]), thus providing a significant enhancement of solubility and bioavailability of these small molecular drugs. The emulsions consisted of spherical micelles with a mean hydrodynamic diameter around $100-220 \mathrm{~nm}$, with good biocompatibility (low cytotoxic and hemolytic effect).

Taking advantage of organotropism effect of certain steroid compounds (such as cholesterol and cholic acid), steroid-drug conjugates enable enhanced active targeting of drug delivery into certain organelles to improve their bioavailability. Some bile acid-based prodrugs are prepared by conjugating drugs through degradable bonds, either direct or via spacer molecules to the carboxylic group or to the chemically different (C-3, C-7, and C-12) hydroxyl groups [75]. Tolle-Sander et al. found that cholic acid-acyclovir conjugated prodrugs could target human apical sodium-dependent bile acid transporter (ASBT) to enhance acyclovir bioavailability. In this case, a valine linker between cholic acid and acyclovir could be cleaved upon esterase hydrolysis and release acyclovir [76]. Later, other bile acid-based prodrugs such as cholic acid-cytarabine conjugates [77], cholic acid-5-fluorouracil (FU) conjugates [78], and bile acid-tamoxifen conjugates [79] were developed. The bile acid-based prodrug transport systems showed improved drug absorption, membrane permeation, as well as the "trojan horse" effect [80] that largely increased the bioavailability of the antitumor drugs. In 2009, Regen et al. reported molecular umbrella-hydrophobic drug conjugates, which exhibit enhanced uptake capability to enter living (such as HeLa) cells and increased drug activity, suggesting the conjugates could be used as drug carriers [81]. Besides, the organ-specific targeting properties, especially the liver and small intestine distribution effect, were making the bile acid-based prodrug transport systems efficient candidates for the delivery of low-bioavailability molecular pharmaceutics [82]. The bile acid-based prodrugs provide efficient building blocks for constructing and developing supramolecular prodrug drug delivery systems (SPDDS), which also inspired the extensive R\&D of other steroid-based 
SPDDS [83]. It could be envisioned that, by choosing certain functional moieties to construct steroid-based prodrugs and followed by self-assembly, efficient SPDDS toward controllable chemotherapy could be achieved (Figure 10).

Recently Wei et al. designed and prepared a novel diosgenin-PEG (derivative)based prodrug nanocarrier for inhibiting thrombosis. The steroid diosgenin was conjugated to PEG by means of a $\mathrm{pH}$-sensitive Schiff base bond to prepare the prodrug, then which was self-assembled into nanomicelles in aqueous solution. Under acidic condition (around thrombosis places), the diosgenin-PEG-containing micelles could be cleaved and released and could improve the blood diosgenin concentration to efficiently inhibit thrombosis. Moreover, the diosgenin-PEG micelles without bleeding risk prevented thrombosis by inhibiting activation and apoptosis of platelet. In this study, the observed efficiency of diosgenin-PEG was better than that of the nonsteroid antithrombotic agent aspirin [84].

Multicomponent nanotherapeutic (by combining two or more drugs/prodrugs into a single system) drug delivery systems (MCNDDS) and related formulations have attracted more and more attention. With the merit of easy-to-manipulate, good storage stability, high drug-loading capacity, low cytotoxicity, as well as controllable drug-releasing features, R\&D on MCNDDS could be expected to serve as a promising field in nanopharmaceutics and clinical medicine [85]. As mentioned above, cholesterol has been known to play important roles in membrane property regulation, cell adhesion, and signal transduction, regulating lipid bilayer interaction and intracellular trafficking of nanoparticles, thus bringing new potential applications in biomedical engineering. In one case, cholesterol-based adenosine triphosphate has been prepared, which could be efficiently transported across bilayer membranes of liposomes [86]. In recent studies, we prepared a series of combo-nanotherapeutics by controllable incorporation of cholesterol-based/-conjugated doxorubicin prodrug (Chol-LK-Dox) with tocopherol polyethylene glycol succinate (TPGS), a helper lipid in the construction of functional liposomes or solid lipid nanoparticles, using a thin-film hydration method (Figure 11). Among them, we found that a series of Chol-Dox/TPGS assemblies (molar ratios 2:1, 1:1, and 1:2) were able to form nanoscaled particles with the average hydrodynamic particle diameter of 100-250 $\mathrm{nm}$ and remarkable solution stability (in $0.1 \mathrm{M}$ PBS, 30 days). Notably, the doxorubicin loading and releasing properties could be adjusted by changing the molar ratio of Chol-Dox and TPGS, thus leading to controllable tumor cell inhibition properties to breast cancer (MCF-7 and MDA231) cells. Likewise, the physicochemical properties and bioactivity of another cholesterol-based nanodelivery system (Chol-LK-Dox/TPGS) could also be tuned by changing the (bioresponsive) linkers and molar ratio of Chol-LK-Dox and TPGS. The cellular biological properties of Chol-LK-Dox/TPGS systems in other cancer cell lines and in vivo therapeutic properties in xenograft mice models will be deeply investigated (project ongoing in our lab).

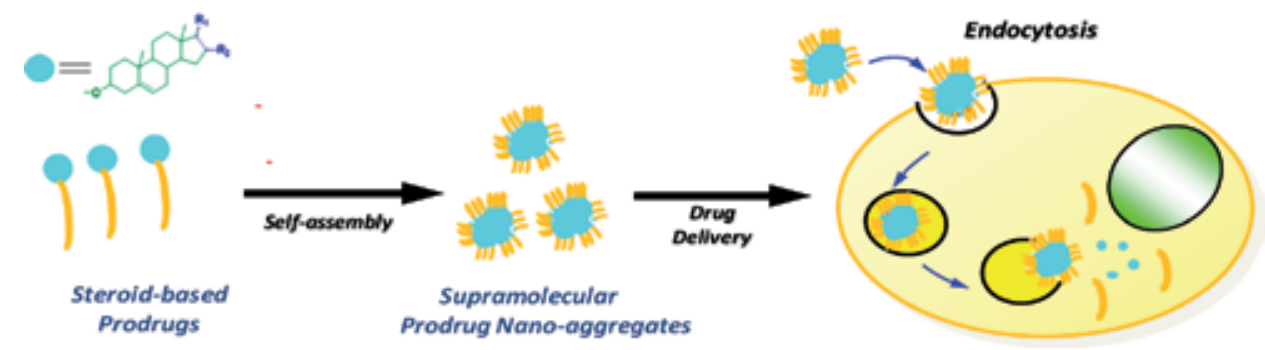

Figure 10.

Self-assembly of steroid-based prodrugs into supramolecular payloads for drug delivery application. 


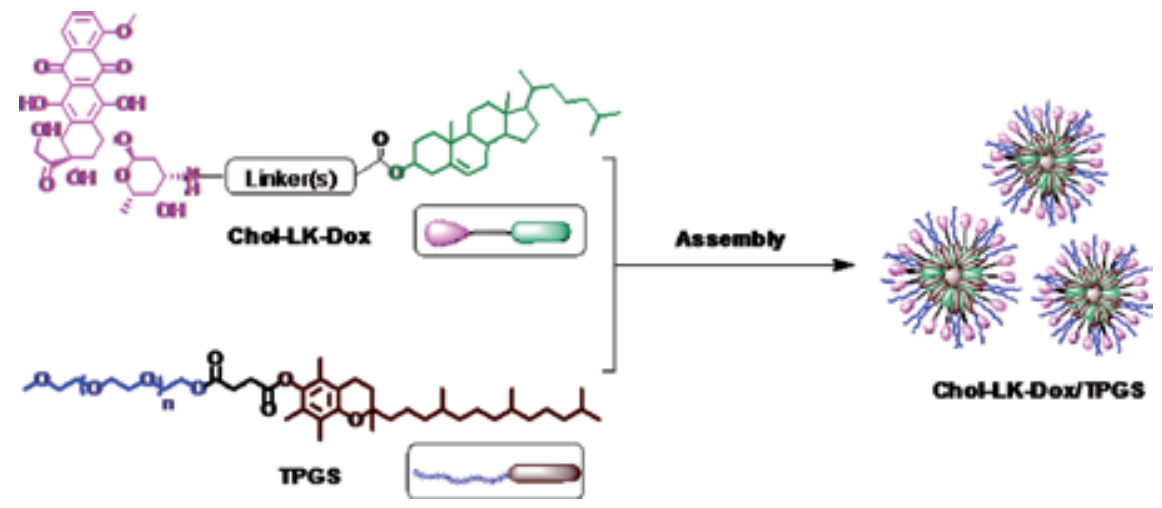

Figure 11.

Self-assembly of steroid (cholesterol)-doxorubicin prodrug (Chol-LK-Dox) with TPGS to prepare MCNDDS for combo-chemotherapy.

Nowadays, for the requirement of "precise biomedical treatment," the steroidbased supramolecular prodrug systems with smart manners such as stimulisensitive (temperature, ultrasound, light, electric, $\mathrm{pH}$, redox, biomolecules, and enzyme) features and targeting (cell membrane, subcellular organelles, and cell nuclei) properties need to be further developed.

\section{Conclusions}

In this chapter, we reviewed the main biomedical application of steroid-based compounds "beyond the molecule"-supramolecular level. The renewable, economic natural steroid compounds could be employed as building blocks in the design and construction of steroid-based supramolecular systems. Based on the specific physicochemical features (size, shape, topology, hydrophobicity, chemical modifiability, etc.) and biological properties (biocompatibility, biodegradability, bioaffinity, etc.), through chemical synthesis, modification, and by means of intermolecular weak interactions (such as hydrogen bonding, $\pi-\pi$ stacking, van der Waals forces, inclusion interactions, chiral interactions, electrostatic interactions, and so on), the steroid-based functional molecules could be organized to supramolecules for molecular recognition/sensing and/or be self-assembled into various functional supramolecular assemblies for biomedical applications. The specific physicochemical and biological properties, good biocompatibility, and biological activity endow the steroid-based supramolecular systems good feasibility to be employed in biomolecular recognition/sensing and biomolecular transportation (gene/drug delivery). The examples in this chapter illustrated the transformation of natural steroid-based compounds into functional steroid-based supramolecular systems through molecular and supramolecular engineering technology, which may inspire the systematic study of natural product-based supramolecular (nano) materials toward the future pharmaceutical and biomedical industry.

Although many natural steroid-based supramolecular/nano-systems have been developed and studied, there are still many problems which need to be solved and vast spaces that need to be filled in further extensive research: (1) At molecular level, apart from the natural steroid-based supramolecular shown above, the steroid-based compounds with unique structures (molecular symmetry, geometry and topology, polarity, amphiphilicity, multivalency, etc.), physicochemical (thermal, optical, magnetic, acoustic, radioactive, etc.), properties and biofunctions (biorecognition, targeting, endocytosis, cell signaling, etc.), as well as green synthesis 
techniques of the building blocks/units that need to be further developed. (2) At supramolecular level, the self-/forced assembly properties of many natural steroidbased supramolecular/nano-systems were still not well studied; especially their structure-property relationships need to be further explored, realizing the control/ adjustment of the steroid-based nanoassemblies with specific physicochemical and/ or biological functions. (3) For biomedical application, we need to continue exploring the related biological functions (such as biocompatibility, biometabolic activity, biomimicking manners, etc.) of the steroid-based supramolecular systems and reveal the relationship between the molecular/supramolecular structure and their biological behaviors. Moreover, we anticipated that molecular-level properties of the steroid-based molecules/building blocks would be transferred, enhanced, and/or magnified into supramolecular-level properties, providing a "bottom-up" method to create new renewable resource-derived nanostructures and nanomaterials.

Finally, we need to notice that the steroid-based supramolecular system as aforementioned in this chapter is mostly restricted in low-dimensional OD and 1D level and, therefore, for real practical application toward complexity systems, higherordered steroid-based supramolecular systems (such as 2D and 3D) are needed to be further developed; especially, as for the emergence of natural-based tissue engineering materials and rapid development of 3D bioprinting technology, steroidbased supramolecular system for cell culture and regenerative medicine needs to be taken into consideration and systematically developed in the near future.

\section{Acknowledgements}

The author Prof. Dr. Ruilong Sheng thanks Shanghai Institute of Organic Chemistry, CAS; National Science Foundation of China (21002116 and 21372251); the CAS-Canada Young Visiting Scientist Scholarship; Youth Innovation Promotion Association (YIPA 2012204); ARDITI-Agência Regional para o Desenvolvimento da Investigação Tecnologia e Inovação through the project M1420-01-0145-FEDER000005-Centro de Química da Madeira-CQM ${ }^{+}$(Madeira 14-20) and ARDITI2017-ISG-003; Fundação para a Ciência e a Tecnologia (FCT project PEst-OE/QUI/ UI0674/2019, CQM, Portuguese government funds); and Madeira 14-20 Program, project PROEQUIPRAM-Reforço do Investimento em Equipamentos e Infraestruturas Científicas na RAM (M1420-01-0145-FEDER-000008), for the sponsorship. Ruilong Sheng also thanks the main collaborators Prof. Amin Cao, Prof. Pengfei Wang, Prof. Shikang Wu, Prof. Xiangyang Shi, Prof. João Rodrigues, Prof. Helena Tomás, Prof. Shi Tang, Prof. Lintao Zeng, Prof. Minhuan Lan, Prof. Timothy Hughes, Prof. Joseph Matt Kinsella, Prof. Julian X Zhu, Prof. Lin Jia, Prof. Chen Peng, Prof. Jian Chen, Prof. Yunxu Yang, Dr. Zhao Wang, Dr. Xiaoqing Zhuang, Dr. Jingjing Sun, Mr. Ting Luo, Dr. Hui Li, Dr. Mingrui Li, Dr. Ana Rute Neves, Mr. Filipe Olim, and Mr. Junchao Xu for their contribution on the related experiment, project support, coordination, and suggestion.

\section{Conflict of interest}

No “conflict of interest."

\section{Notes/thanks/other declarations}

The author also thanks Madeira Chemistry Research Centre and Shanghai Institute of Organic Chemistry, CAS for their support. 
Steroid-Based Supramolecular Systems and their Biomedical Applications: Biomolecular... DOI: $h$ ttp://dx.doi.org/10.5772/intechopen.86752

\section{Author details}

Ruilong Sheng ${ }^{1,2,3}$

1 CQM—Centro de Química da Madeira, Universidade da Madeira, Funchal, Portugal

2 Key Laboratory of Synthetic and Self-assembly Chemistry for Organic Functional Molecules, Shanghai Institute of Organic Chemistry, Shanghai, China

3 Department of Bioengineering, McGill University, Montréal, Québec, Canada

*Address all correspondence to: ruilong.sheng@staff.uma.pt

\section{IntechOpen}

(C) 2020 The Author(s). Licensee IntechOpen. This chapter is distributed under the terms of the Creative Commons Attribution License (http://creativecommons.org/licenses/ by/3.0), which permits unrestricted use, distribution, and reproduction in any medium, provided the original work is properly cited. (cc) BY 


\section{References}

[1] Albrecht MA, Evans CW, Raston CL. Green chemistry and the health implications of nanoparticles. Green Chemistry. 2006;8:417-432

[2] Zhang K, Wang Y, Yu A, Zhang Y, Tang H, Zhu XX. Cholic acid-modified dendritic multimolecular micelles and enhancement of anticancer drug therapeutic efficacy. Bioconjugate Chemistry. 2010;21:1596-1601

[3] Li C, Lavigueur C, Zhu

$\mathrm{XX}$. Aggregation and thermoresponsive properties of new star block copolymers with a cholic acid Core. Langmuir. 2011;27:11174-11179

[4] Lehn J-M. Perspectives in supramolecular chemistry-From molecular recognition towards molecular information processing and self-organization. Angewandte Chemie, International Edition. 1990;29:1304-1319

[5] Persch E, Dumele O, Diederich F. Molecular recognition in chemical and biological systems. Angewandte Chemie, International Edition. 2015;54:3290-3327

[6] Gale PA, Davis JT, Quesada R. Anion transport and supramolecular medicinal chemistry. Chemical Society Reviews. 2017;46:2497-2519

[7] Webb SJ. Supramolecular approaches to combining membrane transport with adhesion. Accounts of Chemical Research. 2013;46:2878-2887

[8] Lehn JM. Supramolecular chemistry: Receptors, catalysts, and carriers.

Science. 1985;227:849-856

[9] Uhlenheuer DA, Petkau K, Brunsveld L. Combining supramolecular chemistry with biology. Chemical Society Reviews. 2010;39:2817-2826
[10] Liu Z, Nalluri SKM, Stoddart JF. Surveying macrocyclic chemistry: From flexible crown ethers to rigid cyclophanes. Chemical Society Reviews. 2017;46:2459-2478

[11] Chhatra RK, Kumar A, Pandey PS. Synthesis of a bile acid-based click-macrocycle and its application in selective recognition of chloride ion. The Journal of Organic Chemistry. 2011;76:9086-9089

[12] Li Y, Li G, Wang X, Li W, Su $Z$, Zhang Y, et al. Unique twisted ribbons generated by self-assembly of oligo(p-phenylene ethylene) bearing dimeric bile acid pendant groups. Chemistry - A European Journal. 2009;15:6399-6407

[13] Davis AP, Gilmer JF, Perry JJ. A steroid-based crypt and for halide anions. Angewandte Chemie International Edition in English. 1996;35:1312-1315

[14] Peng L, Mo F, Zhang Q. Cholatebased synthesis of size-tunable cage compounds. The Journal of Organic Chemistry. 2015;80:1221-1228

[15] Wu J, Lu J, Liu J, Zheng C, Gao Y, $\mathrm{Hu}$ J, et al. A deoxycholic acid-based macrocycle: Recognition of mercury ion and cascade enantioselective sensing toward amino acids. Sensors and Actuators B: Chemical. 2017;241:931-937

[16] Rivera DG, Wessjohann

LA. Architectural chemistry: Synthesis of topologically diverse macromulticycles by sequential multiple multicomponent macrocyclizations. Journal of the American Chemical Society. 2009;131:3721-3732

[17] Gale PA, Busschaert N, Haynes CJ, Karagiannidis LE, Kirby IL. Anion receptor chemistry: Highlights from 2011 and 2012. Chemical Society Reviews. 2014;43:205-241 
[18] Edwards SJ, Valkenier H,

Busschaert N, Gale PA, Davis AP. Highaffinity anion binding by steroidal squaramide receptors. Angewandte Chemie, International Edition. 2015;54:4592-4596

[19] Rao P, Maitra UA. New bile acid-based ditopic adenine/biotin receptor with convergent carboxyl groups. Supramolecular Chemistry. 1998;9:325-328

[20] Davis AP, Perry JJ, Williams RP. Anion recognition by tripodal receptors derived from cholic acid. Journal of the American Chemical Society. 1997;119:1793-1794

[21] Davis AP, Lawless LJ. Steroidal guanidinium receptors for the enantioselective recognition of $\mathrm{N}$-acyl $\alpha$-amino acids. Chemical Communications. 1999:9-10

[22] Chattopadhyay P, Nagpal R, Pandey PS. Recognition properties of flavin analogues with bile acidbased receptors: Role of steric effects in hydrogen bond based molecular recognition. Australian Journal of Chemistry. 2008;61:216-222

[23] Sheng R, Wang P, Liu W, Wu X, Wu S. A new colorimetric chemosensor for $\mathrm{Hg}^{2+}$ based on coumarin azine derivative. Sensors and Actuators B: Chemical. 2008;128:507-511

[24] Sheng R, Wang P, Gao Y, Wu Y, Liu W, Ma J, et al. Colorimetric test kit for $\mathrm{Cu}^{2+}$ detection. Organic Letters. 2008;10:5015-5018

[25] Sheng R, Ma J, Wang P, Liu W, $\mathrm{Wu}$ J, Li H, et al. Enzyme sensing based on a controllable oxidation reaction. Biosensors \& Bioelectronics. 2010;26:949-952

[26] Yan L, Yang Y, Zhang W, Chen X. Advanced materials and nanotechnology for drug delivery. Advanced Materials. 2014;26:5533-5540
[27] Jo J, Tabata Y. How controlled release technology can aid gene delivery. Expert Opinion on Drug Delivery. 2015;12:1689-1701

[28] Jain KK. Current status and future prospects of drug delivery systems. Methods in Molecular Biology (Clifton, NJ). 2014;1141:1-56

[29] Garg T, Rath G, Goyal AK. Colloidal drug delivery systems: Current status and future directions. Critical Reviews in Therapeutic Drug Carrier Systems. 2015;32:89-147

[30] Fliervoet LAL, Mastrobattista E. Drug delivery with living cells. Advanced Drug Delivery Reviews. 2016;106:63-72

[31] Amin MC, Ahmad N, Pandey M, Abeer MM, Mohamad N. Recent advances in the role of supramolecular hydrogels in drug delivery. Expert Opinion on Drug Delivery. 2015;12:1149-1161

[32] Allen TM, Cullis PR. Liposomal drug delivery systems: From concept to clinical applications. Advanced Drug Delivery Reviews. 2013;65:36-48

[33] Guo X, Szoka FC. Chemical approaches to triggerable lipid vesicles for drug and gene delivery. Accounts of Chemical Research. 2003;36:335-341

[34] Niidome T, Huang L. Gene therapy progress and prospects: Nonviral vectors. Gene Therapy. 2002;9:1647-1652

[35] Lv H, Zhang S, Wang B, Cui S, Yan J. Toxicity of cationic lipids and cationic polymers in gene delivery. Journal of Controlled Release. 2006;114:100-109

[36] Morille M, Passirani C, Vonarbourg A, Clavreul A, Benoit J-P. Progress in developing cationic vectors for nonviral systemic gene therapy against cancer. Biomaterials. 2008;29:3477-3496 
[37] Lee ALZ, Venkataraman S, Sirat SBM, Gao S, Hedrick JL, Yang YY. The use of cholesterol-containing biodegradable block copolymers to exploit hydrophobic interactions for the delivery of anticancer drugs. Biomaterials. 2012;33:1921-1928

[38] Dao K-L, Hanson RN. Targeting the estrogen receptor using steroid-therapeutic drug conjugates (hybrids). Bioconjugate Chemistry. 2012;23:2139-2158

[39] Chen C-J, Wang J-C, Zhao E-Y, Gao L-Y, Feng Q, Liu X-Y, et al. Selfassembly cationic nanoparticles based on cholesterol-grafted bioreducible poly(amidoamine) for siRNA delivery. Biomaterials. 2013;34:5303-5316

[40] He Z-Y, Chu B-Y, Wei X-W, Li J, Carl EK, Song X-R, et al. Recent development of poly(ethylene glycol)cholesterol conjugates as drug delivery systems. International Journal of Pharmaceutics. 2014;469:168-178

[41] Bhattacharya S, Bajaj A. Advances in gene delivery through molecular design of cationic lipids. Chemical Communications. 2009:4632-4656

[42] Biswas J, Bajaj A, Bhattacharya $\mathrm{S}$. Membranes of cationic gemini lipids based on cholesterol with hydroxyl headgroups and their interactions with DNA and phospholipid. The Journal of Physical Chemistry B. 2010;115:478-486

[43] Bajaj A, Kondaiah P, Bhattacharya

$S$. Effect of the nature of the spacer on gene transfer efficacies of novel thiocholesterol derived gemini lipids in different cell lines: A structure-activity investigation. Journal of Medicinal Chemistry. 2008;51:2533-2540

[44] Bajaj A, Kondaiah P, Bhattacharya $S$. Synthesis and gene transfection efficacies of PEI-cholesterol-based lipopolymers. Bioconjugate Chemistry. 2008;19:1640-1651
[45] Bajaj A, Kondiah P, Bhattacharya

S. Design, synthesis, and in vitro gene delivery efficacies of novel cholesterol-based gemini cationic lipids and their serum compatibility: A structure-activity investigation. Journal of Medicinal Chemistry. 2007;50:2432-2442

[46] Bajaj A, Kondaiah P, Bhattacharya S. Synthesis and gene transfer activities of novel serum compatible cholesterolbased gemini lipids possessing oxyethylene-type spacers. Bioconjugate Chemistry. 2007;18:1537-1546

[47] Misra SK, Naz S, Kondaiah P, Bhattacharya S. A cationic cholesterol based nanocarrier for the delivery of p53-EGFP-C3 plasmid to cancer cells. Biomaterials. 2014;35:1334-1346

[48] Ghosh A, Mukherjee K, Jiang X, Zhou Y, McCarroll J, Qu J, et al. Design and assembly of new nonviral RNAi delivery agents by microwave-assisted quaternization (MAQ) of tertiary amines. Bioconjugate Chemistry. 2010;21:1581-1587

[49] Medvedeva DA, Maslov MA, Serikov RN, Morozova NG, Serebrenikova GA, Sheglov DV, et al. Novel cholesterol-based cationic lipids for gene delivery. Journal of Medicinal Chemistry. 2009;52:6558-6568

[50] Ivanova EA, Maslov MA, Kabilova TO, Puchkov PA, Alekseeva AS, Boldyrev IA, et al. Structuretransfection activity relationships in a series of novel cationic lipids with heterocyclic head-groups. Organic \& Biomolecular Chemistry. 2013;11:7164-7178

[51] Maslov MA, Kabilova TO, Petukhov IA, Morozova NG, Serebrennikova GA, Vlassov VV, et al. Novel cholesterol spermine conjugates provide efficient cellular delivery of plasmid DNA and small interfering RNA. Journal of Controlled Release. 2012;160:182-193 
[52] Maslov MA, Morozova NG, Chizhik EI, Rapoport DA, Ryabchikova EI, Zenkova MA, et al. Synthesis and delivery activity of new cationic cholesteryl glucosides. Carbohydrate Research. 2010;345:2438-2449

[53] Sheng R, Luo T, Zhu Y, Li H, Sun J, Chen S, et al. The intracellular plasmid DNA localization of cationic reducible cholesterol-disulfide lipids. Biomaterials. 2011;32:3507-3519

[54] Sheng R, Luo T, Li H, Sun J, Wang Z, Cao A. Cholesterol-based cationic lipids for gene delivery: Contribution of molecular structure factors to physicochemical and biological properties. Colloids and Surfaces. B, Biointerfaces. 2014;116:32-40

[55] Cline LL, Janout V, Fisher M, Juliano RL, Regen SL. A molecular umbrella approach to the intracellular delivery of small interfering RNA. Bioconjugate Chemistry. 2011;22:2210-2216

[56] Janout V, Cline LL, Feuston BP, Klein L, O'Brien A, Tucker T, et al. Molecular umbrella conjugate for the ocular delivery of siRNA. Bioconjugate Chemistry. 2014;25:197-201

[57] Yi W-J, Zhang Q-F, Zhang J, Liu Q, Ren L, Chen Q-M, et al. Cyclen-based lipidic oligomers as potential gene delivery vehicles. Acta Biomaterialia. 2014;10:1412-1422

[58] Zhang Q-F, Yi W-J, Wang B, Zhang J, Ren L, Chen Q-M, et al. Linear polycations by ring-opening polymerization as non-viral gene delivery vectors. Biomaterials. 2013;34:5391-5401

[59] Liu J-L, Ma Q-P, Huang Q-D, Yang W-H, Zhang J, Wang J-Y, et al. Cationic lipids containing protonated cyclen and different hydrophobic groups linked by uracil-PNA monomer: Synthesis and application for gene delivery. European
Journal of Medicinal Chemistry. 2011;46:4133-4141

[60] Sheng R, Luo T, Li H, Sun J, Wang Z, Cao A. 'Click' synthesized sterol-based cationic lipids as gene carriers, and the effect of skeletons and headgroups on gene delivery. Bioorganic \& Medicinal Chemistry. 2013;21:6366-6377

[61] Xiang S, Tong H, Shi Q, Fernandes JC, Jin T, Dai K, et al. Uptake mechanisms of non-viral gene delivery. Journal of Controlled Release. 2012;158:371-378

[62] Bae YU, Kim BK, Park JW, Seu YB, Doh KO. Endocytic pathway and resistance to cholesterol depletion of cholesterol derived cationic lipids for gene delivery. Molecular Pharmaceutics. 2012;9:3579-3585

[63] Pozzi D, Marchini C, Cardarelli F, Rossetta A, Colapicchioni V, Amici $A$, et al. Mechanistic understanding of gene delivery mediated by highly efficient multicomponent envelopetype nanoparticle systems. Molecular Pharmaceutics. 2013;10:4654-4665

[64] Nam HY, Kwon SM, Chung H, Lee S-Y, Kwon S-H, Jeon H, et al. Cellular uptake mechanism and intracellular fate of hydrophobically modified glycol chitosan nanoparticles. Journal of Controlled Release. 2009;135:259-267

[65] Sheng R, Wang Z, Luo T, Cao A, Sun J, Kinsella JM. Skeletoncontrolled pDNA delivery of renewable steroid-based cationic lipids, the endocytosis pathway analysis and intracellular localization. International Journal of Molecular Sciences. 2018;19:369

[66] Lyu Y, Cui D, Sun H, Miao Y, Duan $\mathrm{H}, \mathrm{Pu} \mathrm{K}$. Dendronized semiconducting polymer as photothermal nanocarrier for remote activation of gene expression. Angewandte 
Chemie, International Edition. 2017;129:9283-9287

[67] Qiu N, Gao J, Liu Q, Wang J, Shen Y. Enzyme-responsive charge-reversal polymer-mediated effective gene therapy for intraperitoneal tumors. Biomacromolecules. 2018;19:2308-2319

[68] Lino CA, Harper JC, Carney JP, Timlin JA. Delivering CRISPR: A review of the challenges and approaches. Drug Delivery. 2018;25:1234-1257

[69] Janout V, Jing B, Staina IV, Regen SL. Selective transport of ATP across a phospholipid bilayer by a molecular umbrella. Journal of the American Chemical Society. 2003;125:4436-4437

[70] Janout V, Zhang LH, Staina IV, Di Giorgio C, Regen SL. Molecular umbrella-assisted transport of glutathione across a phospholipid membrane. Journal of the American Chemical Society. 2001;123:5401-5406

[71] Janout V, Jing B, Regen

SL. Molecular umbrella-assisted transport of an oligonucleotide across cholesterol-rich phospholipid bilayers. Journal of the American Chemical Society. 2005;127:15862-15870

[72] Li Y, Zhu C. Mechanism of hepatic targeting via oral administration of DSPE-PEG-cholic acid-modified nanoliposomes. International Journal of Nanomedicine. 2017;12:1673-1684

[73] Cunningham AJ, Robinson M, Banquy X. Bile acid-based drug delivery systems for enhanced doxorubicin encapsulation: Comparing hydrophobic and ionic interactions in drug loading and release. Molecular Pharmaceutics. 2018;15:1266-1276

[74] Le Devedec F, Strandman S, Hildgen P, Leclair G, Zhu XX. PEGylated bile acids for use in drug delivery systems: Enhanced solubility and bioavailability of itraconazole. Molecular Pharmaceutics. 2013;10:3057-3066
[75] Faustino C, Serafim C, Rijo P, Reis

CP. Bile acids and bile acid derivatives: Use in drug delivery systems and as therapeutic agents. Expert Opinion on Drug Delivery. 2016;13:1133-1148

[76] Tolle-Sander S, Lentz KA, Maeda DY, Coop A, Polli JE. Increased acyclovir oral bioavailability via a bile acid conjugate. Molecular Pharmaceutics. 2004;1:40-48

[77] Chen DQ, Wang X, Chen L, He JX, Miao ZH, Shen JK. Novel liver-specific cholic acid-cytarabine conjugates with potent antitumor activities: Synthesis and biological characterization. Acta Pharmacology Sinica. 2011;32:664-672

[78] Qian S, Wu JB, Wu XC, Li J, Wu Y. Synthesis and characterization of new liver targeting 5-fluorouracil-cholic acid conjugates. Archiv der Pharmazie (Weinheim). 2009;342:513-520

[79] Sreekanth V, Bansal S, Motiani RK, Kundu S, Muppu SK, Majumdar TD, et al. Design, synthesis, and mechanistic investigations of bile acid-tamoxifen conjugates for breast cancer therapy. Bioconjugate Chemistry. 2013;24:1468-1484

[80] Kramer W. Transporters, trojan horses and therapeutics: Suitability of bile acid and peptide transporters for drug delivery. Biological Chemistry. 2011;392:77-94

[81] Janout V, Regen SL. Bioconjugatebased molecular umbrellas. Bioconjugate Chemistry. 2009;20: 183-192

[82] Vivian D, Polli JE. Synthesis and in vitro evaluation of bile acid prodrugs of floxuridine to target the liver. International Journal of Pharmaceutics. 2014;20(475):597-604

[83] Hu XY, Wang LY. Two sides to supramolecular drug delivery 
Steroid-Based Supramolecular Systems and their Biomedical Applications: Biomolecular.. DOI: http://dx.doi.org/10.5772/intechopen.86752

systems. Supramolecular Chemistry. 2018;8:664-666

[84] Wei Z, Xin G, Wang H, Zheng H, Ji C, Gu J, et al. The diosgenin prodrug nanoparticles with $\mathrm{pH}$-responsive as a drug delivery system uniquely prevents thrombosis without increased bleeding risk. Nanomedicine: Nanotechnology, Biology and Medicine. 2018;14:673-684

[85] Sau S, Tatiparti K, Alsaab H, Kashaw SK, Lyer AK. A tumor multicomponent targeting chemoimmune drug delivery system for reprograming the tumor microenvironment and personalized cancer therapy. Drug Discovery Today. 2018;23:1344-1356

[86] Pradere U, Garnier-Amblard EC, Coats SJ, Amblard F, Schinazi RF. Synthesis of nucleoside phosphate and phosphonate prodrugs. Chemical Reviews. 2014;114:9154-9218 


\section{Edited by Jorge António Ribeiro Salvador and Maria Manuel Cruz Silva}

The steroid scaffold continues to be the structural basis of new drugs for a variety of targets and diseases. Indeed, steroids interact with enzymes and receptors in a strikingly specific manner. Chemistry and Biological Activity of Steroids aims to provide an updated overview of recent advances in the medicinal chemistry of steroids. Novel synthetic methods in the steroids field, including steroid biotransformations, new steroids able to tackle steroid receptors, and steroid enzymes with clinical relevance, are critically reviewed in this book. Furthermore, the diverse physiopathological roles of oxysterols and their therapeutic value are also discussed.

\section{IntechOpen}

